\title{
IntechOpen
}

\section{Food Preservation and Waste Exploitation}

Edited by Sonia A. Socaci, Anca C. Fărcaş, Thierry Aussenac and Jean-Claude Laguerre 



\section{Food Preservation and Waste Exploitation}

Edited by Sonia A. Socaci, Anca C. Fărcaş, Thierry Aussenac and Jean-Claude Laguerre 

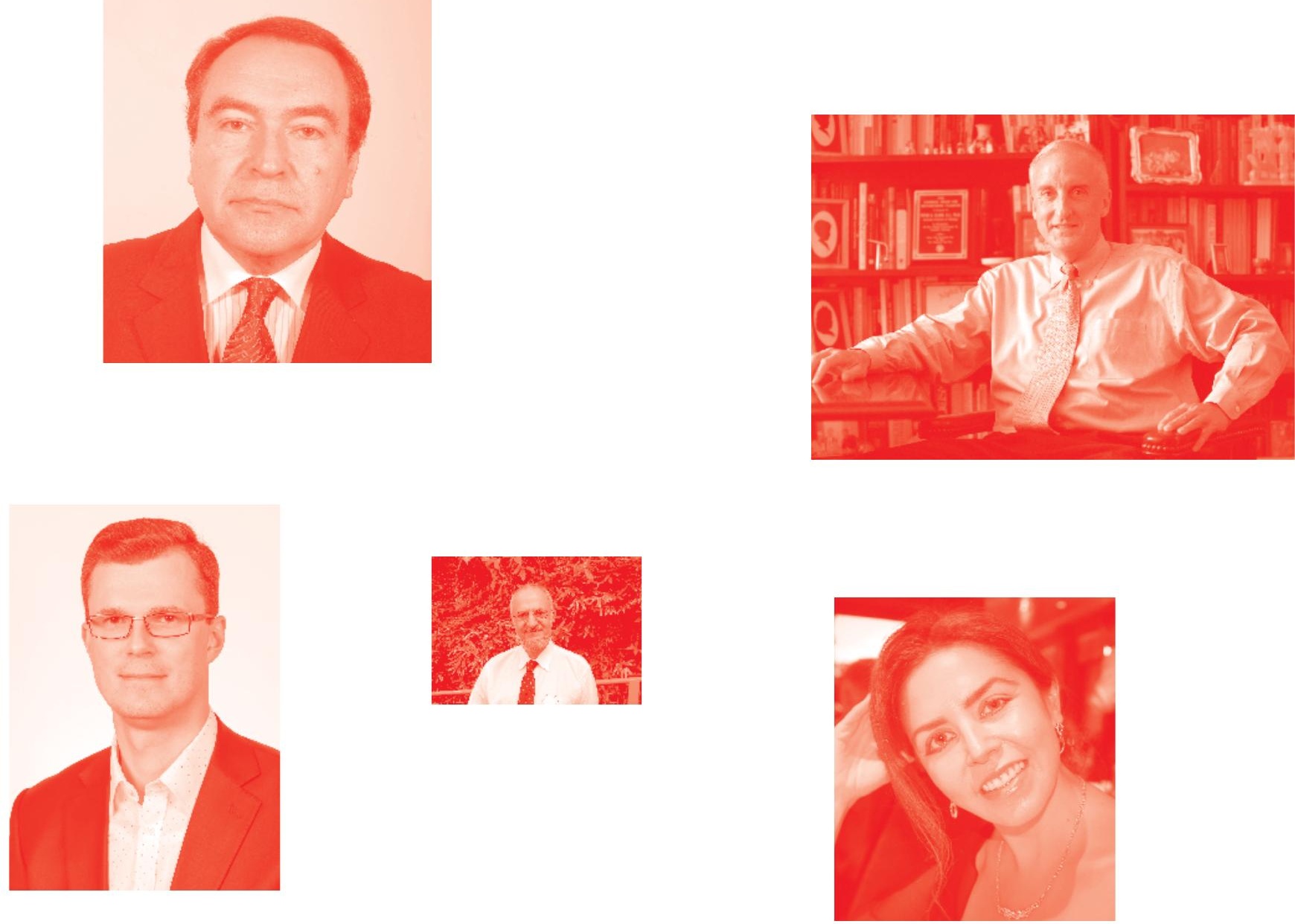

Supporting open minds since 2005
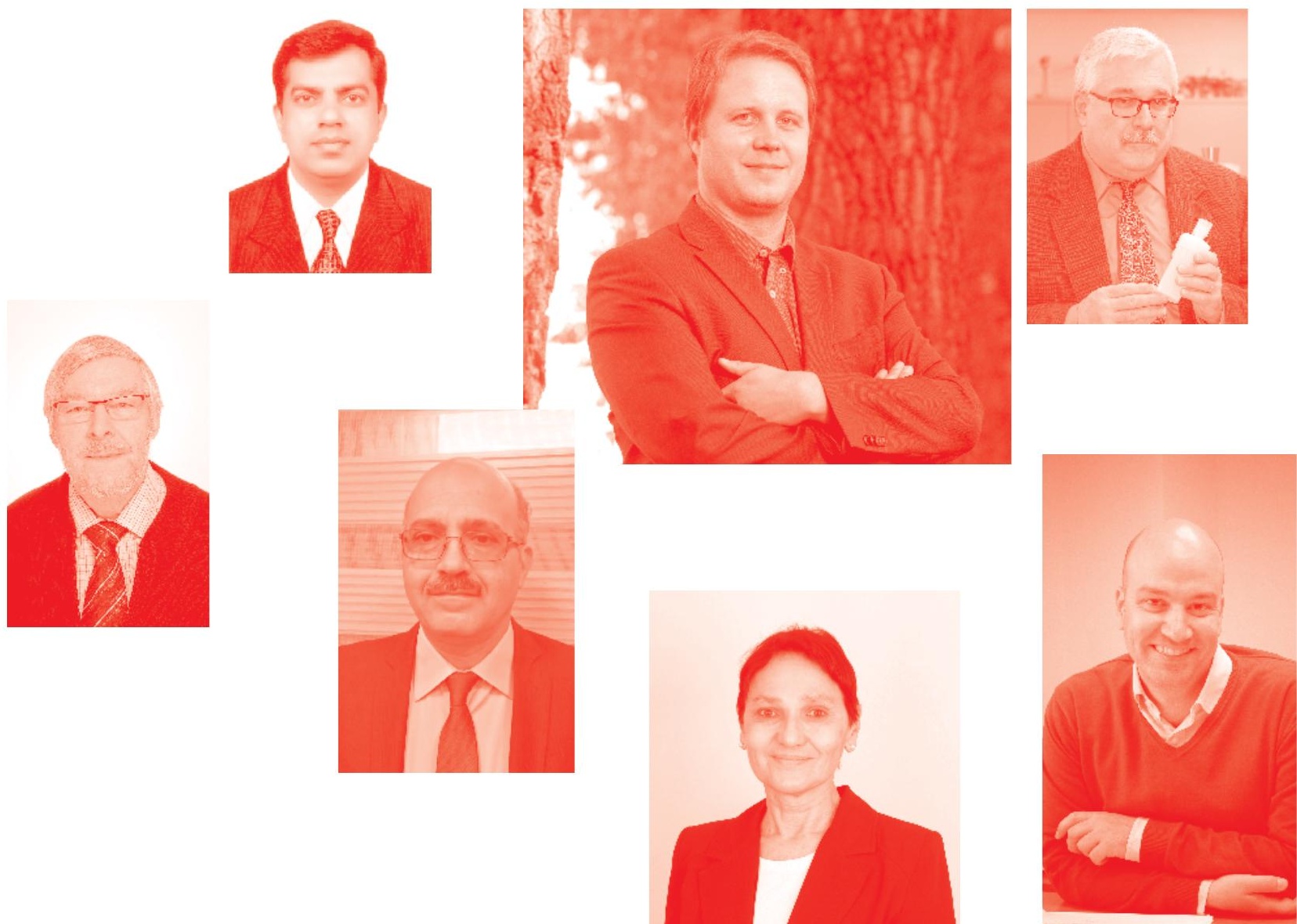
Food Preservation and Waste Exploitation

http : //dx. doi. org/10.5772/intechopen. 78920

Edited by Sonia A. Socaci, Anca C. Fărcaş, Thierry Aussenac and Jean-Claude Laguerre

Contributors

Romika Dhiman, Neeraj Kumar Aggarwal, Mohamad Mazen Hamoud-Agha, Karim Allaf, Jean-Claude Laguerre, Saroat Rawdkuen, Pimonpan Kaewprachu, Sunantha Ketnawa, Younes Moussaoui, Faten Mannai, Hanedi Elhleli, Ramzi Khiari, John Rojas, Javier Silva-Agredo, Julian Quintero, Yhors Ciro, Ricardo A. Torres-Palma, Alfredo Moreno, Sonia A. Socaci, Anca C. Fărcaş, Zorita M. Diaconeasa

() The Editor(s) and the Author(s) 2020

The rights of the editor(s) and the author(s) have been asserted in accordance with the Copyright, Designs and Patents Act 1988. All rights to the book as a whole are reserved by INTECHOPEN LIMITED. The book as a whole (compilation) cannot be reproduced, distributed or used for commercial or non-commercial purposes without INTECHOPEN LIMITED's written permission. Enquiries concerning the use of the book should be directed to INTECHOPEN LIMITED rights and permissions department (permissions@intechopen.com).

Violations are liable to prosecution under the governing Copyright Law .

\section{(cc) BY}

Individual chapters of this publication are distributed under the terms of the Creative Commons Attribution 3.0 Unported License which permits commercial use, distribution and reproduction of the individual chapters, provided the original author(s) and source publication are appropriately acknowledged. If so indicated, certain images may not be included under the Creative Commons license. In such cases users will need to obtain permission from the license holder to reproduce the material. More details and guidelines concerning content reuse and adaptation can be found at http : //www . intechopen . com/copyright-policy . html.

\section{Notice}

Statements and opinions expressed in the chapters are these of the individual contributors and not necessarily those of the editors or publisher. No responsibility is accepted for the accuracy of information contained in the published chapters. The publisher assumes no responsibility for any damage or injury to persons or property arising out of the use of any materials, instructions, methods or ideas contained in the book.

First published in London, United Kingdom, 2020 by IntechOpen

IntechOpen is the global imprint of INTECHOPEN LIMITED, registered in England and Wales,

registration number: 11086078, 7th floor, 10 Lower Thames Street, London,

EC3R 6AF, United Kingdom

Printed in Croatia

British Library Cataloguing-in-Publication Data

A catalogue record for this book is available from the British Library

Additional hard and PDF copies can be obtained from orders@intechopen.com

Food Preservation and Waste Exploitation

Edited by Sonia A. Socaci, Anca C. Fărcaş, Thierry Aussenac and Jean-Claude Laguerre

p. cm.

Print ISBN 978-1-78985-425-1

Online ISBN 978-1-78985-426-8

eBook (PDF) ISBN 978-1-78984-@84-1 


\section{We are IntechOpen, \\ the world's leading publisher of Open Access books}

\section{Built by scientists, for scientists}

\section{$4,600+$}

Open access books available

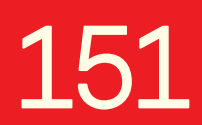

Countries delivered to

\section{$120,000+$}

International authors and editors

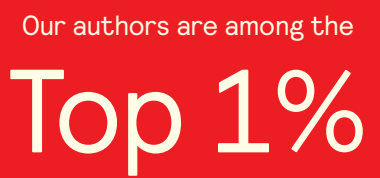

most cited scientists

Contributors from top 500 universities
$135 \mathrm{M}+$

Downloads
$12.2 \%$

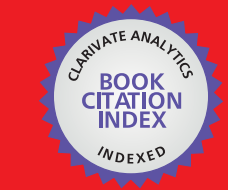

WEB OF SCIENCE ${ }^{\text {M }}$

Selection of our books indexed in the Book Citation Index in Web of Science ${ }^{\mathrm{TM}}$ Core Collection (BKCI)

\section{Interested in publishing with us? \\ Contact book.department@intechopen.com}

Numbers displayed above are based on latest data collected.

For more information visit www.intechopen.com 



\section{Meet the editors}

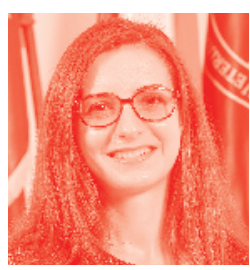

Sonia A. Socaci has a $\mathrm{PhD}$ degree in Biotechnologies awarded by the University of Agricultural Sciences and Veterinary Medicine Cluj-Napoca, Romania, and is currently a researcher and associate professor at the Faculty of Food Science and Technology. She has a solid background in the field of extraction and characterization of bioactive compounds from vegetal matrices, food waste exploitation, development of new functional products, food authentication, and quality control. She was involved in multiple national and international research projects as a member or project leader. Her current research is to continue in the previous interdisciplinary direction of characterizing the chemical composition of vegetal matrices and exploiting non-conventional sources of bioactive compounds using modern methods and innovative technology.

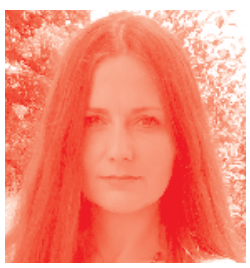

Anca C. Fărcaş is currently a postdoctoral researcher and assistant professor in the Department of Food Science, University of Agricultural Sciences and Veterinary Medicine Cluj-Napoca, Romania. She is an active member of the Laboratory for Testing of Food Quality and Safety, having a solid background in the field of food waste exploitation, extraction and analysis of bioactive compounds, development of new functional products, food authentication, and quality control. She was awarded a $\mathrm{PhD}$ in Biotechnology, and is currently working on a project that aims to develop an integrated system for the recovery of bioactive compounds from food waste. She has published more than 60 research articles and several book chapters in the field.

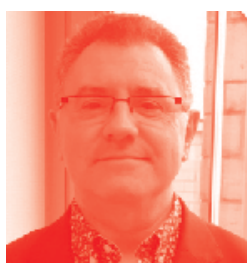

Thierry Aussenac is Scientific Director at UniLaSalle Polytechnic Institute, France, and since 2016 has been head of a research unit, Transformations and Agro-Resources (UP 2018.C103). He received his MSc in Production and Transformations of Agro-Resources from ESAP, France, in 1986, and his PhD and HDR (ability to conduct research) in Plant Science and Biochemistry from the National Polytechnic Institute of Toulouse (INPT), France, in 1990 and 1998, respectively. Since 2012, he has been the scientific coordinator of the national R\&D program OZONE2020 (ozone and food safety). He has published 60 papers in national and international peer-reviewed journals in the fields of cereal chemistry, food science, and analytical chemistry. He is a member of numerous international societies, a member of the editorial board of Advances in Biochemistry, and serves as reviewer of different international journals. 
Jean-Claude Laguerre has been working as faculty at UniLaSalle since 1991. He obtained his PhD diploma in Process Engineering (1991) from ENSIA of Massy, France (currently AgroParisTech). From 1995 he has been the coordinator of the specialty «Industrial organization in the agro-food industry,» which is dedicated to fifth year agroindustry students at UniLaSalle. He teaches various courses in the field of agro-food processes (i.e. food process basics, unit operations, product design, experimental design, and process optimization). He is a member of the research unit «Transformation and Agro-resources» at UniLaSalle. His research activities focus on thermal and microwave processes (drying, cooking, pasteurization, and sterilization). He has participated in several European research programs as task manager or scientific leader. He regularly collaborates with food companies by helping them to develop and/or optimize their processes. He is co-author of 19 articles published in peer-reviewed journals and 19 papers presented at international conferences. To date he has supervised or co-supervised two postdoctoral fellows, three PhD students, as well as $10 \mathrm{MSc}$ students. 


\section{Contents}

Preface

Section 1

Food Waste and Food Preservation Overview

Chapter 1

Introductory Chapter: From Waste to New Resources

by Anca C. Fărcaş, Sonia A. Socaci and Zorita M. Diaconeasa

Section 2

Food Preservation

Chapter 2

Instant Controlled Pressure Drop (DIC) Technology in Food Preservation:

Fundamental and Industrial Applications

by Mohamad Mazen Hamoud-Agha and Karim Allaf

Chapter 3

Microwave Heating for Food Preservation

by Jean-Claude Laguerre and Mohamad Mazen Hamoud-Agha

Chapter 4

Efficacy of Plant Antimicrobials as Preservative in Food

by Romika Dhiman and Neeraj Kumar Aggarwal

\section{Section 3}

Exploitation of Food Waste

Chapter 5

Extraction, Characterization, and Application of Agricultural and Food Processing By-Products

by Saroat Rawdkuen and Sunantha Ketnawa

Chapter 6

Valorization of Food Processing By-Products as Smart Food Packaging Materials and Its Application

by Saroat Rawdkuen and Pimonpan Kaewprachu 
Chapter 7

Comparative Assessment of Shrimp Hydrolyzates as Alternative Organic

Fertilizers for Legumes

by John Rojas, Julian Qunitero, Yhors Ciro, Alfredo Moreno, Javier Silva-Agredo

and Ricardo A. Torres-Palma

Chapter 8

Cellulosic Fibers from Lignocellulosic Biomass for Papermaking Applications by Faten Mannai, Hanedi Elhleli, Ramzi Khiari and Younes Moussaoui 


\section{Preface}

One of the biggest challenges facing the food industry and society is the reduction of food waste. Annually, all over the world, millions of tons of agro-food waste are produced, and their efficient management and valorization represents one of the main objectives of EU actions towards sustainable development.

This book compiles information on the possibilities of the recovery of valuable compounds from food waste and their valorization in different food and nonfood applications, as well as new preservation methods for optimizing food waste reduction. The book is divided into the following sections:

Section 1-Food Waste and Food Preservation Overview, which includes Chapter 1, gives a brief overview of the main extraction techniques used for the recovery of bioactive compounds from food waste and the conventional and modern preservation methods used for minimizing food waste.

Section 2-Food Preservation includes Chapters 2-4. The first two chapters focus on two modern preservation techniques, namely instant controlled pressure drop technology and microwave technology. The last chapter of this section discusses the efficacy of plant antimicrobials in assuring an enhanced shelf-life and the safety of food products.

Section 3-Exploitation of Food Waste, which includes four chapters, describes various ways in which food waste can be used to produce different value-added products with manifold applications.

The authors involved in writing these chapters are recognized professionals with solid expertise in their working field. All discussed topics are of major interest for researchers, scientists, and university students as well as experts from the private sector interested in developing innovative and sustainable products.

We would like to acknowledge all the authors and the co-editors for their contributions to this book. Also, we are grateful to the Author Service Managers, Ms. Sara Bacvarova and Ms. Sandra Maljavac, for their great support and assistance throughout the publication process of this book.

Sonia A. Socaci

Faculty of Food Science and Technology, University of Agricultural Sciences and Veterinary Medicine Cluj-Napoca, 
Anca C. Fărcaş

University of Agricultural Sciences and Veterinary Medicine Cluj-Napoca, Romania

Thierry Aussenac and Jean-Claude Laguerre UniLaSalle Polytechnic Institute,

France 
Section 1

\section{Food Waste and Food Preservation Overview}





\title{
Introductory Chapter: From Waste to New Resources
}

\author{
Anca C. Fărcaş, Sonia A. Socaci and Zorita M. Diaconeasa
}

\section{Introduction}

Food represents as one of the most basic human needs, providing our physical integrity. The entire planet is facing an alarming issue, regarding the amount of edible food and by-products, which are wasted in an increasingly manner. Moreover, food manufacturing requires resources such as soil and water and involves various processes, which generate huge amounts of food waste. As the production of food is resource-intensive, food losses and wastes are strongly correlated with a broad range of environmental problems, such as water and air pollution, soil erosion, and greenhouse gas emissions; all of these undesirable effects occur in all stages of production, storage, and transportation as well as in the case of adopting a deficient management system [1].

The generation of food waste is inevitable, especially during the pre-consumption stage. It is estimated that up to $42 \%$ of food waste is generated from household activities, 39\% occur from the food manufacturing industry, and 14\% occur from the food service sector (catering and restaurants), while $5 \%$ is lost during storage and distribution. This problem is intensified by the global population growth leading consequently to an increasing demand for natural resources like food and energy $[2,3]$.

Nowadays, the biggest challenge of the scientific world is to provide viable alternative models that combine food production with an efficient valorization strategy of waste and by-product, minimization of energy consumption, and environmental protection. In this context, the exploitation of food waste or by-products for the recovery of valuable functional compounds can be considered as being one of the most feasible approaches [4].

In order to implement a circular economy in any industrial sector, two main strategies are needed: reducing waste levels and finding the most sustainable solution to manage the remaining waste. In particular, the waste management of new strategies focus on the following actions: waste prevention, reuse, recycling, energy recovery, and, lastly, disposal [5].

Until a few decades ago, food waste was considered neither a cost nor a benefit being usually discarded to landfills, sent for composting, or used as animal feed. The negative perception on these by-products and implicitly the application of a deficient management lead to environmental degradation and especially to significant loss of valuable material that could otherwise be exploited as food, fuels, and a great variety of additives [6].

At present, the attitude has changed radically, the researches being intensely oriented toward the identification and extraction of valuable compounds from residues and their reintegration in the food industry but also in other fields such as cosmetics, pharmaceuticals, or agriculture (Figure 1). 


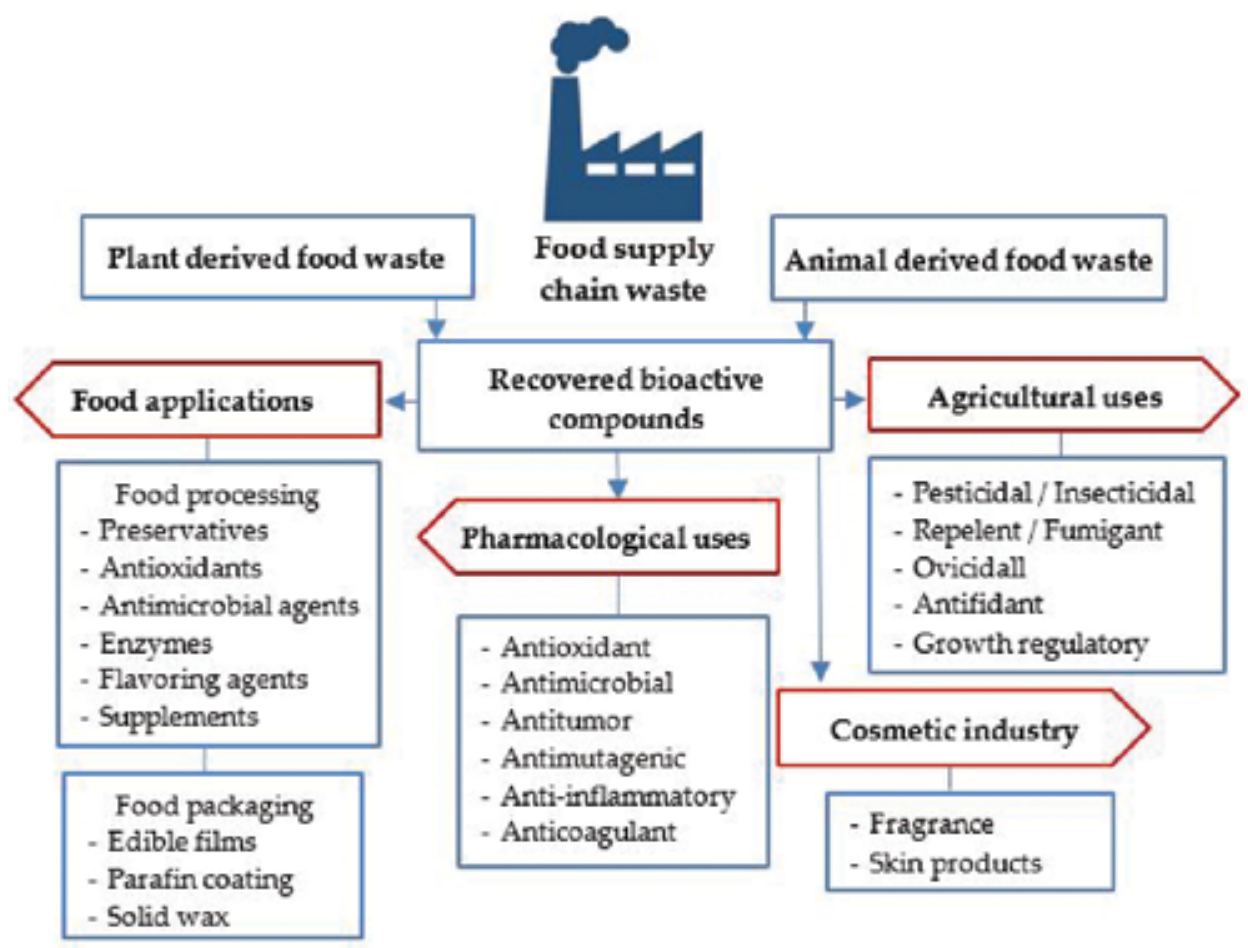

Figure 1.

The main applications of bioactive compounds extracted from agri-food waste.

Using the recovered bioactive molecules as functional ingredients represents a sustainable alternative of food waste exploitation as an inexpensive source of valuable compounds while developing innovative food and nonfood products with health-promoting benefits and at the same time contributing to an efficient waste reduction management.

\section{Extraction technologies for bioactive compounds from food waste}

Most of the wastes generated by the agri-food industries are difficult to store, transport, and process because of the biological instability, pathogenic potential, high levels of nutrients or enzyme activity, high water content, and the potential for self-oxidation.

The new aspects concerning the use of agri-food wastes as by-products for further exploitation in the production of various functional products must be environmentally friendly and sustainable from the economic point of view [7-9]. Therefore, it is imperative to identify the most feasible and optimized stabilization methods in order to ensure a flow of biomass with a constant composition and reduced storage and transport costs.

For this purpose, technological innovation has favored the development of many effective exploitation methods, with cogeneration of electricity and thermal biogas, also called green energy. In addition, the implementation of a biorefinery concept offers remarkable opportunities to valorize biomass by converting it to a wide range of chemicals with many applications in food, cosmetic, and pharmaceutical industries $[10,11]$.

The innovative approach of converting food waste in new generation of useful products involves the application of unconventional methods and advanced techniques in order to model the most appropriate and sustainable recovery system (Figure 2). 


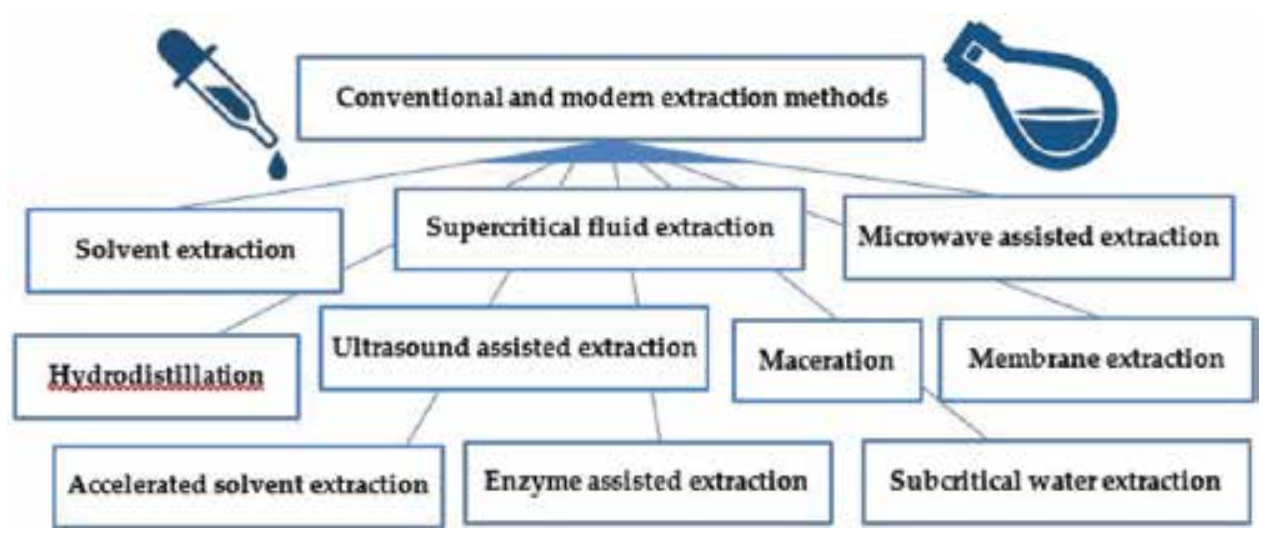

Figure 2.

A schematic representation of the most used conventional and novel techniques suitable for extracting biomolecules.

Nevertheless, the extraction protocols cannot be used indiscriminately, and their choice depends on the type of bioactive compounds and matrix structure, the processing scale (pilot or industrial level), the balance between processing costs and economic income of the recovered component, and their new assigned destinations [6].

In the last years, the researches focused on the development and optimization of the methods for the recovery and purifications of the functional compounds; some of them are based on new emerging techniques, but some are effective by applying and modeling the existing conventional method. In both situations, the extraction of the high-value components must be environmentally friendly and economically feasible to perform.

The applied parameters have a major impact on the release of the bioactive compounds from the matrix but also on their structure and functionality. Therefore, selecting the most suitable extraction protocol is a decisive step for the recovery of the valuable component $[6,9,12]$.

Several examples of bioactive compounds recovered from food processing byproducts and the selected extraction methods are presented in Table 1.

\section{Food preservation for minimizing food waste}

Beside the possibilities mentioned before for the proper management of food waste and its valorization through the recovery of the bioactive compounds, we also need to consider the role of food preservation to reduce food waste. Following harvest, slaughter, or manufacture, all foods start to lose quality. The rate at which food quality is lost is dependent on food type, composition, the way it was processed, packed and storage conditions. On the other hand, the lost of quality and safety attributes of the foods may occur at any stage in the food chain generating food waste: raw material storage; product formulation; processing; packaging; storage in the factory; distribution to depots and storage; distribution to retail outlets; display in stores; sale to the consumer and further storage; preparation for consumption. Nonetheless, by applying conventional, highly advanced or hurdle preservation techniques (Figure 3), one can impede the chemical or microbiological deteriorations, thus preventing outbreaks of foodborne illness and at the same time limiting the food waste. As it is illustrated in Figure 3, in the food industry, beside the commonly used preservation techniques, a number of new ones are being developed to 


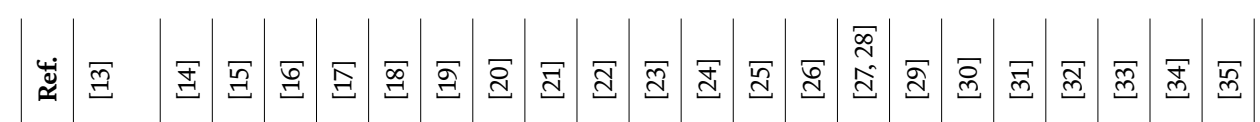

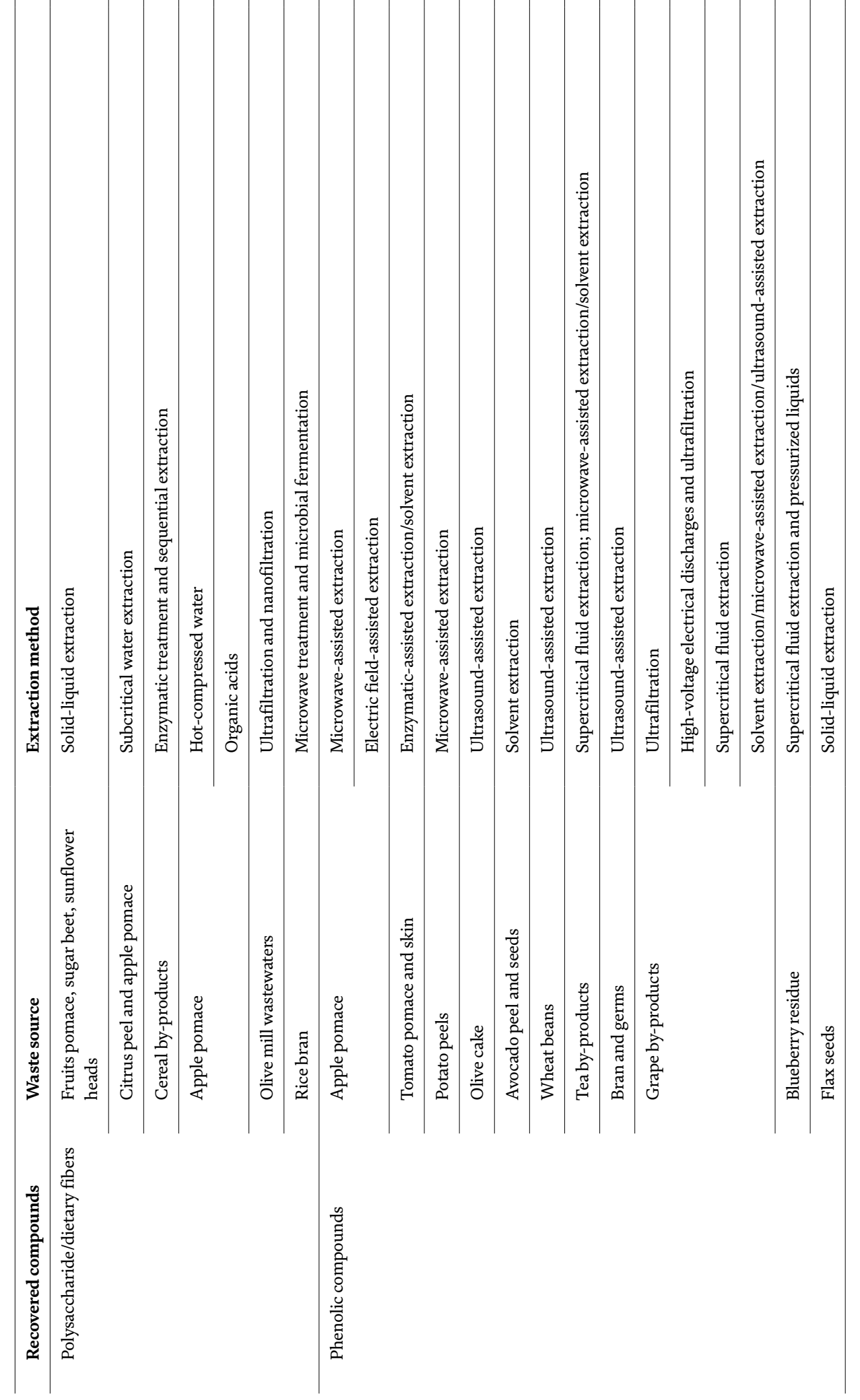




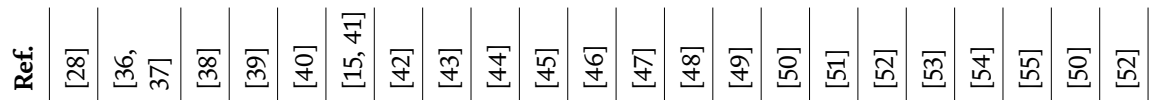

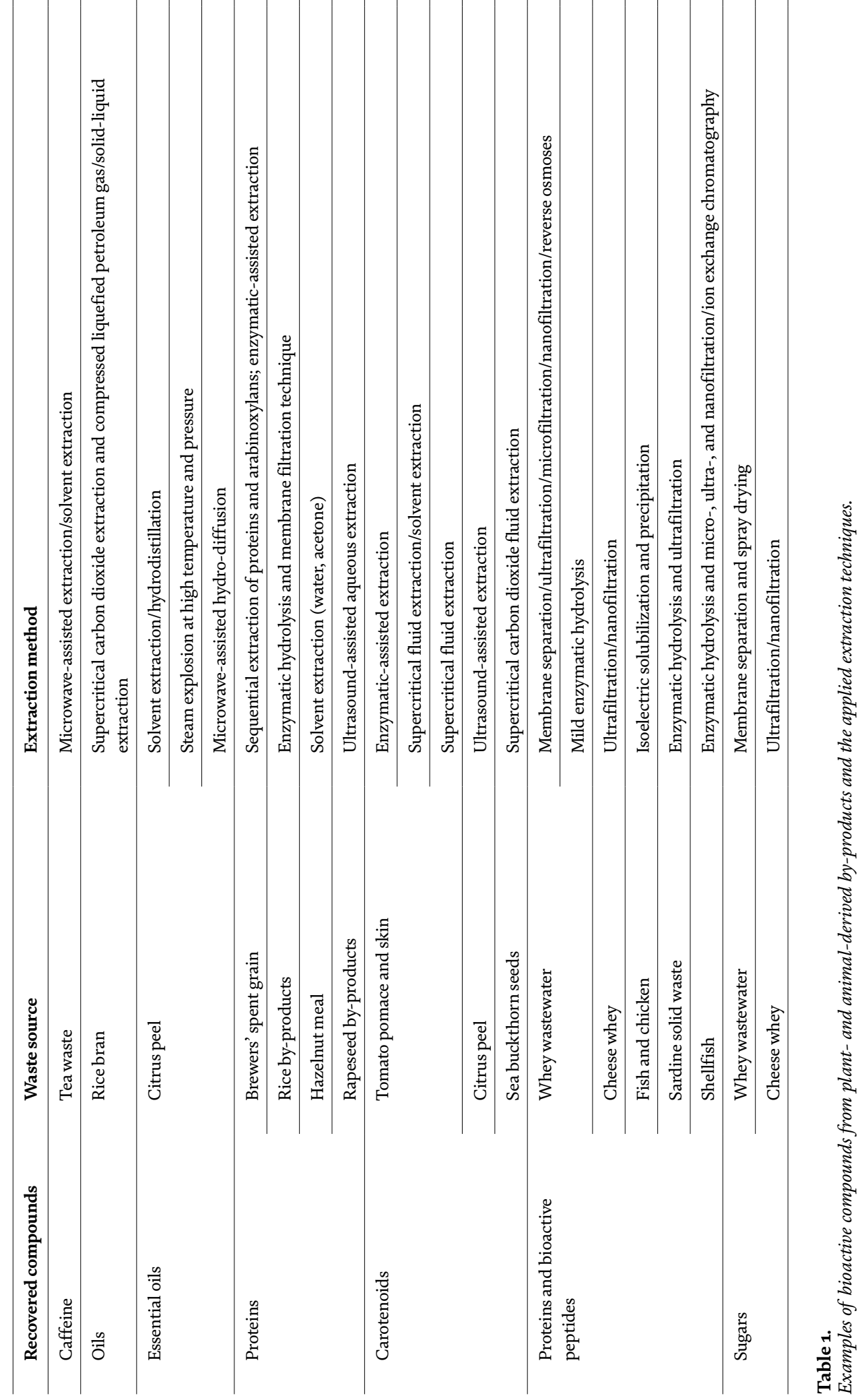




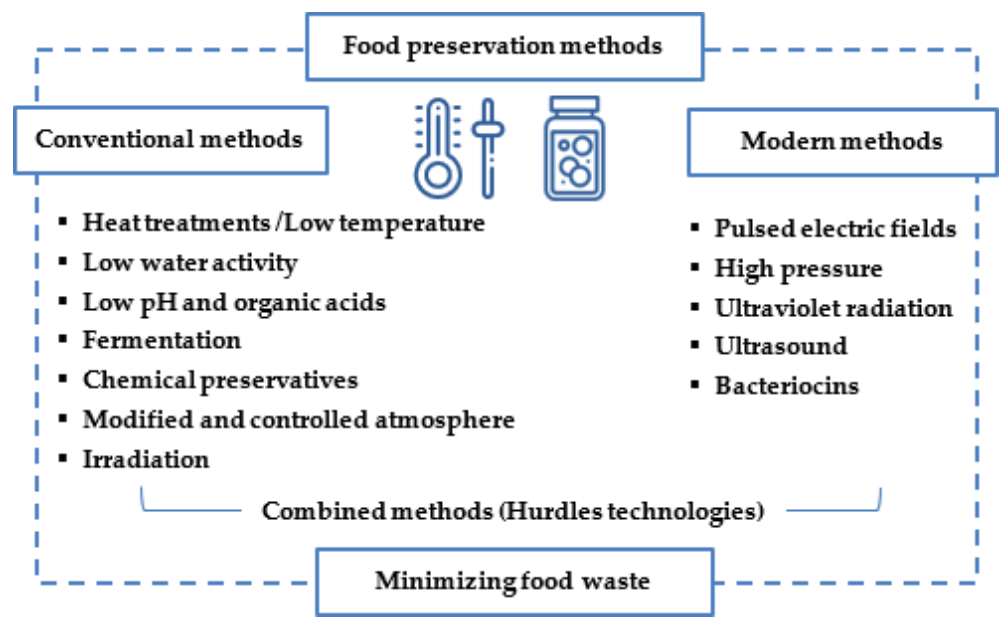

Figure 3.

A schematic representation of the most used conventional and novel techniques for foods preservation.

satisfy the current demands of economic preservation and consumer satisfaction in safety, nutritional and sensory aspects. Also, as the preservation of foods is often a multicomponent issue, the "hurdle" concept was introduced, highlighting the complex interaction between the factors that are significant for food safety and stability [56-58].

\section{Concluding remarks and future trends}

The idea of converting the agri-food waste into functional ingredients is an area of research with huge potential and opportunities. Many researches in biotechnology have already shown that agri-food by-products are no longer regarded as a waste but rather a valuable substrate for producing a new range of useful compounds. Based on this, it is an undeniable fact that, through compatible biotechnological processes, every food processing by-product possesses a relevant potential for a sustainable reuse.

The recent findings, presented in the chapters of this book, highlighted the potential reuse of food industry by-products and led to the idea that multidisciplinary approaches should be implemented in order to achieve the most effective exploitation protocol or to develop integrated biorefineries

\section{Acknowledgements}

This work was supported by three grants of Ministry of Research and Innovation, CNCS - UEFISCDI, project number PN-III-P1-1.1-PD-2016-0869, CNCS - UEFISCDI, project number PN-III-P1-1.1-TE-2016-0973 and CNCSUEFISCDI Projects for Financing the Excellence in CDI, Contract no. 37PFE/06.11.2018. 


\section{Author details}

Anca C. Fărcaş, Sonia A. Socaci* and Zorita M. Diaconeasa Faculty of Food Science and Technology, University of Agricultural Sciences and Veterinary Medicine, Cluj-Napoca, Romania

*Address all correspondence to: sonia.socaci@usamvcluj.ro

\section{IntechOpen}

(C) 2019 The Author(s). Licensee IntechOpen. This chapter is distributed under the terms of the Creative Commons Attribution License (http://creativecommons.org/licenses/ by/3.0), which permits unrestricted use, distribution, and reproduction in any medium, provided the original work is properly cited. (cc) BY 


\section{References}

[1] Mourad M. Recycling, recovering and preventing food waste: Competing solutions for food systems sustainability in the United States and France. Journal of Cleaner Production. 2016;126:461-477

[2] Ravindran R, Jaiswal AK. Exploitation of food industry waste for high-value products. Trends in Biotechnology. 2016;(34):58-69

[3] Kumar K, Yadav A, Kumar V, Vyas P, Dhaliwal HS. Food waste: A potential bioresource for extraction of nutraceuticals and bioactive compounds. Bioresources and Bioprocessing. 2017;4:18

[4] Socaci SA, Farcas AC, Galanakis CM. Introduction in functional components for membrane separations. In: Galankis C, editor. Separation of Functional Molecules in Food by Membrane Technology 2019. London, UK: Academic Press. pp. 31-77

[5] Garcia-Garcia G, Stone J, Rahimifard S. Opportunities for waste valorisation in the food industry-A case study with four UK food manufacturers. Journal of Cleaner Production. 2019;211:1339-1356

[6] Baiano A. Recovery of biomolecules from food wastes-A review. Molecules. 2014;19:14821-14842

[7] Mathias TR, de Mello PM, Sérvulo EF. Solid wastes in brewing process: A review. Journal of Brewing and Distilling. 2014;5(1):1-9

[8] Mussatto SI. Brewer's spent grain: A valuable feedstock for industrial applications. Journal of the Science of Food and Agriculture. 2014;94(7):1264-1275

[9] Farcas AC, Socaci SA, Mudura E, Dulf FV, Vodnar DC, Tofana M, et al.
Exploitation of brewing industry wastes to produce functional ingredients.

In: Kanauchi M, editor. Brewing Technology. Rijeka, Croatia: InTech; 2017. pp. $137-156$

[10] Otles S, Kartal C. Food waste valorisation. In: Galanakis C, editor. Sustainable Food Systems from Agriculture to Industry. Academic Press; 2018

[11] Tsang YF, Kumar V, Samadar P, Yang Y, Lee J, Ok YS, et al. Production of bioplastic through food waste valorization. Environment International. 2019;127:625-644

[12] Socaci SA, Farcas AC, Vodnar DC, Tofana M. Food wastes as valuable sources of bioactive molecules. In: Shiomi N, editor. Superfood and Functional Food-The Development of Superfoods and Their Roles as Medicine. Rijeka, Croatia: InTech; 2017. pp. 75-93

[13] Waldron K. Handbook of Waste Management and Co-Product Recovery in Food Processing. Cambridge, UK: Woodhead Publishing; 2009

[14] Wang X, Chen Q, Lü X. Pectin extracted from apple pomace and citrus peel by subcritical water. Food Hydrocolloids. 2014;38:129-137

[15] Vieira E, Rocha MAM, Coelho E, Pinho O, Saraiva JA, Ferreira I, et al. Valuation of brewer's spent grain using a fully recyclable integrated process for extraction of proteins and arabinoxylans. Industrial Crops and Products. 2014;52:136-143

[16] Wang X, Lü X. Characterization of pectic polysaccharides extracted from apple pomace by hot-compressed water. Carbohydrate Polymers. 2014;102:174-184 
[17] Panchami PS, Gunasekaran S. Extraction and characterization of pectin from fruit waste. International Journal of Current Microbiology and Applied Sciences. 2017;6(8):943-948

[18] Galanakis CM, Tornberg E, Gekas V. Clarification of highadded value products from olive mill wastewater. Journal of Food Engineering. 2010;99:190-197

[19] Liu Q, Cao X, Zhuang X, Han W, Guo W, Xiong J, et al. Rice bran polysaccharides and oligosaccharides modified by Grifola frondosa fermentation: Antioxidant activities and effects on the production of NO. Food Chemistry. 2017;223:49-53

[20] Chandrasekar V, San Martín-González MF, Hirst P, Ballard TS. Optimizing microwaveassisted extraction of phenolic antioxidants from Red delicious and Jonathan apple pomace. Journal of Food Process Engineering. 2015;38(6):571-582

[21] Lohani UC, Mutukumarappan K, Meletharayl GH. Application of hydrodynamic cavitation to improve antioxidant activity in sorghum flour and apple pomace. Food and Bioproducts Processing. 2016;100 (Part A):335-343

[22] Azabou S, Abid Y, Sebii H, Felfoul I, Gargouri A, Attia H. Potential of the solid-state fermentation of tomato by products by Fusarium solani pisi for enzymatic extraction of lycopene. LWT-Food Science and Technology. 2016;68:280-287

[23] Singh A, Sabally K, Kubow S, Donnelly DJ, Gariepy Y, Orsat V, et al. Microwave-assisted extraction of phenolic antioxidants from potato peels. Molecules. 2011;16:2218-2232

[24] Mojerlou Z, Elhamirad A. Optimization of ultrasound-assisted extraction (UAE) of phenolic compounds from olive cake. Journal of Food Science and Technology. 2018;55(3):977-984

[25] Deng GF, Shen C, Xu XR, Kuang RD, Guo YJ, Zeng LS, et al. Potential of fruit wastes as natural resources of bioactive compounds. International Journal of Molecular Sciences. 2012;13:8308-8323

[26] Pasqualone A, Delvecchio LN, Gambacorta G, Laddomada B, Urso V, Mazzaglia A, et al. Effect of supplementation with wheat bran aqueous extracts obtained by ultrasound-assisted technologies on the sensory properties and the antioxidant activity of dry pasta. Natural Product Communications. 2015;10(10):1739-1742

[27] Li J, Chase HA. Applications of membrane techniques for purification of natural products. Biotechnological Letters. 2010;32(5):601-608

[28] Serdar G, Demir E, Sökmen M. Recycling of tea waste: Simple and effective separation of caffeine and catechins by microwave assisted extraction (MAE). International Journal of Secondary Metabolite. 2017;2:78-89

[29] Wang J, Sun B, Cao Y, Tian Y, Li X. Optimisation of ultrasound-assisted extraction of phenolic compounds from wheat bran. Food Chemistry. 2008;106:804-810

[30] Galanakis CM, Markouli E, Gekas V. Fractionation and recovery of different phenolic classes from winery sludge via membrane filtration. Separation and Purification Technology. 2013;107:245-251

[31] Liu D, Vorobiev E, Savoire R, Lanoisellé JL. Intensification of polyphenols extraction from grape seeds by high voltage electrical 
discharges and extract concentration by dead-end ultrafiltration. Separation and Purification Technology.

2011;81:134-140

[32] Casas L, Mantell C, Rodríguez M, de la Ossa EM, Roldán A, De Ory I, et al. Extraction of resveratrol from the pomace of Palomino fino grapes by supercritical carbon dioxide. Journal of Food Engineering. 2010;96:304-308

[33] Drosou C, Kyriakopoulou K, Bimpilas A, TsimogiannisD, KrokidaM. A comparative study on different extraction techniques to recover red grape pomace polyphenols from vinification byproducts. Industrial Crops and Products. 2015;75:141-149

[34] Paes J, Dotta R, Barbero GF, Martinez J. Extraction of phenolic compounds and anthocyanins from blueberry (Vaccinium myrtillus L.) residues using supercritical $\mathrm{CO}_{2}$ and pressurized liquids. Journal of Supercritical Fluids. 2014;95:8-16

[35] Sainvitu P, Nott K, Richard G, Blecker C, Jérôme C, Wathelet JP, et al. Structure, properties and obtention routes of flaxseed lignan secoisolariciresinol: A review. Biotechnologie, Agronomie, Société et Environnement. 2012;16:115-124

[36] Soares JF, Dal Prá V, de Souza M, Cavalheiro Lunelli F, Abaide E, da Silva JRF, et al. Extraction of rice bran oil using supercritical $\mathrm{CO}_{2}$ and compressed liquefied petroleum gas. Journal of Food Engineering. 2016;170:58-63

[37] Javed F, Ahmad SW, Rehman A, Zafar S, Malik SR. Recovery of rice bran oil using solid-liquid extraction technique. Journal of Food Process Engineering. 2014;38(4):357-362

[38] Thongnuanchan P, Benjakul S. Essential oils: Extraction, bioactivities, and their uses for food preservation.
Journal of Food Science. 2014;79(7):1231-1249

[39] Golmohammadi M, Borghei A, Zenouzi A, Ashrafi N, Taherzadeh MJ. Optimization of essential oil extraction from orange peels using steam explosion. Heliyon. 2018;4(11):e00893

[40] Auta M, Musa U, Tsado DG, Faruq AA, Isah AG, Raji S, et al. Optimization of citrus peels D-limonene extraction using solvent-free microwave green technology. Chemical Engineering Communications. 2018;205(6):789-796

[41] Niemi P, Martins D,

Buchert J, Faulds CB. Pre-hydrolysis with carbohydrases facilitates the release of protein from brewer's spent grain. Bioresource Technology. 2013;136:529-534

[42] Ferry M, Graen-Heedfeld J, Bretz K, Guillon F, Michelini E, Calabretta MM, et al. Peptide fractions obtained from rice by-products by means of an environment-friendly process show in vitro health-related bioactivities. PLoS One. 2017;12(1):e0170954

[43] Aydemir LY, Gökbulut AA, Baran Y, Yemenicioglu A. Bioactive, functional and edible film-forming properties of isolated hazelnut (Corylus avellana L.) meal proteins. Food Hydrocolloids. 2014;36:130-142

[44] Yu X, Gouyo T, Grimi N, Bals O, Vorobiev E. Ultrasound enhanced aqueous extraction from rapeseed green biomass for polyphenol and protein valorization. Comptes Rendus Chimie. 2016;19:766-777

[45] Kong KW, Khoo HE, Prasad KN, Ismail A, Tan CP, Rajab NF. Revealing the power of the natural red pigment lycopene. Molecules. 2010;15:959-987

[46] Kehili M, Kammlott M, Choura S, Zammel A, Zetzl C, Smirnova I, et al. 
Supercritical CO2 extraction and antioxidant activity of lycopene and $\beta$-carotene-enriched oleoresin from tomato (Lycopersicum esculentum L.) peels by-product of a Tunisian industry. Food and Bioproducts Processing. 2017;102:340-349

[47] Nobre BP, Palavra AF, Pessoa FL, Mendes RL. Supercritical $\mathrm{CO}_{2}$ extraction of trans-lycopene from Portuguese tomato industrial waste. Food Chemistry. 2009;116:680-685

[48] Boukroufa M, Boutekedjiret C, Chemat F. Development of a green procedure of citrus fruits waste processing to recover carotenoids. Resource-Efficient Technologies. 2017;3:252-262

[49] Kagliwal LD, Patil S, Pol A, Singhal R, Patravale V. Separation of bioactives from seabuckthorn seeds by supercritical carbon dioxide extraction methodology through solubility parameter approach. Separation and Purification Technology. 2011;80(3):533-540

[50] Prazeres AR, Carvalho F, Rivas J. Cheese whey management: A review. Journal of Environmental Management. 2012;110:48-68

[51] Muro Urista C, Álvarez Fernández R, Riera Rodriguez F, Arana Cuenca A, Téllez JA. Review: Production and functionality of active peptides from milk. Food Science and Technology International. 2011;17(4):293-317

[52] Galanakis CM, Chasiotis S, Botsaris G, Gekas V. Separation and recovery of proteins and sugars from Halloumi cheese whey. Food Research International. 2014;65:477-483

[53] Shi L, Beamer SK, Yin T, Matak KE, Yang H, Jaczynski J. Mass balance for isoelectric solubilization/precipitation of carp, chicken, menhaden, and krill.
LWT_Food Science and Technology. 2017;81:26-34

[54] Benhabiles MS, Abdi N, Drouiche N, Lounici H, Pauss A, Goosen MFA, et al. Fish protein hydrolysate production from sardine solid waste by crude pepsin enzymatic hydrolysis in a bioreactor coupled to an ultrafiltration unit. Materials Science and Engineering. 2012;32(4):922-928

[55] Beaulieu L, Thibodeau J, Bonnet C, Bryl P, Carbonneau ME. Detection of antibacterial activity in an enzymatic hydrolysate fraction obtained from processing of Atlantic rock crab (Cancer irroratus) by-products. Pharma and Nutrition. 2013:149-157

[56] Amit SK, Uddin MM, Rahman R, Islam R, Khanet MS. A review on mechanisms and commercial aspects of food preservation and processing. Agriculture and Food Security. 2017;6:51

[57] Shajil S, Mary A, Rani Juneius CE. Recent food preservation techniques employed in the food industry. In: Patra J, Das G, Shin HS, editors. Microbial Biotechnology. Springer; 2018

[58] Prokopov T, Tanchev S. Methods of food preservation. In: McElhatton A, Marshall RJ, editors. Food Safety a Practical and Case Study Approach. Springer; 2007 

Section 2

\section{Food Preservation}





\title{
Instant Controlled Pressure Drop (DIC) Technology in Food Preservation: Fundamental and Industrial Applications
}

\author{
Mohamad Mazen Hamoud-Agha and Karim Allaf
}

\begin{abstract}
Alternative to conventional processes, many innovative techniques have been studied to preserve the nutritional quality and to protect food from deterioration. This chapter represents the principles and the applications of the instant controlled pressure drop (DIC) process in food drying and decontamination. This process is considered as a highly appropriate HTST-type treatment induced by subjecting the material to saturated steam, during a short time, followed by an instant pressure drop leading to auto evaporation of water, product texturing, and cooling. This effect results in improved drying of foods and in killing of the vegetative bacteria and/or spores with no impact on thermosensitive molecules or on the product quality. A wide range of foods and pharmaceutical products were effectively treated by DIC technology at both laboratory and industrial scales.
\end{abstract}

Keywords: instant controlled pressure drop, DIC, food drying, swell drying, decontamination, microbiological safety, food preservation

\section{Introduction}

Food safety is a major concern to researchers and industries. Conventional technologies are generally easy-to-use methods to transform and to conserve foods. Some of these methods create unsuitable conditions in order to inhibit the microbial growth such as drying, chilling, freezing, salting, etc.; otherwise, other methods aim to kill or eliminate the pathogens such as the heat treatments and microfiltration for example [1]. The international standards and the consumer attitudes are becoming increasingly straight regarding the safety and the quality of food products. Many food compounds and ingredients are well known to be sensitive to heat and vulnerable to other chemical or physical changes. Low production efficiency, losses of some nutritional elements, and time and energy consumption are often encountered using the traditional food processing technologies. This is why there is an acute need for improved and appropriate production methods, which ensure the microbiological safety and allow better preservation of organoleptic and nutritional quality at the same time [2]. 
Innovative food drying and decontamination techniques have become commercially an important alternative to conventional processes due to their profound advantages over the classic ones. The innovative methods are characterized by higher product quality, better production efficiency, energy saving, and environmental preservation compared with the conventional food processing methods $[1,3,4]$.

Drying is a widely used process for preservation of agricultural and food products [3]. It consists in removing water, thus lowering the water activity, which limits the development of microorganisms, slows down or stops the majority of chemical and/ or enzymatic reactions [5], and extends, as a result, the shelf life of these products. It is necessary to distinguish between drying and dehydration: drying refers to the removal of excess free water contained in the product, while dehydration means to remove all traces of water in the product [6]. Conventional drying techniques (convective drying by hot air, conduction, atomization, etc.) may have major disadvantages regarding the nutritional and sensory quality of foods [7]. Degradation of some nutritional compounds and loss of color and aroma of dried products are reported in the literature [8]. Furthermore, conventional drying usually results in shrinkage of the biological material, which has often prejudicial impact on the functional and rehydration properties of the dried products [9]. Various advanced methods were proposed in the literature to overcome the disadvantages of conventional drying such as lyophilization (freeze-drying) for example [3]. Nevertheless, the high cost of this technology limits its use at industrial scale to high value-added products, such as pharmaceuticals. This method is slow and has no influence on the initial microbiological load of the fresh product [10].

Likewise, the conventional decontamination thermal processes (pasteurization, sterilization, and blanching) are the major methods for food preservation [11]. Although relatively effective, these methods often require an intense heat treatment to ensure the inactivation of some enzymes and pathogenic and spoilage microorganisms, which naturally alters the qualities of the end product.

Ultra-high-temperature (UHT) treatment is successfully used to provide safe and accepted quality products, but this method is limited for liquids. The decontamination of solid foods, particularly powders and granular products, stays a challenge. Several new decontamination treatments were presented in the literature to treat the solid foods such as the dielectric heating for example [12]. This method is characterized by noncontact volumetric and rapid heating due to the interaction of dipoles (principally: water) and ionic charges contained within the product with electromagnetic alternating fields. However, nonuniformity of dielectric heating is still the main drawback of this technology $[13,14]$. Furthermore, in order to preserve the natural aspects of food products, some nonthermal decontamination methods were also studied, such as the pulsed electric fields, high pressure processing, etc. [4]. However, the industrial application of these technologies is still limited.

An innovative process called instant controlled pressure drop (Détente instantannée contrôlée in French, DIC) was invented as a drying and decontamination food process. This process is based on the thermomechanical effect induced by a rapid pressure drop leading to instant evaporation of water and inactivation of vegetative bacteria and spores. DIC technology is distinguished by its ability to handle a wide range of solid food products. In addition, this process results in volume expansion and positive texture modification. Preservation of sensory aspects and nutriment compounds of food products was also reported using this technology. Based on the DIC technology, many industrial projects were realized and several patents were filed [15]. The DIC technology as a food drying and microbial decontamination process is reviewed in this chapter. 


\section{Instant controlled pressure drop (DIC) technology}

\subsection{Theoretical principles}

Instant controlled pressure drop (French acronym: DIC, for "Détente Instantané Contrôlée") was invented by Allaf and Vidal as, practically, a high temperature short time (HTST) type process followed by an abrupt pressure drop toward a vacuum [16]. The different steps of a typical DIC treatment are presented in detail in (Figure 1).

This process consists of, in the first place, a short heating step (10-60 s) including a saturated steam injection under high-pressure (up to $1 \mathrm{MPa}$ ) applied to product put initially under vacuum. This step involves vapor condensation and product heating, in which the moisture content of the product increases by $0.1 \mathrm{~g} \mathrm{H}_{2} \mathrm{O} / \mathrm{g}$ dry basis. The initial vacuum ensures rapid contact between the steam and the sample and consequently improves the heat transfer. Sometimes, the compressed air could be used as a pressurized agent as for the multicycle DIC treatment. Following the first heating step, the abrupt dropping of pressure $\left(0.5 \mathrm{MPa}^{-1}\right)$ toward a vacuum (3-5 kPa) over only 10-60 ms results in an auto evaporation of water within the product, which produces an amount of vapor and a significant mechanical stress enabling the product to be expanded. Furthermore, the auto evaporation of water ensures rapid cooling, which prevents the thermal degradation of the sensitive compounds and thus ensures the high quality of treated products. The cooling rate can reach exceptional levels of $1500-2000 \mathrm{~kW} \mathrm{~m}^{-2}$ [17].

Moreover, the extension stress within the product creates a new expanded and porous structure [18]. The new structure increases the specific surface area and the mass transfer diffusivity as well as the stating accessibility of the product, thus improving the drying process, solvent extraction, and many other functional properties of foods [19]. The energy costs can also be reduced.

DIC equipment is mainly composed of four components [20] as presented in Figure 2:

- A processing vessel, which is an autoclave with a heating jacket where the product to be treated is placed.

- A pneumatic valve, which ensures a nearly instant liberation of steam pressure contained in the treatment vessel to the vacuum tank.

- A vacuum system composed of a vacuum pump and a tank with a cooling jacket. The tank volume is usually 100-130 times higher than the volume of the processing vessel. A water ring pump maintains the tank pressure at about $2.5-5 \mathrm{kPa}$.

- An extract collection trap used to recover condensates.

The operating pressure profile during a DIC cycle is presented in Figure 3.

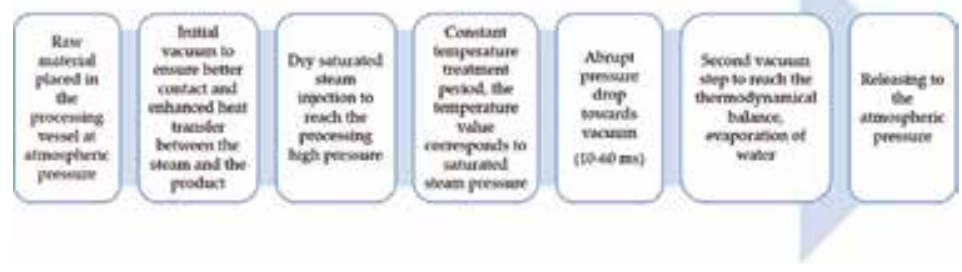

Figure 1.

DIC treatment steps. 


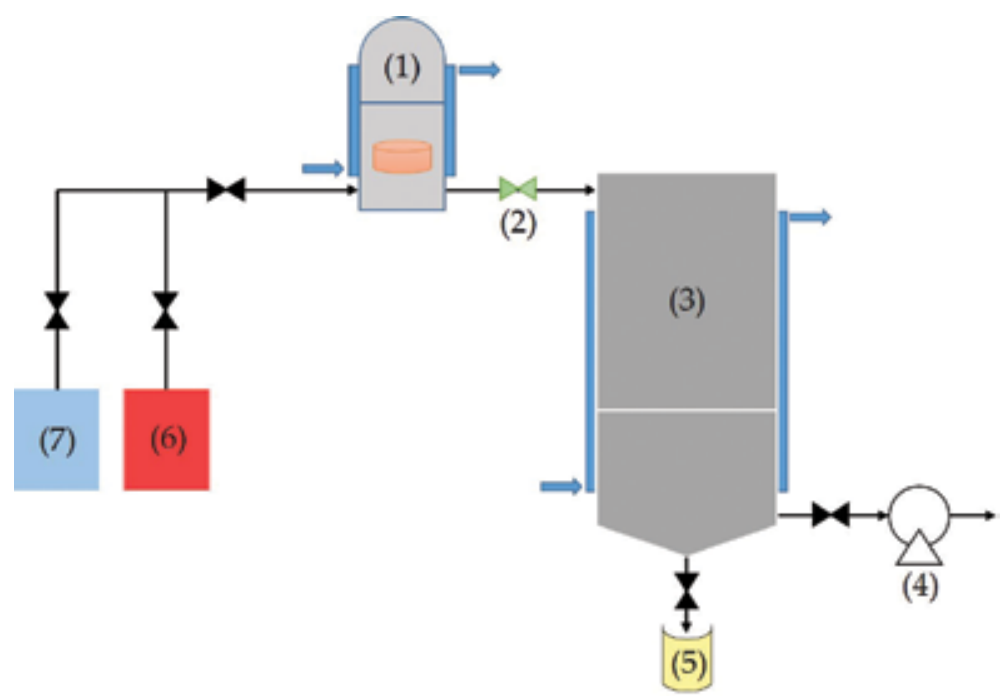

Figure 2.

Schematic presentation of a typical DIC reactor: (1) treatment vessel, (2) controlled instant pressure drop valve, (3) vacuum tank with cooling jacket, (4) vacuum pump, (5) extract collection trap, (6) steam generator, and (7) air compressor.

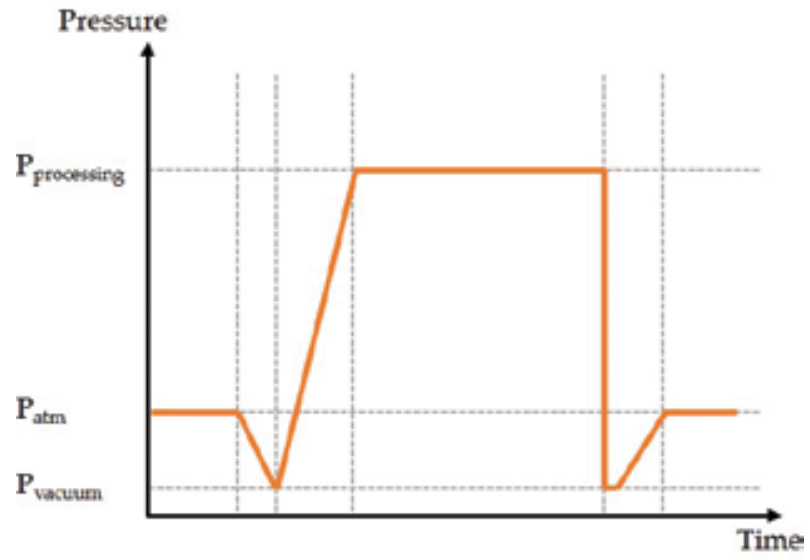

Figure 3.

Pressure profile of a typical DIC treatment.

\section{Instant controlled pressure drop (DIC) drying}

Drying of fruits and vegetables is one of the most efficient and ancient preservation methods. However, consumer demands have become increasingly restraint in terms of the quality of dried foods. Several scientific researches were attempted to improve the conventional drying process using innovative methods or a combination of conventional and novel technologies [21].

Convective airflow drying is the main drying operation in food processing. However, airflow drying undergoes fundamental problems such as low operation performance and poor end-product quality. The drying time is relatively long, which implies crucial energy consumption. The poor quality of the traditionally dried product is related principally to the thermal degradation and in particular to the compactness of texture at the end stages of the drying process [22]. 
Drying steps are presented in Figure 4. The first step is defined as an interaction between the product surface and the heating surrounding air, which includes a convective external heat transfer and vapor removal to the surrounding atmosphere [23]. This initial and relatively rapid step is defined by the term of the initial accessibility [24] expressed in $\mathrm{gH}_{2} \mathrm{O} / 100 \mathrm{~g}$ dry basis, which would indicate the quantity of water removed from the surface before starting the second internal diffusion drying phase. The second step consists of conductive heat transfer, coupled with moisture transfer due to capillary forces and internal diffusion of liquid and vapor within the product [20]. However, the water elimination causes shrinkage of foods, which decreases the internal water diffusivity and increases the thermal conductivity. This phenomenon slows down the drying rate and amplifies the thermal degradation $[25,26]$.

In fact, the external heat and mass transfers can be optimized by adequate operating parameters such as surrounding air temperature, velocity, and relative humidity. This is why the external transfer phenomena are not considered, generally, as a limiting factor for drying kinetics. Otherwise, because of shrinkage of foods during drying, the water will be entrapped in a dense matrix and its movement toward the external surface becomes difficult. Consequently, the internal transfer is the driving and limiting factor of the traditional hot air drying [18].

In order to intensify the overall drying operation, the amelioration of the internal transfer process is needed. To overcome the shrinkage problems, a modification of product structure must be made. It would be possible to make notable improvements, in terms of drying kinetics, by inserting the DIC texturing process, which will increase the effective water diffusivity and the specific exchange surface [20].

Another advantage for the DIC technology over the conventional drying methods is related to the glass transition phenomenon, which has an essential role to control the quality of the end-products. Angella and others suggested that the quality of dried foods could be ameliorated by keeping the product temperature close to the glass transition temperature range to avoid structural damages and other quality changes during dehydration [27]; however, this point has received little attention in the literature.

In fact, the applications of glass transition in food technology were reviewed in many papers $[28,29]$. Several studies have reported glass transitions and state diagrams for foods, such as fruits [30-32], vegetables [33,34], and meat products $[35,36]$. Glass transition is an important element to understand and to predict the behavior of foods during processing and storage [29, 37]. The glass transition phenomenon is a reversible state transition of amorphous substances occurring when a glassy state material is changed into a supercooled melt during heating or, conversely, to the reverse transformations during cooling below its glass transition temperature $\left(\mathrm{T}_{\mathrm{g}}\right)$ at a more rapid rate than the rate of crystallization [38]. The rapid cooling of a liquid below its equilibrium melting temperature does not allow the regular crystallization of food molecules which will be frozen at their disordered

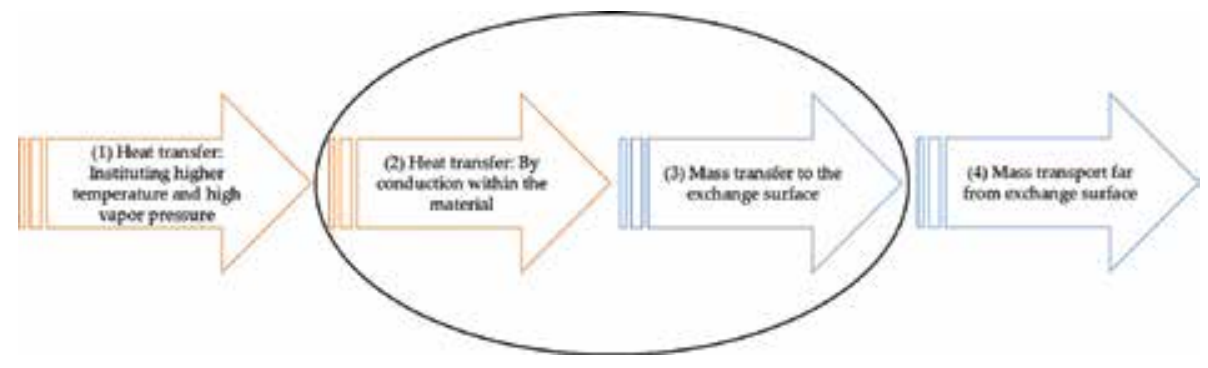

Figure 4.

Four steps of traditional hot air drying. 
random positions and form a solid-like noncrystalline glass [38]. This glassy solid state is nonequilibrium thermodynamically and its properties are time-dependent. Moreover, Roos and Karel described the glass solid formation as a result of rapid removal of water by freezing or drying [39]. The residual water contents and high temperatures at the later stages of the drying process may cause stickiness of powder particles and/or their adhesion on the processing equipment's surfaces.

At the end of the DIC drying process, the product water content and temperature support perfectly the solid glassy state conditions. Figure 5 represents the drying process by the conventional (ABCD) and the DIC (DEF) drying methods regarding the glass transition curve. In general, an initial hot air drying step is applied in order to decrease the product humidity down to $20-30 \%$ dry basis which is a recommended value to guarantee the viscoelastic behavior of the product under the DIC expanding and drying proceeding. The saturated steam, during the compression step, heats the product and may increase slightly the product humidity. Due to the instant pressure drop, an abrupt auto evaporation of water cools the product and allows the crossing of the glass transition frontier [27]. It was reported that structure collapse, stickiness, and agglomeration are never observed in the temperature/water content domain below glass transition. These conditions are guaranteed by the DIC process.

\subsection{How to include a DIC drying treatment}

The DIC treatment combined with classical hot air drying may be considered as an innovative and alternative intensifying drying process. This combination is very flexible and easy to be realized. Several protocols were proposed in the literature [8]. In general, swell drying is defined as an operation that combines optimized hot air drying step with a DIC texturing operation (Figure 5). In this method, instant pressure drop (DIC) step is inserted generally after a hot air drying treatment or, often, between two steps of conventional hot air drying. The first drying step allows the product to reach an elastic state with a water content of $20-30 \mathrm{~g} \mathrm{H}_{2} \mathrm{O} / 100 \mathrm{~g}$ dry

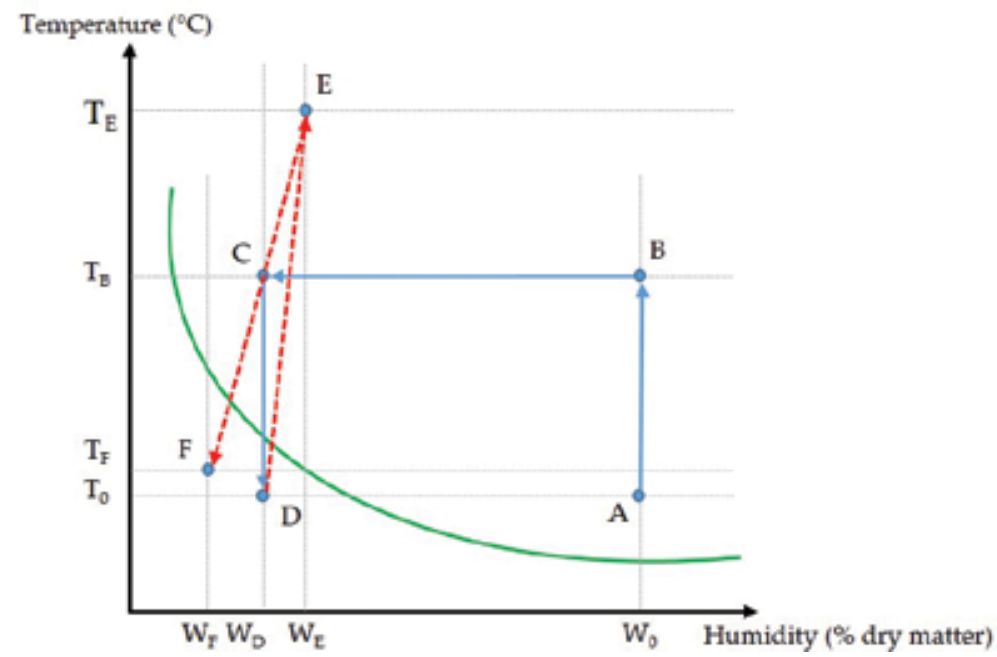

Figure 5.

The DIC and hot air drying process with regard to the glass transition curve. Here, $W_{o}$ is the initial product humidity, $W_{D}$ is the humidity at the end of hot air drying step (20-30\% dry basis), $W_{E}$ is the humidity at the end of compression by saturated steam step, $W_{F}$ is the final dried product humidity, $T_{o}$ is the initial product temperature, $T_{B}$ is the hot air drying temperature, $T_{E}$ is the DIC processing temperature depending on the processing pressure, and $T_{F}$ is the product temperature at the end of the DIC process (usually about $32^{\circ} \mathrm{C}$ ). 
basis, which is an essential condition before application of DIC treatment. The swell drying process has been successfully applied to fruits [40], vegetables [41], dairy components [20], granular powders [40], and meat products [19, 42]. In the case of meat and sea products, it has been possible to start the DIC texturing of the fresh material prior to hot air drying step. Swell drying reduces the drying shrinkage phenomenon, which takes place during the first hot-air drying step, via a controlled expansion. It improves also the drying kinetics by increasing water diffusivity (2-10 times) and initial accessibility (about two times). The reduction in processing time (often reduced by more than 50\%) leads to a significant improvement in product quality and energy consumption [8]. Furthermore, the swell drying process ensures effective microbiological decontamination of the end products [41].

For example, swell drying of apple and onion was studied [40]. Three drying steps were adopted (initial hot air drying, DIC texturing, and final hot air drying). DIC texturing reduced the final hot air drying step time from $6 \mathrm{~h}$, for the untreated DIC conventionally dried product, to $1 \mathrm{~h}$ in the case of DIC treated samples. The effective diffusivity in the onion is extensively accelerated after DIC treatment up to $7.5610^{-10}$ against $0.46 .10^{-10} \mathrm{~m}^{2} . \mathrm{s}^{-1}$ for untreated DIC samples.

Swell drying is also a suitable method for fragile fruit such as strawberries [43]. At optimized DIC condition ( $0.35 \mathrm{MPa}, 10 \mathrm{~s})$, the dried strawberries were higher in anthocyanins and phenolic compound contents compared to classical drying treatment.

Moreover, coupling of the DIC process with spray drying was also investigated. Mounir and Allaf defined a new industrial operation composed of three stages (spry drying, DIC texturing, and hot air drying) with the aim of increasing the specific surface area of some dairy powders (skim milk, sodium caseinates, and whey proteins). For example, specific surface area of whey protein powder was tripled compared to conventional spray dried powders. A positive relation was reported between the steam pressure used in DIC operation and the specific surface area. Scanning electron microscopy analyses showed that DIC textured powders have very porous textures with numerous differently sized cavities and pores, which may explain the rapid drying and improved drying kinetics [20]. At the final drying stage of skim milk, less than 22 min were required to reach a humidity of 5\% for the DIC treated powders compared to 55-60 min for the nontreated powders.

Carrot swell drying was also studied compared to traditional simple hot air drying [44]. The porosity of DIC-textured samples was five times higher than the control's dried samples. A linear correlation was defined between the product porosity and DIC operating pressure and thermal holding time. Due to important increase of effective diffusivity of moisture content, a significant reduction in drying time and energy consumption was reported in this study. About $450 \mathrm{Wh} / \mathrm{kg}$ dry basis was saved, thanks to reducing drying time of 150 min after the DIC texturing step.

\section{Instant controlled pressure drop (DIC) decontamination of food}

Microbiological, organoleptic, and nutritional qualities of powders and granular products are a very important issue for the researchers and industrials. Additionally, high microbial load generally characterizes the dried foods such as spices and herbs [45] due to their traditional methods of harvesting, drying, preparation, and storage [46]. The use of these ingredients in ready-to-eat plates without further heat treatment can be a serious source of hazards [47]. Moreover, it has been reported that the heat resistance of microorganisms is greater in water-poor environments such as the spices and dried herbs [48]. 
Thermal decontamination of microorganisms in solid foods faces several difficulties. During a heat treatment, high temperature and/or long treatments cause color changes and loss in aromatic compounds and nutritional value. Conventional heat exchangers are not appropriate for granular and powder products. A strong temperature gradient is often produced, during heating or cooling stages, which typically involves damage to the end product and reduces its overall quality. The development of a specific and effective heat treatment in the case of solid or powder foods is still required.

Steam treatment is a simple way to decontaminate foods $[49,50]$. However, the effectiveness of this method depends on the type of product and target microorganisms. Also, the exposure time needs to be reduced in order to limit the heat quality degradation. Moreover, due to thermal sensitivity of food powders, athermic decontamination processes seem to be more appropriate such as high pressure decontamination processes. However, despite its numerous advantages, the effectiveness of powder decontamination under high pressures is not yet validated (about $1 \log$ ) because of their very low water content [51].

Beside its application as a drying method, the instant controlled pressure drop (DIC) technology can be used as a decontamination process for powders, species, pharmaceutical products, animal feed, and fresh-cut fruits and vegetables. The efficiency of DIC technology as a microbial inactivation process was studied and approved against spores and vegetative forms, such as Bacillus stearothermophilus, Enterococcus faecalis, Saccharomyces cerevisiae, and Escherichia coli $[52,53]$ (Figure 6). In this case, the DIC process could be considered as a specific HTST treatment for solid and powder foods. DIC technology combines the advantages of steam heating and high pressure treatments. Three patents describe in detail this application [52].

The effective microbial inactivation with DIC is due to the thermomechanical impacts resulting in irreversible changes in the microorganism cells, such as protein denaturation and break of the cellular membrane. Two main mechanisms are involved in DIC bactericidal effect: a controlled high thermal treatment and instant excessive pressure release. In addition to the well-known thermal effects on the bacterial mortality, the auto evaporation of water contained in the microorganisms, during the pressure release, causes the explosion of the bacterial cells and spores $[8,52,54]$.

This process is very flexible to apply. The operating parameters can be adjusted depending on the product nature and target microorganisms. The published results show that both steam pressure, which determines the temperature, and holding time under these conditions had a significant effect on the microbial inactivation.

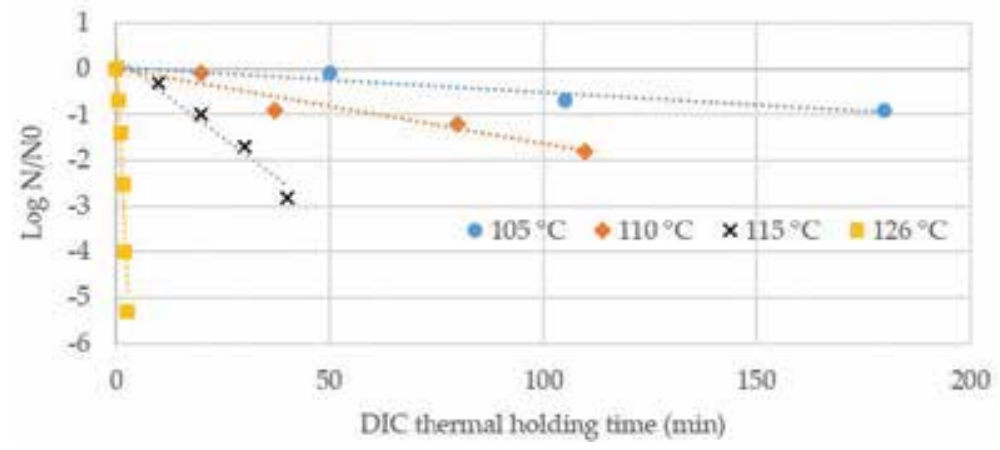

Figure 6.

Inactivation of Bacillus stearothermophilus spores by DIC technology. The process temperature is defined by the operating pressure, data adopted from [53]. 
Higher saturated steam pressure and longer treatment time result in more effective decontamination. In addition, the number of pressure-drop cycles is another important factor to take into account [54].

\section{Other applications of instant controlled pressure drop (DIC) technology in food processing}

In addition to its application as a decontamination and intensifying drying process, DIC technology can be used in other various operations in food processing [15], such as, blanching-steaming of vegetables. DIC Treatment of fresh cut onions allows a perfect decontamination of raw materials and a preservation of the natural structure of the end product. Onion samples were treated firstly by DIC under high natural initial moisture content before a dehydration step by gentle hot air flow. As the effective diffusivity increased by the DIC technology, consequently, the drying time, in the second step, was highly reduced by about $78 \%$, with an effective increase of moisture diffusivity. In addition, natural contamination of raw onions has been eliminated. A decontamination of 1.7-3.9, depending on the operation conditions, was obtained [41].

Similarly, as a post harvesting treatment, DIC assisted steaming and parboiling of paddy rice followed by conventional airflow drying was also studied. Total treatment time was significantly reduced (205 min compared to $1110 \mathrm{~min}$ ) as well as the rate of broken kernels (less than 3\% compared to $25 \%$ at least for the traditional treatment). DIC treated rice was characterized by better cooking behavior [55].

Furthermore, the DIC process has been used to enhance or assist the conventional edible oil extraction from various vegetal materials [17]. Multi-DIC cycles allow the extraction of essential oils of aromatic plants with low energy and low water consumption. The structure expansion by DIC increases the porosity and the specific surface area of the treated plants and improves, as a result, the solvent extraction. DIC texturing is considered, thus, as a solvent extraction pretreatment, which decreases the extraction time. Indeed, Mkaouar and others (2015) reported that DIC texturing step, before polyphenol extraction from olive leaves, improves the extraction yield up to $312 \%$ [56]. Other studies have showed that DIC texturing permits enhancing essential oils and lipid extraction from Jatropha and rapeseed seeds [57], rosemary leaves [17], orange peel [58], and microalgae [59].

\section{Quality of instant controlled pressure drop (DIC)-treated products}

The nutritive quality of processed food is effectively influenced by the operating conditions. High temperature and long heating times result in important degradation of vitamins and bioactive molecules [60]. The nutritive values of DIC-treated products were evaluated $[43,61]$. Thanks to its effective heating and rapid cooling, DIC-dried products are characterized by higher content and availability of bioactive compounds. The open porous structure, because of DIC texturing, allows increasing the availability of these compounds. As an example, the Quercetin content in DIC textured apple was higher than fresh apple by about 700\% dry basis [6] as presented in Figure 7.

Sensory characteristics are crucial quality attributes and normally influence the consumer preferences [62]. DIC dried, or treated products in general, are distinguished by preserved and even improved sensory properties such as flavor, color, and texture. Conventional hot air dried food products suffer from color and flavor changes as a result of severe drying conditions. Several studies have been carried 


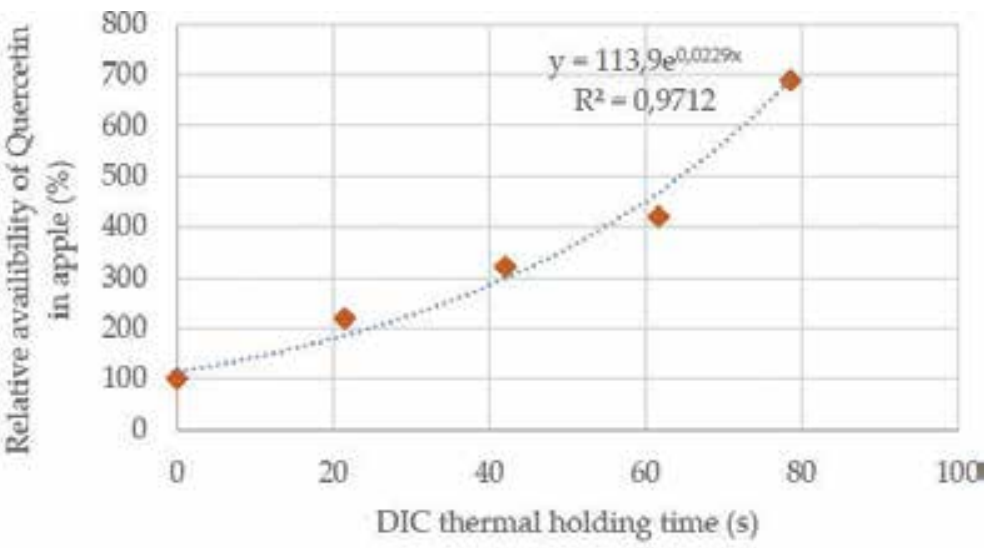

Figure 7.

Increase in the relative availability of quercetin in apple (dry basis) after DIC treatment compared to fresh untreated apple, data modeled from [8].

out to enhance color, aroma content, and texture quality of several food products using DIC technology [63]. The results proved the high quality of swell dried carrots, potatoes, green beans, and tomatoes for example. Wang and others (2014) reported similar industrial results for green tea, wherein the DIC process intensifies the color as well as availability of antioxidant nutritional molecules [64].

Crispness is an important sensorial and textural characteristic often associated with the firmness of fresh or dried food products. Alonzo-Macías and others reported that swell dried strawberry has a higher porosity and preferred crunchiness properties compared to conventional dried samples [43]. The dense structure of hot air dried products, due to the shrinkage phenomenon, solidifies excessively the structure.

In addition, the expansion ratio of DIC swell dried vegetables, such as carrots, onions, and potatoes, was about 200-300\% compared to control samples [63, 65]. The expansion phenomenon results in increasing the specific surface area, which was two times higher for swell dried apples compared to hot air dried samples [40]. Relative expansion ratio is defined as a volumetric ratio between DIC and conventional hot air dried products, which allows evaluating the macrostructural changes caused by DIC texturing. Alonzo-Macías and others found that the relative expansion ratio of DIC swell dried strawberry was about 3.6 compared to the conventional hot air dried product [43]. Similar results were also reported for cheese, chicken breast meat, and sodium caseinate [8]. Powders issued from an adequate grinding of these swell-dried products have the specificity to be "expanded granule powders" with high functional properties such as the rehydration ability for example. In the specific cases of dairy products, such expanded-granule powders have had instantaneous rehydration behavior without inserting any agglomerating steps.

The rehydration of DIC dried products was compared to freeze-dried and hotdried references. The rehydration ability of DIC swell dried chicken breast meat was higher than that of the hot dried samples but slightly lower than that of freeze-dried meat [66]. These results are in agreement with those of others studies [43, 61]. It was found that freeze-dried Moroccan green pepper and strawberry had a better rehydration ability (i.e., starting accessibility and effective diffusivity) compared with conventional hot air dried and DIC swell dried samples. However, the freezedried samples have a low water holding capacity (WHC) compared to DIC swell dried samples. Water holding capacity is defined as the total quantity of water retained or absorbed by a food matrix under defined conditions [67]. This property is very important to be considered for incorporation of the dried ingredients into 
food formulation. The high rehydration ability of DIC swell dried products is due to the open texture formed of large intercellular spaces (porosity), which leads to higher water diffusivity during the rehydration process [8]. Several researchers have found that saturated steam pressure, during the DIC operation, has positively a significant impact on increasing the rehydration ability and water holding capacity of treated products.

In a similar way, oil holding capacity (OHC) of some DIC treated foods was studied. This factor is very important in food formulation. Setyopratomo and others observed that oil holding capacity of DIC textured cassava flour increased compared to conventional hot air dried flour. It was about 2.0 versus only $0.4 \mathrm{~g}$ oil/g dry cassava for DIC treated and hot air dried samples, respectively. These results may be related to starch gelatinization combined with microstructural changes as a result of DIC textured treatment [68]. Mounir and Allaf studied the OHC of egg white and yolk powder dried by different methods. The results showed that freeze dried powders exhibit the highest oil retention capacity compared to DIC swell and hot air dried powders. Under optimized operating conditions for DIC swell drying had an intermediate value of oil holding capacity of $1.5 \mathrm{ml}$ oil/g powder between freeze dried ( $2.2 \mathrm{ml}$ oil $/ \mathrm{g}$ powder) and hot-air dried powders $(0.91 \mathrm{ml}$ oil $/ \mathrm{g}$ powder $)$. In the same study, the emulsifying capacity (EC) of egg yolk was investigated. DIC textured egg yolk had high EC (66 g oil/g dry basis), compared to 57 and $56 \mathrm{~g}$ oil/g dry basis for freeze-dried and conventional hot air dried egg yolk, respectively. This could be due to the exposure of hydrophobic groups of unfold proteins. Under soft operating conditions, the foaming ability of egg white powders dried by the DIC swell drying method was better than those of the other methods. The foam volume of DIC-treated egg white powders increased by 28 and 188\% compared to hot air and freeze-dried samples, respectively [69].

\section{Industrial applications of the instant controlled pressure drop (DIC) process}

Based on instant controlled pressure drop (DIC) technology, several industrial projects were realized in several sectors of food and pharmaceutical industries [15]. This process is applied to decontamination, extraction, and texturation of many materials. Actually, the DIC process is principally used for swell drying applications. More than 200 commercial varieties of fruits and vegetables are dried by this technology [6]. Thermal drying operations consume $10-25 \%$ of the national industrial energy in the developed countries. Conventional industrial driers usually operate at only 30-70\% efficiency levels. The DIC texturing step in the swell drying process increases the stating accessibility and water diffusivity, which decreases the drying time and thus the energy consumption. At the industrial scale, DIC treatment requires about $0.8 \mathrm{kWh}$ total energy consumption for $1 \mathrm{~kg}$ of removed water. Since 2001, the DIC process is operated by ABCAR-DIC Process, a French start-up company that employed DIC development, equipment design, and fabrication. Different models of DIC reactors are now operating worldwide; for example, in the United States, Mexico, Spain, France, Italy, Malaysia, and China.

Several DIC reactors at laboratory and industrial scales are proposed by the ABCAR-DIC process. Thanks to its flexibility, the different operating parameters in the DIC process can be optimized in order to meet the industrial needs. According to the product to be treated and the target temperature, different heating fluids can be used, such as superheated or saturated steam for high temperature treatments. In addition, low temperature steam under low pressure can be used as well as the hot air for heat sensitive products. Five models of DIC laboratory-scale equipment are 
available with different capacities from $30 \mathrm{cc}$ to 15 liters and pressure values from 0.08 to $1 \mathrm{MPa}$. The ABCAR-DIC process offers also four models of industrial scale DIC reactors. The processing capacity ranges between $40 \mathrm{~kg} / \mathrm{h}$ up to 8 tons/h such as the case for rice steaming for example. Batch and continuous reactors are also available [6].

\section{Conclusion}

Instant controlled pressure drop (DIC) technology can be considered as an intensification operation for several processes in food and pharmaceutical industries, such as drying, decontamination, extraction, decaffeination, steaming, and thermal transformations. Briefly, the DIC process consists in holding the product under high pressure (0.08-1 MPa) during a short time (5-60 s) followed by an instant pressure drop toward a vacuum (about $5 \mathrm{kPa}$ ) which results in auto evaporation of water, expansion, and rapid cooling of the product. DIC swell drying is the principal application of this technology. It is an alternative method used to improve conventional hot air drying and to overcome the shrinkage problems. Expanding and texturing the raw materials by the DIC process, before the final hot air drying step, result in intensifying the drying kinetics and, as a result, saving drying time and energy compared to traditional methods. In addition, DIC technology can be defined as a highly appropriate HTST type process that can be applied to powder and dry solids. The coupled thermomechanical impact leads to high decontamination of microorganisms. The DIC process is very effective for a wide variety of heat sensitive materials. DIC treated products are well characterized by preserved nutritive values, attractive sensorial properties, and ameliorated functional behavior. DIC technology is developed and marketed since 2001 at pilot and industrial scales by the ABCAR-DIC Process company for different sectors. Instant controlled pressure drop is a flexible technology. The operating parameters can be optimized to meet the exact needs of different industrial applications. DIC coupling with other innovative processes is an interesting research topic.

\section{Author details}

Mohamad Mazen Hamoud-Agha ${ }^{1,2}$ and Karim Allaf ${ }^{3 *}$

1 Institut Polytechnique UniLaSalle, Beauvais, France

2 Minoteries PAULIC, France

3 Laboratory of Engineering Science for Environment, University of La Rochelle, La Rochelle, France

*Address all correspondence to: kallaf@univ-lr.fr

IntechOpen

(C) 2019 The Author(s). Licensee IntechOpen. This chapter is distributed under the terms of the Creative Commons Attribution License (http://creativecommons.org/licenses/ by/3.0), which permits unrestricted use, distribution, and reproduction in any medium, provided the original work is properly cited. (cc) BY 


\section{References}

[1] Khan I, Tango CN, Miskeen S, et al. Hurdle technology: A novel approach for enhanced food quality and safety - A review. Food Control. 2017;73:1426-1444

[2] Morais RMSC, Morais AMMB, Dammak I, et al. Functional dehydrated foods for health preservation. Journal of Food Quality. 2018;2018:1-29

[3] Onwude DI, Hashim N, Janius R, et al. Non-thermal hybrid drying of fruits and vegetables: A review of current technologies. Innovative Food Science and Emerging Technologies. 2017;43:223-238

[4] Chemat F, Rombaut N, Meullemiestre A, et al. Review of green food processing techniques. Preservation, transformation, and extraction. Innovative Food Science and Emerging Technologies. 2017;41:357-377

[5] Gadonna-Widehem P, Laguerre J-C. Characterization of microbial inactivation by microwave heating. In: Barbosa-Cánovas GV, María Pastore G, Candoğan K, et al., editors. Global Food Security and Wellness. New York, NY: Springer New York; 2017. pp. 489-517

[6] Mounir S, Allaf T, Mujumdar AS, et al. Swell drying: Coupling instant controlled pressure drop DIC to standard convection drying processes to intensify transfer phenomena and improve quality-An overview. Drying Technology. 2012;30:1508-1531

[7] Vadivambal R, Jayas DS. Changes in quality of microwave-treated agricultural products-A review. Biosystems Engineering. 2007;98:1-16

[8] Mounir S, Allaf T, Allaf K. Swell drying. In: Drying Technologies for Foods: Fundamentals And Applications: Part-III. New Delhi: NIPA Publications; 2018. pp. 63-91
[9] Dehnad D, Jafari SM, Afrasiabi M. Influence of drying on functional properties of food biopolymers: From traditional to novel dehydration techniques. Trends in Food Science and Technology. 2016;57:116-131

[10] Mounir SM, Allaf K. Préservation de la production agricole par couplage du séchage classique à la texturation par detente instatanée controlée (DIC). Dakar: P3A-UCAD-ESP, 2007, p. 7

[11] Niakousari M, Hashemi Gahruie $H$, Razmjooei M, et al. Effects of innovative processing technologies on microbial targets based on food categories. In: Innovative Technologies for Food Preservation. London: Elsevier; 2018. pp. 133-185

[12] Pan Y, Sun D-W, Han Z.

Applications of electromagnetic fields for nonthermal inactivation of microorganisms in foods: An overview. Trends in Food Science and Technology. 2017;64:13-22

[13] Hamoud-Agha MM, Curet S, Simonin $\mathrm{H}$, et al. Holding time effect on microwave inactivation of Escherichia coli K12: Experimental and numerical investigations. Journal of Food Engineering. 2014;143:102-113

[14] Hamoud-Agha MM, Curet S, Simonin H, et al. Microwave inactivation of Escherichia coli K12 CIP 54.117 in a gel medium: Experimental and numerical study. Journal of Food Engineering. 2013;116:315-323

[15] Allaf T. In: Allaf K, editor. Instant controlled pressure drop (D.I.C.) in food processing: from fundamental to industrial applications. New York, NY: Springer; 2014

[16] Allaf K, Vidal P. Feasibility study of a new process of drying/swelling by instantaneous decompression toward 
vacuum of in pieces vegetables in view of a rapidfire hydration. Gradient Activity Plotting UTC. 1988;CR/89/103

[17] Allaf T, Tomao V, Ruiz K, et al. Instant controlled pressure drop technology and ultrasound assisted extraction for sequential extraction of essential oil and antioxidants. Ultrasonics Sonochemistry. 2013;20:239-246

[18] Al Haddad M, Mounir S, Sobolik V, et al. Fruits \& vegetables drying combining hot air, DIC technology and microwaves. International Journal of Food Engineering. 2008;4(6). DOI: 10.2202/1556-3758.1491

[19] Haddad J, Louka N, Gadouleau M, et al. Application du nouveau procédé de séchage/ texturation par Détente Instantanée Contrôlée (DIC) aux poissons: Impact sur les caractéristiques physicochimiques du produit fini. Sciences des Aliments. 2001;21:481-498

[20] Mounir S, Allaf K. Three-stage spray drying: New process involving instant controlled pressure drop. Drying Technology. 2008;26:452-463

[21] Onwude DI, Hashim N, Chen G. Recent advances of novel thermal combined hot air drying of agricultural crops. Trends in Food Science and Technology. 2016;57:132-145

[22] Toledo RT, Singh RK, In KFD. Fundamentals of Food Process Engineering. Switzerland: Springer International Publishing. pp. 321-354

[23] Maritza A-M, Sabah M, Anaberta $\mathrm{C}-\mathrm{M}$, et al. Comparative study of various drying processes at physical and chemical properties of strawberries (Fragariavarcamarosa). Procedia Engineering. 2012;42:267-282

[24] Lebovka NI, Vorobiev E, Chemat F. Enhancing Extraction Processes in the Food Industry. Boca Raton: CRC Press; 2012
[25] Curcio S, Aversa M. Influence of shrinkage on convective drying of fresh vegetables: A theoretical model. Journal of Food Engineering. 2014;123:36-49

[26] Ortiz-García-Carrasco B, YañezMota E, Pacheco-Aguirre FM, et al. Drying of shrinkable food products: Appraisal of deformation behavior and moisture diffusivity estimation under isotropic shrinkage. Journal of Food Engineering. 2015;144:138-147

[27] Angella SA, Wang J, Karel M. Quality changes of eggplant due to drying regime. In: Annual Meeting Institute of Food Technologists.

Chicago: Institute of Food

Technologists; 1993

[28] Roos YH. Glass transition temperature and its relevance in food processing. Annual Review of Food Science and Technology. 2010;1:469-496

[29] Rahman MS. State diagram of foods: Its potential use in food processing and product stability. Trends in Food Science and Technology. 2006;17:129-141

[30] Fabra MJ, Talens P, Moraga G, et al. Sorption isotherm and state diagram of grapefruit as a tool to improve product processing and stability. Journal of Food Engineering. 2009;93:52-58

[31] Guizani N, Al-Saidi GS, Rahman MS, et al. State diagram of dates: Glass transition, freezing curve and maximalfreeze-concentration condition. Journal of Food Engineering. 2010;99:92-97

[32] Zhao J-H, Liu F, Wen X, et al. State diagram for freeze-dried mango: Freezing curve, glass transition line and maximal-freeze-concentration condition. Journal of Food Engineering. 2015;157:49-56

[33] Zhao J-H, Ding Y, Nie Y, et al. Glass transition and state diagram for freezedried Lentinus edodes mushroom. Thermochimica Acta. 2016;637:82-89 
[34] Suresh S, Al-Habsi N, Guizani N, et al. Thermal characteristics and state diagram of freeze-dried broccoli: Freezing curve, maximal-freezeconcentration condition, glass line and solids-melting. Thermochimica Acta. 2017;655:129-136

[35] Akköse A, Aktaş N. Determination of glass transition temperature of beef and effects of various cryoprotective agents on some chemical changes. Meat Science. 2008;80:875-878

[36] Kurozawa LE, Barbin DF, Hubinger MD. Implications of non-equilibrium states and glass transitions in frozen and dried fish and meat products. In: NonEquilibrium States and Glass Transitions in Foods. 1st ed. United Kingdom:

Woodhead Publishing; pp. 325-348

[37] Rgm van der S. Progress in understanding of supplemented state diagrams of hydrophilic food materials. Current Opinion in Food Science. 2018;21:32-38

[38] Sperling LH. In: Hoboken NJ, editor. Introduction to Physical Polymer Science. 4th ed. New Jersey: Wiley; 2006. 845 p

[39] Roos Y, Karel M. Amorphous state and delayed ice formation in sucrose solutions. International Journal of Food Science and Technology. 2007;26:553-566

[40] Mounir S, Besombes C, Al-Bitar $\mathrm{N}$, et al. Study of instant controlled pressure drop DIC treatment in manufacturing snack and expanded granule powder of apple and onion. Drying Technology. 2011;29:331-341

[41] Albitar N, Mounir S, Besombes C, et al. Improving the drying of onion using the instant controlled pressure drop technology. Drying Technology. 2011;29:993-1001

[42] Mounir S, Allaf K. Enhancing hot air drying of chicken meat by instant controlled pressure drop DIC. In: 1st Middle-East Drying Conference (MEDC2012). Mahshar, Iran: Shahid Chamran University of Ahvaz; 2012

[43] Alonzo-Macías M, CardadorMartínez A, Mounir S, et al.

Comparative study of the effects of drying methods on antioxidant activity of dried strawberry (Fragaria Var. Camarosa). Journal of Food Research. 2013;2:92

[44] Nguyen TH, Lanoisellé J, Allaf K. Effect of instant controlled pressure drop DIC treatment on the properties of dried carrot. In: 19th International Drying Symposium (IDS 2014). France: Lyon; 2014. p. 9

[45] Hara-Kudo Y, Ohtsuka LK, Onoue $\mathrm{Y}$, et al. Salmonella prevalence and total microbial and spore populations in spices imported to Japan. Journal of Food Protection. 2006;69:2519-2523

[46] Schweiggert U, Carle R, Schieber A. Conventional and alternative processes for spice production - A review. Trends in Food Science and Technology. 2007;18:260-268

[47] Little C, Omotoye R, Mitchell $\mathrm{R}$. The microbiological quality of ready-to-eat foods with added spices. International Journal of Environmental Health Research. 2003;13:31-42

[48] Laroche C, Fine F, Gervais P. Water activity affects heat resistance of microorganisms in food powders. International Journal of Food Microbiology. 2005;97:307-315

[49] Fine F, Gervais P. Décontamination des Poudres limentaires: Revue bibliographique et nouvelles perspectives. Sciences des Aliments. 2003;23:367-394

[50] Cenkowski S, Pronyk C, Zmidzinska D, et al. Decontamination of food products with superheated 
steam. Journal of Food Engineering. 2007;83:68-75

[51] Colas de la Noue A. Utilisation des hautes pressions gazeuses et inactivation de contaminants potentiels des produits secs : Influence de l'hydratation. $\mathrm{PhD}$ thesis, Université de Bourgogne, 2013

[52] Allaf T, Besombes C, Mih I, et al. Decontamination of solid and powder foodstuffs using DIC technology. In: Schmidt M, editor. Advances in Computer Science and Engineering. Croatia: InTech; 22 March 2011. DOI: 10.5772/16025. [Epub ahead of print]

[53] Kamal I, Mounir S, Allaf K. New tendencies in preservation of fruits and vegetables by drying and by Edible coatings. In: The first Frano-MFLU

Seminar. Thailand: Kasetsart; 2006

[54] Mounir S, Albitar N, Allaf K. DIC decontamination of solid and powder foodstuffs. In: Allaf T, Allaf K, editors. Instant Controlled Pressure Drop (D.I.C.) in Food Processing. New York, NY: Springer. pp. 83-94

[55] Thai Cong D, Al Haddad M, Maache-Rezzoug Z, et al. Definition of a new post-harvesting treatment of paddy rice characterization of final product. Journal of Drying Technology. 2008;26:443-451

[56] Mkaouar S, Bahloul N, Gelicus A, et al. Instant controlled pressure drop texturing for intensifying ethanol solvent extraction of olive (Olea europaea) leaf polyphenols. Separation and Purification Technology. 2015;145:139-146

[57] Van CN. Maîtrise de l'aptitude technologique des oléagineux par modification structurelle: Applications aux opérations d'extraction et de transestérification in-situ. $\mathrm{PhD}$ Thesis, Université de la Rochelle, LaSIE UMR 7356 CNRS, 2010
[58] Allaf T, Tomao V, Besombes C, et al. Thermal and mechanical intensification of essential oil extraction from orange peel via instant autovaporization. Chemical Engineering and Processing Process Intensification. 2013;72:24-30

[59] Kamal I, Besombes C, Allaf $\mathrm{K}$. One-step processes for in situ transesterification to biodiesel and lutein extraction from microalgae Phaeodactylum using instant controlled pressure drop (DIC). Green Processing and Synthesis. 2014;3:431-440. Epub ahead of print 1 January 2014. DOI: 10.1515/gps-2014-0047

[60] Lešková E, Kubíková J, Kováčiková E, et al. Vitamin losses: Retention during heat treatment and continual changes expressed by mathematical models. Journal of Food Composition and Analysis. 2006;19:252-276

[61] Téllez-Pérez C, Sobolik V, Montejano-Gaitán JG, et al. Impact of swell-drying process on water activity and drying kinetics of moroccan pepper (Capsicum annum). Drying Technology. 2015;33:131-142

[62] Asioli D, Rocha C, Wongprawmas R, Popa M, Gogus F, Almli VL. Microwavedried or air-dried? Consumers' stated preferences and attitudes for organic dried strawberries. A multi-country investigation in Europe. Food Research International. 2018. DOI: 10.1016/j. foodres.2018.11.037

[63] Louka N, Allaf K. Expansion ratio and color improvement of dried vegetables texturized by a new process "controlled sudden decompression to the vacuum". Journal of Food Engineering. 2004;65:233-243

[64] Wang Y, Xu P, Feng L, et al. Impact of instantaneous controlled pressure drop on microstructural modification of green tea and its infusion quality. Journal of Food Science and Technology. 2014;51:51-58 
[65] Iguedjtal T, Louka N, Allaf K. Sorption isotherms of potato slices dried and texturized by controlled sudden decompression. Journal of Food Engineering. 2008;85:180-190

[66] Mounir S, Allaf T, Sulaiman I, et al. Instant controlled pressure drop (DIC) texturing of heat-sensitive spray-dried powders: Phenomenological modeling and optimization. Drying Technology. 2015;33:1524-1533

[67] Moure A, Sineiro J, Domínguez H, et al. Functionality of oilseed protein products: A review. Food Research International. 2006;39:945-963

[68] Setyopratomo P, Fatmawati A, Allaf K. Texturing by instant controlled pressure drop DIC in the production of cassava flour: Impact on dehydration kinetics, product physical properties and microbial decontamination. In: Proceedings of the World Congress on Engineering and Computer Science (WCECS). San Francisco, USA: International Association of Engineers (IAENG); 2009. p. 7

[69] Mounir S, Allaf K. Response surface methodology (RSM) as relevant way to study and optimize texturing by instant controlled pressure drop DIC in innovative manufacturing of egg white and yolk powders. Drying Technology. 2018;36:990-1005 



\title{
Chapter 3
}

\section{Microwave Heating for Food Preservation}

\author{
Jean-Claude Laguerre and Mohamad Mazen Hamoud-Agha
}

\begin{abstract}
Since food is generally of low thermal conductivity, heating by conventional methods remains relatively slow. Thanks to its volumetric and rapid heating, microwave (MW) technology is successfully used in many applications of food processing. In this chapter, fundamental principles of MW heating are briefly presented. MW drying and MW microbial decontamination are extensively reviewed as innovative methods for food preservation. However, the complex interactions between microwaves and materials to be heated are not yet sufficiently controlled. Moreover, MW heating heterogeneity and thermal runaway are the main drawbacks of this technology. Several methods have been proposed and investigated in the literature to overcome these problems in order to assure the microbiological safety and quality of food products.
\end{abstract}

Keywords: microwave heating, microwave modeling, drying, pasteurization, sterilization, microbial decontamination, food safety, food quality

\section{An overview of microwave heating}

Microwaves (MWs) are electromagnetic (EM) waves, which are synchronized perpendicularly oscillations of electric and magnetic fields that propagate at the speed of light in a free space. MWs are characterized by the frequency (between $300 \mathrm{MHz}$ and $300 \mathrm{GHz}$ ) and the wavelength (ranging from $1 \mathrm{~m}$ to $1 \mathrm{~mm}$ ).

According to the countries and regions, five frequencies (433, 896, 915, 2375, and $2450 \mathrm{MHz}$ ) are authorized for MW heating operations. The $2450 \mathrm{MHZ}$ is the exclusive frequency for home appliances.

\subsection{Mechanisms of microwave heating}

The interaction of a wave with the material depends on its own characteristics (frequencies, wavelength) and the nature of the material, particularly its absolute permittivity $\varepsilon^{*}$, a complex number that determines how the material stores the electrical energy of the EF and its dissipation into heat. The readers can consult more specialized references for detailed information [1]. We can define rapidly here the real permittivity, or dielectric constant, of a material which denotes the capacity of the material to store electrical energy and the effective loss factor which expresses the ability of the material to absorb energy of the wave and dissipate it into the heat by dielectric relaxation and ionic conduction. If a material contains free charges (ions) and polar molecules (e.g., water molecule) when this material is subjected to an EF, the ions will move at an accelerated rate according to their charge, which will 
cause collisions between them and, by the result, a conversion of the kinetic energy into heat (ohmic heating). In the same way, the polar molecules of this material, which was initially randomly oriented, will be oriented according to the polarity of the field. If the EF is an alternative, these molecules will rotate to remain aligned on it. This dipolar rotation will generate frictions between the molecules which will lead to an internal generation of heat (dielectric heating).

\subsection{Penetration and absorption of a wave in a material}

When an EM wave is directed toward a material, a part of the wave is reflected on the surface, while the other part penetrates it to be absorbed. The absorption of the wave during its crossing results in a decrease of the amplitude of the internal $\mathrm{EF}$ and so of its power. For small or thin materials, the accurate calculation of the internal electric field is recommended by using the Maxwell equations. Lambert's law (exponential EF decayed) may be used for larger objects.

The penetration depth is defined as the penetration distance in the material for which the $63 \%$ of incident power of the incident wave has been absorbed. This depth depends on the dielectric properties of the material as well as the wavelength. The penetration depth at $915 \mathrm{MHz}$ is larger than the penetration depth at $2450 \mathrm{MHz}$ at the same conditions. More power will be absorbed when the loss factor is high [1].

\subsection{About the heterogeneity of microwave heating}

MW heating is inherently heterogeneous for several reasons:

- For most cases, product size is very large compared to the penetration depth; thus, the energy of the EM wave will be completely absorbed before being able to reach the core or the bottom of the product. All the parts of the product not crossed by the EM wave will not undergo heating. Smaller products will heat faster than large ones, because MWs are able to penetrate the entire product. However, small products are also more sensitive to variations in EM fields that exist in the oven, particularly in a multimode cavity.

- Dimensional resonance phenomena: sometimes, the wave is reflected against the lower edge of the product leading to interference phenomena. This results in producing cold spots (transmitted and reflected waves cancel each other) and/or hot spots (transmitted and reflected waves add up).

- If the product is made of several components, the component with the highest dielectric constant tends to concentrate the energy, and its temperature will increase strongly compared to the other components which leads to selective overheating. The dependence of dielectric properties with the temperature often leads to increase the local temperature of the already hot points. As foods are generally low thermal conductivities, this phenomenon leads to local overheating (thermal runaway).

- The shape of the product plays a major role in the heterogeneity of MW heating. The shape of the sample influences the penetration depth of the MWs and the location of the hot spots. In general, the presence of sharp edges and right angles leads to significant local overheating at these locations. Sundberg et al. $[2,3]$ found that the power density at the edge decreased with the increase of the opening angle; thus, oval or circular forms may in some cases reduce this problem. However, in these forms the MW power is concentrated in the center [4]. 


\section{Microwave drying}

\subsection{Introduction}

Drying is one of the most used methods for preserving food and preventing microbiological degradation. Food drying is also used for economic interests by lightening the product to minimize the transport costs (e.g., milk powder) or even for consumption aspects by creating new textures and/or products (e.g., prunes). This process aims to reduce the water activity ( $\mathrm{Aw}$ ) of the food product by removing some of its water. The amount of water to be removed to achieve the microbiological stability can be determined thanks to the sorption isotherm curve which shows the relationship between the water content and the water activity of a product. Generally, the water activity threshold from which there is no further development of pathogenic bacteria is $0.85-0.86$ and 0.7 and 0.6 for yeasts and molds, respectively.

It is interesting to note that Aw does not only control the development of microorganisms, it also influences the rate of the chemical and biochemical reactions that take place within the food. The nonenzymatic browning (Maillard reaction) has a maximal activity for an Aw of 0.6-0.7, while the oxidation of lipids develops rather at very low and very high values of Aw. Thus, it is proper to adjust the final moisture of the product according to these considerations. The area generally targeted for good stability of the dried product is the range of Aw between 0.3 and 0.4. An important aspect must be emphasized here, namely, that drying has almost no lethal effect on the microorganisms present on the product due to insufficient product temperatures reached during drying. Proper packaging is therefore essential to avoid moisture recovery and keep the quality of the dehydrated product.

Industrial drying techniques are very varied depending on the nature of the product to dry (liquid, pasty, solid, or particulate) and of the desired final qualities. Most often, hot air (HA) convective drying is the main dehydration technique used in food industries. However, this method undergoes several problems such as poor end-product quality and low operation performance. Generally, in conventional drying method, two steps take place: a heat transfer from hot and dry surrounding medium to the product and then a mass (water and/or volatile compounds) transfer from the product to the surrounding atmosphere. In general, external heat and mass transfer can be easily controlled by a good monitoring of the drying air characteristics (velocity, temperature, relative humidity); thus, the internal transfer is the limiting step and the effective driving force for the drying operation. The drying rate decreases with time, and the removal of water becomes difficult. Therefore, conventional HA drying requires the application of severe conditions, particularly at the end of operation, which result in overheating and overdrying of the product surface. These reasons have greatly encouraged engineers to develop and propose new drying techniques such as MW drying. For example, MW drying was successfully applied to dry potatoes chips, pasta, and snacks [5]. Several studies of MW drying were resumed in the literature [6].

\subsection{Microwave drying versus hot air drying}

During MW drying of strong moisture content product, EM energy is supplied directly to the volume of the product, which causes a rapid increase of the product temperature and an instantaneous vaporization of water inside the product [7]. This phenomenon causes an increase in the internal pressure and drives the water to liquid state toward the product surface [8]. This forced outflow of water increases the drying rate and so reduces the operation time (up to five times less than HA air drying for many products). Likewise, the increase in internal pressure prevents 
food shrinkage and case hardening during drying, which have a positive impact on the texture of the MW dried product. Indeed, it promotes a greater porosity and increases the rehydration ability [9].

The action of conservation provided by the drying to foodstuffs is mainly due to the decrease of Aw which thus makes it possible to limit the development of microorganisms. However, an additional action is observed in the case of MW drying. In fact, the rapid rise in temperature for water-rich products seems to produce a thermal shock effect on thermosensitive microorganisms. Laguerre et al. [10] have shown, in a comparative study of drying of onions either by HA or by MWs, a reduction of the total microbial count ten times greater for MW drying (about one to two log reductions). This is a significant advantage of MW drying compared to hot air drying.

Although the selectivity of EF may cause heating heterogeneity, this selectivity is rather an advantage in the case of MW drying. The level of energy absorption is controlled by the wet parts, resulting in positive selective heating of the inner layers of the product still having a relatively high moisture content without affecting the relatively dry outer layers, thereby facilitating the outflow of water to the surface.

However, even if the MW drying is faster than that of HA method, the MW drying efficiency is limited because of the rapid saturation of the surrounded air due to its low temperature. For this reason, MWs are usually associated with HA flow to improve water transfer at the surface of the product. Another difference between MW and HA drying is the surface temperature. During HA drying, the surface temperature does not exceed the controlled surrounding air temperature, which may be low $\left(30-40^{\circ} \mathrm{C}\right)$ during thermosensitive product drying (e.g., aromatic plants), whereas excessive surface temperature may occur during MW drying, especially along the corner or edges, resulting in product carbonization and production of off-flavors especially during the final stages of operation [6].

\subsection{Controlled power microwave drying: innovative method to prevent runaway heating}

In many works, a constant MW applied power is usually used throughout the drying period. This practice promotes the phenomena of thermal runaway (local overheating) at the end of drying. During MW drying performed at constant power, the applied specific power (power/product mass) increases exponentially as can be seen in Figure 1 for the drying of tomato as an example [11]. Thus, the product receives more and more energy over time while it needs less and less. Moreover, the thermal properties of the product (specific heat and thermal diffusivity) decrease at the same time as the moisture of the product; therefore, it becomes easier to heat the product while the heat accumulated in a zone can less easily diffuse to the whole product. All this, combined with the phenomenon of dimensional resonance, can lead to thermal runaway. This phenomenon can be observed in the case of drying onions [10,12]. Figure 2 shows the evolution of hot spots up to charring on onion slices during MW drying. The fact that the black spots are very localized initially confirms the presence of dimensional resonance phenomena in this case.

To improve the quality of MW dried foods, the control of the applied power throughout the drying was studied in the literature. Li et al. [13] proposed the control of applied power according to the set product temperature, whereas Soysal et al. [14] adapted the applied power as a function of processing time. A very good quality product was obtained by Laguerre et al. $[10,15]$. The authors controlled the power as a function of the product mass. This method was successfully tested for drying onions and tomatoes as presented in Table 1. A final product of fresh-like color, without any black spots, was obtained. 


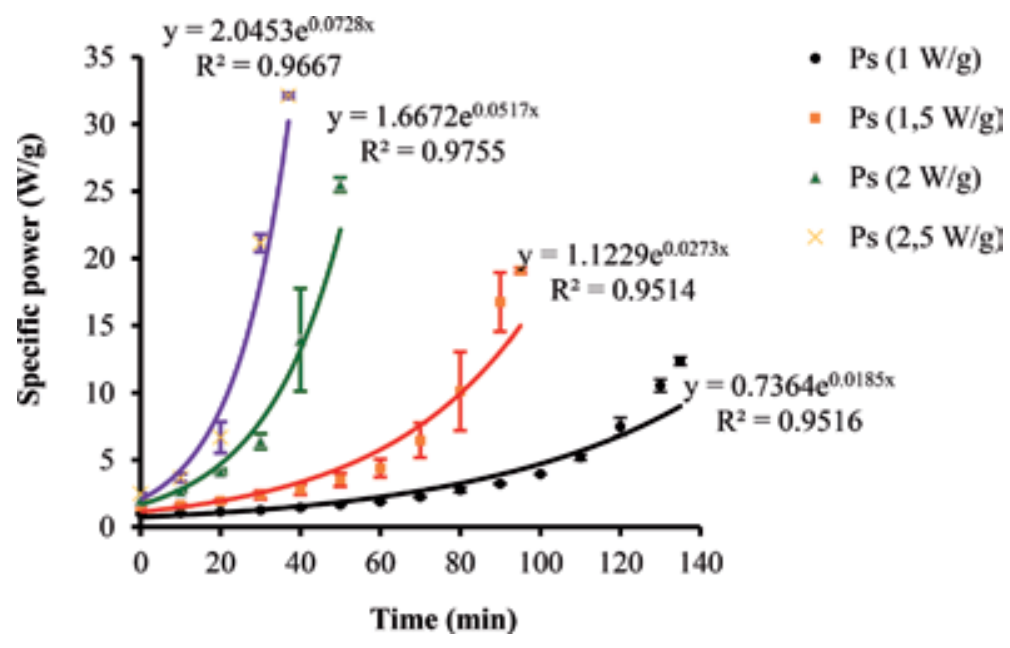

Figure 1.

Evolution of the specific power (W/g) as a function of time (min) for different initial specific power values during drying of tomatoes [11].

\subsection{Combined microwave drying technologies}

Despite its several advantages over the conventional methods, MW drying has some crucial problems as explained above. However, MW drying combined with other conventional heating methods enhances the drying efficiency as well as the dried product quality compared to MW drying alone. Applications of combined MW drying, principally, include MW-assisted hot air (HA) drying, MW vacuum drying, and MW freeze drying.

\subsubsection{MW-assisted hot air drying}

The application of MW energy (internal heating) associated with hot air flow (superficial heating) is a good method to overcome certain problems related to the use of these two methods separately. MW heating may be applied at the beginning of the drying process to heat the internal layers of the product rapidly. MW heating can be also applied at the second step of drying process, when the temperature profile is established, to force vapor out of the product which leads to create a porous structure. MW heating can also be applied at the end of drying process, where the mass transfer is reduced to improve the drying rate by removing the bound water [9]. For example, MW drying combined with HA drying at the last stage reduced the drying time by $64 \%$ as compared to convective air drying [16]. Saving drying time and improved quality were also reported, using this method, for other fruits such as blueberries [17], macadamia nuts [18], and green peas [19].

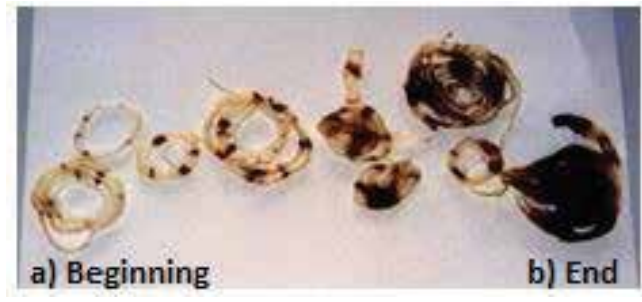

Figure 2.

Evolution of hot spot during MW drying of onion slices [10]. 


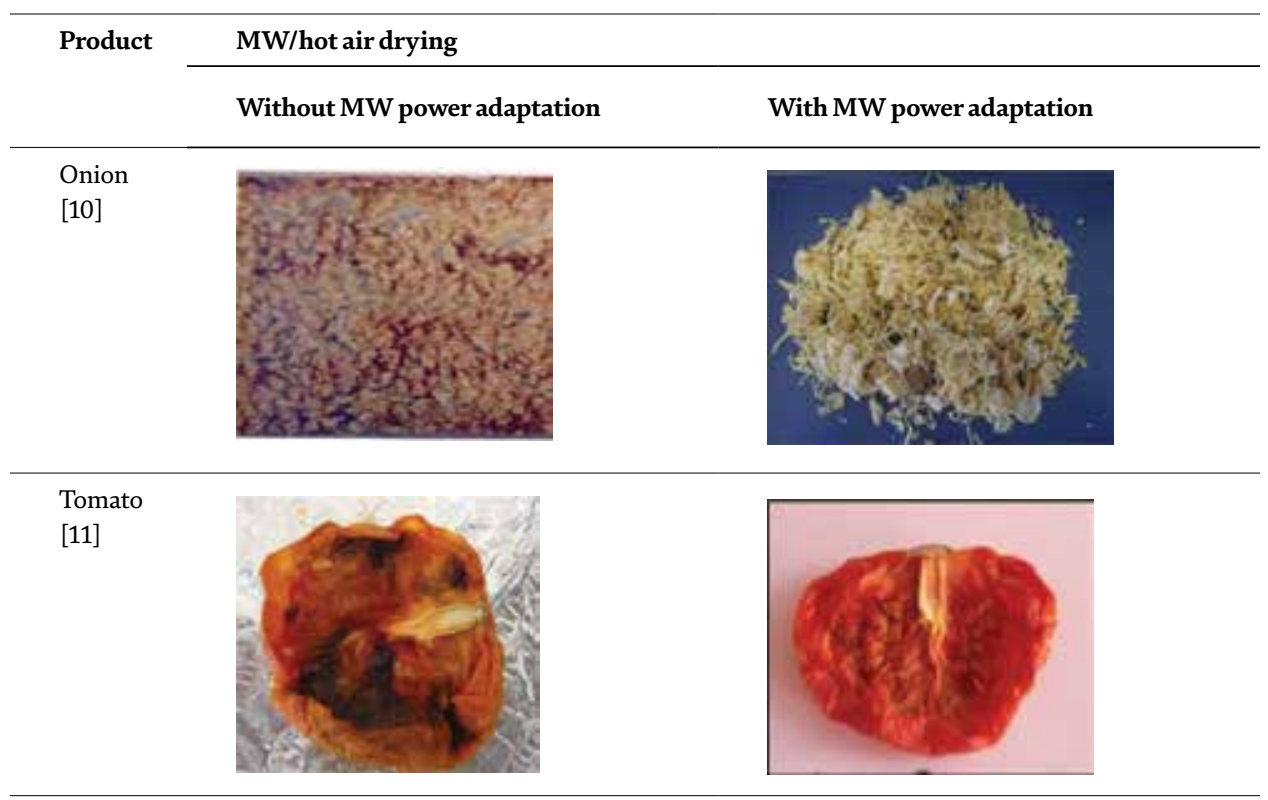

Table 1.

Effect of the adaptation of the power applied on the color of the dried product.

\subsubsection{MW vacuum drying}

In order to reduce the boiling point of water and to prevent the oxidation reactions, MW heating can be associated with a vacuum to maintain the quality (color and flavor) of the dried products. This method was successfully used to dry apple slices [20], pumpkin [21], and cranberries [22]. This method is better than MW air drying in terms of energy consumption, drying time, and quality of the dried products [6].

\subsubsection{MW freeze drying}

Lyophilization, also known as freeze drying, is a low-temperature dehydration process, which involves freezing the product at the first step and then removing the ice by sublimation under low-pressure conditions. It is used for dehydration of very heat-sensitive materials particularly in food and pharmaceutical industries. This method preserves the structure and minimizes the loss of valuable compounds. However, this technology is limited by its high cost. In MW freeze drying, MW heating can be applied concurrently during the sublimation to supply the heat under vacuum conditions. MW heating can also be applied separately after a traditional lyophilization step. MW freeze drying offers many advantages due to its low processing temperature and lack of oxygen in the processing environment $[23,24]$. However, as the MW energy does not interact with frozen water, thermal runaway might take place which may result in poor product quality [6].

\section{Microwave pasteurization and sterilization of foods}

Pasteurization and sterilization are widely used to extend the shelf life of most foods. The main goals of pasteurization are to destroy vegetative pathogenic microorganisms and to deactivate some enzymes in foods. Pasteurization temperatures and treatment time vary, primarily, depending on the nature, the $\mathrm{pH}$ of the product, 
and the target microorganism. In most pasteurization processes, the food is heated up to $60-85^{\circ} \mathrm{C}$ for a time varying from a few seconds to an hour. Pasteurization requires refrigerated storage conditions $\left(3-4^{\circ} \mathrm{C}\right)$ for a storage life of $2-6$ weeks. Sterilization, which can be seen as further pasteurization, destroys bacterial spores [25]. In solid or semisolid products, the heat transfer takes place mainly by conduction from the surface to the center often considered as the "cold" point. This leads to apply more severe conditions to reach the target temperature at the cold point, which results in an overcooking of the surface and a degradation of the quality of products. Optimizing thermal treatments (i.e., maximizing inactivation of bacteria while minimizing nutrient degradation) is therefore an important issue. However, this is not an easy task and it is always a technical and scientific challenge. Thanks to the direct and volumetric interaction between MWs and food, MW heating has the advantage of overcoming the limitation imposed by slow thermal diffusion of conventional heating.

\subsection{Microbial decontamination by microwave heating}

Many studies demonstrated the effectiveness of using MW heating for pasteurization and sterilization of food [26-28]. Furthermore, different strains of microorganisms have been inactivated by MW heating, for example, Bacillus cereus, Campylobacter jejuni, Clostridium perfringens, Escherichia coli, Enterococcus faecalis, Listeria monocytogenes, Staphylococcus aureus, and Salmonella [29, 30].

\subsection{Thermal and athermal effects of microwave heating on microorganisms}

The study of microbial destruction mechanisms during an MW heating has attracted a lot of interest [31, 32]. In particular, the possible existence of nonthermal (athermal) effects of microwaves is a subject of debate. Several theories have been proposed to explain how electromagnetic fields can inactivate microorganisms at sublethal temperature conditions. This effect would be due to the interaction between microwaves and certain cellular constituents. In contrast, many studies have refuted the lethal nonthermal effect of MWs. To distinguish between thermal and nonthermal effects, most studies are based on the experimental evaluation of conventional and MW inactivation under identical heating conditions.

Fujikawa et al. [33] showed no difference between inactivation treatments for E. coli (suspended in $\mathrm{PB}$ phosphate buffer) in a conventional water bath and in a MW oven. Welt et al. [34] have developed a device to evaluate the possible nonthermal effects of microwaves. They compared the inactivation of Clostridium sporogenes spores in a model medium (a phosphate buffer) under a same time-temperature condition for conventional and MW treatment. The results demonstrate the absence of a nonthermal effect.

On the other hand, several studies demonstrated that the microwaves have a more important bactericidal effect $[35,36]$. Sato et al. [37] found that the inactivation of E. coli $\mathrm{K} 12$ exposed to MW radiation was higher than that obtained in a water bath at the same temperature $\left(45,47\right.$, and $\left.50^{\circ} \mathrm{C}\right)$.

Some authors support the thesis of improved bactericidal effect of microwaves. Kozempel et al. [38] developed an experimental device for detecting a possible nonthermal effect of microwaves on microorganisms at low temperature. The process combines instantaneous energy input to the food system by microwaves with rapid removal of thermal energy. The system used is a double-tube heat exchanger installed inside a continuous MW tunnel. The outer tube is microwaveable, while the inner tube is stainless steel and was used to cool the system instantly to keep the temperature at $45^{\circ} \mathrm{C}$. The nonthermal effect of MW radiation has not been 
observed for yeast, Pediococcus sp., Escherichia coli, Listeria innocua, or Enterobacter aerogenes, in various liquids. However, the author has reported that MWs can improve or amplify the thermal effect in lethal conditions [38]. In the same context, Ramaswamy et al. [39] found that the inactivation of S. cerevisiae inoculated in apple juice treated with steam, hot water, or MW was not significantly different at sublethal temperature $\left(<40^{\circ} \mathrm{C}\right)$. However, they found that MW radiations enhanced inactivation for same lethal temperature conditions $\left(55-65^{\circ} \mathrm{C}\right)$.

Numerous studies on the interactions between MWs and certain cellular constituents, such as DNA, the cell membrane, enzymes, and proteins, have been carried out. Kakita et al. [40] studied the survival of bacteriophage PL-1, which is specific for Lactobacillus casei, under MW irradiation. More viral DNA fragmentation was found for MW heating over conventional heating. Shamis et al. [41] studied the effects of MW radiation on the membrane of the $E$. coli cell under sublethal temperature conditions $\left(<40^{\circ} \mathrm{C}\right)$. Compared to conventional treatment, a different cellular morphology was observed (the cells are contracted and dehydrated). Nevertheless, this effect seems to be temporary; $10 \mathrm{~min}$ after the end of the exposure, the morphology of the cell seemed to return to the initial state of untreated controls. In this experiment, cell viability test revealed that the MW treatment was not bactericidal, since $88 \%$ of the cells were recovered. Similarly, Woo et al. [42] reported that MW radiation of Escherichia coli and Bacillus subtilis resulted in an increase in the amounts of nucleotides and protein released from cells. This leak was strongly correlated to MW power. The authors observed, by scanning electron microscopy, a significant damage on the surface of MW-treated E. coli cells; however, there was no significant change observed for B. subtilis cells. Likewise, Shin and Pyun [43] showed that MW treatment (at $50^{\circ} \mathrm{C}$ ) causes irreversible damage to the membrane of Lactobacillus plantarum, associated with increase of the permeability. Also, observations by electron microscopy showed a change in cellular morphology on Candida albicans treated with MW [44].

To prove the existence of nonthermal effect of microwaves on microorganisms, exactly the same thermal history must be reproduced for MW and conventional treatments. Most of studies previously cited applied temperature measurement techniques inappropriate to MW heating, where the temperature was monitored at a single point of the sample. In addition, it is also important to eliminate the heating heterogeneity inherent in MW processing. Consequently, microorganisms are subjected to uneven heating as a result of the presence of cold and hot spots within the same sample. In summary, so far, the existence of nonthermal effect of MWs on microorganisms has not been proven; even if this effect exists, it has no significant consequence on the MW heating of foods.

\subsection{Advantages and limitations of microwave microbial decontamination}

In fact, it is difficult to compare the efficiency of MW over conventional heating process because of the inherent differences of heating principle between the two technologies [45].

In the case of conventional heating, a slow heat exchange occurs between the heating medium and the product. The heat diffusion inside the product depends on its physical properties (specific heat, thermal conductivity, porosity, etc.). However, it is well known that foods are bad thermal conductors, heat diffusion toward the cold spot is usually slow, and MW heating is generally faster than conventional heating. The heat is generated directly within the food. This direct volumetric heating significantly reduces the processing time resulting in greater retention of nutrients, sensitive vitamins, and aromatic constituents. Microwave-processed foods may also have better texture, taste, and appearance than products processed by conventional methods. For example, a two times faster MW pasteurization treatment of pickled 
asparagus at $915 \mathrm{MHz}$ was published [46]. This advantage reduced significantly the thermal degradation of asparagus compared to a conventional treatment in a water bath. Similarly, an acceptable MW pasteurization of foie gras was reported with a time saving of $50 \%$ and better organoleptic qualities compared to a traditional method [47]. Moreover, MW pasteurization of packaged products is possible for different packaging materials (plastic, paper, and glass) $[48,49]$. Furthermore, this technology can be combined with other technologies such as infrared heating for surface cooking, for example [50].

Despite the numerous advantages of MW decontamination technology, heating heterogeneity is a serious problem that leads to incomplete inactivation of microorganisms. Several studies have reported the survival of pathogens such as Salmonella spp. [51] and L. monocytogenes [52], in foods heated in MW ovens.

Goksoy et al. [53, 54] studied the effect of short-time MW exposures on Escherichia coli $\mathrm{K} 12$ and Campylobacter jejuni inoculated on chicken meat. A temperature variation of $20^{\circ} \mathrm{C}$ was measured between different parts of the sample. The auteurs reported that the samples subjected to MWs showed signs of partial cooking areas. There was no evidence that short-time exposure (up to $30 \mathrm{~s}$ ) to MWs had any bactericidal effect on microorganisms. Apostolou et al. [55] confirmed these results. MW heating of chicken portions did not eliminate E. coli O157: H7. A significant variation of temperature (from 66.7 to $92^{\circ} \mathrm{C}$ ) was also observed.

On the other hand, the heterogeneous heating causes a severe deterioration of food quality. Local overheating often results in irremediable changes of color where the temperature is highest [56]. These phenomena are mainly observed at the corners and the edges of the product due to wave reflection.

Another difficulty concerning MW decontamination is the problem of cold spot localization. During a typical thermal process, the cold point is well defined and located often at the center of the product. During MW pasteurization, one point temperature monitoring within the product is not sufficient to ensure food safety [57]. For example, Schnepf and Barbeau [58] studied the inactivation of inoculated Salmonella in poultry. Their results showed that measuring the internal temperature during MW treatment does not reflect the surface inactivation, where the temperature was lower. To locate the cold spot, the chemical marker method developed by Kim and Taub [59] was successfully used [60-62]. Combined with experimental investigations, numerical simulations are highly recommended to find the cold spot and to achieve an accurate study to develop a reliable MW decontamination process $[57,63,64]$.

\subsection{Minimizing the heterogeneity of microwave heating}

Before accepting MW technology as a reliable method for pasteurization and/ or sterilization of food, it is important to ensure uniform heating during treatment. Several studies have been conducted to improve the quality and safety of MW-treated products, and various solutions have been proposed.

Fung and Cunningham [65] reported that MW heating in combination with conventional heating results in more uniform heating of food and better inactivation of bacteria. Datta et al. [66] found that MW heating in combination with infrared heating or air jets decreases the nonuniformity of temperature distribution. In the same field, Maktabi et al. [67] investigated the synergistic killing effect of laser, MW, and UV radiation on E. coli and on some other spoilage and pathogenic bacteria. It was found that the overall reduction in viable counts was significantly higher than the sum of the reduction values for the individual treatments. The order of the treatment processes had also a significant influence on microbial destruction. A successive process by laser, MW, and then UV was the most effective. Similarly, Lau and Tang [46] studied the heating uniformity and textural quality of pickled 
asparagus pasteurized by MW in comparison with the conventional hot-water pasteurization method. Two successive heating steps, first in water bath and then in $915 \mathrm{MHz}$ MW oven, were successfully applied. Moreover, covering the top onethird of the product glass bottle with aluminum foil eliminated the overheating at the edges. MW pasteurization also reduced the cook value for pickled asparagus and reduced textural degradation.

On the other hand, the presence of an absorbent medium around the product can reduce the overheating of edges and corners. For example, some authors reported that immersion of the sample in hot water [48] or the use of a steam flow into the oven cavity [68] may be used to ensure a safer and better quality end product. Microwave-circulated water combination (MCWC) heating system demonstrated a relatively uniform heat distribution within packaged food products. Guan et al. [48] reported that microbial destruction by a pilot-scale MCWC heating system matched with designed degrees of sterilization $\left(\mathrm{F}_{0}\right.$ value $)$ for a conventional treatment.

Koskiniemi et al. [69] improved the heating uniformity of packaged acidified vegetables using a continuous $915 \mathrm{MHz}$ MW system with a two-stage rotation device to rotate the products $180^{\circ}$ during treatment. This method increased also the average temperature at the cold point to meet the industrial standard for in-pack pasteurization of acidified vegetables.

Pulsed MW heating technique was also successfully tested. In this method, pulsed application of energy-i.e., turning the magnetron power "on" and "off" intermittently-leads to thermal energy equalization via conduction from hot to cold region during the power-off periods. This results in more uniform temperature distribution within the sample than during continuous application of energy [70, 71]. Sato et al. [37] reported also an enhanced killing rate of Escherichia coli K12 by using pulsed waves compared to continuous treatment.

\subsection{Modeling and optimization of microwave heating}

Computational fluid dynamics (CFD) is widely used as an established approach for understanding and then optimizing food processing based on the solution to partial differential equations of mass, momentum, and energy transport. MW heating is a multiphysics phenomenon that requires electromagnetic propagation equations (i.e., Maxwell's equation) to be combined simultaneously with the heat transfer equation to predict the MW power absorption as well as the temperature distribution inside the product [72]. Modeling of MW heating is widely studied in the literature. Interested readers can consult specialized references for more details [73].

In order to design and optimize a reliable MW pasteurization and/or sterilization process, heating model needs to be coupled with kinetic models correlating microbial decontamination. The resulting global model has to mimic the spatial temperature distribution as well as the microbial inactivation at every point within the sample. Few coupled numerical studies of bacterial inactivation by MW heating are reported in the literature. Recently, Masood et al. [64] published an excellent review about emerging technologies modeling to ensure microbial safety of foods.

The classical concept of decimal reduction time and thermal resistance constant ( $\mathrm{D}$ and $\mathrm{z}$ values) was also used to characterize the microbial inactivation by MW heating. Cañumir et al. [74] determined D-values at constant power levels and proposed a z-value in watt to represent the resistance of a target germ during MW heating. Laguerre et al. [75] proposed new specific power destruction parameters, $\mathrm{D}_{\mathrm{p}}$ - and $\mathrm{z}_{\mathrm{p}}$-values, to qualify $\mathrm{MW}$ heating. The decimal reduction time $\left(D_{p}\right.$ value) is the treatment time required to reduce microbial population by $90 \%$ at a constant applied specific power expressed in $\mathrm{W} / \mathrm{mL}$ or in $\mathrm{W} / \mathrm{g}$. The $\mathrm{z}_{\mathrm{p}}$ value is the change of specific power necessary to cause a tenfold change in the $\mathrm{D}_{\mathrm{p}}$ values 
of microorganism under specified conditions. This concept has been successfully tested for sterilization of infant food in a lab-scale MW pilot. The optimal condition for MW sterilization of infant food was also determined.

Because of the heterogeneity of MW heating, microbial inactivation kinetics need to be coupled with nonlinear heat transfer model to calculate the temporospatial survival of bacteria [63]. Mallikarjunan et al. [76] developed a mathematical model that includes mass heat transfer to microbial inactivation kinetics. The variation of the dielectric properties with respect to the temperature is taken into account in the simulation process. A good agreement with experimental data was obtained. Hamoud-Agha et al. [57, 63] used COMSOL Multiphysics to investigate the inactivation of E. coli $\mathrm{K} 12$ suspended in a gel medium, comparing MW processing with conventional thermal treatment in a water bath. The authors coupled the thermal nonlinear microbiological inactivation model of Geeraerd et al. [77] with heat transfer and Maxwell's equations integrated into a finite element model under dynamic heating conditions. The results revealed uneven temperature distribution during MW heating which led to a lower inactivation efficiency than water bath treatment. Simulation results were in good agreement with experimental data. The modeling approach to estimate efficiency of microbial inactivation was reliable despite the thermal heterogeneity inherent in the MW treatment. Application of holding time at lethal temperatures $\left(55\right.$ and $\left.57^{\circ} \mathrm{C}\right)$ did not help to homogenize the temperature distribution within the sample $[57,63]$.

However, because of digital resources required and time consumption, the use of physical models as presented before could be delicate for real industrial applications in the food industry. On the other hand, another approach based on experimental designs (EDs) and response surface methodology (RSM) can be relatively easy, fast to implement, and quite useful [78]. Nevertheless, RSM has some limitations [8]: (1) it uses a priori models (quadratic model whatever the studied response); (2) the number of tests to be reset can increase very quickly with the number of factors in the plan; (3) the factors must be completely independent; and (4) uncontrolled factors cannot be taken into account.

Another method proposed by Lesty et al. [79], based on iconographic correlations (CORICO), makes it possible to circumvent these difficulties [8]. After analysis of the experimental plan data, CORICO proposes regression models whose regressors are logical interactions (AND, Exclusive OR, IF, etc.) between factors. In addition, CORICO tolerates linked factors and allows the consideration of uncontrolled factors. Furthermore, it needs few numbers of essays comparatively to classical EDs, (17 essays for a 9-factor CORICO designs against 533 for a 9-factor Doehlert design), which allows to minimize costs. This method has recently been used in the agri-food sector for the optimization of the drying process of different food products (tomato, microalgae, apple) [11, 80, 81] as well as for MW cooking processes (beef burgundy, fish) [82, 83].

\section{Conclusions}

Conventional heat treatments for food preservation are generally characterized by poor end-product quality. Furthermore, these methods are not optimized for solid foods because of slow heat transfer from the surface to the cold point, often at the center of the product. Enhanced organoleptic and nutritional food properties combined with food safety is the aim of modern food processing technologies. Microwave (MW) heating has the advantages to overcome the limitation of slow thermal diffusion imposed by conventional heating. This technology knows a growing industrial demand thanks to its flexible and rapid heating performance. MW 
heating is successfully used for food drying and decontamination. However, this process is still relatively poorly controlled because of complex interactions between foods and MWs. Furthermore, the heating heterogeneity is the major drawback of this technology. Several methods were, nevertheless, proposed in the literature to improve the heating homogeneity. In general, coupling MW heating with other heating methods largely improved the microbiological safety, the drying efficiency, and the quality of various food products. Physical modeling and simulation are important tools to understand and to optimize MW heating processes. The application of these models is limited in industrial scale; however, experimental designbased approaches could be promising methods. Even so, developing a reliable industrial MW heating process is still a challenge.

\section{Author details}

Jean-Claude Laguerre ${ }^{1 *}$ and Mohamad Mazen Hamoud-Agha ${ }^{2}$

1 Institut Polytechnique UniLaSalle, Beauvais, France

2 Minoteries Paulic, St-Gerand, France

*Address all correspondence to: jean-claude.laguerre@unilasalle.fr

\section{IntechOpen}

(C) 2019 The Author(s). Licensee IntechOpen. This chapter is distributed under the terms of the Creative Commons Attribution License (http://creativecommons.org/licenses/ by/3.0), which permits unrestricted use, distribution, and reproduction in any medium, provided the original work is properly cited. (cc) BY 


\section{References}

[1] Datta AK, Anantheswaran RC. The Handbook of Microwave Technology for Food Applications. 1st ed. New York: Marcel Dekker; 2001. Epub ahead of print 2001. DOI: 10.1017/ CBO9781107415324.004

[2] Sundberg M, Kildal P, Ohlsson T. Moment method analysis of a microwave tunnel oven. Journal of Microwave Power and Electromagnetic Energy. 1998;33:36-47

[3] Sundberg R, Risman PO, Kildal P-S, et al. Analysis and design of industrial microwave ovens using the finite difference time domain method. Journal of Microwave Power and Electromagnetic Energy. 1996;31:142-157

[4] Zhang Z, Su T, Zhang S. Shape effect on the temperature field during microwave heating process. Journal of Food Quality. 2018;2018:1-24

[5] Schiffmann RF. Microwave processes for the food industry. In: Datta AK, Anantheswaran RC, editors. Handbook of Microwave Technology for Food Applications. New York: Marcel Dekker; 2001. pp. $115-166$

[6] Chandrasekaran S, Ramanathan S, Basak T. Microwave food processing-A review. Food Research International. 2013;52:243-261

[7] Onwude D, Hashim N, Chen G. Recent advances of novel thermal combined hot air drying of agricultural crops. Trends in Food Science \& Technology. 2016;57:132-145

[8] Morais RMSCSC, Morais AMMBMB, Dammak I, et al. Functional dehydrated foods for health preservation. Journal of Food Quality. 2018;2018:1-29

[9] Zhang M, Tang J, Mujumdar AS, et al. Trends in microwave-related drying of fruits and vegetables. Trends in Food Science and Technology. 2006;17:524-534

[10] Laguerre J-C, Abhayawick L, Beaumont-Lang L. Tailoring the onion crop for the 21st century. The Development of High Quality Fresh and Processed Onions-Annual Progress Report 3rd Year; Beauvais. 1999

[11] Koné KY. Amélioration de la qualité de la tomate séchée par microondes assistés par air chaud avec pilotage de la puissance spécifique. [Thesis]. Paris: AgroParisTech; 2011

[12] Abhayawick L, Laguerre J-C, Duquenoy A. Runaway heating of onions during microwave drying. In: Kerkhof PJAM, Coumans WJ, Mooiwer GD, editors. IDS 2000-12th International Drying Symposium; Noordwijkerhout. 2000

[13] Li Z, Raghavan GSV, Orsat V. Temperature and power control in microwave drying. Journal of Food Engineering. 2010;99:263-268

[14] Soysal Y, Ayhan Z, Estürk O, et al. Intermittent microwave-convective drying of red pepper: Drying kinetics, physical (colour and texture) and sensory quality. Biosystems Engineering. 2009;103:455-463

[15] Laguerre J-C, Koné KY, Druon C, et al. Control of thermal runaway during microwave convective air drying of tomatoes. In: 16th IUFOST World Congress of Food Science and Technology. 2012

[16] Maskan M. Microwave/air and microwave ( $r$ )nish drying of banana. Journal of Food Engineering. 2000;44:71-78

[17] Zielinska M, Michalska A. Microwave-assisted drying of 
blueberry (Vaccinium corymbosum L.) fruits: Drying kinetics, polyphenols, anthocyanins, antioxidant capacity, colour and texture. Food Chemistry. 2016;212:671-680

[18] Silva FA, Marsaioli A, Maximo GJ, et al. Microwave assisted drying of macadamia nuts. Journal of Food Engineering. 2006;77:550-558

[19] Chahbani A, Fakhfakh N, Amine M, et al. Food bioscience microwave drying effects on drying kinetics, bioactive compounds and antioxidant activity of green peas (Pisum sativum L.). Food Bioscience. 2018;25:32-38

[20] Schulze B, Hubbermann EM, Schwarz K. LWT_-Food science and technology stability of quercetin derivatives in vacuum impregnated apple slices after drying (microwave vacuum drying, air drying, freeze drying) and storage. LWTFood Science and Technology. 2014;57:426-433

[21] Lemos R, Varaschim J, Tribuzi G, et al. Effect of multi-flash drying and microwave vacuum drying on the microstructure and texture of pumpkin slices. LWT_-Food Science and Technology. 2018;96:612-619

[22] Zielinska M, Ropelewska E, Markowski M. Thermophysical properties of raw, hot-air and microwave-vacuum dried cranberry fruits (Vaccinium macrocarpon). LWT_Food Science and Technology. 2017;85:204-211

[23] Li CUI, Li-ying NIU, Da-jing LI, et al. Effects of different drying methods on quality, bacterial viability and storage stability of probiotic enriched apple snacks. Journal of Integrative Agriculture. 2018;17:247-255

[24] Kröncke N, Böschen V, Woyzichovski J, et al. Comparison of suitable drying processes for mealworms (Tenebrio molitor). Innovative Food Science and Emerging Technologies. 2018;50:20-25

[25] Ahmed J, Ramaswamy HS, Raghavan VGS. Dielectric properties of butter in the MW frequency range as affected by salt and temperature. Journal of Food Engineering. 2007;82:351-358

[26] Salazar-gonzález C. Recent Studies Related to Microwave Processing of Fluid Foods. 2012. pp. 31-46

[27] Shaheen MS, El-massry KF, El-ghorab AH, et al. Microwave Applications in Thermal Food

Processing. 2012. pp. 3-16

[28] Guo Q, Sun D, Cheng J, et al. Microwave processing techniques and their recent applications in the food industry. Trends in Food Science \& Technology. 2017;67:236-247

[29] Gedikli S, Tabak Ö, Tomsuk Ö, et al. Effect of microwaves on some gram negative and gram positive bacteria. Journal of Applied Biological Science. 2008;2:67-71

[30] Zhou BW, Shin SG, Hwang KH, et al. Effect of microwave irradiation on cellular disintegration of gram positive and negative cells. Applied Microbiology and Biotechnology. 2010;87:765-770

[31] Heddleson RA, Doores S. Factors affecting microwave heating of foods and microwave induced destruction of foodborne pathogens-A review. Journal of Food Protection. 1994;57:1025-1037

[32] Valsechi OAA, Horii J, De Angelis DF, et al. The effect of microwaves on microorganisms. Arquivos do Instituto Biológico. 2004;71:399-404

[33] Fujikawa H, Ushioda H, Kudo Y. Kinetics of Escherichia coli destruction 
by microwave irradiation. Applied and Environmental Microbiology. 1992;58:920-924

[34] Welt BA, Tong CH, Rossen JL, et al. Effect of microwave radiation on inactivation of clostridium sporogenes (PA 3679) spores. Applied and Environmental Microbiology. 1994;60:482-488

[35] Barnabas J, Siores E, Lamb A. Nonthermal microwave reduction of pathogenic cellular population. International Journal of Food Engineering. 2010;6. Epub ahead of print. DOI: $10.2202 / 1556-3758.1878$

[36] Bohr H, Bohr J. Microwaveenhanced folding and denaturation of globular proteins. Physical Review E-Statistical Physics, Plasmas, Fluids, and Related Interdisciplinary Topics. 2000;61:4310-4314

[37] Sato S, Shibata C, Yazu M.

Nonthermal killing effect of microwave irradiation. Biotechnology Techniques. 1996;10:145-150

[38] Kozempel M, Cook RD, Scullen OJ, et al. Nonthermal effects of microwave energy on microorganisms at low temperature. Journal of Food Processing and Preservation. 2000;24:287-301

[39] Ramaswamy HS, Koutchma T, Tajchakavit S. Enhanced thermal effects under microwave heating conditions. In: Group CP-T\& F, editor. Engineering and Food for the 21st Century. Boca Raton: CRC Press; 2002. pp. 739-761

[40] Kakita Y, Kashige N, Watanabe K, et al. Inactivation of lactobacillus bacteriophage PL-1 by microwave irradiation. Microbiology and Immunology. 1995;39:571-576

[41] Shamis Y, Taube A, Mitik-Dineva N, et al. Specific electromagnetic effects of microwave radiation on Escherichia coli. Applied and Environmental Microbiology. 2011;77:3017-3022

[42] Woo IS, Rhee IK, Park HD. Differential damage in bacterial cells by microwave radiation on the basis of cell wall structure. Applied and Environmental Microbiology. 2000;66:2243-2247

[43] Shin JK, Pyun YR. Inactivation of Lactobacillus plantarum by pulsedmicrowave irradiation. Journal of Food Science. 1997;62:163-166

[44] Rosaspina S, Salvatorelli G, Anzanel $D$, et al. Effect of microwave radiation on Candida albicans. Microbios. 1994;78:55-59

[45] Shamis Y, Croft R, Taube A, et al. Review of the specific effects of microwave radiation on bacterial cells. Applied Microbiology and Biotechnology. 2012;96:319-325

[46] Lau MH, Tang J. Pasteurization of pickled asparagus using $915 \mathrm{MHz}$ microwaves. Journal of Food Engineering. 2002;51:283-290

[47] Massoubre E. Foie gras et plats cuisinés: Micro onde pour une bonne qualité sensorielle. Viandes et Produits Carnés. 2003;23:49-52

[48] Guan D, Gray P, Kang DH, et al. Microbiological validation of microwave-circulated water combination heating technology by inoculated pack studies. Journal of Food Science. 2003;68:1428-1432

[49] Tang Z, Mikhaylenko G, Liu F, et al. Microwave sterilization of sliced beef in gravy in 7-oz trays. Journal of Food Engineering. 2008;89:375-383

[50] Datta AK, Rakesh V. Principles of microwave combination heating. Comprehensive Reviews in Food Science and Food Safety. 2013;12:24-39 
[51] Heddleson RA, Doores S, Anantheswaran RC, et al. Viability loss of salmonella species, Staphylococcus aureus, and Listeria monocytogenes in complex foods heated by microwave energy. Journal of Food Protection. 1996;59:813-818

[52] Farber JM, D’Aoust JY, Diotte M, et al. Survival of listeria spp. on raw whole chickens cooked in microwave ovens. Journal of Food Protection. 1998;61:1465-1469

[53] Goksoy EO, James C, James SJ. Non-uniformity of surface temperatures after microwave heating of poultry meat. Journal of Microwave Power and Electromagnetic Energy.

1999;34:149-160

[54] Göksoy EO, James C, Corry JEL. Effect of short-time microwave exposures on inoculated pathogens on chicken and the shelf-life of uninoculated chicken meat. Journal of Food Engineering. 2000;45:153-160

[55] Apostolou I, Papadopoulou C, Levidiotou S, et al. The effect of short-time microwave exposures on Escherichia coli O157:H7 inoculated onto chicken meat portions and whole chickens. International Journal of Food Microbiology. 2005;101:105-110

[56] Tang J. JFS Special Issue: 75 Years of Advancing Food Science, and Preparing for the Next 75 Unlocking Potentials of Microwaves for Food Safety and Quality. 80. Epub ahead of print. 2015. DOI: 10.1111/1750-3841.12959

[57] Hamoud-Agha MM, Curet S, Simonin $\mathrm{H}$, et al. Holding time effect on microwave inactivation of Escherichia coli K12: Experimental and numerical investigations. Journal of Food Engineering. 2014;143:102-113

[58] Schnepf M, Barbeau WE. Survival of Salmonella Typhimurium in roasting chickens cooked in a microwave, convection microwave, and a conventional electric oven. Journal of Food Safety. 1989;9:245-252

[59] Kim HJ, Taub IA. Intrinsic chemical markers for aseptic processing of particulate foods. Food Technology. 1993;47:91-97

[60] Auksornsri T, Bornhorst ER, Tang J, et al. Developing model food systems with rice based products for microwave assisted thermal sterilization. LWT_Food Science and Technology. 2018;96:551-559

[61] Pandit RB, Tang J, Liu F, et al. Development of a novel approach to determine heating pattern using computer vision and chemical marker (M-2) yield. Journal of Food Engineering. 2007;78:522-528

[62] Bornhorst ER, Tang J, Sablani SS, et al. Development of model food systems for thermal pasteurization applications based on Maillard reaction products novas. LWT_Food Science and Technology. 2017;75:417-424

[63] Hamoud-Agha MM, Curet S, Simonin H, et al. Microwave inactivation of Escherichia coli K12 CIP 54.117 in a gel medium: Experimental and numerical study. Journal of Food Engineering. 2013;116:315-323

[64] Masood H, Trujillo FJ, Knoerzer K, et al. Designing, Modeling, and Optimizing Processes to Ensure Microbial Safety and Stability Through Emerging Technologies. Elsevier Inc. Epub ahead of print 2018. DOI: 10.1016/ B978-0-12-811031-7.00006-6

[65] Fung DYC, Cunningham FE. Effect of microwaves on microorganisms in foods. Journal of Food Protection. 1980;43:641-650

[66] Datta AK, Geedipalli SSR, Almeida MF. Microwave combination heating. Food Technology. 2005;59:36-40 
[67] Maktabi S, Watson I, Parton R. Synergistic effect of UV, laser and microwave radiation or conventional heating on E. coli and on some spoilage and pathogenic bacteria. Innovative Food Science and Emerging Technologies. 2011;12:129-134

[68] Lacroix K, Orsat V, Nattress DF, et al. Dielectric heating of fresh meat for antimicrobial treatment. In: The 93rd Annual International Meeting of American Society of Agricultural Engineers (ASAE); Milwaukee. 2000

[69] Koskiniemi CB, Den TV, Simunovic $\mathrm{J}$, et al. Improvement of heating uniformity in packaged acidified vegetables pasteurized with a $915 \mathrm{MHz}$ continuous microwave system. Journal of Food Engineering. 2011;105:149-160

[70] Yang HW, Gunasekaran S. Comparison of temperature distribution in model food cylinders based on Maxwell's equations and Lambert's law during pulsed microwave heating. Journal of Food Engineering. 2004;64:445-453

[71] Gunasekaran S, Yang HW. Effect of experimental parameters on temperature distribution during continuous and pulsed microwave heating. Journal of Food Engineering. 2007;78:1452-1456

[72] Curet S, Rouaud O, Boillereaux L. Microwave tempering and heating in a single-mode cavity: Numerical and experimental investigations. Chemical Engineering and Processing: Process Intensification. 2008;47:1656-1665

[73] Zhao X, Huang K, Yan L. Review of Numerical Simulation of Microwave Heating Process. Intech Open Access Publisher 2011;27-28

[74] Cañumir JA, Celis JE, de Bruijn J, et al. Pasteurisation of apple juice by using microwaves. LWT-Food Science and Technology. 2002;35:389-392
[75] Laguerre JC, Pascale GW, David M, et al. The impact of microwave heating of infant formula model on neo-formed contaminant formation, nutrient degradation and spore destruction. Journal of Food Engineering. 2011;107:208-213

[76] Mallikarjunan P, Hung Y-C, Gundavarapu S. Modeling microwave cooking of cocktail shrimp. Journal of Food Process Engineering. 1996;19:97-111

[77] Geeraerd AH, Herremans CH, Van Impe JF. Structural model requirements to describe microbial inactivation during a mild heat treatment. International Journal of Food Microbiology. 2000;59:185-209

[78] Bas D, Boyacı İH. Modeling and optimization I: Usability of response surface methodology. Journal of Food Engineering. 2007;78:836-845

[79] Lesty M. Une nouvelle approche dans le choix des régresseurs de la régression multiple en présence d'interactions et de colinéarités. La Revue Modulad. 1999;22: 41-77

[80] Laguerre J-C, Ratoandromalala LP, Humeau A, et al. Iconographic correlation method and Fourier transform infrared spectroscopy (FTIR) for the optimization of a combined microwave hot air drying of the microalgae Isochrysis sp. In: Procedings of the 17th World Congress of Food Science and Technology-IUFOST. Montreal; 2014

[81] Laguerre J-C, Ratovoarisoa LG, Vivant A-C, et al. An iconographic correlation method for optimizing a combined microwave/hot air drying of apple Malus domestica sp. Journal of Food Processing \& Technology. 2017;8:7110 
[82] Jouquand C, Tessier FJ, Bernard J, et al. Optimization of microwave cooking of beef burgundy in terms of nutritional and organoleptic properties. LWT_Food Science and Technology. 2015;60:271-276

[83] Laguerre J-C, Douiri-Bedoui I, Chireux C, et al. The iconographic correlation (CORICO) method, a new approach for the optimization of microwave cooking processes: Application for cooking fish. In: EFFOST Annual Meeting. 2013 


\title{
Chapter 4
}

\section{Efficacy of Plant Antimicrobials as Preservative in Food}

\author{
Romika Dhiman and Neeraj Kumar Aggarwal
}

\begin{abstract}
Safe and hygienic food is a requirement for a healthy society. The problem of food-borne outbreaks has built a challenge against the food and health regulatory authorities to control the pathogenic microorganisms. Chemical preservative has created some health problems in foods, so the recent trend is towards the use of natural antimicrobials in foods. Plants are valuable source of bioactive molecules exhibiting antimicrobial activities. The plant antimicrobial compounds have diverse chemical nature such as alkaloids, phenolics, terpenes, terpenoids, flavonoids, essential oil, etc. Many plant antimicrobials possess antimicrobial activity against pathogens and spoilage microorganisms. But variation in effectiveness of these compounds against microorganisms in laboratory system and in real food systems is major determinant in their food use. Several plant extract or purified compounds are part of human diet since thousands of years. Although some plant compounds enjoy the status of generally recognised as safe (GRAS), typical toxicological information of their use in food is not available. So the improvement in cost-effective isolation and toxicological information of these compounds is helpful in their use as biopreservative in foods.
\end{abstract}

Keywords: biopreservative, antimicrobial, essential oil, flavonoids

\section{Introduction}

Food preservation is dominant features in all food sectors and mainly comprises curbing the rise of microorganisms that increase the health-related issues in consumers [1]. The food attributes that attract the attention of the consumer are freshness and their naturalness and minimal processing. The perception of naturalness drives the consumer towards the food without chemical preservatives [2]. Modernization coupled with the change in the life style of the consumer shifts them towards the use of ready-to-use food. Thermal processing, drying, freezing, refrigeration, irradiation, modified atmosphere packaging (MAP) and addition of antimicrobial agents or salts are some conventional methods to prevent the growth of microbes in foods $[1,3]$.

Thermal processing is commonly applied in food industry to inactivate the microorganisms and enhance shelf life of food. However, pasteurisation reduces the level of some bioactive compounds such as anthocyanin pigment, carotenoids and vitamin $\mathrm{c}$ that has been reported in several fruits. Emerging nonthermal technology like high hydrostatic pressure (HHP), ultraviolet, ozone processing, pulsed electric fields and ultrasound has promising role in maintaining the nutritional and sensory quality of food. Dense phase carbon dioxide (DPCD) technique is generally employed for liquid foods. Pressure used in DPCD damages the tissues of the fruits [3-5]. 
The high intensity and longer duration time used in PEF affect the nutritional quality of foods. [6]. High dosage of ozone processing used for decontaminating food surface alters the sensory quality of the food. Nonetheless, the main limitation of applying UV-C light in food is its penetration, so it is only effective for the surface decontamination of food [7].

Besides, these some chemical preservatives such as sodium benzoate, potassium sorbate and nitrites have been used commercially in fruit juices, dairy products, confectionary, meat and meat products, etc. Nitrites and nitrates are applied in meat industry to inhibit the growth of the microorganisms, retain the red colour of the meat and reduce the oxidation of lipid. However, blue baby syndrome occurs in children owing to the presence of high amount of nitrites in their blood [8]. Some chemical preservatives such as sodium benzoate and potassium sorbate used in fruit juice industry have also constraints like benzoic acid that is converted into benzene in foods, and S. cerevisiae and Pichia anomala are able to decarboxylate sorbic acid to 1,3 pentadiene which cause kerosene-like off-odour. Schizosaccharomyces pombe may produce off-flavours in the presence of sulphite. Due to growing evidences about the harmful effects of chemical preservatives, there is continuous pressure to reduce the amount of added preservative in foods [9-12].

To avoid the health risks associated with the consumption of foods, natural antimicrobial compounds like bacteriocins, chitosan-fermented ingredients and plant antimicrobials provide another alternative for preserving food. Spices and herbs are used in food since the ancient time not for flavouring but also for the preservation. Plant extracts, essential oil and peptides exhibit a broad-spectrum activity. The antimicrobial and antioxidant properties of plants are attributed to secondary metabolites such as phenylpropanoids, terpenes, flavonoids and anthocyanins $[3,11,13-14]$. Several studies have been conducted around the globe to prove the efficacy of plant products, and various compounds isolated from these plants are secondary metabolites which possess antimicrobial and medicinal properties $[3,11,13,15,16]$. The main purpose of this review article is to examine application of plant antimicrobials in food and their chemical diversity and limitation.

\section{Current scenario of food-borne outbreaks}

Food-borne diseases occur at a fast rate. The key concern of public health authorities are now more concerted on food pathogens and food-borne outbreaks. Due to lack of awareness, a large number of food-borne-associated incidences become unnoticed. Food-borne diseases are only reported when this pathogen cause infection in a large number of people which resulted in an outbreak. Therefore, it is essential to shrink the load of food-borne diseases through vigilant monitoring of the food-borne outbreaks and causal organism [17].

Consumption of raw foods such as fruits, vegetables, fruit juices and raw sprouts is the main cause of food-borne outbreaks. The major food-borne pathogens are Salmonella enterica, E. coli, Clostridium perfringens, Staphylococcus aureus, Shigella spp., Campylobacter spp., Bacillus cereus, Vibrio parahaemolyticus, Clostridium botulinum and Listeria monocytogenes. In the USA, norovirus is implicated in a number of food-borne outbreaks associated with consumption of salad, and millions of people are affected $[18,19]$. Salmonella and E. coli are involved in multistate outbreak in the USA. E. coli that causes severe haemolytic diarrhoea infected 3000 people in Germany and killed 53 people. Fresh produce and water is the main source of protozoan infection [18]. Listeria monocytogenes was implicated in 31 outbreaks in Switzerland during 2013-2014 which is associated with consumption of readyto-eat salad [20]. L. monocytogenes has also been observed where frozen corn and 
frozen vegetable mixes including corn, frozen spinach and frozen green bean were consumed in European countries [21]. Consumption of frozen berry was responsible for hepatitis A in Italy. Hepatitis A was found in people who travelled to Italy during 2013-2014 [22]. Salmonella and S. aureus were involved in a large number of outbreaks associated with consumption of pork or pork products in the USA during 1998-2015 [23]. Hennekinne et al. [24] reviewed the occurrence of $S$. aureus food poisoning worldwide. The major share of food-borne outbreak in Canada is related to nontyphoidal Salmonella spp., Campylobacter and Listeria monocytogenes [25].

\section{Antimicrobial from plants}

To circumvent the losses due to food-borne outbreaks, an effective method of preservation should be adopted in food factories and restaurant for controlling the food-borne outbreaks. Application of antimicrobials in foods retards the growth of spoilage microorganisms and prevents the growth of pathogenic microorganisms. Natural antimicrobial compounds are obtained from plant, animal and microbes. Lactoferrin, lactoperoxidase and lysozyme are naturally occurring antimicrobials in animals. Bacteriocins like nisin and pediocin are biopreservative from microbial origin used commercially in food. Several forms of plant products such as essential oil, plant extract either in pure or crude form and plant antimicrobial peptide have also potential to utilise as a biopreservative in food $[5,11]$.

\subsection{Essential oil}

Essential oils are oily liquids derived from several plant parts (flower, buds, leaves, fruits, twigs, bark, seed, wood and roots) belonging to angiospermic families that can be used by several industries for different purposes [26]. The essential oils are mainly investigated for their pharmacological attributes [27-30]. Food companies utilise essential oil as flavouring agent; however, antimicrobial and antioxidant aspects of essential oil make it the best candidate for food preservation [31]. Methods employed for the extraction of essential oil are steam distillation, hydro distillations, critical carbon dioxide, subcritical water, solvent extraction, hydrodiffusion and solvent-free microwave [32].

Harvesting time, types of plant, season and methods adopted for the extraction of essential oil influence the chemical diversity of the essential oil. The active groups that leverage the antimicrobial property of essential oil have been categorised into four main groups: terpenes, terpenoids, phenylpropenes, and other chemical groups [33,34].

The mode of action of essential oil is not clearly defined till date. One particular mechanism does not justify the activity of diverse chemical groups present in the essential oil. Several researchers advocate that essential oil penetrates the bacterial cell membrane due to their lipophilic nature and disrupts the cell functioning [35-37]. Phenolic compounds alter the cell membrane permeability of the bacteria and hinder the generation of ATP and proton-motive force [38]. The hydrophobicity of essential oil displayed more activity against Gram-positive bacteria than Gram-negative bacteria which is attributed to difference in their cell structure [9]. The antimicrobial potential of essential oil is also influenced by concentration. Low concentration inhibits enzymes that are involved in energy production, and high concentration precipitates the protein. Thymol, eugenol and carvacrol inhibit ATPase activity and release of intracellular ATP and other components of cell membrane [15].

Different studies have demonstrated the effectiveness of Eos and their active compounds to control or inhibit the growth of pathogenic and spoilage 
microorganisms in both fresh-cut fruit and fruit juices. Literature study reveals the effectiveness of essential oil and their active compounds to retard the growth of microorganisms (Table 1).

The pink pepper tree (Schinus terebinthifolius Raddi) is a native plant of Brazil, Paraguay and Argentina. Essential oil obtained from pink pepper exhibit antimicrobial and antioxidant activity in cheese. Two percent essential oil concentration was effective in cheese for controlling the growth of microorganisms [1].

Sharafati-Chaleshtori et al. [39] studied the use of basil essential oil in beef burger reduced the growth of Staphylococcus aureus PTCC 1189 from $3 \log \mathrm{cfu} / \mathrm{g}$ to $2 \log \mathrm{cfu} / \mathrm{g}$ at $4^{\circ} \mathrm{C}$ after 24 hours. The clove oil enhanced the shelf life of red meat at $2^{\circ} \mathrm{C}$ for 15 days and reduced the $3.78 \mathrm{log}$ cycles of bacterial count as comparison to control that contain untreated meat. Similar results were obtained in cumin oil treatment [40].

The combination of thyme EO (at $0.4,0.8$ and 1.2\%) and nisin (at 500 or $1000 \mathrm{IU} / \mathrm{g}$ ) decreases Listeria monocytogenes population below the acceptable level ( $2 \log \mathrm{cfu} / \mathrm{g}$ ) and displayed strong antibacterial activity than the individual usage of $\mathrm{EO}$ or nisin in minced fish meat during storage period ( $4^{\circ} \mathrm{C}$ for 12 days) [41]. Samy Selim [42] studied the effect of eucalyptus, juniper, mint, rosemary, sage, clove and thyme oils on vancomycin-resistant Enterococci (VRE) and E. coli O157:H7 in minced beef meat and observed that sage and thyme oil exhibit strong antimicrobial activity against the tested microorganism.

The combination of Zataria multiflora Boiss essential oil (ZEO) and grape seed extract (GSE) at a concentration of $0.1 \%$ and $0.2 \%$, respectively, was more effective for controlling the growth of the Listeria monocytogenes in raw buffalo patty than individual usage of Zataria multiflora Boiss essential oil (ZEO) and grape seed extract and showed antioxidant activity and confirmed the synergistic effect against the tested microorganism [43]. In another study the synergistic effect of Mentha piperita essential oil and bacteriocin was significant to prevent the growth of microorganisms in minced beef meat as comparison to individual role [44].

\subsection{Antimicrobial peptides}

Plants are easily attacked by the insects, fungi and bacteria. To nullify the effect of plant pathogens, plants develop an efficient defence system with the synthesis of secondary metabolite phenols, oxygen-substituted derivatives, terpenoids, quinines, tannins and antimicrobial peptides (AMPs) [45]. AMPs are widely distributed in plants and plant parts [46] and integral part of the immune system, enzymatic network needed during metabolism, as a nutrient and a storage molecule. Antimicrobial peptides are the first line of defence during pathogen encounter with the host [47]. Over the last two decades, about 1500 antimicrobial peptides are identified in various sources such as insects, plants, microorganisms, amphibians and mammals [48]. Antimicrobial peptides are biologically active peptides that exhibit antimicrobial, antioxidant, antithrombotic, antihypertensive and immunomodulatory attributes [49-53].

Antimicrobial peptides are grouped into two types on the basis of their biosynthetic pathway. The first group comprises the peptides that are not ribosomally made (bacitracins and glycopeptides), and the second group comprises the ribosomally synthesised peptides involved in innate defence system of the body of the organisms [54]. To realise the need of the basic information of AMPs, an online antimicrobial peptide database (APD) was framed in 2003. The current version of APD was issued in 2016 comprises more than 2600 peptides from different sources [55].

Amphiphilic nature and presence of positively charged residues in antimicrobial peptide enable them to partition into bacterial membrane and alter the 
Efficacy of Plant Antimicrobials as Preservative in Food

DOI: http://dx.doi.org/10.5772/intechopen. 83440

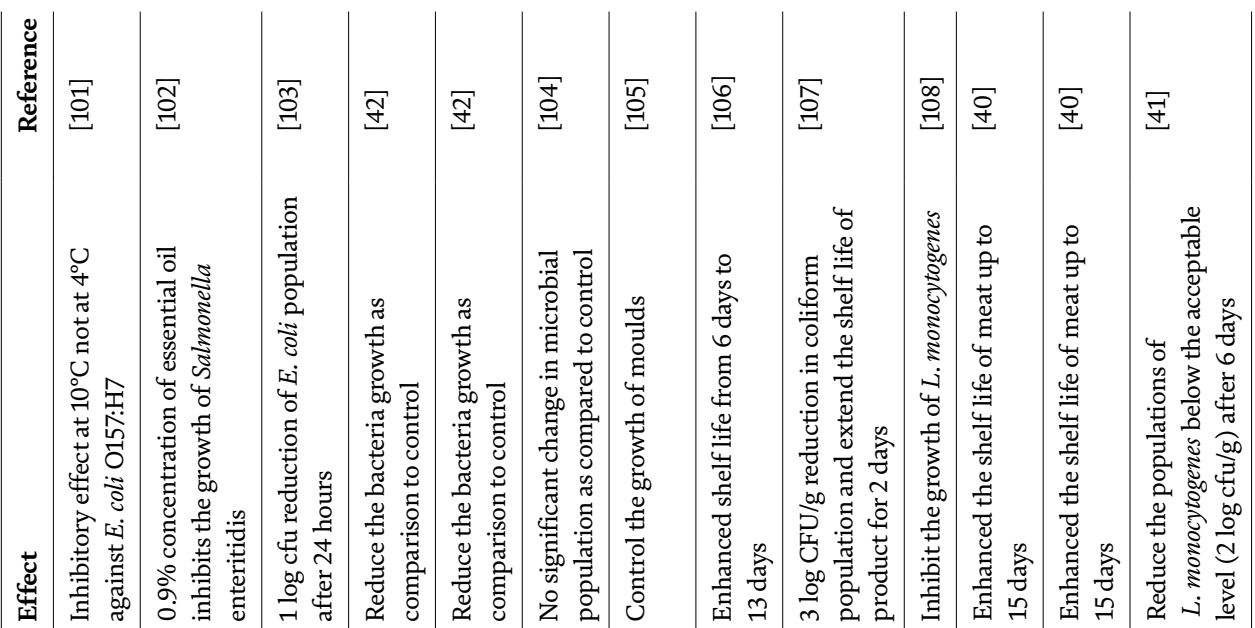

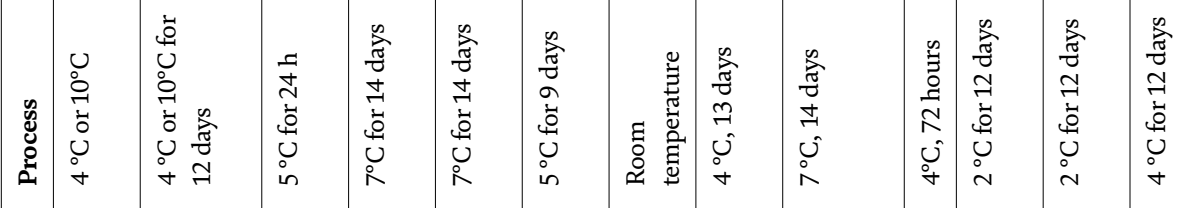

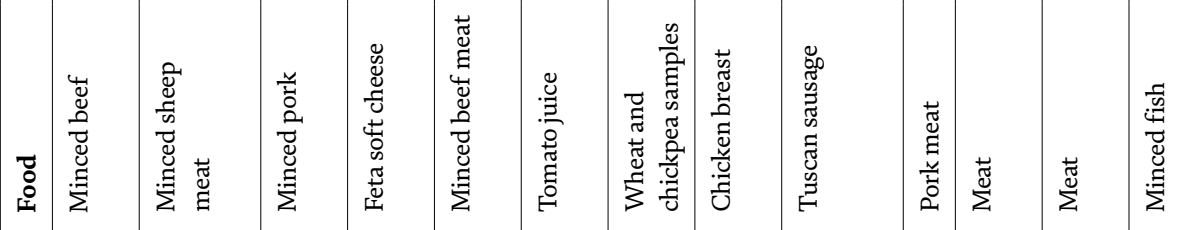
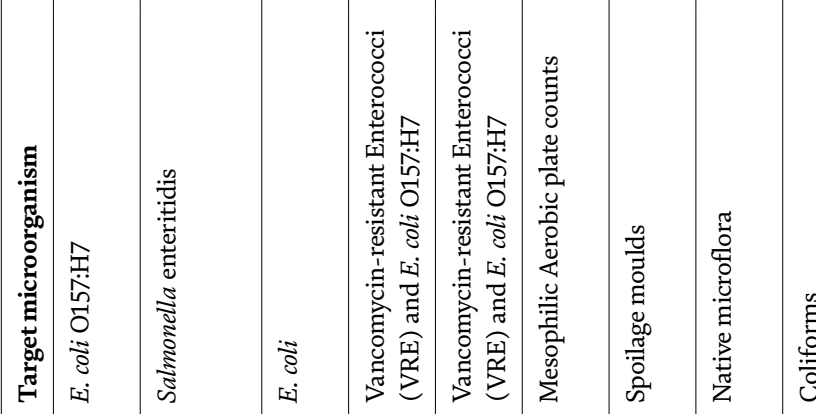

:

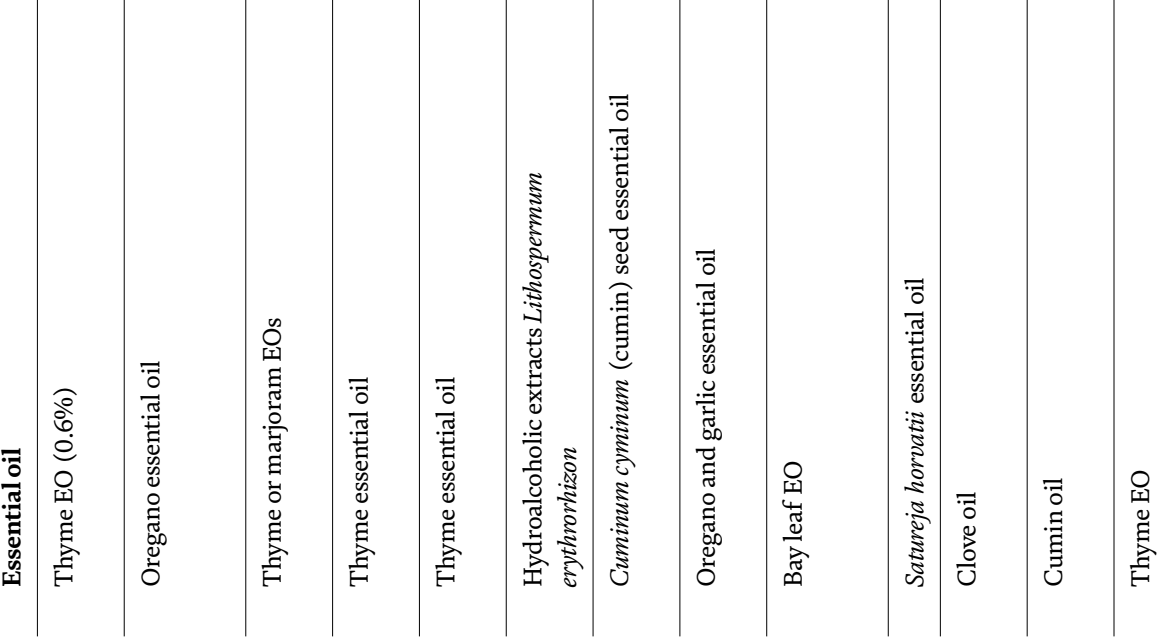




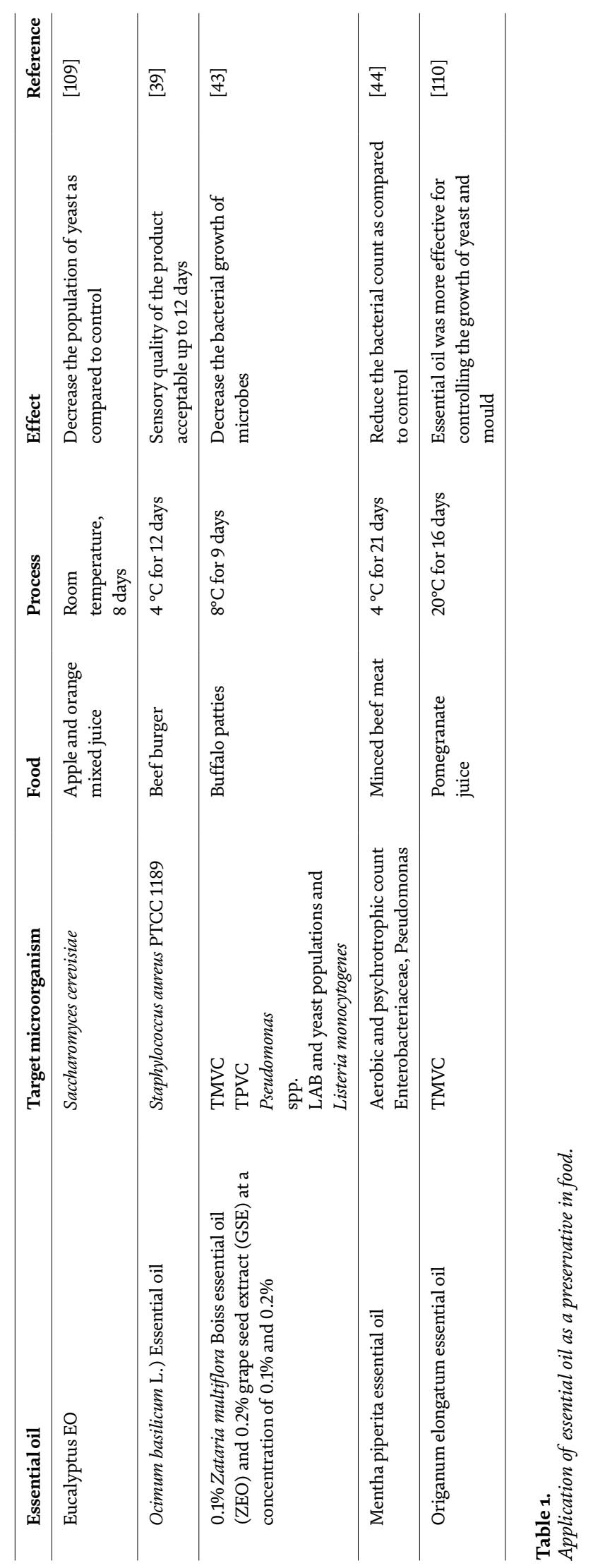




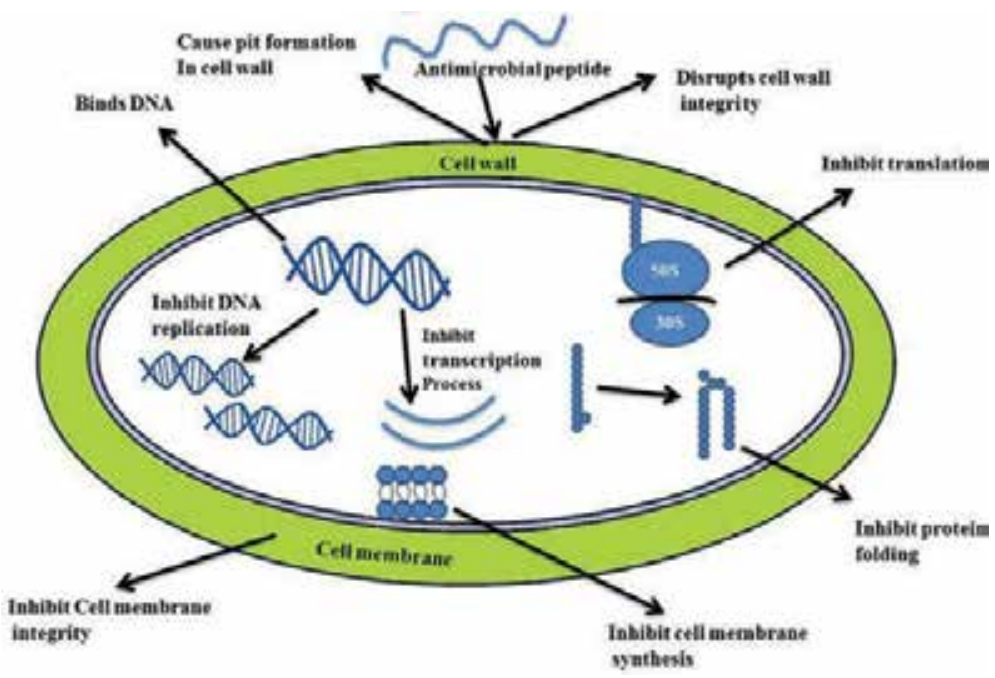

Figure 1.

Mechanism of action of antimicrobial peptide (adapted from [53]).

membrane permeability [56]. Antifungal property of AMPs lies in the attack of peptide on chitin, component of fungal cell wall, which hinders its synthesis and changes the membrane permeability (Figure 1) [46,57]. AMPs bind the glycosaminoglycan moiety of cell membrane and prevent the virus-cell interaction as evident by the cationic lactoferrin peptide [58]. Bacterial antimicrobial peptides, such as bacteriocins, have been used in food preservation over many years [59].

The first antimicrobial peptide identified in plant is purothionin, which displays antimicrobial activity against Pseudomonas solanacearum, Xanthomonas phaseoli and $X$. campestris, Erwinia amylovora, Corynebacterium flaccumfaciens, C. michiganense, C. poinsettiae, C. sepedonicum and C. fascians [58]. The main groups incorporate thionins (types I-V), defensins, cyclotides, $2 \mathrm{~S}$ albumin-like proteins and lipid transfer proteins $[60,61]$ along with knottin peptides, impatiens, puroindolines, vicilin like, glycine-rich, shepherins, snakins and heveins [62, 63] based on their sequence similarity, Cys motifs and distinctive disulphide bond patterns which, in turn, determine their tertiary structure folding [46].

\subsubsection{Thionins}

Thionins are cationic peptide comprised of 45-48 amino acids with 3 to 4 disulphide bond. Previously it was considered as toxic compound. Microbial attack on plant elicits the expressions of thionins, which belong to the release of the hormone methyl jasmonate. $\alpha$-Purothionin was isolated from the endosperm of wheat. Crambin, viscotoxins, apratoxin A, $\alpha$-/ $\beta$-purothionins, $\alpha$-/ $\beta$-hordothionins, hellethionin-D, Pyrularia pubera thionin (Pp-TH) and Tulipa gesneriana bulb-purified AMPs (Tu-AMPs) belong to thionins [46]. Thionins from wheat flour showed antibacterial activity against food pathogen Listeria monocytogenes and Listeria ivanovii in vitro with MIC of $2 \mu \mathrm{g} / \mathrm{mL}$ [64].

\subsubsection{Defensins}

Plant defensins are cationic peptides comprising 45-54 amino acids with 4 to 5 disulphide bonds [65]. They exhibit several biological functions such as antifungal, antibacterial, $\alpha$-amylase and trypsin inhibitory activity [46]. Firstly, they were recognised as $\gamma$-thionin from wheat and barley grains. Plant defensins are found 
in wide variety of plants $[66,67]$. Defensins attach to glucosylceramides which are present on the fungal cell membrane resulted into the insertion and repulsion between defensins owing to their positive charges which disrupt the cell membrane [68]. $\gamma$-Hordothionin, PhD1 from Petunia hybrida and defensins 1 and 2 from Vigna radiata belong to defensins [69].

Plant defensins exhibit lower antibacterial activity against Listeria monocytogenes and Listeria ivanovii [64]. Defensin KT43C from cowpea seeds delays the growth of yeast in dough for about 2 days [67].

\subsubsection{Hevein-like peptides}

Hevein-like peptides contain 29-45 amino acids with 3 to 5 disulphide bonds rich in Gly. It comprises conserved chitin-binding motif that distinguishes it from other peptides. Hevein was first observed in the latex of the rubber tree Hevea brasiliensis, displayed antifungal activity in vitro. IWF4 from Beta vulgaris, Ac-AMP1 from Amaranthus caudatus, EAFP1 and EAFP2 from the bark of Eucommia ulmoides, PMAPI from paper mulberry, WjAMP1 from the leaves of Wasabia japonica $\mathrm{L}$ and vaccatides $\mathrm{vH} 1$ and $\mathrm{vH} 2$ from Vaccaria hispanica are under hevein-like peptides [61, 70]. Hevein is effective against Gram-positive bacteria and fungi, but it shows some allergic reaction creating a hurdle in the use of it as a biopreservative [71].

\subsubsection{Knottin-type peptides}

Plant knottins contain 30 amino acids and comprises inhibitors of $\alpha$-amylase, trypsin and carboxypeptidase families as well as cyclotides. They perform several functions like enzyme-inhibitory, cytotoxic, antimicrobial, insecticidal and antiHIV activities [72, 73]. Initially, it was identified as protease inhibitors [74]. Linear knottins are observed in plants as well as in fungi, insects and spiders also. However, cyclotides and their acyclic variants are only found in plants [75]. They exhibit antibacterial as well as antifungal activity [64].

\subsubsection{Lipid transfer protein (LTP)}

LTPs consist of 70 and 90 amino acids cationic proteins with 8 Cys residues. They are implicated in lipid transfer activity between the membranes in vitro. Hydrophobic cavity covered by four helices is the common structural feature in all LTPs [76]. They are identified in several plants such radish, barley, maize, Arabidopsis, spinach, grapevine, wheat and onion [61].

\subsubsection{Snakin}

Snakin-1 and snakin- 2 consist of 63 and 66 amino acid long residues, respectively, which are identified in potato tubers [77]. Snakin showed strong antibacterial activity against Listeria monocytogenes and Listeria ivanovii [78].

\subsection{Plant extracts}

Spices and herb are used as flavouring agents as well as a preservative since the ancient time. Plant parts are used as spice like leaves (mint, rosemary), flower (clove), bulb (garlic, onion) and fruit (cumin, red chilli). They enjoy the status of GRAS [79]. Factors that affect the antimicrobial efficacy of a compound incorporate target microorganism, initial microflora of the food and environmental factors. The chemical nature of the phytochemicals determines its activity against microorganisms. Plant extracts are widely used in the food industry, and 
antimicrobial nature of the plant extract is influenced by its phytochemicals [13, 34, 64]. Phenolics, phenolic acids, quinones, saponins, flavonoids, tannins, coumarins, terpenoids and alkaloids are the major classes of chemical constituents that influence the antimicrobial and antioxidant activity as well as flavours of the plant. The hydroxyl group of the phenolic compounds imparts its antimicrobial activity. $\mathrm{OH}$ group interferes with the function of the cell membrane and shifts the electrons that act as proton exchangers, disintegrates proton-motive force, inhibits ATP synthesis and causes cell death [80].

Clove exhibits antibacterial activity against Escherichia coli, Listeria monocytogenes, Salmonella enterica, Campylobacter jejuni and Staphylococcus aureus [81] and antifungal activity against Candida albicans and Trichophyton mentagrophytes [82]. The antimicrobial activity of the clove is owing to the presence of eugenol [11]. Cinnamaldehyde, cinnamyl alcohol and eugenol confer the antimicrobial activity of cinnamon. Cinnamaldehyde exerts its action on bacteria via inhibiting their cell wall synthesis, impairing cell membrane function and affecting the synthesis of nucleic acids [83]. Phenolic compounds of black pepper damage the bacterial membrane and affect the antimicrobial activity. In addition to antibacterial activity, antifungal activity of black pepper was also observed against the Fusarium graminearum and Penicillium viridicatum [84]. Carnosic acid and phenolic compounds influence the antimicrobial and antioxidant activity of rosemary plant [85] (Almela et al., 2006). Polyphenolic compounds such as 6-gingerol present in ginger confer the antimicrobial and antioxidant activity of the ginger [86]. Carbazole alkaloids and coumarins influence the antimicrobial activity of curry leaves [87]. Raisin extract in wheat at a concentration of $7.5 \%$ is effective for control of spoilage mould and enhances the shelf life of bread; however, this result does not significantly differ from the positive control (0.24\% propionate) [88].

The plants that possess antioxidant property which belong to Lamiaceae, rosemary, oregano, thyme, sage, marjoram, basil, coriander and pimento are predominant [79]. Lipid peroxidation is the main culprit in the rejection of meat and meat products. Antioxidant compound decreases the lipid peroxidation. Plant extract comprises antioxidant activity attributed to their phenolic component. Selection of solvent is an important tool for the extraction of antioxidant property of the plant. Several studies support the antioxidant activity of plants in meat. The antioxidant activity of grape seed extract in pork patties stored at $-18^{\circ} \mathrm{C}$ for 6 months was higher than that of oregano extract, oleoresin rosemary, butylated hydroxyanisole and butylated hydroxytoluene [89]. Similar results of antioxidant activity of grape seed extract were observed in beef patties, and the freshness and sensory quality of the product were retained for 4 months at $-18^{\circ} \mathrm{C}$ and 6 months at the same temperature $[90,91]$ and in frankfurters [92], restructured mutton slices at refrigeration temperature [93]. The $0.1 \%$ of clove essential oil had higher antioxidant activity in buffalo patties at $8^{\circ} \mathrm{C}$ for 9 days in comparison to grape seed extract [94].

\section{Hurdles in plant antimicrobials as preservative in foods}

Plant antimicrobial compounds have an efficacy as preservative and food ingredients. Before October 1994, food additives from plant sources are used without any regulatory test. Currently the trend has moved towards the rapid expansion of utilisation of plant antimicrobials as additive, ingredient or supplement in several health food products [95]. The US FDA and European commission approved some essential oil as food preservative. The main barrier encountered in the use of essential oil in food is the inability of the reproducibility of their activity. Although they contain diverse nature of the chemical compounds, they have different qualitative 
and quantitative fluctuations in the content of the compounds which influence their biological effectiveness $[96,97]$. The other major obstacle that limits the use of essential oil in food is their strong aroma that alters the organoleptic property of food. Beside that the nature of the food also affects the efficacy of essential oil in food. Food is comprised of different microenvironments; hence, the concentration of essential oil is also increased that leverage the taste of the food resulting in the rejection of food $[13,98]$. Strong aroma flavour of essential oil is minimised by meticulously choosing the essential oil according to the type of food. Availability of raw material and risk of the loss of biodiversity also hinder the use of plant essential oil as preservative $[95,99]$.

The in vitro antimicrobial activity of plants has been demonstrated in several studies. However, hardly an antimicrobial study of plant extract has been available in food. In most of the studies, the results of in vitro antimicrobial activity of plant extract differ from the antimicrobial activity observed in food. The low activity of the plant in food is attributed to involvement of crude extract in most cases, and they possess low activity in contrast to pure compounds. Crude extract which comprises of flavonoids in glycosidic form retards their effectiveness against the microorganisms $[13,100]$. The presence of extracting solvent also creates a hurdle for the use of plant extracts in food $[11,13]$. The application of antimicrobial peptides derived from plants in food is at its infancy stage. Lots of work have to be done to prove its potential as preservative in food.

\section{Conclusion and future remarks}

Plant-derived antimicrobials have promising probability to be used as preservative in food. Literature studies revealed the inefficiency of plant antimicrobial as a preservative in food systems and also have inadequate scientific reports that support their safety in food. Although food authorities around the world have issued guidelines regarding the food additives, there is lacking data related to standardisation of plant extract. There is stringent need for approval of plant antimicrobial as a preservative by the food authorities as its potential as natural preservative is proved. The method of the extraction of plant is also impediment in the passage of preservative action of plant. Development of cost-effective methods for the extraction of plant antimicrobials should be search out, so that there is no loss of original antimicrobial compound, and preservative from plant should be used on large scale. Nanotechnology approach also enhances the potential of plant antimicrobials. Most of the essential oils were incorporated into packaging system where they impart the antimicrobial activity and enhance the shelf life of food. Nanoencapsulation of plant antimicrobial will also helpful for maintaining the bioactivity of plant antimicrobial in food systems.

\section{Conflict of interest}

There is no conflict of interest between authors. 


\section{Author details}

Romika Dhiman $^{1 *}$ and Neeraj Kumar Aggarwal ${ }^{2}$

1 Department of Microbiology, DAV College for Girls, Yamunangar, Haryana, India

2 Department of Microbiology, Kurukshetra University, Kurukshetra, Haryana, India

*Address all correspondence to: romikadhiman@gmail.com

\section{IntechOpen}

(C) 2019 The Author(s). Licensee IntechOpen. This chapter is distributed under the terms of the Creative Commons Attribution License (http://creativecommons.org/licenses/ by/3.0), which permits unrestricted use, distribution, and reproduction in any medium, provided the original work is properly cited. (cc) BY 


\section{References}

[1] da Silva Dannenberg G, Funck GD, Mattei FJ, da Silva WP, Fiorentini ÂM. Antimicrobial and antioxidant activity of essential oil from pink pepper tree (Schinus terebinthifolius Raddi) in vitro and in cheese experimentally contaminated with Listeria monocytogenes. Innovative Food Science \& Emerging Technologies. 2016;36:120-127. DOI: 10.1016/j.ifset.2016.06.009

[2] Pasha I, Saeed F, Sultan MT, Khan MR, Rohi M. Recent developments in minimal processing: A tool to retain nutritional quality of food. Critical Reviews in Food Science and Nutrition. 2014;54(3):340-351. DOI: $10.1080 / 10408398.2011 .585254$

[3] Aneja KR, Dhiman R, Aggarwal NK, Aneja A. Emerging preservation techniques for controlling spoilage and pathogenic microorganisms in fruit juices. International Journal of Microbiology. 2014;2014:14. DOI: $10.1155 / 2014 / 758942$

[4] Rawson A, Patras A, Tiwari BK, Noci F, Koutchma T, Brunton N. Effect of thermal and non thermal processing technologies on the bioactive content of exotic fruits and their products: Review of recent advances. Foodservice Research International. 2011;44(7):1875-1887. DOI: 10.1016/j. foodres.2011.02.053

[5] Aneja KR, Dhiman R, Aggarwal N, Aneja A. Bacteriocins as potential biopreservative in foods: An overview. In: Sharma C, Sharma AK, Aneja KR, editors. Frontiers in Food Biotechnology. USA: Nova Publishers; 2016. pp. 75-94

[6] Zhang ZH, Zeng XA, Brennan CS, Brennan M, Han Z, Xiong XY. Effects of pulsed electric fields (PEF) on vitamin $\mathrm{C}$ and its antioxidant properties. International Journal of Molecular Sciences. 2015;16(10):24159-24173. DOI: 10.3390/ijms161024159
[7] Guerrero-Beltrán JA, BarbosaCánovas GV, Swanson BG. High hydrostatic pressure processing of peach puree with and without antibrowning agents. Journal of Food Processing \& Preservation. 2004;28(1):69-85

[8] Gassara F, Kouassi AP, Brar SK, Belkacemi K. Green alternatives to nitrates and nitrites in meat-based products-a review. Critical Reviews in Food Science and Nutrition. 2016;56(13):2133-2148. DOI: 10.1080/10408398.2013.812610

[9] Burt S. Essential oils: Their antibacterial properties and potential applications in foods-A review. International Journal of Food Microbiology. 2004;94(3):223-253. DOI: 10.1016/j.ijfoodmicro.2004.03.022

[10] International Commission on Microbiological Specifications of Foods (ICMSF). Sugar, syrups and honey. In: Microorganisms in Foods 6: Microbial Ecology of Food Commodities. 2nd ed. New York: Kluwer Academic and Plenum Publishers; 2005. pp. 522-543

[11] Tajkarimi MM, Ibrahim SA, Cliver DO. Antimicrobial herb and spice compounds in food. Food Control. 2010;21(9):1199-1218. DOI: 10.1016/j. foodcont.2010.02.003

[12] Tserennadmid R, Takó M, Galgóczy L, Papp T, Pesti M, Vágvölgyi $\mathrm{C}$, et al. Anti yeast activities of some essential oils in growth medium, fruit juices and milk. International Journal of Food Microbiology. 2011;144(3):480-486. DOI: 10.1016/j. ijfoodmicro.2010.11.004

[13] Negi PS. Plant extracts for the control of bacterial growth: Efficacy, stability and safety issues for food application. International Journal of Food Microbiology. 2012;156(1):7-17. DOI: 10.1016/j.ijfoodmicro.2012.03.006 
[14] Aziz M, Karboune S. Natural antimicrobial/antioxidant agents in meat and poultry products as well as fruits and vegetables: A review. Critical Reviews in Food Science and Nutrition. 2018;58(3):486-511. DOI: 10.1080/10408398.2016.1194256

[15] Raybaudi-Massilia RM, MosquedaMelgar J, Soliva-Fortuny R, MartínBelloso O. Control of pathogenic and spoilage microorganisms in fresh-cut fruits and fruit juices by traditional and alternative natural antimicrobials. Comprehensive Reviews in Food Science and Food Safety. 2009;8(3):157-180. DOI: 10.1111/j.1541-4337.2009.00076.x

[16] Ota A, Ulrih NP. An overview of herbal products and secondary metabolites used for management of type two diabetes. Frontiers in Pharmacology. 2017;8:436. DOI: 10.3389/fphar.2017.00436

[17] Boqvist S, Söderqvist K, Vågsholm I. Food safety challenges and one health within Europe. Acta Veterinaria Scandinavica. 2018;60(1):1. DOI: 10.1186/s13028-017-0355-3

[18] Callejón RM, Rodríguez-Naranjo MI, Ubeda C, Hornedo-Ortega R, Garcia-Parrilla MC, Troncoso AM. Reported foodborne outbreaks due to fresh produce in the United States and European Union: Trends and causes. Foodborne Pathogens and Disease. 2015;12(1):32-38. DOI: 10.1089/ fpd.2014.1821

[19] Bhunia AK. Foodborne Microbial Pathogens: Mechanisms and

Pathogenesis. Switzerland AG: Springer; 2018. DOI: $10.1007 / 978-1-4939-7349-1$

[20] Stephan R, Althaus D, Kiefer S, Lehner A, Hatz C, Schmutz C, et al. Foodborne transmission of Listeria monocytogenes via ready-to-eat salad: A nationwide outbreak in Switzerland, 2013-2014. Food Control. 2015;57:14-17. DOI: 10.1016/j.foodcont.2015.03.034
[21] EFSA. EFSA panel on biological hazards (BIOHAZ) scientific opinion on chronic wasting disease (II). EFSA Journal. 2018;5132:59. DOI: 10.2903/j. efsa.2018.5132

[22] Severi E, Verhoef L, Thornton L, Guzman-Herrador BR, Faber M, Sundqvist L, et al. Large and prolonged food-borne multistate hepatitis A outbreak in Europe associated with consumption of frozen berries, 2013 to 2014. Euro Surveillance. 2015;20(29):21192

[23] Self JL, Luna-Gierke RE, Fothergill A, Holt KG, Vieira AR. Outbreaks attributed to pork in the United States, 1998-2015. Epidemiology and Infection. 2017;145(14):2980-2990

[24] Thomas MK, Murray R, Flockhart L, Pintar K, Fazil A, Nesbitt A, et al. Estimates of foodborne illness-related hospitalizations and deaths in Canada for 30 specified pathogens and unspecified agents. Foodborne Pathogens and Disease. 2015;12(10):820-827

[25] Hennekinne JA. Staphylococcus aureus as a leading cause of foodborne outbreaks worldwide. Staphylococcus aureus. 2018;129:129-146. DOI: 10.1016/ B978-0-12-809671-0.00007-3

[26] Pavela R. Essential oils for the development of eco-friendly mosquito larvicides: A review. Industrial Crops and Products. 2015;76:174-187. DOI: 10.1016/j.indcrop.2015.06.050

[27] Zu Y, Yu H, Liang L, Fu Y, Efferth T, Liu X, et al. Activities of ten essential oils towards Propionibacterium acnes and PC-3, A-549 and MCF-7 cancer cells. Molecules. 2010;15(5):3200-3210. DOI: $10.3390 /$ molecules 15053200

[28] Yen HF, Hsieh CT, Hsieh TJ, Chang FR, Wang CK. In vitro anti-diabetic effect and chemical component analysis of 29 essential oils products. Journal of Food 
and Drug Analysis. 2015;23(1):124-129. DOI: 10.1016/j.jfda.2014.02.004

[29] Brahmi F, Abdenour A, Bruno M, Silvia P, Alessandra P, Danilo F, et al. Chemical composition and in vitro antimicrobial, insecticidal and antioxidant activities of the essential oils of Mentha pulegium L. and Mentha rotundifolia (L.) Huds growing in Algeria. Industrial Crops and Products. 2016;88:96-105. DOI: 10.1016/j.indcrop.2016.03.002

[30] Periasamy VS, Athinarayanan J, Alshatwi AA. Anticancer activity of an ultrasonic nanoemulsion formulation of Nigella sativa L. essential oil on human breast cancer cells. Ultrasonics Sonochemistry. 2016;31:449-455. DOI: 10.1016/j.ultsonch.2016.01.035

[31] Solórzano-Santos F, MirandaNovales MG. Essential oils from aromatic herbs as antimicrobial agents. Current Opinion in Biotechnology. 2012;23(2):136-141. DOI: 10.1016/j. copbio.2011.08.005

[32] Tongnuanchan P, Benjakul S.

Essential oils: Extraction, bioactivities, and their uses for food preservation. Journal of Food Science. 2014;79(7):R1231-R1249.

DOI: 10.1111/1750-3841.12492

[33] Dhifi W, Bellili S, Jazi S, Bahloul N, Mnif W. Essential oils' chemical characterization and investigation of some biological activities: A critical review. Medicine. 2016;3(4):25. DOI: 10.3390/medicines3040025

[34] Chouhan S, Sharma K, Guleria S. Antimicrobial activity of some essential oils-Present status and future perspectives. Medicine. 2017;4(3):58. DOI: $10.3390 /$ medicines 4030058

[35] Fisher K, Phillips C. The mechanism of action of a citrus oil blend against Enterococcus faecium and Enterococcus faecalis. Journal of Applied Microbiology. 2009;106(4):1343-1349. DOI: $10.1111 / j .1365-2672.2008 .04102 . x$
[36] Guinoiseau E, Luciani A, Rossi PG, Quilichini Y, Ternengo S, Bradesi P, et al. Cellular effects induced by Inula graveolens and Santolina corsica essential oils on Staphylococcus aureus. European Journal of Clinical Microbiology \& Infectious Diseases. 2010;29(7):873-879. DOI: 10.1007/s10096-010-0943-x

[37] Bajpai VK, Baek KH, Kang SC. Control of Salmonella in foods by using essential oils: A review. Foodservice Research International. 2012;45(2): 722-734. DOI: 10.1016/j.foodres. 2011.04.052

[38] Calo JR, Crandall PG, O’Bryan CA, Ricke SC. Essential oils as antimicrobials in food systems-A review. Food Control. 2015;54:111-119. DOI: 10.1016/j. foodcont.2014.12.040

[39] Chaleshtori S, Rokni N, RafieianKopaei M, Deris F, Salehi E. Antioxidant and antibacterial activity of basil (Ocimum basilicum L.) essential oil in beef burger. Journal of Agricultural Science and Technology. 2015;17(4):817-826

[40] Hernández-Ochoa L, AguirrePrieto YB, Nevárez-Moorillón GV, Gutierrez-Mendez N, Salas-Muñoz E. Use of essential oils and extracts from spices in meat protection. Journal of Food Science and Technology. 2014;51(5):957-963. DOI: $10.1007 /$ s13197-011-0598-3

[41] Abdollahzadeh E, Rezaei M, Hosseini H. Antibacterial activity of plant essential oils and extracts: The role of thyme essential oil, nisin, and their combination to control Listeria monocytogenes inoculated in minced fish meat. Food Control. 2014;35(1):177-183. DOI: 10.12989/eas.2017.12.1.047

[42] Selim S. Antimicrobial activity of essential oils against Vancomycinresistant enterococci (VRE) and Escherichia coli O157: H7 in feta soft cheese and minced beef meat. Brazilian Journal 
of Microbiology. 2011;42(1):187-196. DOI: $10.1590 /$ S1517-83822010005000005

[43] Tajik H, Aminzare M, Mounesi Raad T, Hashemi M, Hassanzad Azar H, Raeisi M, et al. Effect of Zataria multiflora boiss essential oil and grape seed extract on the shelf life of raw buffalo patty and fate of inoculated Listeria monocytogenes. Journal of Food Processing \& Preservation. 2015;39(6):3005-3013. DOI: $10.1111 /$ jfpp.12553

[44] Smaoui S, Hsouna AB, Lahmar A, Ennouri K, Mtibaa-Chakchouk A, Sellem I, et al. Bio-preservative effect of the essential oil of the endemic Mentha piperita used alone and in combination with BacTN635 in stored minced beef meat. Meat Science. 2016;117:196-204. DOI: 10.1016/j.meatsci.2016.03.006

[45] Abreu AC, Borges A, Simoes LC, Saavedra MJ, Simões M.

Antibacterial activity of phenyl isothiocyanate on Escherichia coli and Staphylococcus aureus. Medicinal Chemistry. 2013;9:756-761. DOI: 10.2174/1573406411309050016

[46] Tam JP, Wang S, Wong KH, Tan WL. Antimicrobial peptides from plants. Pharmaceuticals. 2015;8(4): 711-757. DOI: $10.3390 / p h 8040711$

[47] Sinha S, Zheng L, Mu Y, Ng WJ, Bhattacharjya S. Structure and interactions of a host defense antimicrobial peptide thanatin in lipopolysaccharide micelles reveal mechanism of bacterial cell agglutination. Scientific Reports. 2017;7(1):17795. DOI: 10.1038/s41598-017-18102-6

[48] Wang S, Zeng X, Yang Q, Qiao S. Antimicrobial peptides as potential alternatives to antibiotics in food animal industry. International Journal of Molecular Sciences. 2016;17(5):603. DOI: $10.3390 /$ ijms17050603

[49] Pálffy R, Gardlík R, Behuliak M, Kadasi L, Turna J, Celec P. On the physiology and pathophysiology of antimicrobial peptides. Molecular Medicine. 2009;15(1-2):51. DOI: 10.2119/molmed.2008.00087

[50] Rotem S, Mor A. Antimicrobial peptide mimics for improved therapeutic properties. Biochimica et Biophysica Acta (BBA) - Biomembranes. 2009;1788(8):1582-1592. DOI: 10.1016/j. bbamem.2008.10.020

[51] Brogden NK, Brogden KA. Will new generations of modified antimicrobial peptides improve their potential as pharmaceuticals? International Journal of Antimicrobial Agents. 2011;38(3):217-225. DOI: 10.1016/j. ijantimicag.2011.05.004

[52] Espitia PP, Soares NF, Coimbra JS, De Andrade NJ, Renatom SC, Medeiros E. Bioactive peptides: Synthesis, properties, and applications in the packaging and preservation of food. Comprehensive Reviews in Food Science and Food Safety. 2012;11:187-204. DOI: 10.1111/j.1541-4337.2011.00179.x

[53] Rai M, Pandit R, Gaikwad S, Kövics G. Antimicrobial peptides as natural bio-preservative to enhance the shelf-life of food. Journal of Food Science and Technology. 2016;53(9):3381-3394. DOI: $10.1007 /$ s13197-016-2318-5

[54] McIntosh JA, Donia MS, Schmidt EW. Ribosomal peptide natural products: Bridging the ribosomal and nonribosomal worlds. Natural Product Reports. 2009;26(4):537-559

[55] Wang G, Li X, Wang Z. APD3: The antimicrobial peptide database as a tool for research and education. Nucleic Acids Research. 2015;44(D1):D1087-D1093. DOI: 10.1093/nar/gkv1278

[56] Li J, Koh JJ, Liu S, Lakshminarayanan R, Verma CS, Beuerman RW. Membrane active antimicrobial peptides: Translating mechanistic insights to design. Frontiers 
in Neuroscience. 2017;11:73. DOI: 10.3389/fnins.2017.00073

[57] Hegedüs N, Marx F. Antifungal proteins: More than antimicrobials? Fungal Biology Reviews. 2013;26(4): 132-145. DOI: 10.1016/j.fbr.2012.07.002

[58] Salas CE, Badillo-Corona JA, Ramírez-Sotelo G, Oliver-Salvador C. Biologically active and antimicrobial peptides from plants. BioMed Research International. 2015;2015:1-11. DOI: $10.1155 / 2015 / 102129$

[59] Ahmed I, Lin H, Zou L, Brody AL, Li Z, Qazi IM, et al. A comprehensive review on the application of active packaging technologies to muscle foods. Food Control. 2017;82:163-178. DOI: 10.1016/j.foodcont.2017.06.009

[60] Stotz HU, Thomson J, Wang Y. Plant defensins: Defense, development and application. Plant Signaling \& Behavior. 2009;4(11):1010-1012. DOI: 10.4161/ psb.4.11.9755

[61] Nawrot R, Barylski J, Nowicki G, Broniarczyk J, Buchwald W, GoździckaJózefiak A. Plant antimicrobial peptides. Folia Microbiologica. 2014;59(3):181196. DOI: $10.1007 / \mathrm{s} 12223-013-0280-4$

[62] Zottich U, Da Cunha M, Carvalho AO, Dias GB, Silva NC, Santos IS, et al. Purification, biochemical characterization and antifungal activity of a new lipid transfer protein (LTP) from Coffea canephora seeds with $\alpha$-amylase inhibitor properties. Biochimica et Biophysica Acta (BBA) General Subjects. 2011;1810(4):375-383. DOI: 10.1016/j.bbagen.2010.12.002

[63] Remuzgo C, Oewel TS, Daffre S, Lopes TR, Dyszy FH, Schreier S, et al. Chemical synthesis, structureactivity relationship, and properties of shepherin I: A fungicidal peptide enriched in glycine-glycine-histidine motifs. Amino Acids. 2014;46(11):25732586. DOI: $10.1007 / \mathrm{s} 00726-014-1811-2$
[64] Hintz T, Matthews KK, Di R. The use of plant antimicrobial compounds for food preservation. BioMed Research International. 2015;2015:12. DOI: $10.1155 / 2015 / 246264$

[65] Cools TL, Struyfs C, Cammue BP, Thevissen K. Antifungal plant defensins: Increased insight in their mode of action as a basis for their use to combat fungal infections. Future Microbiology. 2017;12(5):441-454. DOI: 10.2217/fmb-2016-0181

[66] Lacerda A, Vasconcelos ÉA, Pelegrini PB, Grossi-de-Sa MF. Antifungal defensins and their role in plant defense. Frontiers in Microbiology. 2014;5:116. DOI: 10.3389/ fmicb.2014.00116

[67] Thery T, Arendt EK. Antifungal activity of synthetic cowpea defensin Cp-thionin II and its application in dough. Food Microbiology. 2018;73: 111-121. DOI: 10.1016/j.fm.2018.01.006

[68] Pelegrini PB, Franco OL. Plant gamma-thionins: Novel insights on the mechanism of action of a multifunctional class of defense proteins. The International Journal of Biochemistry \& Cell Biology. 2005;37:2239-2253

[69] Padovan L, Segat L, Tossi A, Calsa J, Ederson AK, Brandao L, et al. Characterization of a new defensin from cowpea (Vigna unguiculata (L.) Walp.). Protein and Peptide Letters. 2010;17(3):297-230

[70] Wong KH, Tan WL, Kini SG, Xiao T, Serra A, Sze SK, et al. Vaccatides: Antifungal glutamine-rich hevein-like peptides from Vaccaria hispanica.

Frontiers in Plant Science. 2017;8:1100. DOI: $10.3389 /$ fpls.2017.01100

[71] Tavares LS, Santos MD, Viccini LF, Moreira JS, Miller RN, Franco OL.

Biotechnological potential of antimicrobial peptides from flowers. Peptides. 2008;29(10):1842-1851. DOI: 10.1016/j.peptides.2008.06.003 
[72] Heitz A, Avrutina O, Le-Nguyen D, Diederichsen U, Hernandez JF, Gracy J, et al. Knottin cyclization: Impact on structure and dynamics. BMC Structural Biology. 2008;8(1):54. DOI: 10.1186/1472-6807-8-54

[73] Molesini B, Treggiari D, Dalbeni A, Minuz P, Pandolfini T. Plant cystine-knot peptides: Pharmacological perspectives. British Journal of Clinical Pharmacology. 2017;83(1):63-70. DOI: 10.1111/bcp.12932

[74] Kim JY, Park SC, Hwang I, Cheong H, Nah JW, Hahm KS, et al. Protease inhibitors from plants with antimicrobial activity. International Journal of Molecular Sciences. 2009;10(6): 2860-2872. DOI: $10.3390 /$ ijms10062860

[75] Nguyen GK, Lian Y, Pang EW, Nguyen PQ, Tran TD, Tam JP. Discovery of linear cyclotides in monocot plant Panicum laxum of Poaceae family provides new insights into evolution and distribution of cyclotides in plants. The Journal of Biological Chemistry. 2013;288(5): 3370-3380. DOI: 10.1074/jbc.M112.415356

[76] Yeats TH, Rose JKC. The biochemistry and biology of extracellular plant lipid-transfer proteins (LTPs). Protein Science. 2008;17:191-198. DOI: 10.1110/ ps. 073300108

[77] Harris PW, Yang SH, Molina A, López G, Middleditch M, Brimble MA. Plant antimicrobial peptides snakin-1 and snakin-2: Chemical synthesis and insights into the disulfide connectivity. Chemistry-A European Journal. 2014;20(17):5102-5110. DOI: 10.1002/chem.201303207

[78] López-Solanilla E, González-Zorn B, Novella S, Vázquez-Boland JA, Rodríguez-Palenzuela P. Susceptibility of Listeria monocytogenes to antimicrobial peptides. FEMS Microbiology Letters. 2003;226(1): 101-105. DOI: 10.1016/S0378-1097 (03) 00579
[79] De La Torre Torres JE, Gassara F, Kouassi AP, Brar SK, Belkacemi K. Spice use in food: Properties and benefits. Critical Reviews in Food Science and Nutrition. 2017;57(6):1078-1088. DOI: 10.1080/10408398.2013.858235

[80] Gyawali R, Ibrahim SA. Natural products as antimicrobial agents. Food Control. 2014;6:412-429. DOI: 10.1016/j. foodcont.2014.05.047

[81] Chaieb K, Hajlaoui H, Zmantar T, Kahla-Nakbi AB, Rouabhia M, Mahdouani K, et al. The chemical composition and biological activity of clove essential oil, Eugenia caryophyllata (Syzigium aromaticum L. Myrtaceae): A short review. Phytotherapy Research: An International Journal Devoted to Pharmacological and Toxicological Evaluation of Natural Product Derivatives. 2007;21(6):501-506. DOI: 10.1002/ptr.2124

[82] Tampieri MP, Galuppi R, Macchioni F, Carelle MS, Falcioni L, Cioni PL, et al. The inhibition of Candida albicans by selected essential oils and their major components. Mycopathologia. 2005;159(3):339-345

[83] Winias S. Effect of cinnamaldehyde from cinnamon extract as a natural preservative alternative to the growth of Staphylococcus aureus bacteria. Indonesian Journal of Tropical and Infectious Disease. 2015;2(1):38-41

[84] Singh G, Marimuthu P, Catalan C, DeLampasona MP. Chemical, antioxidant and antifungal activities of volatile oil of black pepper and its acetone extract. Journal of the Science of Food and Agriculture. 2004 Nov;84(14):1878-1884. DOI: $10.1002 /$ jsfa.1863

[85] Almela L, Sánchez-Munoz B, Fernández-López JA, Roca MJ, Rabe V. Liquid chromatographic-mass spectrometric analysis of phenolics and free radical scavenging activity of rosemary extract from different raw 
material. Journal of Chromatography. A. 2006;1120 (1-2):221-229. DOI: 10.1016/j. chroma.2006.02.056

[86] Stoilova I, Krastanov A, Stoyanova A, Denev P, Gargova S. Antioxidant activity of a ginger extract (Zingiber officinale). Food Chemistry. 2007;102(3):764-770. DOI: 10.1016/j. foodchem.2006.06.023

[87] Murugan K, Anandaraj K, Al-Sohaibani S. Antiaflatoxigenic food additive potential of Murraya koenigii: An in vitro and molecular interaction study. Foodservice Research International. 2013;52(1):8-16. DOI: 10.1016/j.foodres.2013.02.001

[88] Wei Q, Wolf-Hall C, Hall III CA. Application of raisin extracts as preservatives in liquid bread and bread systems. Journal of Food Science. 2009;74(4):M177-M184. DOI: 10.1111/j.1750-3841.2009.01137.x

[89] Sasse A, Colindres P, Brewer MS. Effect of natural and synthetic antioxidants on the oxidative stability of cooked, frozen pork patties. Journal of Food Science. 2009;74(1):S30-S35. DOI: 10.1111/j.1750-3841.2008.00979.x

[90] Kulkarni S, DeSantos FA, Kattamuri S, Rossi SJ, Brewer MS. Effect of grape seed extract on oxidative, color and sensory stability of a pre-cooked, frozen, re-heated beef sausage model system. Meat Science. 2011;88(1):139-144

[91] Colindres P, Susan Brewer M. Oxidative stability of cooked, frozen, reheated beef patties: Effect of antioxidants. Journal of the Science of Food and Agriculture. 2011;91(5): 963-968. DOI: $10.1002 /$ jsfa.4274

[92] Özvural EB, Vural H. The effects of grape seed extract on quality characteristics of frankfurters. Journal of Food Processing \& Preservation. 2012;36(4):291-297. DOI: 10.1111/j.1745-4549.2011.00587.x
[93] Reddy GB, Sen AR, Nair PN, Reddy KS, Reddy KK, Kondaiah N. Effects of grape seed extract on the oxidative and microbial stability of restructured mutton slices. Meat Science. 2013;95(2):288-294. DOI: 10.1016/j.meatsci.2013.04.016

[94] Tajik H, Farhangfar A, Moradi M, Razavi Rohani SM. Effectiveness of clove essential oil and grape seed extract combination on microbial and lipid oxidation characteristics of raw buffalo patty during storage at abuse refrigeration temperature. Journal of Food Processing \& Preservation. 2014;38(1):31-38. DOI: 10.1111/j.1745-4549.2012.00736.x

[95] Prakash B, Kujur A, Yadav A, Kumar A, Singh PP, Dubey NK. Nanoencapsulation: An efficient technology to boost the antimicrobial potential of plant essential oils in food system. Food Control. 2018;89:1-1. DOI: 10.1016/j.foodcont.2018.01.018

[96] Li M, Muthaiyan A, A O’Bryan C, E Gustafson J, Li Y, G Crandall P, et al. Use of natural antimicrobials from a food safety perspective for control of Staphylococcus aureus. Current Pharmaceutical Biotechnology. 2011;12(8):1240-1254. DOI: $10.2174 / 138920111796117283$

[97] Perricone M, Arace E, Corbo MR, Sinigaglia M, Bevilacqua A. Bioactivity of essential oils: A review on their interaction with food components. Frontiers in Microbiology. 2015;6:76. DOI: $10.3389 /$ fmicb.2015.00076

[98] Goñi P, López P, Sánchez C, GómezLus R, Becerril R, Nerín C.

Antimicrobial activity in the vapour phase of a combination of cinnamon and clove essential oils. Food Chemistry. 2009;116(4):982-989. DOI: 10.1016/j. foodchem.2009.03.058

[99] Prakash B, Kiran S. Essential oils: A traditionally realized natural resource 
for food preservation. Current Science. 2016;110(10):1890-1892

[100] Parvathy KS, Negi PS, Srinivas P. Antioxidant, antimutagenic and antibacterial activities of curcumin$\beta$-diglucoside. Food Chemistry. 2009;115(1):265-271. DOI: 10.1016/j. foodchem.2008.12.036

[101] Solomakos N, Govaris A, Koidis $\mathrm{P}$, Botsoglou N. The antimicrobial effect of thyme essential oil, nisin, and their combination against Listeria monocytogenes in minced beef during refrigerated storage. Food Microbiology. 2008;25(1):120-127. DOI: 10.1016/j. fm.2007.07.002

[102] Govaris A, Solomakos N, Pexara A, Chatzopoulou PS. The antimicrobial effect of oregano essential oil, nisin and their combination against Salmonella enteritidis in minced sheep meat during refrigerated storage. International Journal of Food Microbiology. 2010;137(2-3):175-180. DOI: 10.1016/j.ijfoodmicro.2009.12.017

[103] Tserennadmid R, Takó M, Galgóczy L, Papp T, Vágvölgyi C, Gerő L, et al. Antibacterial effect of essential oils and interaction with food components. Open Life Sciences. 2010;5:641-648. DOI: 10.2478/s11535-010-0058-55):641-8

[104] Giner MJ, Vegara S, Funes L, Martí N, Saura D, Micol V, et al. Antimicrobial activity of food-compatible plant extracts and chitosan against naturally occurring micro-organisms in tomato juice. Journal of the Science of Food and Agriculture. 2012;92(9):1917-1923. DOI: $10.1002 /$ jsfa. 5561

[105] Kedia A, Prakash B, Mishra PK, Dubey NK. Antifungal and antiaflatoxigenic properties of Cuminum cyminum (L.) seed essential oil and its efficacy as a preservative in stored commodities. International Journal of Food Microbiology. 2014;168:1-7. DOI: 10.1016/j.ijfoodmicro.2013.10.008
[106] Fernández-Pan I, Carrión-Granda X, Maté JI. Antimicrobial efficiency of edible coatings on the preservation of chicken breast fillets. Food Control. 2014;36(1):69-75. DOI: 10.1016/j. foodcont.2013.07.032

[107] da Silveira SM, Luciano FB, Fronza N, Cunha A Jr, Scheuermann GN, Vieira CR. Chemical composition and antibacterial activity of Laurus nobilis essential oil towards foodborne pathogens and its application in fresh Tuscan sausage stored at 7 C. LWT- Food Science and Technology. 2014;59(1):86-93. DOI: $10.1016 / j$. lwt.2014.05.032

[108] Bukvički D, Stojković D, Soković M, Vannini L, Montanari C, Pejin B, et al. Satureja horvatii essential oil: In vitro antimicrobial and antiradical properties and in situ control of Listeria monocytogenes in pork meat. Meat Science. 2014;96(3):1355-1360. DOI: 10.1016/j.meatsci.2013.11.024

[109] Kumar Tyagi A, Bukvicki D, Gottardi D, Tabanelli G, Montanari C, Malik A, et al. Eucalyptus essential oil as a natural food preservative: in vivo and in vitro antiyeast potential. BioMed Research International. 2014;2014:1-9. DOI: 10.1155/2014/969143

[110] El Moussaoui N, El Ouardy Khay NA, Boujida N, Charfi S, Senhaji NS, Abrini J. Effect of Origanum elongatum essential oil and heating on pomegranate juice quality. International Journal of Current Microbiology and Applied Sciences. 2016;5(4):1-8 

Section 3

Exploitation of Food Waste 



\title{
Extraction, Characterization, and Application of Agricultural and Food Processing By-Products
}

\author{
Saroat Rawdkuen and Sunantha Ketnawa
}

\begin{abstract}
By-products originating from agricultural and food processing are considerable disposal problem for the industry because these waste streams emerge in huge quantities and often have direct impact on the economy and environmental pollution. However, at the same time, it constitute a rich but yet underutilized source of valuable components, which may find application as ingredients in the food and non-food industries. As a result, numerous projects are currently directed toward the utilization of agricultural and food processing by-products such as animal-based (skin, bone, flesh, and internal organs) and plant-based biomaterials (fruit peels and seeds, rice bran, and etc.). In the present work, we would like to focus on the potentialities and the current research of the compounds and extracts deriving from agro-industrial disposable wastes in the food-related utilization. The potential of selected by-products as a source of bioactive/functional compounds in terms of emerging and conventional techniques for extraction, characterization, biological activity monitoring and application of the extracts or isolated compounds as functional food ingredients or bio-based materials for food packaging are highlighted. Considering environmental effect and economic loss, agricultural and food processing by-products should be utilized in various innovative processes in the cause of beneficial product derivation.
\end{abstract}

Keywords: by-products, fish industry, film, food packaging, fruit and vegetables, gelatin, legume seeds, oilseed, rice, utilization

\section{Introduction}

Thailand is situated in the heart of the Southeast Asian mainland, fertile, tropical country with monsoonal climate that reinforce agriculture both in land and off land [1]. Besides, Thailand owes high agricultural output to it alluvial soils and topography, plentiful water supplies, which allows several plantings a year. Agriculture has long been the mainstay of the Thai economy, with abundant natural resources, and the majority of the Thai population engages in agricultural practices. Agricultural products in Thailand can be classified into four types: (1) crops, such as rice (number one export item of the country), tapioca, natural rubber, and pineapple; (2) forestry and timber products (40\% of the area in Thailand has been designated as forests); (3) fishery products, including freshwater and saltwater fisheries; and 
(4) livestock products such as chicken, eggs, and pork, which are also in high demand in the domestic market and exported $[2,3]$.

Thailand is one of the world's leading exporters of rice and also a major exporter of shrimp. The major trading partners with Thailand in agricultural products, ranked by export value, are as follows: (1) rice (Nigeria, China, Japan, and the USA); (2) natural rubber (Benin, Malaysia, the United Kingdom, and Japan); (3) processed chicken (South Africa, Japan, the Netherlands, Canada, and Taiwan); (4) chilled or frozen shrimp (Cote d'Ivoire, the USA, Germany, and the Republic of Korea); and (5) tapioca products (Ghana, the Republic of Korea, Ireland, the United Kingdom, and Indonesia) [2]. Thailand's food processing industry has developed rapidly and is one of the most developed in Southeast Asia with more than 10,000 food and beverage processing factories. Thailand has a large fresh, frozen, and semi-cooked food industry. In 2017, food exports generated an income of more than US $\$ 26$ billion or about 830 billion baht to the country, employing as many as 10.75 million workers in the agricultural and fishery sectors, which is expected to reach US $\$ 27.4$ billion for 2019 [4, 5]. According to the Thai government, "Thailand ranks among the top of the world's food producing countries in several food categories". Thailand is therefore considered one of the world's important food exporting countries. The fast-growing demand for food by the world's population bodes well for the limitless expansion of the consumer market $[2,5,6]$. According to data supplied by the Trade and Economic Information Center, the Ministry of Commerce, the main groups of food export are as follows: (1) frozen seafood group, canned seafood, and processed seafood; (2) fresh chicken and products; (3) other food groups (including ready-to-eat food and semi-cooked food); (4) halal group or food and food products for Muslims, prepared as prescribed by Muslim law; (5) frozen vegetable and fruit group, canned vegetables and fruits, canned fruit in syrup, processed vegetables and fruits, and vegetable pickles [2].

In addition, Thailand government looks set to revitalize the Kitchen of the World campaign, a scheme to accelerate Thailand's plan to become a major world food exporter, as it aims to boost food exports to contribute $>6 \%$ of the country's GDP. Initiated 15 years ago, the Kitchen of the World campaign aims not only to merely accelerate Thailand's plan to become a major world food exporter but also spearhead the export of products from the One Tambon One Product (OTOP) scheme. Thailand also approved the Strategic Framework for Food Management in Thailand (2017-2021), which aims to produce enough food to sustain domestic demand, support access to adequate food at all times, improve food quality, reduce food waste and use food correctly, promote sustainable food production, and support the development of food security and nutrition [7].

From the above information, number of production and exportation, and Thai government policy, we can understandably assume that a large amount of food materials as by-products, which are generated along the chain of food production and transformation, are thrown into the environment as consumption demand is growing. Not only Thailand concern, but the global food losses, by-products and wastes are also hot issue that needs to be taken into consideration. The highest percentage of by-products is found in fruits and vegetables, plus roots and tubers (45\%), followed by fish and seafood (35\%), and oilseed, meat, and dairy (20\%), respectively [8]. According to Ezejiofor et al. [9], by-products from food manufacturing make up to $30-60 \%$ of the product that is utilized for human consumption and animal feeding. Most of the by-products commonly contain proteins, carbohydrates, and lipids, which are promising sources of value-added substances that can be extracted and utilized as a starting material for enzyme, gelatin, collagen, bioactive compounds, for example, enzymes and antioxidants extractions [10]. Current trends in the world as well as in Thailand are to recover and utilize the 
food manufacturing by-products into useful materials as a means of achieving goal of sustainable development. Hence, considerable efforts in the valorization of agricultural and food processing residues have been made with the purpose of minimizing the amounts of by-products, reducing the environment pollution, and increasing sustainability of these by-products. This section reviews by-products from two main food processing industries such as animal-based biomaterials (fish skin, bone, flesh, and internal organs) and plant-based biomaterials (pineapple, mango, longan, tea, sacha inchi, oilseeds, legumes, rice, etc.) that have a potential to be produced as gelatin, seasoning powder, calcium powder, film, protein concentrate, isolate and hydrolysates, bioactive peptides, and others such as protease, tyrosinase, antioxidant, and antimicrobial agents.

\section{Fish industry and by-products}

Thailand is one of the top fish-producing nations in the world, supplying markets in the USA, Europe, and Asia. Fishery production in Thailand demonstrated a remarkable growth over the last three decades. The total production exceeded 0.7 (freshwater fish) and 3 million tons (marine fish) over the last 5 years. Thailand is now the largest exporter of canned tuna, chilled and frozen shrimp, shrimp products, chilled fish, and prawns. Accounting for $1.5 \%$ of various kinds of fishery products for exporting are fresh and frozen prawn, processed shrimp, squid, cuttlefish, fish fillet, and surimi and fish in the form of fresh, chilled-frozen, and processed food [11].

Freshwater fish are widely cultured for commercial exploitation and trade in Thailand. The Mekong giant catfish (Pangasianodon gigas) is one of the economically important farmed fish that has been successfully raised in Northern Thailand, especially in Chiang Rai province [11]. Recently, farmed giant catfish (GC) became an economically important cultured freshwater fish due to their quality attributes (i.e., texture, taste, color, and nutritive values). Morphology of Mekong giant catfish can be seen in Figure 1, and most farm-raised giant catfish are sold raw to restaurants, and in the near future, fish farmers hope to export its meat to other countries, especially in Asia and Europe. It is reported that fish-processing byproducts after filleting account for $\sim 75 \%$ of the total fish weight [12]. The viscera in some species of fish account for approximately $5-10 \%$ of the entire weight of the fish; the viscera percentage tends to increase with the fish body weight [12]. Nile tilapia, Oreochromis niloticus, is popular in freshwater aquaculture. In the global market, the demand for tilapia (TP) in all forms is increasing rapidly. More by-products have been produced from the expansion of the tilapia processing industry [13].

\subsection{Fish-processing by-products}

An increase in fish consumption has resulted in an increase in fish-processing by-products, and these, in turn, may contribute significantly to environmental pollution if there is no further valorization process. With an increase in fish processing, a large amount of internal organs and by-product are also generated. During the filleting, $50-65 \%$ of the body is discarded which are environmental pollutants. More than $60 \%$ of these residues, including of the bone/frame (12-17\%), viscera (4-12\%), heads (18-60\%), cut-offs $(6 \%)$, skin (4-7\%), and roe (2\%) are considered as waste as shown in Table 1 and Figure 2. The waste is used in the production of fish meal, and in a very few cases, it is collected for the production of animal feeds; more frequently it is simply discarded. The utilization of these 

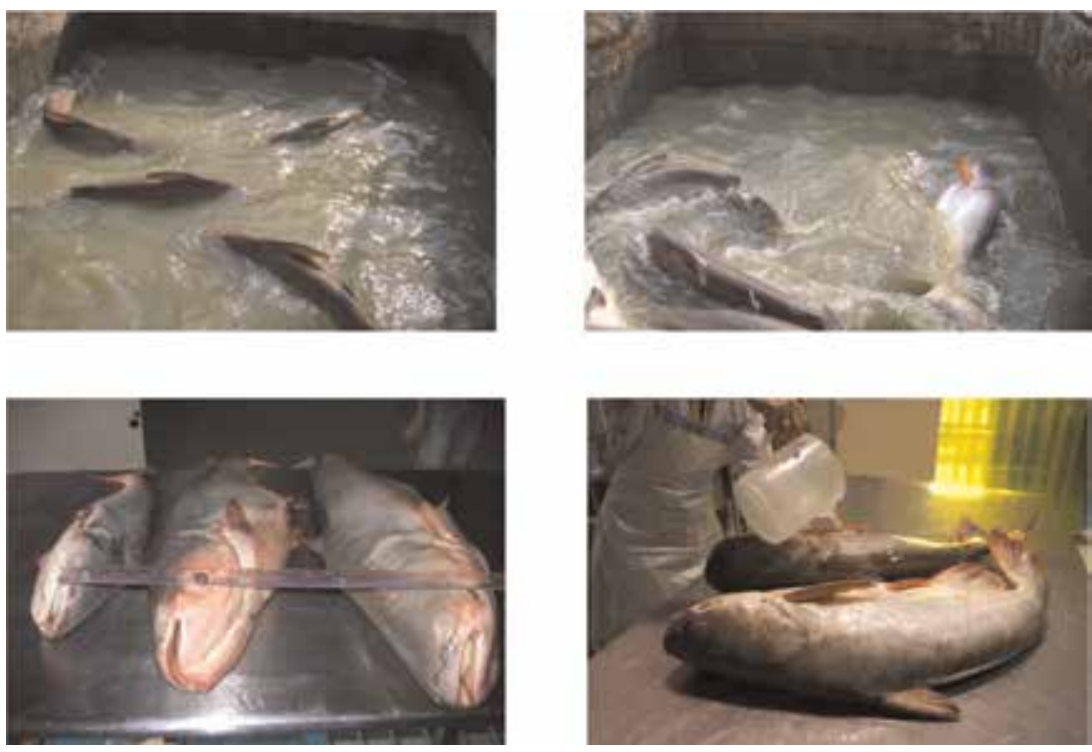

Figure 1.

Farm and morphology of Mekong giant catfish.

\begin{tabular}{lccc}
\hline \multirow{2}{*}{ Component } & \multicolumn{3}{c}{ Yield (\%) } \\
\cline { 2 - 4 } & Giant catfish & Striped catfish & Nile Tilapia \\
\hline Whole fish & $15-17(\mathrm{~kg})$ & $4.1-4.6(\mathrm{~kg})$ & $0.8-1 \mathrm{~kg}$ \\
\hline Fillet skinned & $50-52$ & $42-45$ & $4.6-6$ \\
\hline Skin & $4-6$ & $5-7$ & $4.5-6$ \\
\hline Viscera & $4-5$ & $10-12$ & $5-8$ \\
\hline Head & $25-27$ & $18-20$ & $52-60$ \\
\hline Bone & $12-15$ & $15-17$ & - \\
\hline Scale & - & - & $2-3$ \\
\hline Yield (\%) & $50-52$ & $48-59$ & $64-77$ \\
\hline By-products (\%) & $45-53$ & $48-56$ & $64-77$ \\
\hline
\end{tabular}

Source: Vannabun et al. [14].

Table 1.

Fish-processing by-products of freshwater fish including giant catfish, striped catfish, and Nile tilapia.

by-products could make more profit to the producer and ease environmental problems. Besides, they will be benefit for the producer to gain more profit from their materials instead of discard. These by-products contain a significant amount of protein that could be converted into useful substances and used for food formulation and bioactive ingredients.

In order to upgrade the by-products of the fish industry, various systematic studies were made to fulfill the best utilization of fish-processing by-products. Fish skin, in particular, is a rich source of collagen and gelatin, and these by-products still contain a significant amount of protein-rich material [15-18]. Using proteases from fish viscera in combined with commercial enzymes can be an alternative way to reduce the enzymes costs $[12,14,19]$. Alternatively, digestive enzymes from shrimp or fish viscera can be recovered and be successfully used as processing aids, that is, for the production of gelatin hydrolysate with antioxidant activities and/or 

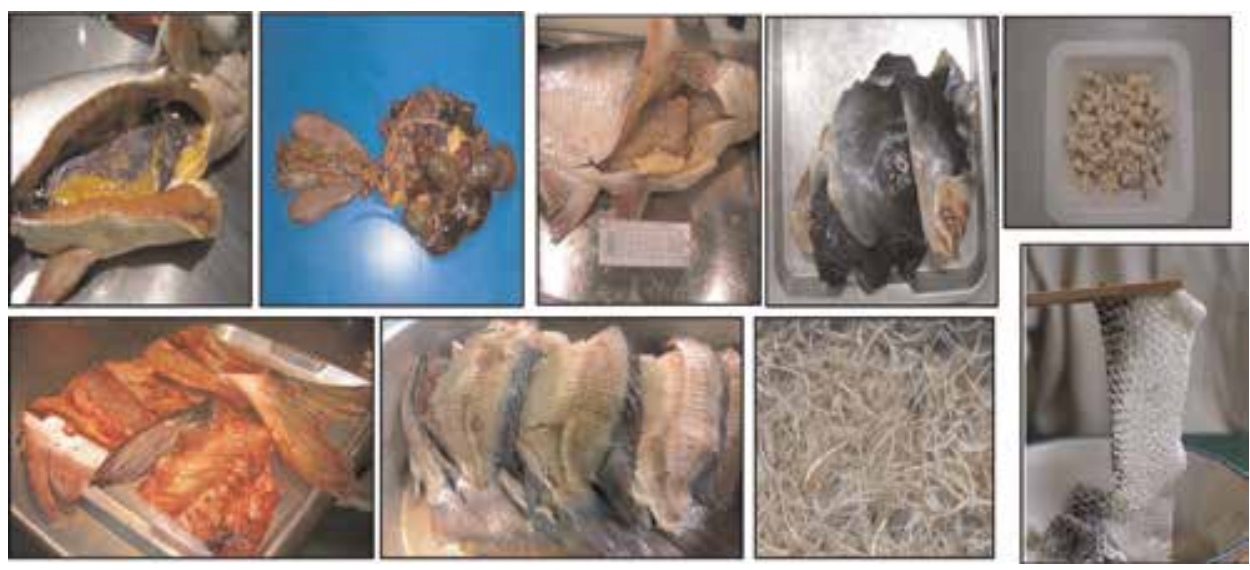

Figure 2.

Wastes and by-products of Nile tilapia and giant catfish. Source: Vannabun et al. [14].

angiotensin-I-converting enzyme (ACE) inhibitory activity [20, 21] or the extraction of carotenoprotein from shrimp waste [22]. Fish bone is another by-product that can serve as a raw material for the production of high value-added compounds that can be used in various sectors including agrochemical, biomedical, food, and pharmaceutical industries [23]. Fish bone is considered as one of the potential biological sources to produce calcium phosphates [23, 24]. Fish bone can be applied to boost nutritional characteristics in seasoning powder [25].

\subsection{Utilization of fishery by-products}

The growing consumer demand for healthy fish products has led to a thriving fish-processing industry worldwide. The fish-processing industry generates significant amounts of by-products and waste as illustrated in Table $\mathbf{1}$ and Figure $\mathbf{2}$ and tends to increase with fish body weight and consumption [26]. It is estimated that $25 \%$ of the global fish production is regarded as waste and is discarded or in the best case scenario processed into fish oil, fishmeal fertilizer, fish silage, and animal feed $[27,28]$. It is costly to treat these wastes because it contains high content of organic matter. In addition, disposing these wastes may cause severe health and environmental issues as well as increase the cost of the fish industry.

\subsection{Gelatin and collagen from fish skin}

In general, gelatin is manufactured from the waste generated during animal slaughter and processing, that is, skin and bone. The most abundant gelatin sources are pig skin (46\%), bovine hide (29.4\%), and pork and cattle bones (23.1\%) [29]. For several reasons, there are still serious concerns among the consumers to consume gelatin which is produced from bovine and porcine bones and skins. This is because of some problems such as religious matter and mad cow disease (bovine spongiform encephalopathy (BSE)) [16]. Thus, it lead to many researchers to discover alternative sources such as fish (marine and freshwater) $[16,18,30]$ and poultry by-products [31]. As a consequence, there has been increasing interest in other sources, especially in fish skin and bone from fishery processing by-products. Gelatin was extracted from the skin of farmed giant catfish with a yield of $19.50 \mathrm{~g} / 100 \mathrm{~g}$ skin sample on wet weight basis (Figure 3 ). The gelatin had high protein $(89.1 \mathrm{~g} / 100 \mathrm{~g})$ but low fat $(0.75 \mathrm{~g} / 100 \mathrm{~g})$ content and contained a high number of imino acids (proline and hydroxyproline) (211 residues per 1000 
residues). Hydroxyproline accounted for 87 residues per 1000 residues. Giant catfish (GC) skin gelatin had a slightly different amino acid composition than calf (BF) skin gelatin. Gelatin was extracted from the skin of GC and tilapia (TP) at a yield of 19.50 and $23.34 \%$, respectively. Gelatin from GC skin was lower in ash content $(0.33 \mathrm{~g} / 100 \mathrm{~g})$. GC skin gelatin was rich in nonpolar amino acid glycine $(35.9 \mathrm{~g} / 100 \mathrm{~g})$, alanine $(10.6 \mathrm{~g} / 100 \mathrm{~g})$, and proline $(12.4 \mathrm{~g} / 100 \mathrm{~g})$ [30].

Microstructures in transverse section photomicrographs of both GC and TP skin clearly projected the arrangement of collagenous bundles in each fish skin (Figure 4). TP showed a small bundle with the same ordered pattern, while in GC, the alternate arrangement was observed with a large bundle. The gaps between collagenous bundles represent the compact structure of the component in the skin. This particular characteristic affected the extractability of the collagen and the gelatin in the structure. The relative thickness of the two dermal layers depends on the presence or absence of scales, and it varies with the fish species. In general, the skin of animal is composed of collagen as a main compound. GC skin showed the large collagenous bundles with ordered arrangement when compared with the TP skin, while TP skin showed more compact and small bundles of collagenous components. These results cause different extraction yields of gelatin. The compact arrangement of the bundle effect to the strength and hardness of the fish skin [16].
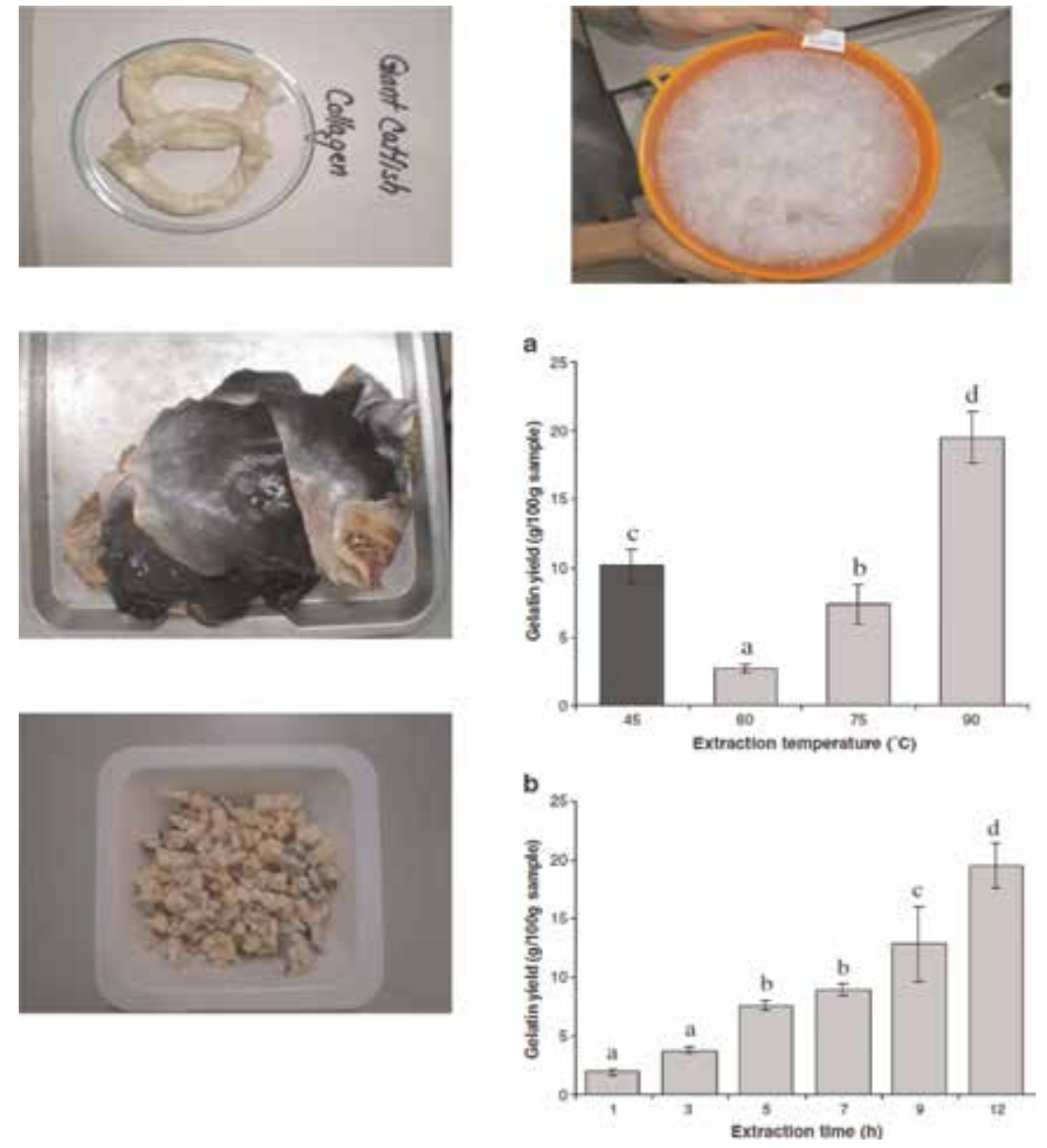

Figure 3.

Extraction of collagen and gelatin form farmed giant catfish skin. Sources: Rawdkuen et al. [16] and Sai-Ut et al. [18]. Different lowercase letters in the bar chart indicate significant difference $(p<0.05)$. 


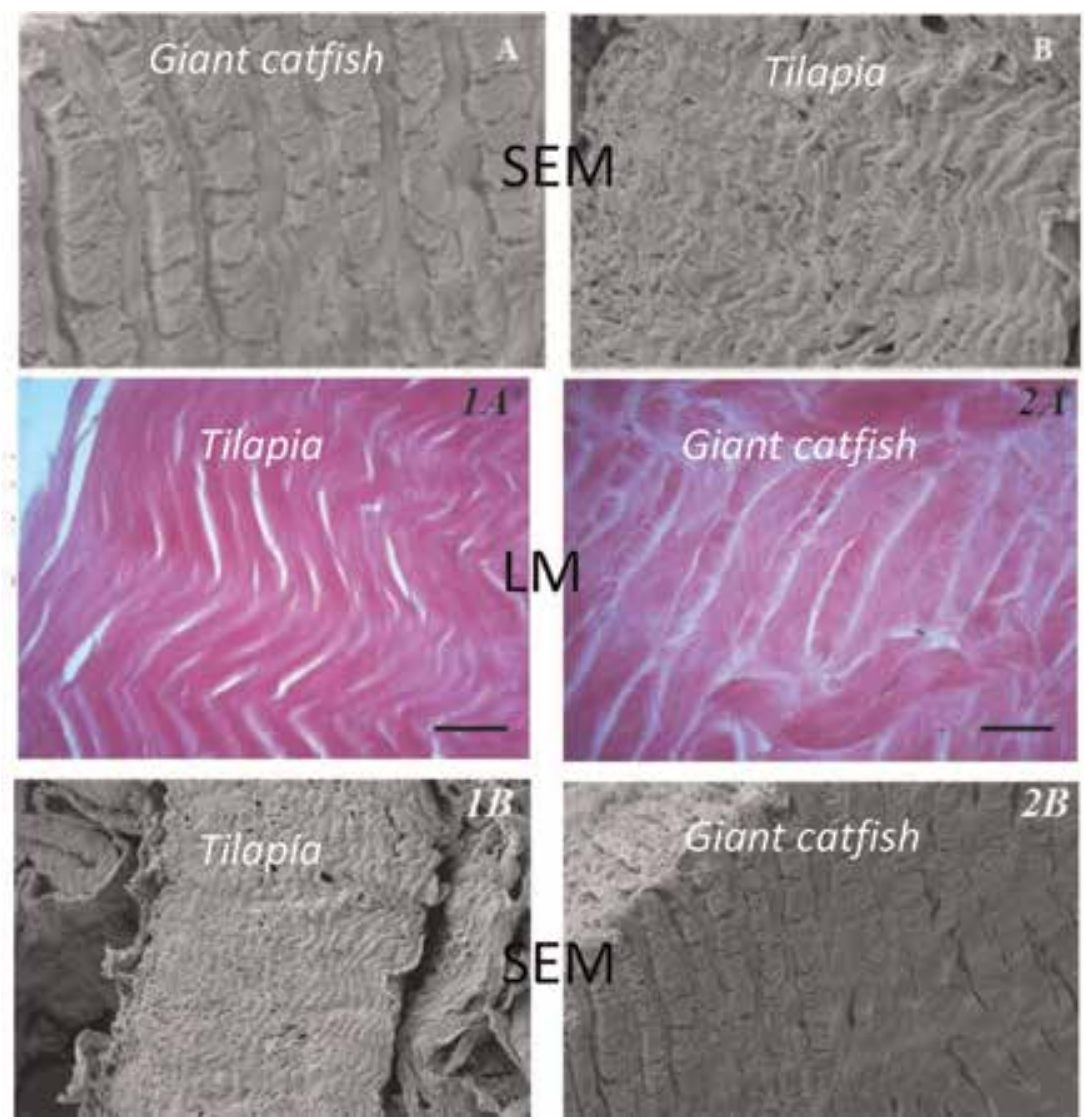

Figure 4.

Microstructure of giant catfish skin (A) and tilapia (B). LM examined at $400 \times$ magnifications and SEM magnification of $500 \times$ at acceleration voltage of $10 \mathrm{kV}$. Source: Rawdkuen et al. [16] and Sai-Ut et al. [18].

Chemical compositions of both the fish skin and the gelatins are also presented in Table 2. Proteins are the major compound ranging 84-88\% (wet wt.). Other components are moisture, ash, and lipid. For the skin of fresh fish, moisture was the major constituent (53-67\%). Protein found in GC was higher than TP.

For the functional properties, the results showed that GC and TP are comparable to BF. Protein patterns by using SDS-PAGE showed high band intensity for the $\alpha$ and $\beta$-components in TP, while BF showed the lowest band intensity of the major

\begin{tabular}{lccccc}
\hline Constituents & \multicolumn{3}{c}{ Gelatin } & \multicolumn{2}{c}{ Fish skin } \\
\cline { 2 - 6 } & Giant catfish & Tilapia & Bovine & Giant catfish & Tilapia \\
\hline Yield (\%) & $19.50 \pm 1.87$ & $23.34 \pm 2.49$ & - & - & - \\
\hline Moisture & $3.39 \pm 0.43$ & $8.49 \pm 0.82$ & $11.38 \pm 0.72$ & $53.8 \pm 5.3$ & $67.7 \pm 0.5$ \\
\hline Protein & $85.27 \pm 0.68$ & $84.28 \pm 1.04$ & $88.33 \pm 1.10$ & $43.0 \pm 0.9$ & $30.6 \pm 0.9$ \\
\hline Lipid & $1.24 \pm 0.15$ & $0.45 \pm 0.18$ & $0.09 \pm 0.01$ & $1.6 \pm 0.5$ & $1.1 \pm 0.1$ \\
\hline Ash & $0.17 \pm 0.03$ & $0.15 \pm 0.09$ & $1.30 \pm 0.22$ & $0.3 \pm 0.1$ & $2.1 \pm 0.4$ \\
\hline
\end{tabular}

Sources: Rawdkuen et al. [16] and Sai-Ut et al. [18].

Table 2.

Gelatin yield and proximate composition of fish skin and gelatin from farmed giant catfish, Nile tilapia, and commercial beef skin gelatin. Values are given as mean $\pm S D$ from triplicate determinations. 
component (Figure 5). From the study, it can be concluded that the GC and TP are a prospective source for gelatin production with desirable functionalities. In addition, fish skin gelatin could be more effectively and widely used in food ingredient industries [16].

\subsection{Gelatin application}

\subsubsection{Antimicrobial film}

Edible films prepared from different types of biomaterials such as proteins, polysaccharide, lipids, or their blends exhibit different film properties. Among all of these materials, proteins are considered to provide desirable mechanical, gas barrier and transparency properties, as well as high nutrition [32]. Rawdkuen et al. [15] prepared edible films from the gelatin of farmed giant catfish skin (GC), bovine bone gelatin (BB), and their combination (50:50) as depicted in Figure 6. The total color difference $(\Delta \mathrm{E})$ value of BB films was lower than CG and GC films, respectively. The GC films showed significantly lower values of $L$ and $a$ but highest in $b$ value $(p<0.05)$. When compared with the low-density polyethylene film, GC and BB films showed the highest and lowest total of color differences, respectively. BB film had a lighter color and more yellowness than other films where the highest redness was observed in GC films. The GC films showed the most compact, smooth, and continuous surface without porous structures, which corresponds to the greater properties of films [15].

\subsubsection{Antimicrobial and antioxidant films}

Some studies regarding to cooperation some natural extracted into protein-based film was summarized in Table 3. Natural extracts such as catechin-Kradon, catechin-lysozyme, nisin-catechin, and longan seed extract were used as active ingredients to delay lipid oxidation or retard microbial growth in soybean oil or fresh meat and fish slice. In vitro antibacterial of films incorporated with nisin and/
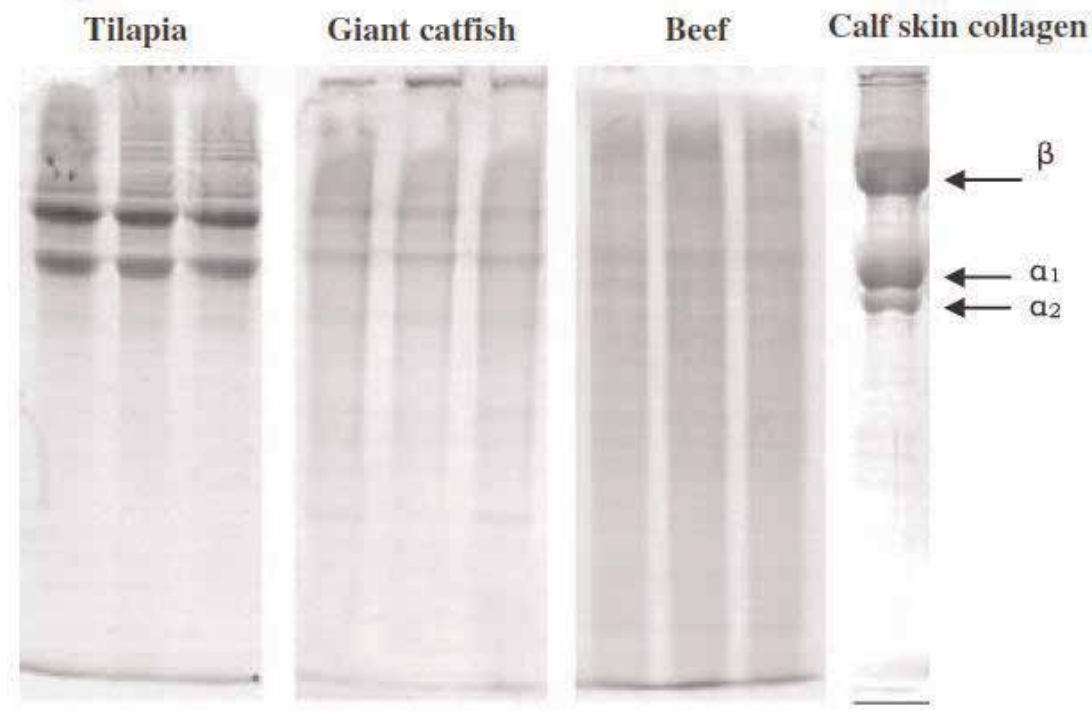

Figure 5 .

SDS-PAGE patterns of gelatin from farmed fish skins and commercial beef skin gelatin under nonreducing conditions. Source: Rawdkuen et al. [16]. 
Extraction, Characterization, and Application of Agricultural and Food Processing By-Products DOI: http://dx.doi.org/10.5772/intechopen.89289

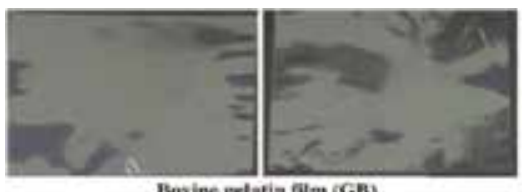

Bovine getatia fitm (GB)

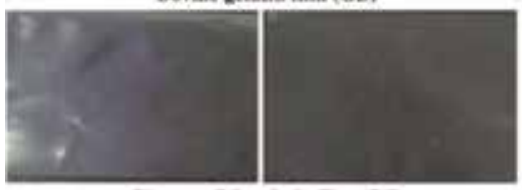

Giant cathsh grhatis film (GC)
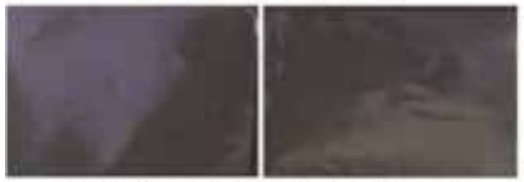

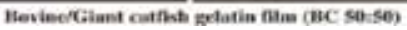
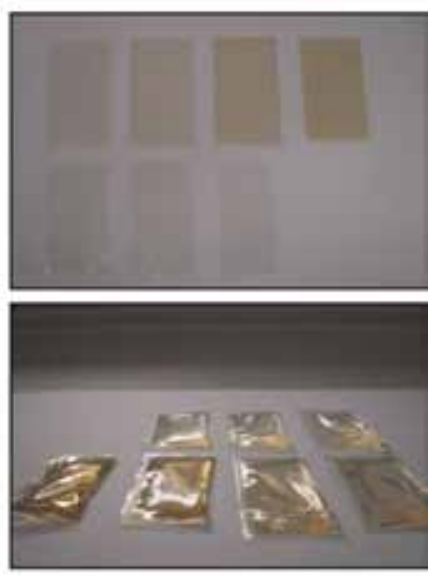

Figure 6.

Surface morphology of gelatin films from bovine bone gelatin, giant catfish skin gelatin and their combination of bovine bone:giant catfish (50:50). Source: Rawdkuen et al. [15].

\begin{tabular}{|c|c|c|c|c|c|}
\hline Protein & $\begin{array}{l}\text { Antioxidant/ } \\
\text { antimicrobial } \\
\text { agents }\end{array}$ & Sample tested & Loading & Observation & References \\
\hline \multirow[t]{5}{*}{ Gelatin } & $\begin{array}{c}\text { Longan seed } \\
\text { extract }\end{array}$ & Soybean oil & $\begin{array}{l}50,100 \\
300, \text { and } \\
500 \mathrm{ppm}\end{array}$ & $\begin{array}{l}\text { Prevent effect on lipid oxidation } \\
30 \text { days of storage }\end{array}$ & $\begin{array}{l}\text { Vichasilp } \\
\text { et al. [37] } \\
\text { and Sai-Ut } \\
\text { et al. [38] }\end{array}$ \\
\hline & $\begin{array}{l}\text { Nisin and/or } \\
\text { catechin }\end{array}$ & Minced pork & $\begin{array}{l}0.12 \mathrm{~g} / \\
100 \mathrm{~g} \\
0.06 \mathrm{~g} / \\
100 \mathrm{~g}\end{array}$ & $\begin{array}{l}\text { Retarded lipid oxidation and } \\
\text { lower microbial growth rates }\end{array}$ & $\begin{array}{c}\text { Kaewprachu } \\
\text { et al. [33] }\end{array}$ \\
\hline & $\begin{array}{l}\text { Catechin- } \\
\text { lysozyme } \\
\text { combination } \\
(1: 1)\end{array}$ & Minced pork & $\begin{array}{l}0.5 \mathrm{~g} / \\
100 \mathrm{~g}\end{array}$ & $\begin{array}{l}\text { Inhibition of lipid oxidation and } \\
\text { lower microbial growth rates than } \\
\text { those of PVC }\end{array}$ & $\begin{array}{c}\text { Kaewprachu } \\
\text { et al. [34] }\end{array}$ \\
\hline & Neem extract & Minced beef & $\begin{array}{c}0,0.1 \\
0.3, \text { and } \\
0.5 \% \\
(\mathrm{w} / \mathrm{v})\end{array}$ & Delay oxidative reactions & $\begin{array}{l}\text { Putsakum } \\
\text { et al. [35] }\end{array}$ \\
\hline & $\begin{array}{l}\text { Catechin- } \\
\text { lysozyme } \\
\text { combination }\end{array}$ & $\begin{array}{l}\text { S. cerevisiae, } S \text {. } \\
\text { aureus, E. coli, } \\
\text { and } L . \text { innocua }\end{array}$ & $\begin{array}{c}0,0.125 \\
0.25, \text { and } \\
0.5 \% \\
(\mathrm{w} / \mathrm{v})\end{array}$ & $\begin{array}{l}\text { Improve mechanical, } \\
\text { physicochemical, and } \\
\text { antimicrobial properties }\end{array}$ & $\begin{array}{l}\text { Rawdkuen } \\
\text { et al. [39] }\end{array}$ \\
\hline \multirow[t]{2}{*}{$\begin{array}{l}\text { Fish } \\
\text { myofibrillar } \\
\text { protein }\end{array}$} & $\begin{array}{l}\text { Catechin and } \\
\text { Kradon } \\
\text { extract }\end{array}$ & $\begin{array}{l}\text { Vibrio } \\
\text { parahaemolyticus }\end{array}$ & $\begin{array}{l}0,3,6,9, \\
\text { and } \\
12 \mathrm{mg} / \mathrm{ml}\end{array}$ & Antimicrobial activity & $\begin{array}{l}\text { Kaewprachu } \\
\text { et al. [40] }\end{array}$ \\
\hline & $\begin{array}{l}\text { Catechin and } \\
\text { Kradon } \\
\text { combination } \\
\text { extracts }\end{array}$ & Tuna slice & $\begin{array}{l}0.9 \% \\
(\mathrm{v} / \mathrm{v})\end{array}$ & $\begin{array}{l}\text { Total volatile base nitrogen, } \\
\text { peroxide value, and TBARS } \\
\text { decreased and lowest growth of } \\
\text { psychrophilic bacteria }\end{array}$ & $\begin{array}{c}\text { Kaewprachu } \\
\text { et al. [36] }\end{array}$ \\
\hline
\end{tabular}

Table 3.

Antioxidant and antimicrobial activity of protein-based films incorporated with antioxidant or antimicrobial agents.

or catechin was investigated by Kaewprachu et al. [33]. Interestingly, gelatin films with nisin and catechin retarded lipid oxidation and microbial growth: the time to reach a total viable count of $10^{7} \mathrm{CFUg}^{-1}$ of meat was extended from 1 to 4 days as 
illustrated in Figure 7. Catechin-lysozyme incorporated gelatin film (CLGF) also showed positive results in preserving the quality and maintaining shelf life of minced pork when compared with that of PVC film [34]. It was found that sample wrapped with CLGF showed less weight loss, less discoloration, and low TBARS content than that wrapped with PVC. Microbial numbers in the sample wrapped with the CLGF (TPC count $4.15 \mathrm{log}$ CFU/g; yeast and mold $2.99 \log \mathrm{CFU} / \mathrm{g}$ ) were lower than those observed in the PVC [34]. The properties of gelatin films incorporated with neem extract (NE; Azadirachta indica) as well as catechin-Kradon extract were determined as depicted in Figure 7. It was found that gelatin film containing NE is potentially a promising film that could help delay oxidative reactions over a 7-day period in a refrigerated storage $\left(4 \pm 1^{\circ} \mathrm{C}\right)$ [35].

Besides, catechin-Kradon extract (Careya sphaerica Roxb.) was incorporated with fish myofibrillar protein films (FMP) [36]. It was found that decreases in the redness index for the tuna slices were coincidental with increases in metmyoglobin content stored in a refrigerator $\left(4 \pm 1^{\circ} \mathrm{C}\right)$ for 10 days (Figure 7). Moreover, the developed film delayed peroxide value, TBARS, and metmyoglobin contents in Bluefin tuna as well as total volatile base nitrogen and psychrophilic bacteria were

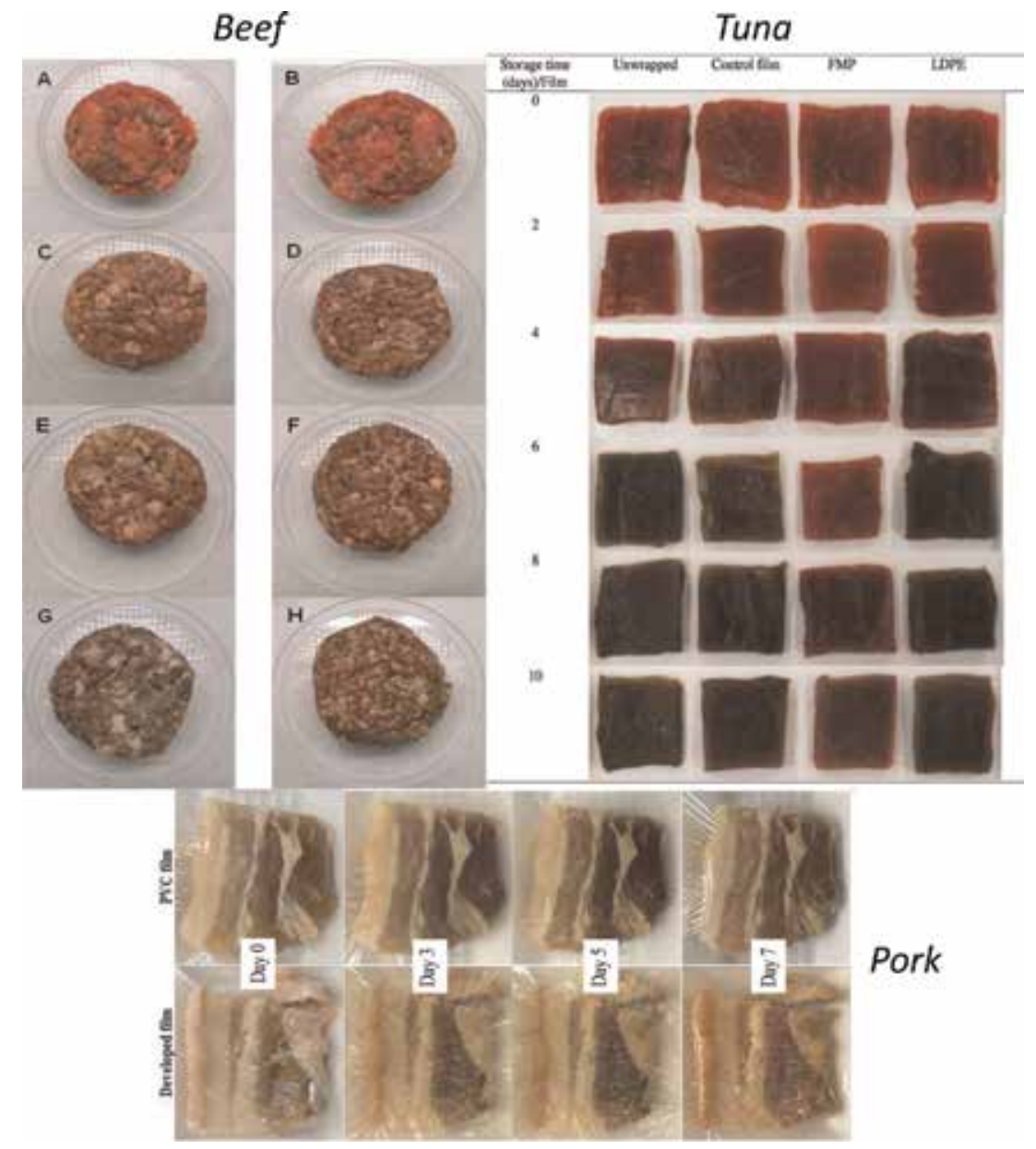

Figure 7.

Quality attribute of meat wrapped with myofibrillar protein film incorporated with natural extract. Sources: Kaewprachu et al. [33], Kaewprachu et al. [34], Kaewprachu et al. [36], and Putsakum et al. [35]. A, C, E, and $G$ represent minced beef wrapped with polyvinyl chloride, $P V C$ and B.D,F, and H represent minced beef wrapped with gelatin film containing $0.3 \%$ neem extract, for $0,3,5$, and 7 day, respectively. 
suppressed Shelf life extension from 4 to 8 days was obtained in FMP sample. FMP showed high efficiency in both antimicrobial and antioxidant activities [36]. Gelatin film incorporated with longan seed extract or BHT could be used as a tool to prolong the shelf life of oily foods [37]. Antioxidant activity of the films incorporated with longan seed extract markedly increased when the storage time increased. LS- or BHT-incorporated films showed the preventive effect on lipid oxidation of soybean oil during storage for 30 days. Longan seed extract film (500 ppm) provided the highest efficacy for lipid oxidation retardation as evidenced by lower conjugated diene values.

\subsubsection{Other applications}

Apart from film application, gelatin from food processing by-products can be applied to make clarification in juice or protection from syneresis of yogurt. In application as guava juice clarifier study by Widyasari and Rawdkuen [31], the addition of gelatin at different concentrations showed different results, where the highest value of turbidity was observed from tilapia gelatin at concentration of $1 \%$ $(\mathrm{w} / \mathrm{v})$ (382 FTU). Furthermore, the lowest turbidity value is purchased at $0.16 \%$ $(\mathrm{w} / \mathrm{v})$ from chicken feet gelatin (108 FTU). On the other hand, the syneresis of yogurt after centrifugation at $4^{\circ} \mathrm{C}$ ranged from 0.0 to $71.49 \%$, where the lowest syneresis index was obtained at $1 \%(\mathrm{w} / \mathrm{v})$ level of the added gelatin from chicken feet and tilapia gelatin.

\subsection{Fish bone}

Fish bone weighs as high as $52-60 \%$ of fish body weight. Proximate composition of giant catfish bone was shown in Table 4. Fish bones can serve as a raw material for the production of high value-added compounds that can be used in various sectors including agrochemical, biomedical, food, and pharmaceutical industries [23]. Those bones can serve as a promising source of calcium. The bone is composed of $34-36 \%$ calcium, based on total ash content, and is also rich in collagen and chondroitin. Additionally, fish bone is the source of hydroxyapatite (HA) known as $\left(\mathrm{Ca}^{2+}\right)_{10-x}\left(\mathrm{H}_{3} \mathrm{O}^{+}\right)_{2-x}\left(\mathrm{PO}_{4}^{3-}\right)_{6}\left(\mathrm{OH}^{-}\right)_{2}$. Those bones could be converted to biocalcium $(\mathrm{BC})$ powder, which is derived from bio-mineralized or a naturally produced resource [24].

Permpoon et al. [25] worked to develop food seasoning powder supplemented with fish bone as depicted in Figure 8. Different concentrations of fish bone powder $(0-3 \%, w / w)$ were added in those recipes with and without monosodium glutamate (MSG). The content of minerals was shown in Table 5. The highest score of overall acceptance was 6.40 in the sample supplemented with $0.5 \%$ fish bone powder containing MSG. High calcium, phosphorus, and sodium were predominant mineral content in the sample supplemented with fish bone [25].

\begin{tabular}{lc}
\hline Composition & Percentage \\
\hline Moisture & $6.79 \pm 0.09$ \\
\hline Protein & $28.14 \pm 0.10$ \\
\hline Fat & $8.61 \pm 0.38$ \\
\hline Minerals & $50.09 \pm 0.19$ \\
\hline Source: Terzioğlu et al. [23]. & \\
\hline
\end{tabular}

Table 4.

Proximate composition of giant catfish bone. 


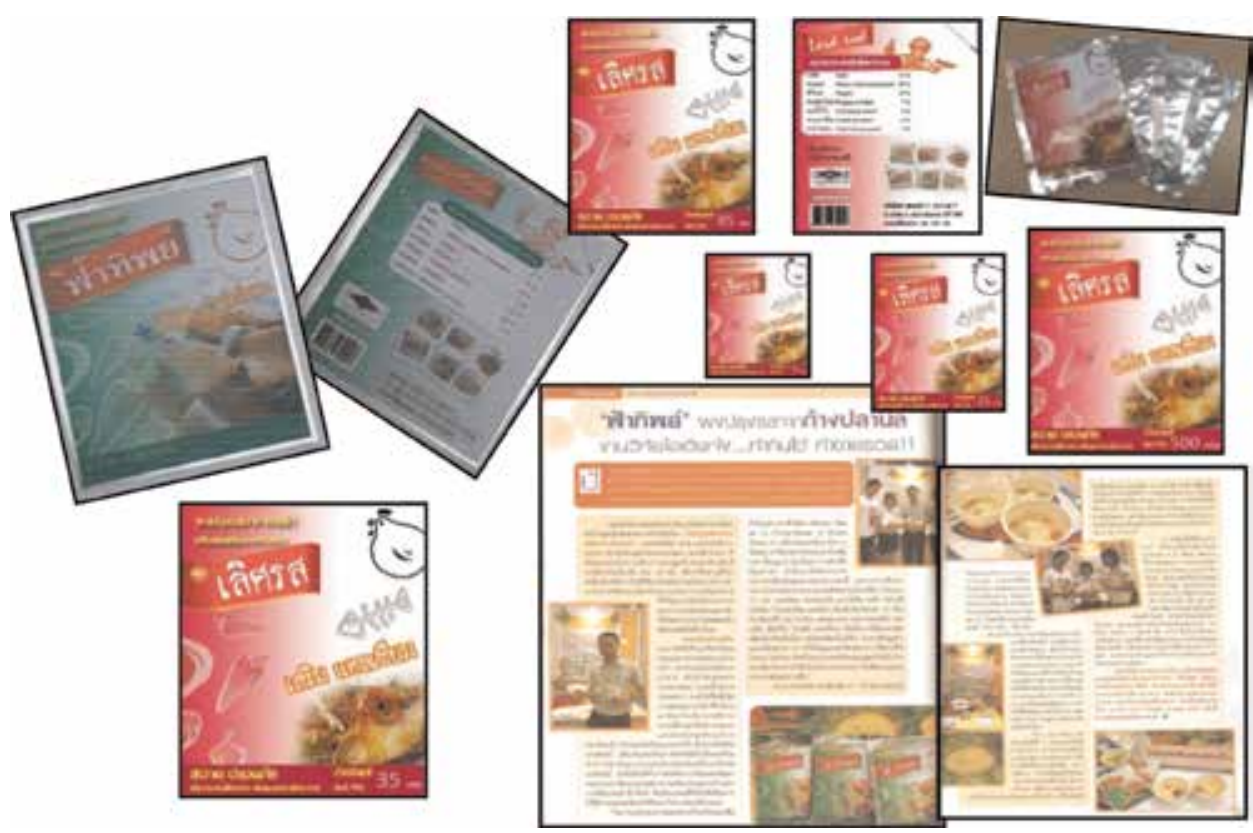

Figure 8.

Food seasoning powder supplemented with fish bone. Source: Permpoon et al. [25].

\begin{tabular}{|c|c|c|c|}
\hline \multirow[t]{2}{*}{ Component } & \multicolumn{3}{|c|}{ Conditions $^{*}$} \\
\hline & Control & 1\% Fish bone & Commercial \\
\hline Calcium $^{* *}$ & $94.48 \pm 8.65^{\mathrm{b}}$ & $1637.50 \pm 252.44^{\mathrm{a}}$ & $120.25 \pm 5.02^{\mathrm{b}}$ \\
\hline Potassium & $2088.50 \pm 41.72^{\mathrm{a}}$ & $2115.50 \pm 85.56^{\mathrm{a}}$ & $2122.50 \pm 136.47^{\mathrm{a}}$ \\
\hline Phosphorus & $493.90 \pm 23.19^{\mathrm{b}}$ & $1338.00 \pm 0.69^{\mathrm{a}}$ & $683.70 \pm 32.24^{\mathrm{b}}$ \\
\hline Magnesium & $60.62 \pm 2.98^{\mathrm{c}}$ & $80.38 \pm 0.69^{\mathrm{b}}$ & $92.52 \pm 3.96^{\mathrm{a}}$ \\
\hline Sodium & $182,550 \pm 6151^{\mathrm{a}}$ & $185,050 \pm 19,728^{a}$ & $171,800 \pm 16,687^{a}$ \\
\hline \multicolumn{4}{|c|}{$\begin{array}{l}\text { Source: Permpoon et al. [25] } \\
\text { "Values are represented as mean } \pm S D(n=2) \text {. Different lowercase letters in the same row indicate significant difference }(p<0.05) \text {. } \\
* m g / k g\end{array}$} \\
\hline
\end{tabular}

Table 5.

Mineral content in food seasoning supplemented with fish bone values which are presented as mean $\pm S D$ $(n=2)$. Different lowercase letters in the same row indicate significant difference $(p<0.05)$.

\subsubsection{Fish bone as calcium and phosphorus source}

Fish bones have high calcium content, and large quantities of this raw material are available as a waste from the fishery industry. Previously, emphasis has been done on producing high-quality products from fish by-products by the use of bacterial proteases [41]. Biocalcium powder from the bones of precooked skipjack tuna was produced and characterized compared with calcined bone (CB) powder. Higher calcium (40.35\%) and phosphorous (15.28\%) contents were found in the CB powder than BC powder (26.91 and $12.63 \%$, respectively). BC powder had a low abundance of volatile compounds, including aldehydes, alcohols, and ketones. Precooked skipjack tuna bone could be used as a raw material for preparing BC powder, which has a different composition than $\mathrm{CB}$ powder. The $\mathrm{BC}$ powder was still composed of collagenous protein. $\mathrm{BC}$ had a low abundance of odorous compounds, whereas the $\mathrm{CB}$ powder had a negligible amount of volatiles. Precooked skipjack 
tuna is considered a promising source for BC production due to its abundance. BC with improved color and odor along with increased solubility in gastrointestinal tract can be used as an alternative calcium supplement to tackle the inadequate intake of dietary calcium.

\section{Plant processing by-products}

The waste portions such as the peel, core, stem, and crown were 29-40, 9-10, $2-5$, and 2-4\% (w/w), respectively (Figures 9 and 10 and Table 6) [42-45]. From the last decade, the use of plant extracts as a source of bioactive components (phytochemicals) has gained wide attention against synthetic antibiotic drugs. Pineapple peels and cores account for about $40 \%$ of the whole fruit, and they are largely wasted after fresh-cut processing. Papaya fruit is the green fruit which is widely used in Thai cuisine and famously in papaya salad. As the consumption increases, large quantities of papaya peels as by-products are left [42]. Usually, the peels are occasionally used for animal feed or disposed, which produce phytopathogens, then cause ecological problems, and pose risks to human health. These wastes are occasionally utilized as fertilizers or animal feed, yet they have very low economic value. Therefore, ways to utilize these residue wastes have become an important focus for research and development, recognizing that a systematic reduction in waste disposal is beneficial both economically and ecologically. Thus, fruit waste extracts are suitable for enhancing the nutritional and antioxidant properties in food, and moreover, they can also be applied in cosmetics and the nutraceutical and pharmaceutical industries [46]. Therefore, the utilization these waste products have become an important task for research and development. Systematically reducing waste and putting it to other uses is profitable both economically and ecologically speaking $[37,38]$.

\subsection{Fruit peel}

Peel is the outermost covering of fruits and not commonly consumed. Pineapple and papaya peels are found to have potential uses as raw materials that could be converted into value-added products, especially as sources for bioactive compound extraction. The utilization of fruit peels as a source of bioactive compounds, especially in proteolytic enzymes extraction means [44, 47].

\subsection{Enzyme extraction and application}

The isolation and characterization of bromelain extract (BE) from the wastes of Nang Lae and Phu Lae pineapple cultivars (economical fruits of Chiang Rai province, Thailand) were investigated by Ketnawa et al. [43] and Ketnawa et al. [44].
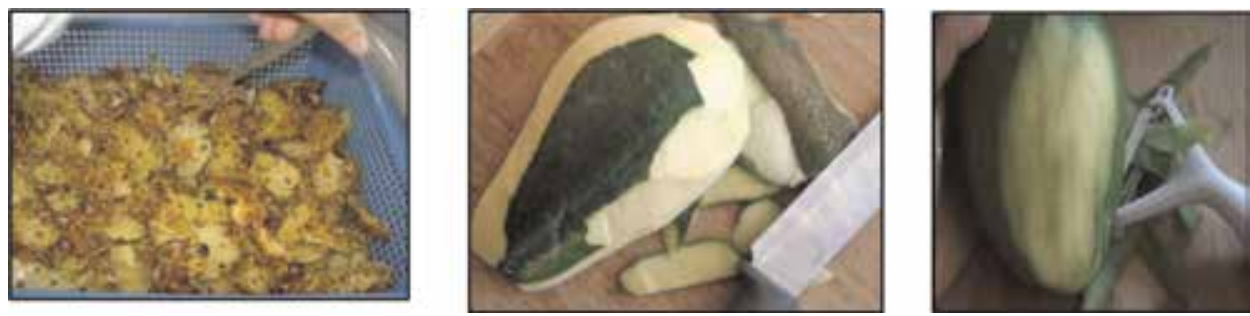

Figure 9.

Peel from agriculture products, pineapple, papaya, and mango (left to right). Source: Ketnawa et al. [42]. 


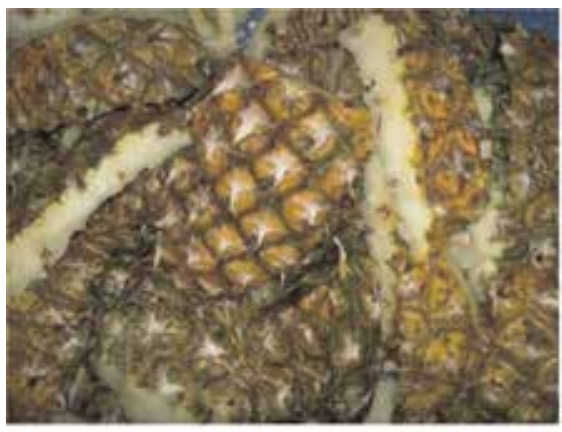

Peel: $30.07 \%$

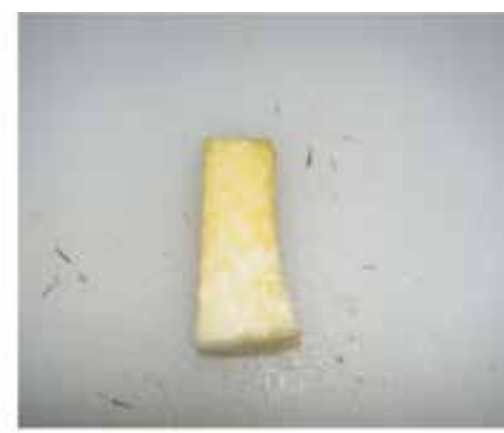

Core $=9.35 \%$

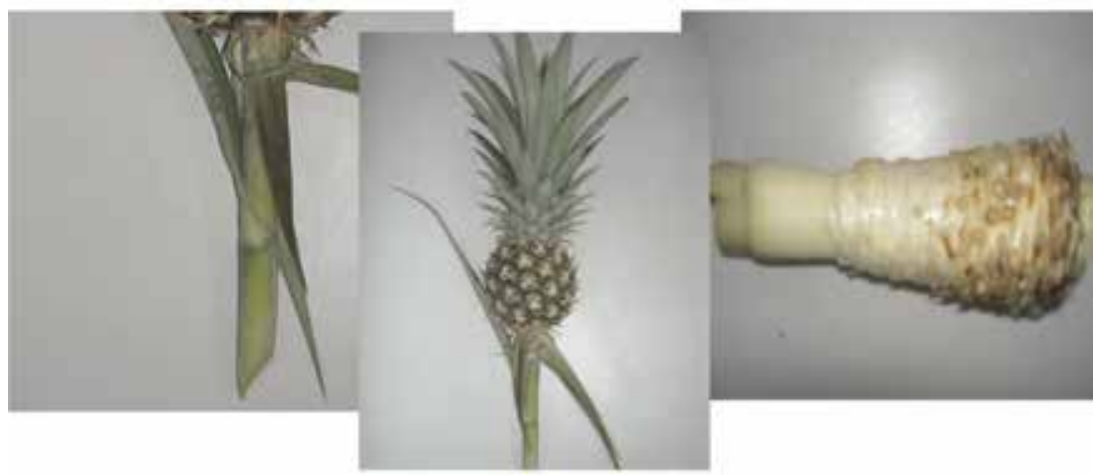

Stem: $5.57 \% \quad$ Crown: $4.72 \%$

Figure 10.

By-products from pineapple fruits. Source: Ketnawa et al. [44].

\begin{tabular}{lcccc}
\hline \multirow{2}{*}{ Part of pineapple } & \multicolumn{2}{c}{ Nang Lae } & \multicolumn{2}{c}{ Phu Lae } \\
\cline { 2 - 5 } & Weight $(\mathrm{g})$ & $\%(\mathrm{w} / \mathrm{w})$ & Weight $(\mathrm{g})$ & $\%(\mathrm{w} / \mathrm{w})$ \\
\hline Peel & 143.40 & 30.09 & 159.86 & 42.20 \\
\hline Core & 44.61 & 9.36 & 40.60 & 10.72 \\
\hline Stem & 26.55 & 5.57 & 9.26 & 2.44 \\
\hline Crown & 22.48 & 4.72 & 10.20 & 2.69 \\
\hline Flesh & 239.86 & 50.33 & 158.94 & 41.95 \\
\hline Total & 476.54 & 100.00 & 378.86 & 100.00 \\
\hline
\end{tabular}

Source: Ketnawa et al. [43].

Table 6.

Proportion of pineapple fruits of Nang Lae and Phu Lae cultivars.

The extract of crown from both cultivars gave the highest proteolytic activity and protein contents, while the extract from the stem exhibited the lowest values.

Bromelain is a major enzyme with the $\mathrm{MW} \sim 28 \mathrm{kDa}$. This study founded that there is much added value into local Thailand pineapple wastes because of bromelain extraction [44]. Chaiwut et al. [47] have reported that they obtained a substantial extraction of proteases from papaya peels. Tyrosinase inhibitor enzyme was extracted from mango seed kernel $[46,48]$. 
Bromelain has been used commercially in the food industry, in certain cosmetics, and in dietary supplements. It is used for meat tenderizing, brewing, and baking, as well as for the production of protein hydrolysates [42]. Toughness is one of the most common quality characteristics of meat and can be subdivided into actomyosin toughness and background toughness. The former is attributable to changes in myofibrillar proteins, whereas the latter is attributable to connective tissues. Treatment by proteolytic enzymes is a popular method for meat tenderization. Proteolytic enzymes derived from plants such as papain, bromelain, and ficin have been widely used as meat tenderizers in most parts of the world. Ketnawa and Rawdkuen [45] used bromelain extract obtained from the top phase of an aqueous two-phase system (18\% PEG-6000 $\left.+17 \% \mathrm{MgSO}_{4}\right)$ to tender the muscle foods with different concentrations of BE $(0-20 \%,(w / w))$ for $1 \mathrm{~h}$. A reduction of meat firmness and toughness was observed in all samples when compared to the control. Electrophoretic patterns revealed extensive proteolysis and a reduction in number and intensity of the protein bands in all of the treated samples. The results showed that the bromelain extract could be used as an effective meat tenderizer. In similar study of Ketnawa et al. [43], the effects of the bromelain extract on the protein patterns of beef, chicken, and squid muscles were also determined as depicted in Figure 11. Trichloroacetic acid-soluble peptide content of all the treated muscles increased when the amount of bromelain extract increased. Decrease in myosin
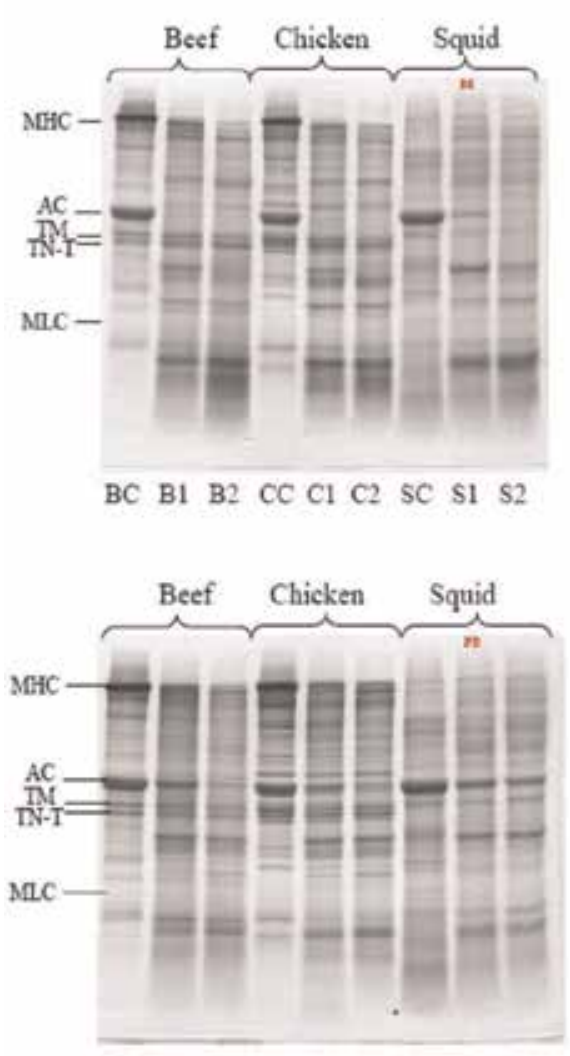

$\begin{array}{llllllllllllll}\mathrm{BC} & \mathrm{B} 1 & \mathrm{~B} 2 & \mathrm{CC} & \mathrm{Cl} & \mathrm{C} 2 & \mathrm{SC} & \mathrm{S} 1 & \mathrm{~S} 2\end{array}$
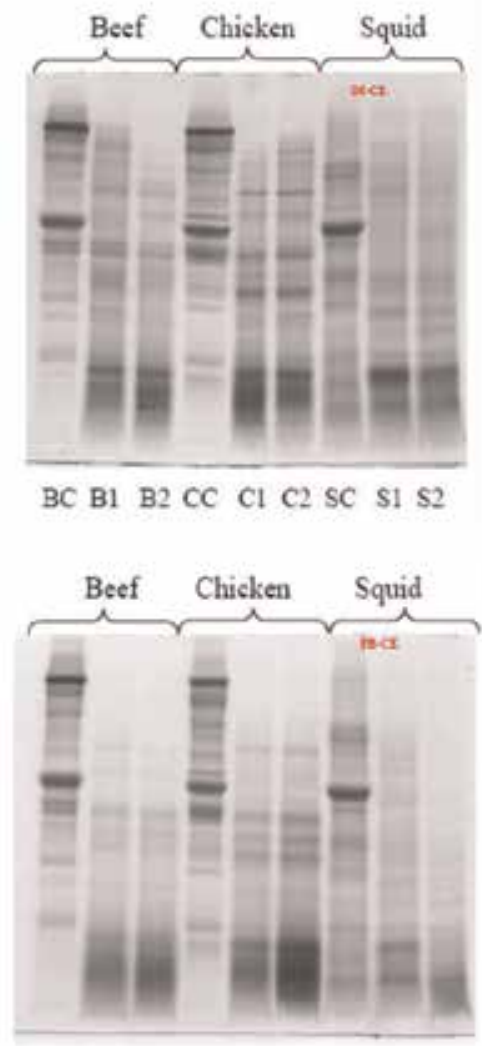

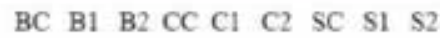

Figure 11.

SDS-PAGE patterns of muscles treated with bromelain from pineapple peels. $B C, C C$, and SC, controls without extract: B, beef; $C$, chicken; and S, squid. The numbers 1 and 2 indicate the amount of extract, 1 and $2 \mathrm{~mL}$, respectively. MHC, myosin heavy chain; AC, actin; TM, tropomyosin; TN-T, troponin-T; and MLC, myosin light chain. Source: Ketnawa et al. [43]. 
heavy chains and actin was observed in all the muscle types when bromelain extract was used [43]. The technology for applying this enzyme is cheaply available and can be exploited at the household or industrial level for tenderizing meat, and it can be used as an alternative to chemical tenderizers or other plant proteases.

\subsection{Fruit seed and kernel}

Recent studies have shown that fruit's waste parts like mango seed contain a noteworthy amount of bioactive component of therapeutic worth [48, 49]. These biologically active components include mangiferin, flavonoids, catechin, phenolic acids, gallic acid, and gallic acid derivatives as shown in Figure 12. The therapeutic importance of these compounds have evaluated through in-vitro and minimal preclinically, but there is a need for proper preclinical trials and afterward clinical trials for health claims and health benefits. The industrial processing of mangoes produces several million tons of waste from their peels and seeds at various stages that cause for a major disposal problem and effect to the environment. The seed alone makes up about $20 \%$ of the whole fruit, with $45-78 \%$ of the seed being the seed kernel $[49,50]$. During processing of mango, by-products such as peel and kernel are generated.

The major polyphenols present in mangos that act as a source of natural antioxidants (Figure 12) are as follows: mangiferin, catechin, quercetin, kaempferol, cinnamic acids, tanins, etc. The extract of the mango peels and the seed kernels also has a great deal of tyrosinase inhibitor, antioxidant activity, and chelating activity $[46,49,51]$.

\subsubsection{Bioactive compound extraction}

To enhance the efficiency of the extraction process, optimization the extraction parameters: the liquid/solid ratio, the ethanol concentration, and the extraction time are consideration. The study describes the optimization of polyphenol extraction from mango seed kernels by using response surface methodology (RSM)

(Figure 13). Sai-Ut et al. [46] applied RSM to optimize the ethanolic extraction of polyphenols from mango peels. Nam-Dokmai peel (NDP) showed significantly higher phenolic content and tyrosinase inhibitor activity than that of the Tong-Dam peel (TDP). The optimal condition that maximized the extraction yields, EPC, and the antioxidant activities for NDP were ethanol proportion of $49 \%$, a temperature of $61^{\circ} \mathrm{C}$, and an extraction time of $221 \mathrm{~min}$, whereas the optimized condition that maximized the extraction yields, TPC, and antioxidant activities from mango

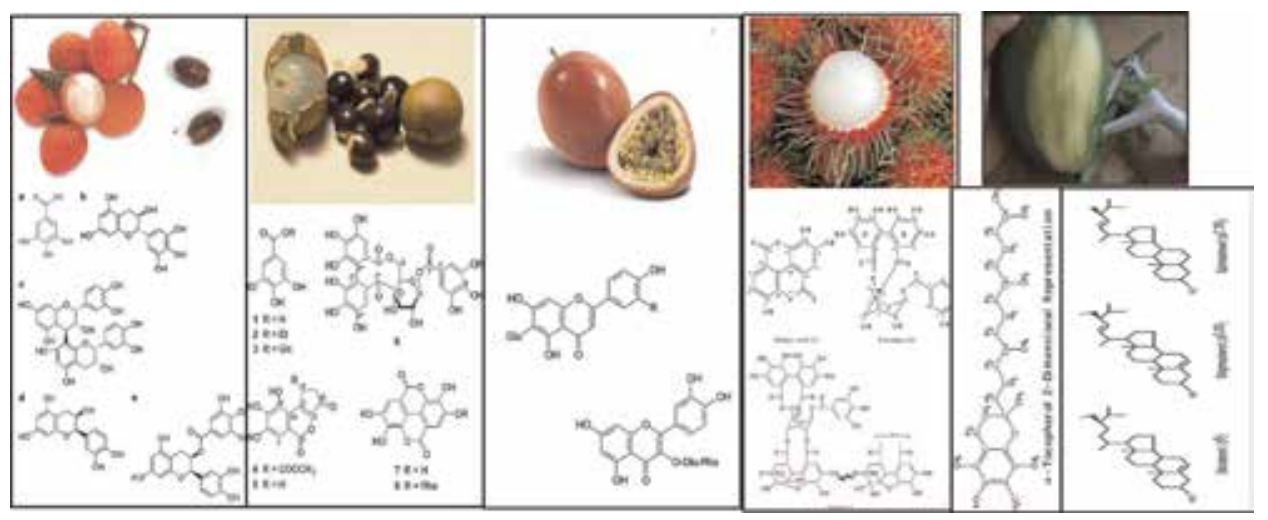

Figure 12.

Chemical structures of some phenolic compounds found in plant by-products. 

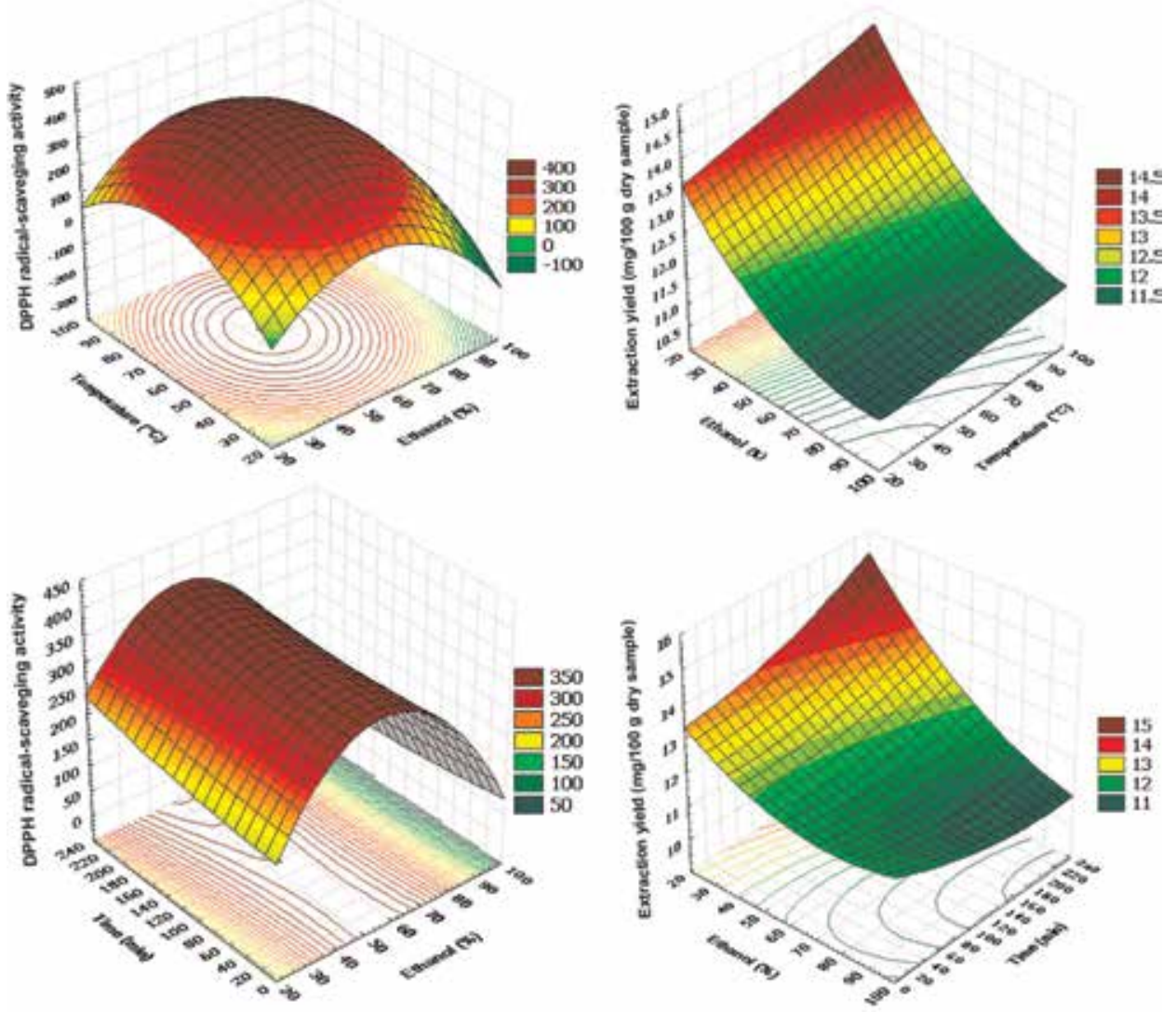

Regression coefficients of predicted models \& response surface model plot showing the effects of temperature and ethanol proportion and effects of time \& ethanol proportion on EPC \& DPPH (mg GAE/100g dry sample) from lychee seeds

Regression coefficients of predicted models \& response surfoce model plot showing the effects of temperature and ethanol proportion and effects of time \& ethanol proportion on extraction yield ( $\mathrm{mg} / 100 \mathrm{~g} d r y$ sample) from rambutan seeds extracts

Figure 13.

Response surface methodology to optimize the extraction of polyphenol compounds from plant wastes. Sources: Rawdkuen et al. [48] Sai-Ut et al. [46].

Tong-Dam kernel (TDK) was an ethanol concentration of $62 \%$, a temperature of $63^{\circ} \mathrm{C}$, and a duration of $150 \mathrm{~min}$ with a fixed ratio of 1:30 solid-liquid [48].

\subsection{Legume/grain/defatted seed flour/rice bran}

Sacha inchi is widely utilized as a raw material in the edible oil industry not only in South Africa but also in Asian country. The de-oiled meals contain high amounts of proteins, which makes it highly desirable for industrial use as value-added products. The proximate compositions of sacha inchi used in this study included protein 459 , carbohydrate 361 , fat 67 , ash 59 , crude fiber 58 , and moisture $53 \mathrm{~g} / \mathrm{kg}$ (wb). A comparative study of pressed cake made from tea and sacha inchi seeds was performed. Sacha inchi seeds contained the largest amount of protein $(62.07 \%)$ and tea seeds contained the largest amount of carbohydrates (82.68\%) as shown in Figure 14. Lysine, leucine, histidine, and phenylalanine were the main essential amino acids. Protein patterns by using SDS-PAGE showed that the main protein component had MWs of 35-63 for sacha inchi and 11-20 kDa for tea seeds. In addition, it contained glycoprotein with a MW of $35 \mathrm{kDa}$. Both pressed cakes 


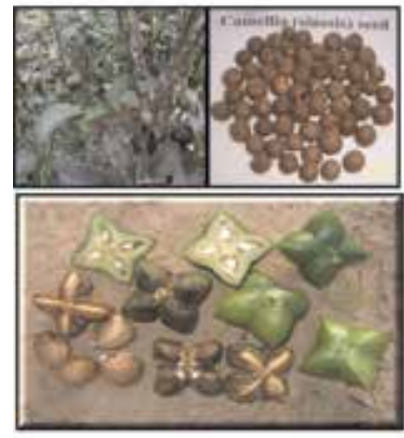

Figure 14.

Some utilization of pressed cake from sacha inchi and tea seeds. Source: Rawdkuen et al. [53]. A and B represent Electrophoresis patterns of protein and glycoprotein of pressed-cake from tea and sacha inchi seeds, respectively.

showed good sources for bioactive compounds with high antioxidant activities. Therefore, the chemical properties of the pressed cakes indicate that this byproduct of oil extraction is a good supplement to functional food ingredients. Nutritional factors such as essential amino acids, essential fatty acids, dietary fiber, and mineral content suggest that the pressed cake with sacha inchi seeds could be a useful ingredient for human consumption $[52,53]$.

\subsubsection{Protein hydrolysate preparation from sacha inchi pressed cake}

Protein concentrate (PC) was prepared (Figure 15), and their hydrolysate (PH) was hydrolyzed by crude papain and Calotropis proteases according to Rawdkuen et al. [53]. PC was hydrolyzed by crude papain (PH-P), and Calotropis proteases (PH-C) had a degree of hydrolysis (DH) of 2.7 and $11.2 \%$, respectively. PH-P contained a higher amount of essential amino acids $(474 \mathrm{~g} / \mathrm{kg})$ than $\mathrm{PH}-\mathrm{C}(410 \mathrm{~g} /$ $\mathrm{kg}$ ). The protein patterns of PC and PHs by using SDS-PAGE showed the molecular weights between $<8$ and $57 \mathrm{kDa}$. DPPH scavenging activity and FRAP assay showed a rising $\mathrm{PH}$ when the $\mathrm{DH}$ was increased. Sacha inchi protein hydrolysates can be produced in a cost-effective way by using natural crude enzyme extracts.

Some applications of protein concentrate in food model system were performed in pork sausage and fish finger (Figure 16). The results showed that when the concentration of protein concentrate increased, the textural properties of the sausage were improved. In addition, with fried fish finger can extent it shelf life when protein hydrolysates was added when compared with the control treatment. Both hydrolysates showed effective bioactivities as well as high nutritional value (Lys, Phe, and Tyr) after in vitro gastrointestinal digestion. Thus, crude papain extracted from papaya peel and Calotropis proteases from latex can be used as alternative natural enzymes for production of protein hydrolysates by using sacha inchi meal as a starting material [53].

\subsubsection{Extraction and isolation of protein form rice bran}

A plenty of rice bran are produced as by-products during rice milling process nowadays following the demand in production and consumption. After rice milling 
Extraction, Characterization, and Application of Agricultural and Food Processing By-Products DOI: http://dx.doi.org/10.5772/intechopen.89289

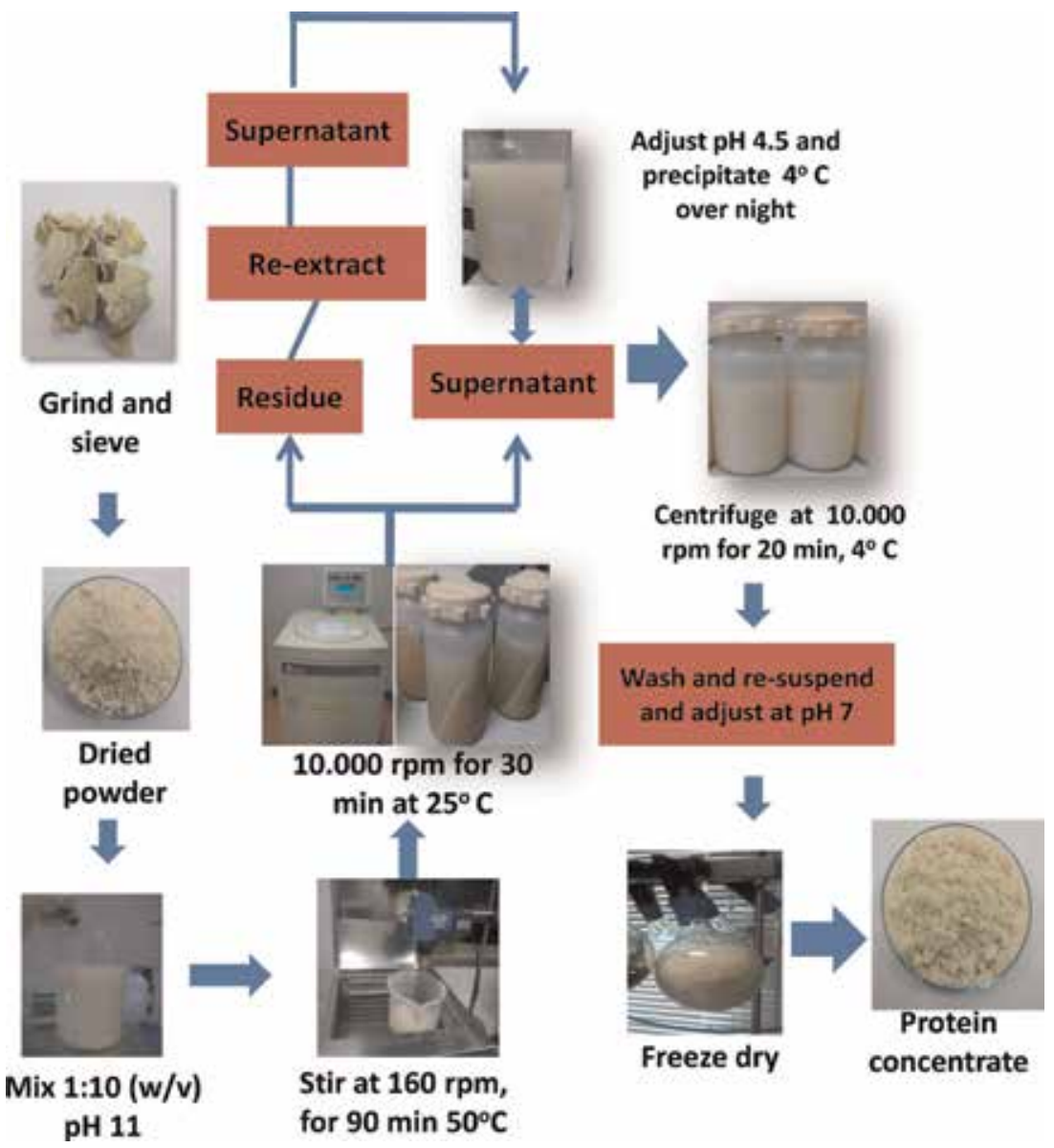

Figure 15.

Preparation of protein concentrate from pressed cake sacha inchi. Source: Rawdkuen et al. [53].
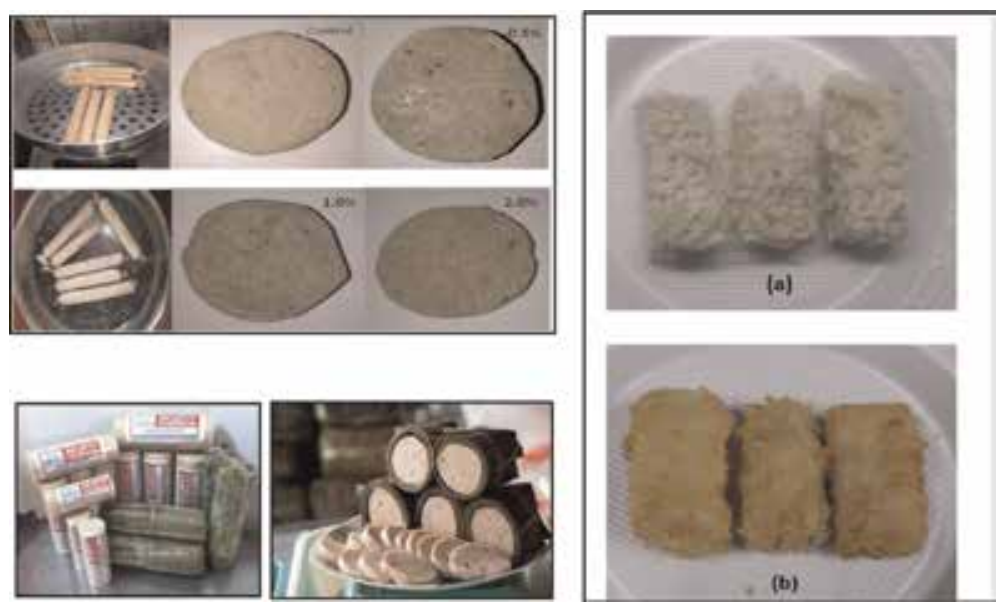

Figure 16.

Application of protein concentrate from sacha inchi defatted meal in fish fingers. Source: Rawdkuen et al. [53]. (a) and (b) represent fish finger contained sacha inchi protein concentrate before and after frying, respectively.

process, $70 \%$ rice is obtained, while rice hull (20\%), rice bran $(8 \%)$, and rice germ (2\%) are the by-products. The major portion of this is used as animal feed or discarded as waste material [54]. However, rice bran is attracting attention from 
researchers because it is an alternative and economic source of plant-based hypoallergenic and high-quality protein $[54,55]$. Besides, rice bran is a rich source of protein, fat, carbohydrate, vitamins, minerals, dietary fiber, and bioactive compound antioxidants. Furthermore, the chemical, functional, and biofunction properties of rice protein seem superior to other proteins such as soya flake, potato starch, peanut, sorghum, kidney bean, and groundnut $[55,56]$. Thus, rice bran has a strong potential to extract certain bioactive compounds, that is, protein concentrate, protein hydrolysates, active peptides, and utilization of those compounds, that is, film production (Figure 17).

Rice bran fraction is the main source of protein in rice grain. The protein content ranges from 10 to $16 \%$ (W/W) depending on its cultivars [57]. Rice bran is an economic source of high-quality plant-based protein that can exhibit an excellent functional properties and interesting bio-functions. Rice bran protein is suggested as one of the important plant-based proteins that can be applied or used as ingredient in many products such as infant food, meat ball, noodles, biscuit, breads, and gluten-free (GF) products. Moreover, its hydrolysate form has a potential to be

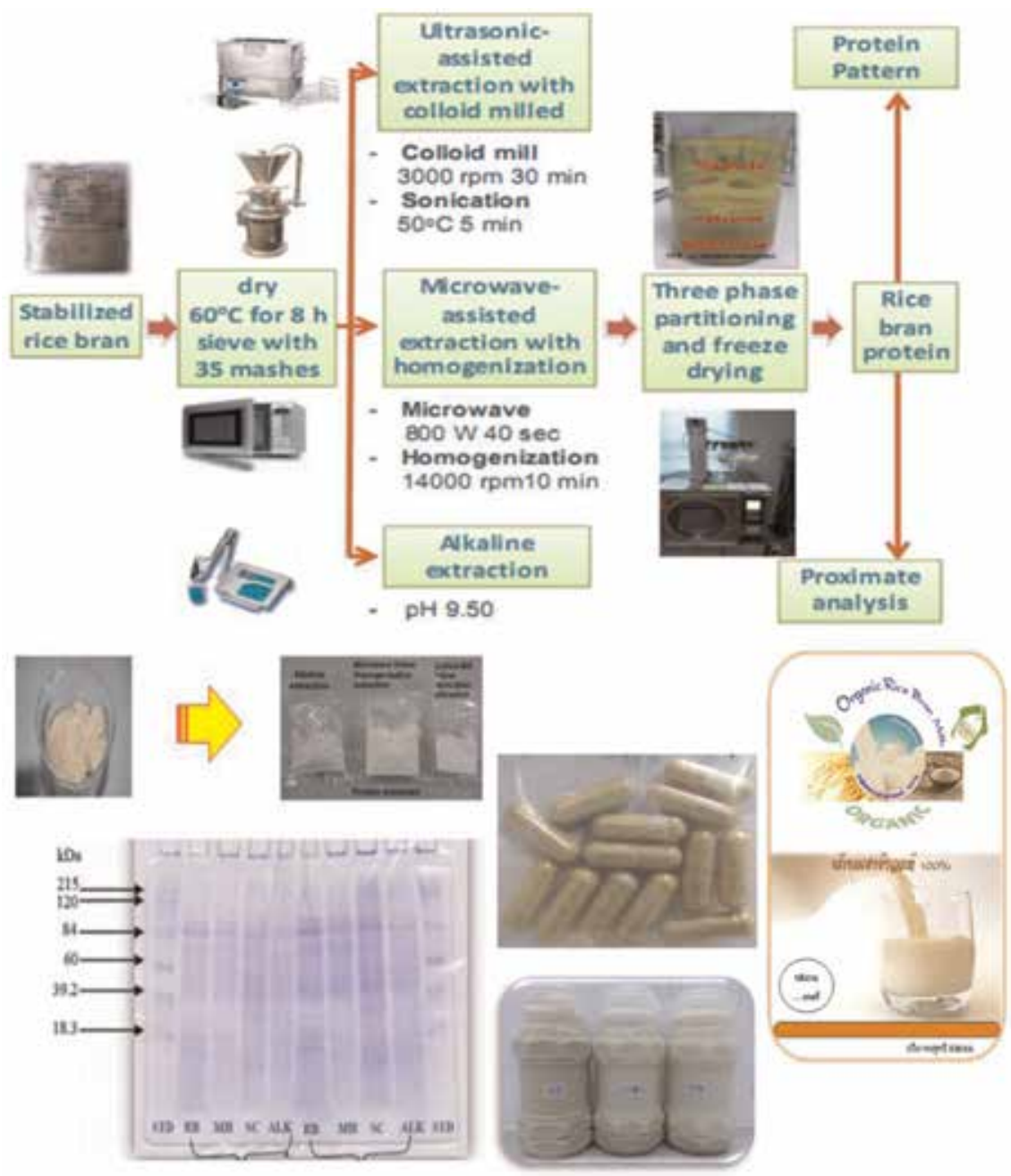

Figure 17.

Different methods for extraction of protein from rice bran. Sources: Phongthai et al. [62], Phongthai et al. [63], and Phongthai et al. [64]. 
applied in nutraceutical products and also cosmetic goods [58]. Thus, the several methods to extract protein from rice bran fraction are of interest and developed through physical, chemical, and enzymatic treatments.

Different extraction methods both conventional extraction such as solvent extraction $[59,60]$, alkaline extraction $[57,58]$ as well as innovative ones such as supercritical fluid [61], microwave [62], ultra-sonication [63] and enzymatic extraction [64] are used to extract protein from rice bran. Conventional method like alkaline extraction is the most common method for extracting protein from plant materials due to its simplicity and low cost. However, severe alkaline conditions negatively affect the nutritional and functional properties of the protein. This process also requires a long time for extraction and consumes large volumes of buffer. Moreover, exposing protein to severe alkaline conditions also affects the nutritional and functional properties of protein [65]. Therefore, other methods such as physical, that is, microwave- and ultrasonic-assisted extraction, as well as enzymatic methods are increasingly being considered as alternative methods.

Nowadays, microwave and ultrasonic are commonly applicable methods in food preparation, especially for solid-liquid extraction. It is high reproducibility in a shorter time, convenience, and less solvent consumption. Response surface methodology could be used instead of other methods that test only one variable at a time, which is time-consuming and not cost-effective. It also provides insight into the interactions of the variables and calculates the optimal response with a limited number of experiments. The integration of ultrasonic and RSM is challenging but beneficial because it could create a systematic, practical, and economical method for rice bran protein extraction.

Phongthai et al. [63] studied of extraction of protein from organic rice bran by three different methods such as alkaline [58], microwave [62], ultra-sonicated extraction [63], enzyme-assisted extraction (EAE) of rice bran protein [64] and then that protein concentrate was isolated by three-phase partitioning (TPP) techniques [66] or utilization of protein concentrate as raw material for production of protein hydrolysate [58], gluten free bread [58] and pasta [67] as depicted Figure 18.

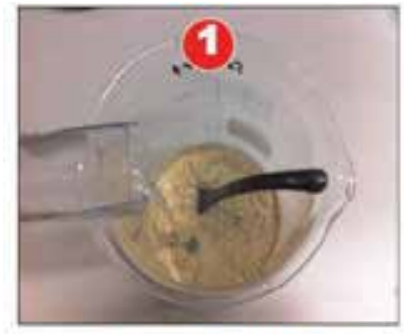

S/L of $1: 10(w / w)$

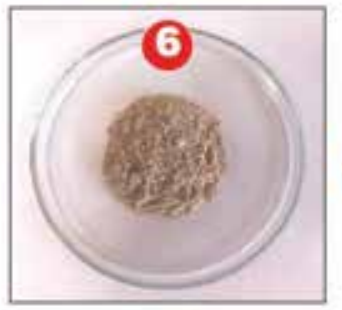

RBPC

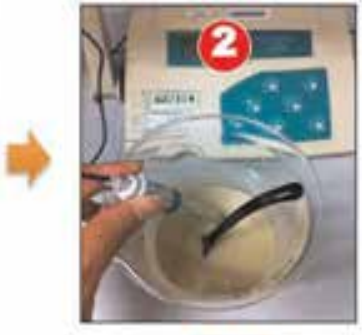

pH 10

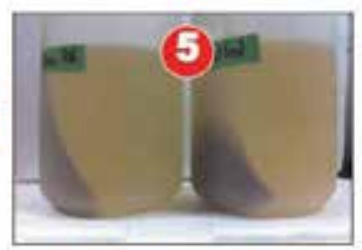

pH 4.5 \& centrifuge

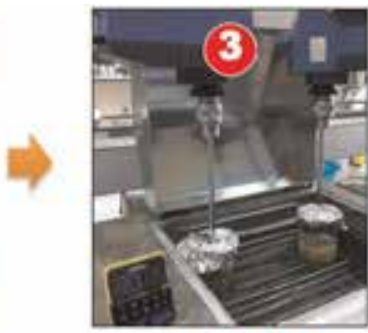

$1 \mathrm{~h}$ at RT

Contrifuge

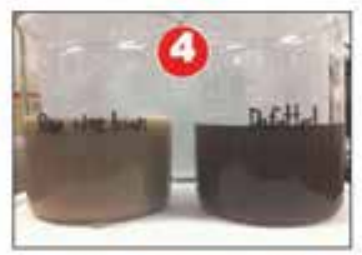

Collect supernatant

Figure 18.

Rice barn protein extraction by conventional alkaline extraction method. Source: Phongthai et al. [58]. 


\subsubsection{Alkaline extraction (ALK)}

Alkaline extraction is the most common method for extracting protein from plant materials due to its simplicity and low cost. Phongthai et al. [58] studied the protein extraction from organic rice bran using alkaline extraction method which is shown in Figure 18. For alkaline extraction, DFRB was dispersed in distilled water $(1: 10, \mathrm{w} / \mathrm{v})$, and the $\mathrm{pH}$ was adjusted to 10 using $3 \mathrm{M}$ sodium carbonate. The mixture was stirred using a pilot-scale stirrer at a temperature of $50^{\circ} \mathrm{C}$ for $1 \mathrm{~h}$. After centrifugation at $10,000 \times g$ for $10 \mathrm{~min}$, the supernatant was collected and adjusted to $\mathrm{pH} 4.5$ using $3 \mathrm{M}$ citric acid and centrifuged at the same conditions. The dried powder is referred to as rice bran protein concentrate (RBPC). From the study, the pilot scale gained RBPC showed a yield of $7.44 \mathrm{~g} / 100 \mathrm{~g}$ based on DFRB weight. Compared with lab scale extraction, the used pilot scale procedure gained much higher yields, 1.6-2.7-fold more protein. The main composition of RBPC was protein with $68.07 \pm 0.54 \% \mathrm{dm}$, which can be labeled as protein concentrate due to the protein content of more than $60 \%$ [58]. In addition, two step statistical design (1) fractional factorial design $2^{4-1}$ (independent variables: $\mathrm{X}_{1}(\mathrm{pH}: 8,9,10), \mathrm{X}_{2}$ (temperature: 25,35 , and $45^{\circ} \mathrm{C}$ ), $\mathrm{X}_{3}$ (stirring speed: 80,100 , and $120 \mathrm{rpm}$ ) and $\mathrm{X} 4$ (stirring time: 60,120 , and $180 \mathrm{~min}$ ) and (2) central composite rotatable design with variables $\mathrm{X}_{1}$ (temperature: $35,38,45,52$, and $55^{\circ} \mathrm{C}$ ) and $\mathrm{X}_{2}$ (stirring time: 120 , $146,210,274$, and $300 \mathrm{~min}$ ) was used to extract rice bran protein [57]. However, with this experimental design provided only $48.53 \%$ of protein content at $\mathrm{pH} 10.0$, $80 \mathrm{rpm}, 300 \mathrm{~min}$ of stirring time, and $52^{\circ} \mathrm{C}$, with an extraction yield of $34.51 \%$.

\subsubsection{Microwave-assisted extraction (MAE)}

Rice bran was extracted for protein by MAE using RSM, and a three-level threefactor Box-Behnken design was chosen to evaluate the effect of microwave power $\left(\mathrm{X}_{1}\right)$, extraction time $\left(\mathrm{X}_{2}\right)$, and solid-liquid ratio $\left(\mathrm{X}_{3}\right)$ as shown in Figure 19 [62]. It was found that the optimal condition was $1000 \mathrm{~W}$ of microwave power, $90 \mathrm{~s}$ of extraction time, and a solid-liquid ratio of $0.89 \mathrm{~g}$ rice bran $/ 10 \mathrm{~mL}$ of distilled water. The protein yield of MAE showed higher than that of ALK by about 1.54-fold [62]. The ratio of rice bran per water as $1: 10 \mathrm{w} / \mathrm{v}$ and the temperature controlled at $40^{\circ} \mathrm{C}$ by a sensor inserted in a control vessel during $90 \mathrm{~s}$ of process time, generating a power range of $350-400 \mathrm{~W}$, showed $11 \%$ yield and $75 \%$ protein content [68]. In the study of Bandyopadhyay et al. [69], the same ration of rice bran solution sample $(100 \mathrm{~mL})$ was simultaneously exposed at a frequency of $2450 \mathrm{MHz}$ and operated at $800 \mathrm{~W}$. The result showed that only $40 \mathrm{~s}$ of microwave treatment could give the protein recovery of $78.4 \%$ as against $28.9 \%$ after $1 \mathrm{~min}$ for conventional boiling.

\subsubsection{Ultrasonic-assisted extraction (UAE)}

Another alternative method like UAE was used by Phongthai et al. [63] to study the condition of sonication amplitude $\left(\mathrm{X}_{1}, 50-90 \%\right)$, extraction time $\left(\mathrm{X}_{2}, 10\right.$ $30 \mathrm{~min})$, and solid-liquid ratio $\left(\mathrm{X}_{3}, 0.5-1.5 \mathrm{~g} \mathrm{RB} / 10 \mathrm{~mL}\right)$ for the extraction of protein, as depicted in Figure 20. The optimal condition for rice bran protein production was $76 \%$ sonication amplitude, 18 min extraction, and $0.99 \mathrm{~g} / 10 \mathrm{~mL}$ solid-liquid ratio, which gave a protein yield of $4.73 \pm 0.03 \%$. It was found that the sonication amplitude and extraction time influenced a protein yield during UAE. The optimized UAE was a more effective method than alkaline extraction method [63]. The ratio of rice bran per water as $1: 10 \mathrm{w} / \mathrm{v}$ showed $11.40 \%$ yield and $73.80 \%$ protein content when using UAE [68]. 
Extraction, Characterization, and Application of Agricultural and Food Processing By-Products DOI: http://dx.doi.org/10.5772/intechopen.89289

\section{MAE extraction}

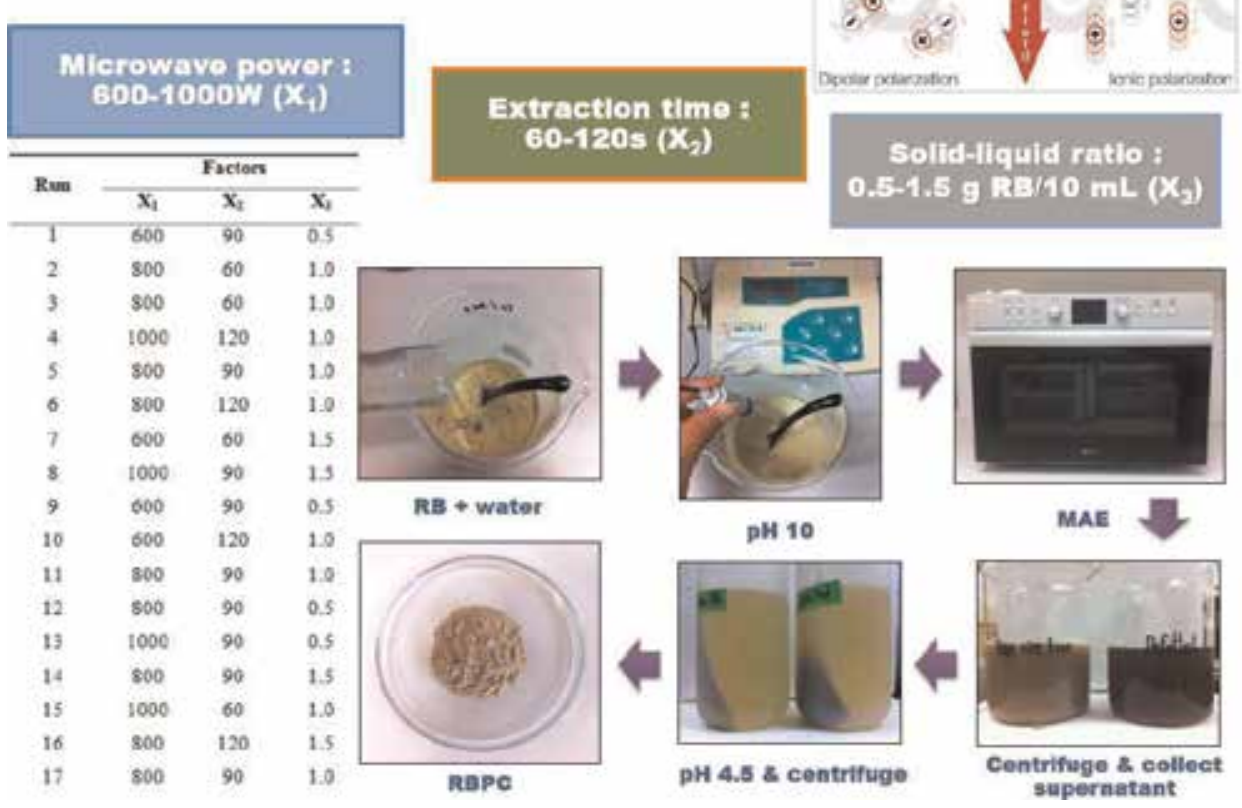

Figure 19.

Rice bran protein extraction by microwave-assisted extraction method. Source: Phongthai et al. [62].

\section{UAE extraction}
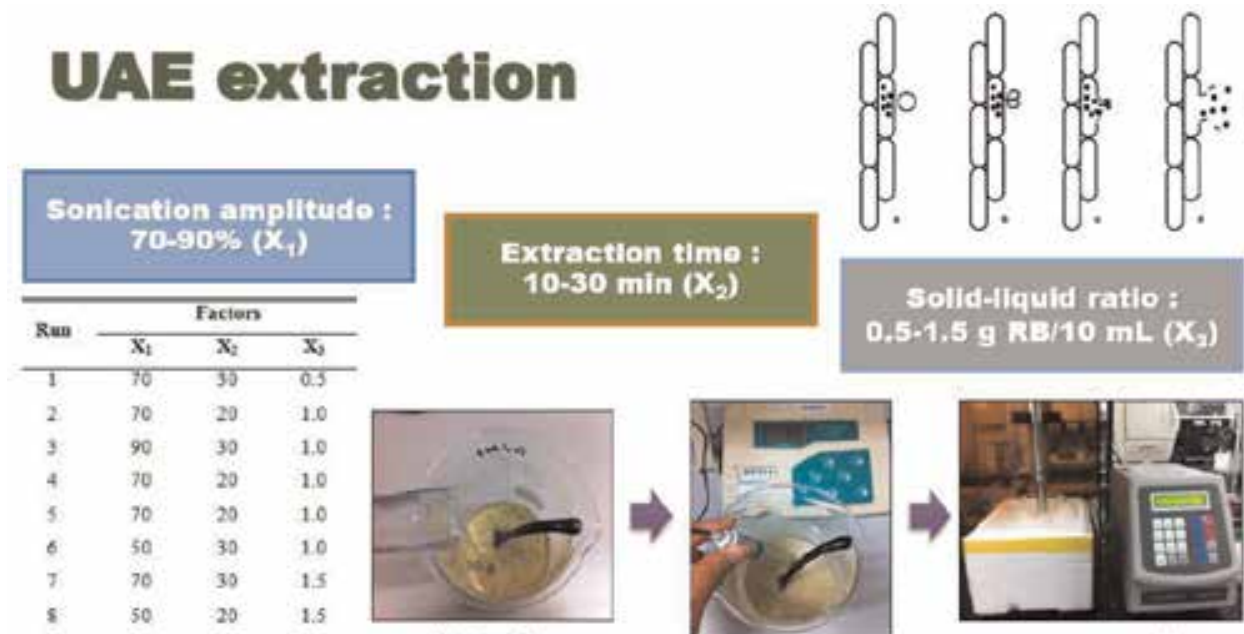

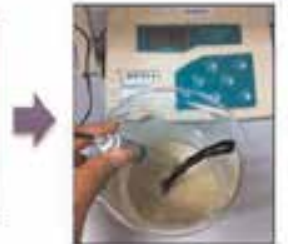

RB + water

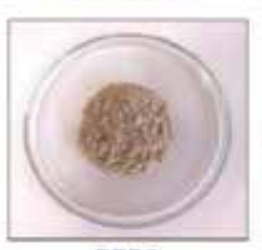

RBPC

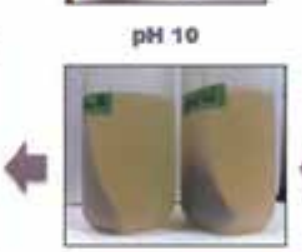

pH 4.5 \& centrifage
Solld-fiquid ratio : $0.5 \cdot 1.5 \mathrm{~g} \mathrm{RB} / 10 \mathrm{~mL}\left(X_{3}\right)$

Figure 20.

Rice barn protein extraction by ultrasonic-assisted extraction method. Source: Phongthai et al. [63]. 


\subsubsection{Enzyme-assisted extraction (EAE)}

Phongthai et al. [64] studied the single study of variables, including solid-liquid ratio (0.5-2 g DFRB/10 $\mathrm{mL})$, extraction time $(2 \mathrm{~h})$, and enzyme concentration (5000 units) in rice bran protein extraction. The results showed that the use of solid-liquid ratio at 0.5:10 and 1.0:10 for rice bran protein extraction gave comparable protein recovery and protein yield, reaching maximum values of 12.06 and $2.78 \%$, respectively (extraction time $3 \mathrm{~h}$ and enzyme concentration $2500 \mathrm{U}$ ). The protein recovery and protein yield increased to $14.20-14.75 \%$ and $3.28-3.35 \%$, respectively, when the extraction time extended to $4-5 \mathrm{~h}$. These values increased as the concentration of enzymes increased. Protein recovery and protein yield reached the maximum values of $16.69 \pm 0.58 \%$ and $3.70 \pm 0.12 \%$, respectively, when $10,000 \mathrm{U}$ of enzyme was used [64]. The yield of RBPC prepared by alkaline extraction followed by acidic precipitation is $10.2 \%$, which is further increased to 14.5 and $22.4 \%$ by papain- and Viscozyme-assisted extraction, respectively [69].

\subsubsection{Application of isolated rice bran protein}

\subsubsection{Bread preparation}

Gluten-free-based products have been studied for several years especially for quality improvement by enriching with proteins. Besides, the allergenic character of common protein source like egg albumin is a limitation factor. Phongthai et al. [58] studied the replacement of egg albumin with rice bran protein concentrate which is a nonallergy protein in order to improve the quality of GF bread. The obtained RBPC was composed of $68.07 \%$ protein (dry basis) preparation from alkaline-acid extraction technique. The summary of GF breads enriched with different levels of egg albumin and RBPC is depicted in Figure 21. The addition of RBPC had strongly influenced the rheological properties, especially elastic modulus $\left(G^{\prime}\right)$ of GF batters during oscillation and the relative elasticity of final GF breads. Breads enriched with $2 \%$ RBPC and a combination of $1 \%$ egg albumin and 1\% RBPC had the highest
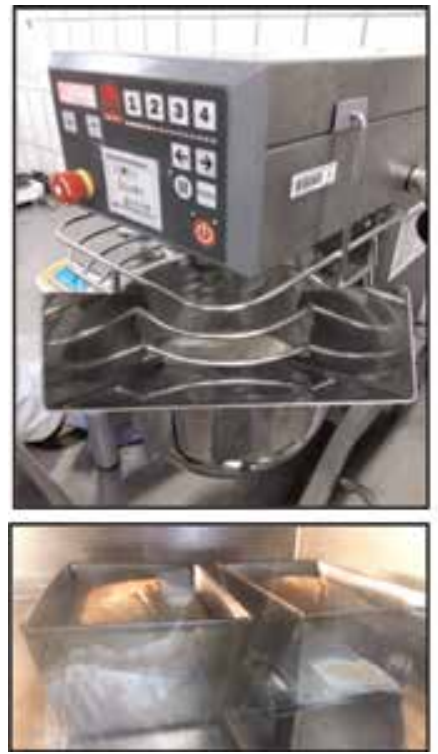
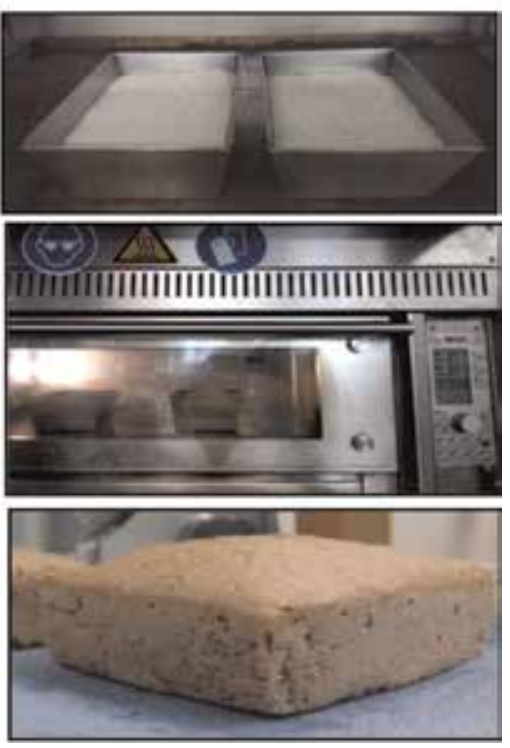

Figure 21.

GF breads enriched with different levels of egg albumin and RBPC preparation. Source: Phongthai et al. [58]. 
specific volume. The properties of GF bread was improved in terms of specific volume, pore size and uniformity, gas retention, and shelf life by addition of $2 \%$ RBPC [58].

For sensory evaluation and attributes, GF bread was determined by those attributes compared with the control bread as shown in Figure 22. High improvements in terms of appearance, color, smell, and overall liking were observed by $2 \%$ RBPC enrichment. In addition, the texture of GF breads (2\% RBPC) was extremely accepted by panels, which is related to the firmness and relative elasticity values of $15.00 \mathrm{~N}$ and $54.11 \%$, respectively. Taste was not significantly different between the breads containing egg albumin or RBPC. It was clearly seen that the addition of $2 \%$ RBPC displayed an important anti-staling effect in GF bread. The GF bread containing $1 \%$ RBPC and $1 \%$ egg albumin had an intermediate staling rate during storage, indicating a slower rate for development of crumb hardness than GF breads enriched with $2 \%$ egg albumin and the control recipe. Additionally, crumb porosity and sensory attributes were improved. RBPC also showed higher efficacy to inhibit bread staling than egg albumin. From this study suggested that RBPC could be used as a protein source as well as extending its shelf life for GF bread [58].

\subsubsection{Gluten-free pasta production}

Since manufacturers have long complained about gluten-free pasta for its apparent low cooking properties and reduced nutritional value, Phongthai et al. proposed to develop a multi-sourced protein-enriched gluten-free pasta [68] as depicted in Figure 23. RBPC is one of the alternative protein sources used in this study. Egg albumen (EB), whey protein concentrates (WP), and soy protein concentrates (SPC) were all enriched into rice flour-based gluten-free pasta in order to test their level of enhancement of cooking properties. In uncooked pasta, the RBPCenriched pasta contained a soluble protein with a protein solubility of 22.9$27.59 \mathrm{mg} / \mathrm{g}$ sample when compared with that of WB 40.77-50.28 mg/g sample, EB (28.40-36.77 mg/g sample), and SP (16.56-21.18 mg/g sample), respectively. However, rice bran protein did not provide satisfied quality of gluten-free pasta. Obviously, RBPC influenced the highest solid loss, which was more than $7.5 \%$. This may

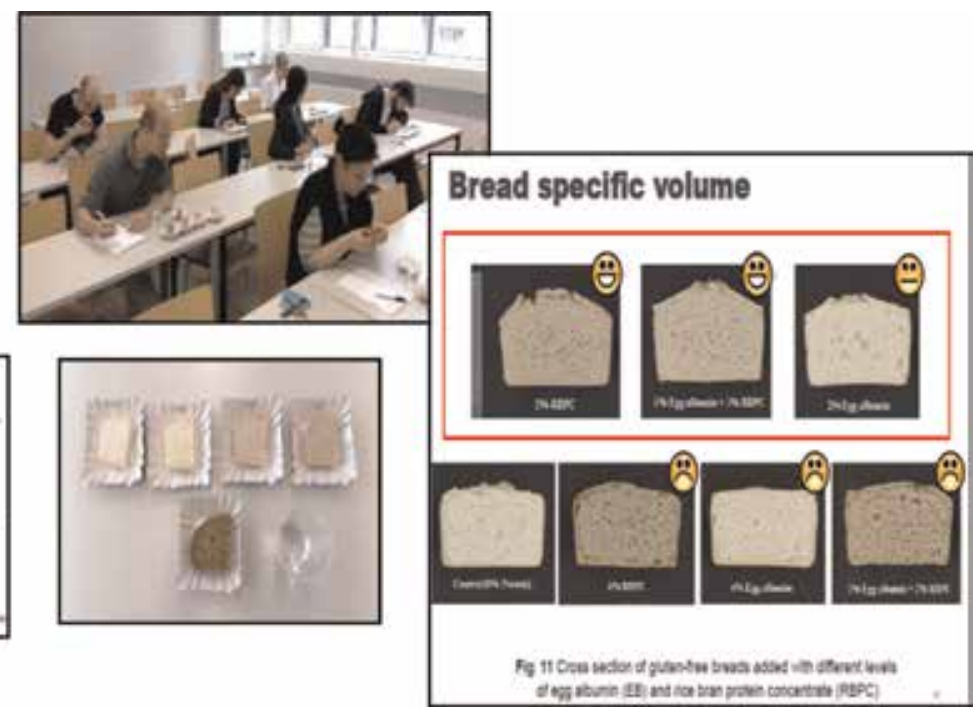

Figure 22.

Gluten-free breads enriched with different levels of egg albumin and RBPC and sensory evaluation attributes of GF breads. Source: Phongthai et al. [58]. 


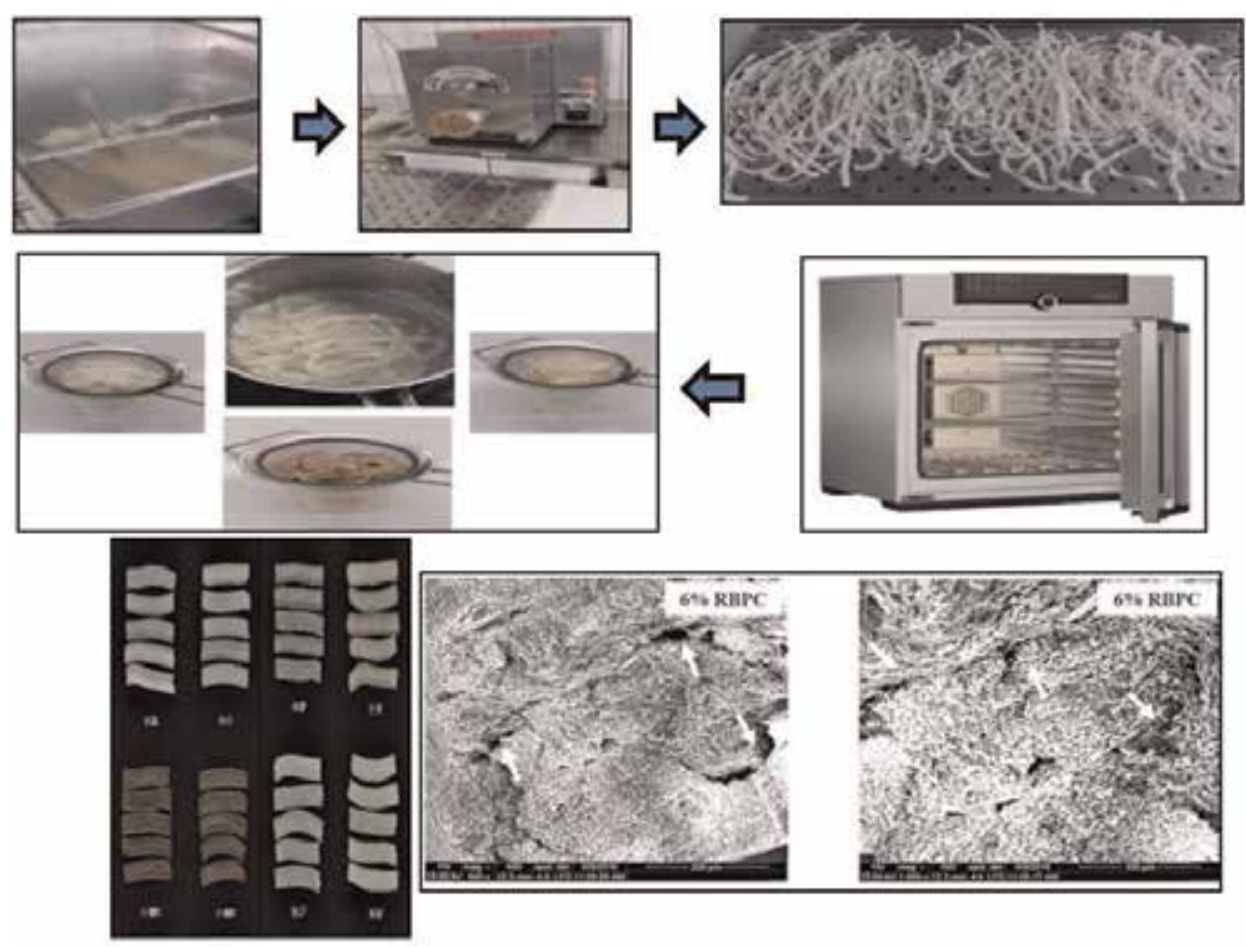

Figure 23.

Characteristic of uncooked gluten-free pasta and scanning electron microscopy images of rice flour-based glutenfree pasta enriched with 6 and 9\% of egg albumen (EB), rice bran protein concentrates, soy protein concentrates, and whey protein concentrates. Source: Phongthai et al. [68].

be because RBPC is comprised of $6.91 \%$ fiber, which would be responsible for weakening the starch network, thereby increasing cooking loss. Besides, the addition of RBPC had a great impact on color parameters as shown in Figure 23, possibly because RBPC was obviously darker than the other protein sources. Egg albumen manifested the greatest potential for improving gluten-free pasta as it gave a short cooking time, a low cooking loss, and a firm texture.

\subsubsection{Rice bran protein hydrolysates}

Rice bran protein can be utilized by the production of rice bran protein hydrolysate (RBPH) by enzymatic techniques. The protein hydrolysates can be subjected to isolation and characterization for study possibility to be functional ingredient that benefits for human health. In the study of Phongthai et al. [64], RBPC that produced from alkaline extraction was used as raw material for rice bran protein hydrolysate production, and the hydrolysate was further fractionated by membrane ultrafiltration (UF, F1: molecular weight (MW) $<3 \mathrm{kDa}$, F2: MW 3-5 kDa, and F3: MW 5-10 kDa) was used to fractionation of the hydrolysate [64]. Both RBPC and $\mathrm{RBPH}$ were digested by pepsin, and the combination of pepsin and trypsin under in vitro gastrointestinal digestion was investigated for its free amino acids (FAAs). The digestion affected the FAA content in each sample by RBPH had the highest FAAs content $(34.44 \mathrm{mg} / \mathrm{g})$ when compared with RBPC $(22.40 \mathrm{mg} / \mathrm{g})$ and pepsinhydrolysates $(27.07 \mathrm{mg} / \mathrm{g})$. For antioxidant properties, it was found that the digestion by pepsin and pepsin-trypsin increased the DPPH radical scavenging activity of RBPC by about 3.1-4.9-fold. The digestion by pepsin and pepsin-trypsin could simulate the metal chelating efficacy of RBPC by about 2.17-2.21-fold. UF had a 
positive effect with DPPH and ABTS but negative effect on the reducing activity of peptide fractions. However, the UF fractions and the RBPH with MW between 3 and $5 \mathrm{kDa}$ showed outstanding activity to chelate. The majority of peptides with $\mathrm{m} / \mathrm{z}$ at 1088 was supposed to be octapeptides, containing eight amino acids; a major peptide fragment in $\mathrm{RBPH}$ that has the highest antioxidant activity was detected at $m / z 1088$.

Rice bran protein hydrolysates at different degrees of hydrolysis (DH) (5.04, 10.37, and 15.04\%) were obtained from RBPC from MAE and produced by Alcalase. The molecular weight (MW) of the rice bran protein concentrate and the PHs ranged between $<11$ and $100 \mathrm{kDa}$ [62]. In addition, another $\mathrm{RBPH}$ was obtained from RBPC from UAE and further hydrolysis by Neutrase $0.8 \mathrm{~L}$ and Subtilisin A [63]. The degree of hydrolysis for the rice bran protein by Subtilisin A, Actinase E, and Neutrase $0.8 \mathrm{~L}$ was $20.03,13.84$, and $5.54 \%$, respectively. The MWs of the isolated proteins ranged between $<11$ and $75 \mathrm{kDa}$. The $\mathrm{RBPH}$ exhibited greater scavenging activity on DPPH radical and ACE-inhibitory activity. The RBPH obtained by using Subtilisin A was efficient in reducing power and metal chelating activities. From these studies, it was found that that the partial hydrolyzed rice bran protein is more suitable for application in food systems rather than the nonhydrolyzed form [63].

\section{Author details}

Saroat Rawdkuen ${ }^{1 *}$ and Sunantha Ketnawa ${ }^{2}$

1 Unit of Innovative Food Packaging and Biomaterials, School of Agro-Industry, Mae Fah Luang University, Chiang Rai, Thailand

2 Postharvest and Food Engineering Laboratory, Graduate School of Horticulture, Chiba University, Chiba, Japan

*Address all correspondence to: saroat@mfu.ac.th

\section{IntechOpen}

(C) 2019 The Author(s). Licensee IntechOpen. This chapter is distributed under the terms of the Creative Commons Attribution License (http://creativecommons.org/licenses/ by/3.0), which permits unrestricted use, distribution, and reproduction in any medium, provided the original work is properly cited. (cc) BY 


\section{References}

[1] Manisan V. Geography and Climatology in every Season of Various Parts in Thailand. Thailand, Bangkok: Technical Document of Meteorological Department; 1995

[2] Hays J. Agricultural in Thailand: History, Land Use, Indebted Farmers, Irrigation and Food Industies. Facts and Details [Internet]. 2014. Available from: http://factsanddetails.com/southeastasia/Thailand/sub5_8h/entry-3319.html [Accessed: 1 August 2019]

[3] Kuneepong P. Facts and Details: Thailand. 2002. Available from: https:// www.ldd.go.th/FAO/z_th/th.htm\#plant [Accessed: 1 August 2019]

[4] Foreign Agriculture Service, U. S. D. o. A. Thailand Exporter Guide. 2019. Available from: https://gain.fas.usda. gov/Recent\%20GAIN\%20Publications/ Exporter\%20Guide_Bangkok_Thailand_ 2-21-2019.pdf [Accessed: 1 August 2019]

[5] Office of Agricultural Economics, A. S. o. T. Agricultural Production Information. 2019. Available from: http://oldweb.oae.go.th/oae_report/ export_import/export.php [Accessed: 1 August 2019]

[6] Pongsrihadulchai A. Thailand Agricultural Policies and Development Strategies. 2019. Available from: http:// ap.fftc.agnet.org/ap_db.php?id=980\& print $=1$ [Accessed: 1 August 2019]

[7] USDA. Country Fact Sheet on Food and Agriculture Policy Trends:

Thailand. 2018. Available from: http:// www.fao.org/3/I8683EN/i8683en.pdf [Accessed: 1 August 2019]

[8] FAO. SAVE FOOD: Global Initiative on Food Loss and Waste Reduction. 2019. Available from: http://www.fao. org/save-food/en/ [Accessed: 1 August 2019]
[9] Ezejiofor TIN, Enebaku UE, Ogueke C. Waste to wealth-value recovery from agro-food processing wastes using biotechnology: A review. British Biotechnology Journal. 2014; 4(4):418-481

[10] Rawdkuen S, Kaewprachu P. Valorization of food processing byproducts as smart food packaging materials and its application. Food Waste as a Resource. Vol 1. IntechOpen. 2019. pp. 1-29

[11] DFT. Production, value and utilization for whole inland fishery and whole marine fishery of Thailand. 2018. Available from: https://www4.fisheries. go.th/index.php/dof_en/view_role/11

[Accessed: 1 August 2019]

[12] Rawdkuen S, Vanabu A, Benjakul S. Recovery of proteases from the viscera of farmed giant catfish (Pangasianodon gigas) by three-phase partitioning. Process Biochemistry. 2012;47(12):

2566-2569

[13] Vannabun A, Ketnawa S, Phongthai S, Benjakul S, Rawdkuen S. Characterization of acid and alkaline proteases from viscera of farmed giant catfish. Food Bioscience. 2014;6:9-16

[14] Kangsanant S, Murkovic M, Thongraung C. Antioxidant and nitric oxide inhibitory activities of tilapia (Oreochromis niloticus) protein hydrolysate: Effect of ultrasonic pretreatment and ultrasonic-assisted enzymatic hydrolysis. International Journal of Food Science \& Technology. 2014;49(8):1932-1938

[15] Rawdkuen S, Sai-Ut S, Benjakul S. Properties of gelatin films from giant catfish skin and bovine bone: A comparative study. European Food Research and Technology. 2010;231(6): 907-916 
[16] Rawdkuen S, Thitipramote N, Benjakul S. Preparation and functional characterisation of fish skin gelatin and comparison with commercial gelatin. International Journal of Food Science and Technology. 2013;48(5):1093-1102

[17] Sai-Ut S, Benjakul S, Sumpavapol P, Kishimura H. Antioxidant activity of gelatin hydrolysate produced from fish skin gelatin using extracellular protease from Bacillus amyloliquefaciens H11.

Journal of Food Processing and Preservation. 2015;39(4):394-403

[18] Sai-Ut S, Jongjareonrak A, Rawdkuen S. Re-extraction, recovery, and characteristics of skin gelatin from farmed giant catfish. Food and Bioprocess Technology. 2012;5(4): 1197-1205

[19] Ketnawa S, Benjakul S, Ling TC, Martínez-Alvarez O, Rawdkuen S. Enhanced recovery of alkaline protease from fish viscera by phase partitioning and its application. Chemistry Central Journal. 2013;7(1):79

[20] Ketnawa S, Benjakul S, MartínezAlvarez O, Rawdkuen S. Fish skin gelatin hydrolysates produced by visceral peptidase and bovine trypsin: Bioactivity and stability. Food Chemistry. 2017;215:383-390

[21] Ketnawa S, Martínez-Alvarez O, Benjakul S, Rawdkuen S. Gelatin hydrolysates from farmed giant catfish skin using alkaline proteases and its antioxidative function of simulated gastro-intestinal digestion. Food Chemistry. 2016;192:34-42

[22] Ketnawa S, Martínez-Alvarez O, Gómez-Estaca J, del Carmen GómezGuillén M, Benjakul S, Rawdkuen S. Obtaining of functional components from cooked shrimp (Penaeus vannamei) by enzymatic hydrolysis. Food Bioscience. 2016;15:55-63
[23] Terzioğlu P, Öğüt H, Kalemtaş A. Natural calcium phosphates from fish bones and their potential biomedical applications. Materials Science and Engineering: C. 2018;91:899-911

[24] Benjakul S, Mad-Ali S, Senphan T, Sookchoo P. Biocalcium powder from precooked skipjack tuna bone:

Production and its characteristics. Journal of Food Biochemistry. 2017; 41(6):e12412

[25] Permpoon J, Theinhom L, Rawdkuen S. Food seasoning powder supplemented with fish bone. Journal of Food Science and Agricultural Technology. 2016;2:1-7

[26] Caruso G. Fishery wastes and byproducts: A resource to be valorised. Journal of Fisheries Sciences. 2016; 10(1):12

[27] Ghaly AE, Ramakrishnan VV, Brooks MS, Budge SM, Dave D. Fish processing wastes as a potential source of proteins, amino acids, and oils: A critical review. Journal of Microbia and Biochemical Technology. 2013;5(4): 107-129

[28] Rustad T, Storrø I, Slizyte R. Possibilities for the utilisation of marine by-products. International Journal of Food Science \& Technology. 2011; 46(10):2001-2014

[29] Gómez-Guillén MC, Giménez B, López-Caballero ME, Montero MP. Functional and bioactive properties of collagen and gelatin from alternative sources: A review. Food Hydrocolloids. 2011;25(8):1813-1827

[30] Jongjareonrak A, Rawdkuen S, Chaijan M, Benjakul S, Osako K, Tanaka M. Chemical compositions and characterisation of skin gelatin from farmed giant catfish (Pangasianodon gigas). LWT-Food Science and Technology. 2010;43(1):161-165 
[31] Widyasari R, Rawdkuen S.

Extraction and characterization of gelatin from chicken feet by acid and ultrasound assisted extraction. Food and Applied Bioscience Journal. 2014;2(1): 85-97

[32] Kaewprachu P, Osako K, Benjakul S, Tongdeesoontorn W, Rawdkuen S. Biodegradable protein-based films and their properties: A comparative study. Packaging Technology and Science. 2016;29(2):77-90

[33] Kaewprachu P, Ben Amara C, Oulahal N, Gharsallaoui A, Joly C, Tongdeesoontorn W, et al. Gelatin films with nisin and catechin for minced pork preservation. Food Packaging and Shelf Life. 2018;18:173-183

[34] Kaewprachu P, Osako K, Benjakul S, Rawdkuen S. Quality attributes of minced pork wrapped with catechinlysozyme incorporated gelatin film. Food Packaging and Shelf Life. 2015;3: 88-96

[35] Putsakum G, Lee DS, Suthiluk P, Rawdkuen S. The properties of gelatin film-neem extract and its effectiveness for preserving minced beef. Packaging Technology and Science. 2018;31(9): 611-620

[36] Kaewprachu P, Osako K, Benjakul S, Suthiluk P, Rawdkuen S. Shelf life extension for Bluefin tuna slices (Thunnus thynnus) wrapped with myofibrillar protein film incorporated with catechin-Kradon extract. Food Control. 2017;79:333-343

[37] Vichasilp C, Sai-Ut S, Benjakul S, Rawdkuen S. Effect of longan seed extract and BHT on physical and chemical properties of gelatin based film. Food Biophysics. 2014;9(3): 238-248

[38] Sai-Ut S, Benjakul S, Rawdkuen S. Retardation of lipid oxidation using gelatin film incorporated with longan seed extract compared with BHT.

Journal of Food Science and

Technology. 2015;52(9):5842-5849

[39] Rawdkuen S, Suthiluk P,

Kamhangwong D, Benjakul S.

Mechanical, physico-chemical, and

antimicrobial properties of gelatin-

based film incorporated with catechin-

lysozyme. Chemistry Central Journal.

2012;6:131-140

[40] Kaewprachu P, Rungraeng N, Osako K, Rawdkuen S. Properties of fish myofibrillar protein film incorporated with catechin-Kradon extract. Food Packaging and Shelf Life. 2017;13:56-65

[41] Malde MK, Bügel S, Kristensen M, Malde K, Graff IE, Pedersen JI. Calcium from salmon and cod bone is well absorbed in young healthy men: A double-blinded randomised crossover design. Nutrition \& Metabolism. 2010;7: 61-61

[42] Ketnawa S, Chaiwut P, Rawdkuen S. Aqueous two-phase extraction of bromelain from pineapple peels ('Phu Lae' cultv.) and its biochemical properties. Food Science and Biotechnology. 2011;20(5):12-19

[43] Ketnawa S, Chaiwut P, Rawdkuen S. Extraction of bromelain from pineapple peels. Food Science and Technology International. 2011;17(4):395-402

[44] Ketnawa S, Chaiwut P, Rawdkuen S. Pineapple wastes: A potential source for bromelain extraction. Food and Bioproducts Processing. 2012;90(3):385-391

[45] Ketnawa S, Rawdkuen S. Application of bromelain extract for muscle foods tenderization. Food and Nutrition Sciences. 2011;2(5):393

[46] Sai-Ut S, Benjakul S, Kraithong S, Rawdkuen S. Optimization of antioxidants and tyrosinase inhibitory activity in mango peels using response 
surface methodology. LWT-Food

Science and Technology. 2015;64(2): 742-749

[47] Chaiwut P, Pintathong P, Rawdkuen S. Extraction and threephase partitioning behavior of proteases from papaya peels. Process

Biochemistry. 2010;45(7):1172-1175

[48] Rawdkuen S, Sai-Ut S, Benjakul S. Optimizing the tyrosinase inhibitory and antioxidant activity of mango seed kernels with a response surface methodology. Food Analytical Methods. 2016;9(11):3032-3043

[49] Torres-León C, Rojas R, ContrerasEsquivel JC, Serna-Cock L, BelmaresCerda RE, Aguilar CN. Mango seed: Functional and nutritional properties. Trends in Food Science \& Technology. 2016;55:109-117

[50] Kittiphoom S. Utilization of mango seed. International Food Research Journal. 2012;19(4):1325-1335

[51] Agatonovic-Kustrin S, Kustrin E, Morton DW. Phenolic acids contribution to antioxidant activities and comparative assessment of phenolic content in mango pulp and peel. South African Journal of Botany. 2018;116: 158-163

[52] Rawdkuen S, Murdayanti D, Ketnawa S, Phongthai S. Chemical properties and nutritional factors of pressed-cake from tea and sacha inchi seeds. Food Bioscience. 2016;15:64-71

[53] Rawdkuen S, Rodzi N, Pinijsuwan S. Characterization of sacha inchi protein hydrolysates produced by crude papain and Calotropis proteases. LWT-Food Science and Technology. 2018;98:18-24

[54] Alauddina M, Islama J, Shirakawaa H, Kosekib T, Komaia AM. Rice Bran as a Functional Food: An Overview of the Conversion of Rice
Bran into a Super Food and Functional

Food, Rijeka, Croatia. InTechOpen; 2017

[55] Phongthai S, Homthawornchoo W, Rawdkuen S. Preparation, properties and application of rice bran protein: A review. International Food Research Journal. 2017;24(1):25-34

[56] Zhang HJ, Zhang H, Wang L, Guo XN. Preparation and functional properties of rice bran proteins from heat-stabilized defatted rice bran. Food Research International. 2012;47(2): 359-363

[57] Bernardi S, Corso MP, Baraldi IJ, Colla E, Canan C. Obtaining concentrated rice bran protein by alkaline extraction and stirringoptimization of conditions. International Food Research Journal. 2018;25(3):1133-1139

[58] Phongthai S, D'Amico S, Schoenlechner R, Rawdkuen S. Comparative study of rice bran protein concentrate and egg albumin on glutenfree bread properties. Journal of Cereal Science. 2016;72:38-45

[59] Wang C, Li D, Xu F, Hao T, Zhang M. Comparison of two methods for the extraction of fractionated rice bran protein. Journal of Chemistry. 2014;10:1-10

[60] Wang C, Xu F, Li D, Zhang M. Physico-chemical and structural properties of four rice bran protein fractions based on the multiple solvent extraction method. Czech Journal of Food Sciences. 2016;33(3):283-291

[61] Chee FL, Iqbal S, Ismail M. Effects of supercritical fluid extraction conditions on yield of protein from defatted rice bran. Journal of The Chemical Society of Pakistan. 2013; 35(1):192

[62] Phongthai S, Lim ST, Rawdkuen S. Optimization of microwave-assisted 
extraction of rice bran protein and its hydrolysates properties. Journal of Cereal Science. 2016;70:146-154

[63] Phongthai S, Lim ST, Rawdkuen S. Ultrasonic-assisted extraction of rice bran protein using response surface methodology. Journal of Food Biochemistry. 2017;41(2):1-11

[64] Phongthai S, D'Amico S, Schoenlechner R, Homthawornchoo W, Rawdkuen S. Fractionation and antioxidant properties of rice bran protein hydrolysates stimulated by in vitro gastrointestinal digestion. Food Chemistry. 2018;240:156-164

[65] Fabian C, Ju YH. A review on rice bran protein: Its properties and extraction methods. Critical Reviews in Food Science and Nutrition. 2011;51(9): 816-827

[66] Patsanguan S, Hisaranusorn N, Phongthai S, Rawdkuen S. Rice bran protein isolates: Preparation and their physico-chemical and functional properties. Food and Applied Bioscience Journal. 2014;2(3):169-182

[67] Phongthai S, D’Amico S, Schoenlechner R, Homthawornchoo W, Rawdkuen S. Effects of protein enrichment on the properties of rice flour based gluten-free pasta. LWTFood Science and Technology. 2017;80: 378-385

[68] Bedin S, Netto FM, Bragagnolo N, Taranto OP. Reduction of the process time in the achieve of rice bran protein through ultrasound-assisted extraction and microwave-assisted extraction. Separation Science and Technology. 2019;1:1-14

[69] Bandyopadhyay K, Chakraborty C, Barman AK. Effect of microwave and enzymatic treatment on the recovery of protein from Indian defatted rice bran meal. Journal of Oleo Science. 2012;

61(10):525-529 


\title{
Valorization of Food Processing By-Products as Smart Food Packaging Materials and Its Application
}

\author{
Saroat Rawdkuen and Pimonpan Kaewprachu
}

\begin{abstract}
Traditional food packaging systems cannot provide any information related to the food quality during storage to consumers. Recently, the renewable resources have been considered as starting materials for making biodegradable packaging film. A variety of food processing by-products have been utilized, either alone or in mixtures, to produce packaging films with proper properties. It shows high possibility for smart biodegradable filmmaking as well as is applicable in the food industry. In order to monitor the food quality and to reduce the food loss and waste, a new packaging technology has been increasingly developed. Smart packaging refers to packaging systems which can monitor, detect, and inform about the qualities of food in real time. Indicator is the most commonly used device, which can communicate through direct visual change, especially in color. Natural extract and synthetic color are usually added into smart packaging films. However, synthetic dyes may be harmful to the consumers' health. Thus, the use of natural extract has been increased. Smart packaging films can be applied to various types of food products in order to monitor the food quality during transportation and storage. Thus, smart packaging could be used as a nondestructive tool to detect the food quality.
\end{abstract}

Keywords: biodegradable, by-products, food packaging, indicators, natural extract, smart films, valorization

\section{Introduction}

Nowadays, the food industry is continuously growing due to increasing levels of population and globalization and is providing a wide variety of food products to meet customer needs. The major food industries of the world include meat, poultry, fish and seafood, fruits and vegetables, dairy, and cereal. During food processing, a large number of by-products are thrown away into the environment, resulting in accumulation in the environment, and may also interfere with natural process of ecosystem. According to the FAO, 1.3 billion tons of foods are by-products. The global food losses and waste are strongly dependent on the kind of foods. The highest percentage of by-product is found in fruits and vegetables, plus roots and tubers (45\%), followed by fish and seafood (35\%), oilseed, meat, and dairy (20\%), 
respectively [1]. In developing countries, food waste is generally generated at postharvest and processing levels at around $40 \%$, while in industrialized countries, the sector contributing a huge by-product (more than $40 \%$ ) is households [1]. These by-products still contain the organic matter that have a potential for making the packaging or developing new valuable products from them for commercial applications. Thus, valorization of food processing products is an interesting concept that offers sustainability rather than landfilling or disposal.

Traditional food packaging has a role to protect the packaged food from mechanical damage and physical stress, communicate with the consumers, provide convenience, and contain the product [2]. This packaging system cannot monitor the quality of packaged food products and inform the status of environment and food conditions to the consumers at any time and cannot meet the consumer preferences. Thus, a new packaging technology has been developed and also proposed with the aim to reduce the food loss and waste throughout the food supply chain. Thus, smart packaging or intelligent packaging concept has been raised, which is considered as innovative packaging. According to EC [3], intelligent materials and articles are materials and articles which monitor the condition of packaged food products or the surrounding environment of the food. Yam [4] defined intelligent packaging (also described as smart packaging) as a packaging system that used to monitor the condition that the packaged food product is exposed to and provide information about the packaged food quality to the consumers through the visual color changes.

Generally, there are three main types of smart packaging, which include sensors, indicators, and radio-frequency identification (RFID) devices [5]. Food spoilage or fermentation process is commonly accompanied with a $\mathrm{pH}$ change. Thus, $\mathrm{pH}$ indicator has gained much popularity, compared with others. Thus, $\mathrm{pH}$ indicator generally comprises a dye that changes in color in a function of $\mathrm{pH}$. There are two main sources of indicators: chemical dye and natural extract. Chemical dyes include methyl red, methyl orange, bromothymol blue, bromocresol green, phenol red, and their combinations. A natural dye can be obtained from the root, flower, leaves of plants, and other parts of plant materials that contain a natural pigment, such as anthocyanins. The advantage of natural dye is safety and being eco-friendly to the consumers, compared to chemical dye. Thus, the natural dye has been increasingly used in smart packaging. These indicators can interact with the internal (metabolites in the head space and food components) and/or external factors (environmental surrounding). As a result of this reaction, they generate the response through the color changes or electrical signal and depend on types of intelligent packaging, which relate to the actual status of packaged food product. Thus, the use of smart packaging could help to decrease the number of food loss and waste by sensing or communicating the actual quality of the packaged food product to the consumer in real time through visible color changes.

Smart packaging has been widely applied on various types of food products [6-9]. The use of these packaging systems could facilitate the consumers to know the quality and the condition of packaged food (food spoilage, ripeness, or degree of fermentation) without damaging the package. From the food quality and safety point of view, smart packaging is very useful to the producers, sellers, and consumers to give information regarding the packaged food condition through a change of tools. In this context, the valorization of food processing by-products to produce packaging films is reviewed. The principle and types of smart/intelligent packaging are presented. The current researches on the applications of smart packaging on various kinds of food products are also discussed. 


\section{Valorization of food processing by-products}

A large amount of food materials as by-products, which are generated along the chain of food production and transformation, are thrown into the environment. Food processing by-products generally include the residues or remain that were discarded after removing the desirable portion for further processing or direct consumption as food. According to Ezejiofor et al. [10], residues from food processing make up $30-60 \%$ of the product that is used for human consumption and animal feeding. Most of the by-products commonly contain an organic component, such as proteins, carbohydrates, and lipids, which are promising sources of value-added substances that can be extracted and utilized as a starting material for forming a smart packaging film. The different types of by-products produced by various food processing industries are listed in Table 1. Current trends in the world are to recover and utilize the food processing by-products into useful materials and to recycle by-products as a means of achieving goal of sustainable development. Hence, considerable efforts in the valorization of food processing by-products have been made with the purpose of minimizing the amounts of by-products, reducing the environment pollution, and increasing sustainability of these by-products. This section reviews by-products from various food processing industries that have a potential to be produced as smart packaging.

\subsection{Meat and poultry processing by-products}

The meat processing industry has emerged as a major food industry of the world. As per the FAO [11], the world pork meat production recorded 118 million tons, followed by poultry (117 million tons), sheep ( 9 million tons), and goat ( 5 million tons). A huge by-product is generated during the various stages of meat and poultry processing in industries. By-products generated during processing of large animals include the skin (6-10\% of live weight), bones (15-20\% of live weight), blood (3-9\% of live weight), fat (3-4\% of live weight), head (6-8\% of live weight), and viscera (10-15\% of live weight), while poultry by-products include the bones (8-10\% of live weight), blood (3-5\% of live weight), feather (5-7\% of live weight), liver and heart (4-6\% of live weight), and viscera (18-20\% of live weight) [12]. Valorization of these by-products is a current trend concept for promoting the sustainable development. However, high value-added by-products from the meat and poultry industries are not exploited to its full potential when compared to the by-products from other industries such as fruits, vegetables, dairy, etc.

In general, humans will not consume bones; hence they are disposed into the environment. They are commonly used for animal feeding. However, bones and skin by-products obtained from meat and poultry are important source of proteins, which can be extracted as collagen and gelatin. Gelatin is a soluble protein obtained by degradation of collagen, which is commonly found in animal skin, bones, and connective tissue. Gelatin from poultry is an alternative source

\begin{tabular}{ll}
\hline Food processing industries & Generated by-products \\
\hline Meat and poultry & Skin, bones, blood, head, feather, viscera \\
\hline Fish and seafood & Skin, viscera, heads, backbones, blood, shells \\
\hline Dairy product & Whey, lactose \\
\hline Fruits and vegetables & Peels, pulp, seeds \\
\hline Source: Ezejiofor et al. $[10]$. & \\
\hline
\end{tabular}

Table 1.

Various food processing industries and their by-products. 
for the halal and kosher market. They have many applications in food industry and have been extensively used as a raw material in packaging. Feathers are byproducts from industrial poultry production and are mostly discharged without any pretreatment, causing environmental problems. Chicken feather can be considered as attractive sources for the production of packaging films. Proteins $(91 \%)$, lipids $(1 \%)$, and water $(8 \%)$ are the main components in chicken feathers [13]. Keratins are proteins found in chicken feathers. Thus, keratins from chicken feather protein are abundant and a cheap source, can be utilized as edible film material, and can reduce the environment pollution related to the by-products disposed by the processing industries.

\subsection{By-products from fish and seafood processing}

The industrial fish and seafood processing generates huge amounts of nonedible parts, which are discarded. According to Olsen et al. [14], fish and seafood by-products contribute to around $70 \%$ of the initial weight of the catch. Fish and seafood by-products generally contained valuable components such as oil, enzymes, collagen, gelatin, chitin, chitosan, and muscle protein. These valuable compounds have a high potential for using in food, packaging, pharmaceutical, medicine, and other industries. Some of these components from fish and seafood by-products have been isolated and currently sold commercially. The composition and the percentage of nonedible parts of fish and seafood processing are greatly dependent on fish and seafood types and processing methods. For example, by-products generated in finfish processing include the head (14-20\%), gut (15-20\%), skin (1-3\%), bones (10-16\%), and trimming (filets) (15-20\%), while shrimp generates $65-85 \%$ (wet weight basis) of by-products, which is mainly obtained from the head and shell [15].

A high value-added compound can be isolated from fish and seafood processing by-product, which include collage, gelatin, chitin, chitosan, etc. Some of these valuable compounds are able to be formed as packaging films [16], which can reduce the environmental pollution at the same time (films are biodegradable). Collagen is the main structural component, which is widely found in the skin, bone, tendon, and cartilage. Collagen and gelatin have a wide range of applications in various industries. Nowadays, collagen and gelatin extracted from fish and seafood by-products have gained great attention due to the requirement of "halal and kosher" food products and the consumers' concern about bovine spongiform encephalopathy in collagen and/or gelatin from mammals [17-19]. Thus, fish and seafood processing by-products are one of the most important sources of marinederived collagen and gelatin.

The crustacean by-products contain chitin content between 2 and $75 \%$, which are dependent on composition, processing methods, and their species [20]. Chitin possesses repeating units of poly- $\beta-(1,4)-N$-acetyl-D-glucosamine (Figure 1). It is the second most abundant natural polysaccharide on earth, after cellulose [21]. It is widely distributed in the nature as a structural polymer in the exoskeleton of insects and crustaceans, which is an important source for chitin industry. Chitin is insoluble in water and even in most organic solvents due to being highly hydrophobic [21]. Chitosan is the $N$-deacetylated derivative of chitin. On the other hand, chitosan is soluble in water, which makes it more convenient to use in different fields. Due to being biodegradable, nontoxic, and biocompatible, chitin and chitosan, which are an agent recovered from shellfish and/or crustacean processing by-products, have been recently found in various industrial applications such as antimicrobial agent, packaging films, pharmaceutical, cosmetic, etc. 


\subsection{Dairy processing by-products}

Dairy processing generates enormous volume of by-products during the processing of milk and manufacture of varied products. These by-products are comprised of high amounts of lipids, proteins, vitamin, etc. The utilization of these by-products can hugely enhance dairy sector profitability. Whey, being a major by-product of the dairy industry, is generated during the manufacturing of cheese. It contains high amounts of proteins which can be converted into various whey protein products, including whey protein concentrates (WPC) and whey protein isolate (WPI). WPC contains $25-85 \%$ protein, while WPI contains $>90 \%$ protein. The pretreatment prior to membrane separation and the membrane used typically affects the whey protein content [22]. Thus, the whey protein obtained has potential for use in the packaging and food industries such as protease inhibitor in surimi processing [23].

\subsection{Fruit and vegetable by-products}

The total worldwide annual production of fruit was reported to be more than 892 million metric tons in 2016 [11]. During fruit and vegetable processing, enormous numbers of peel, pulp, and seed are generated which are disposed into the environment. These by-products represent approximately $30-50 \%$ of the total weight, which can affect the environment and health sectors, due to their methane emissions and biodegradability [10]. These by-products are commonly utilized as animal feed; however, they still comprise of huge amounts of organic components such as polysaccharides, proteins, lipids, and other aliphatic and aromatic compounds. Thus, these by-products can be further utilized or extracted as high-value substance and can be used as alternative sources with a high potential for the development of new packaging technologies.

Banana (Musa paradisiaca L., Musaceae) is the most important fruit crop, with a global annual production of 113 million tons in 2016 [11]. Banana peels are usually discarded during the banana processing or used in the form of animal feed. Peels, by-products from banana, can represent $40 \%$ of the total weight [24]. However, this by-product is considered as a good and cheap source of valuable compounds. Moreover, a huge amount of banana that does not meet the standard exportation is obtained. The whole banana is a good source of polysaccharide, especially starch. Unripe banana generally contains starch more than $70 \%$ with other components (protein, fiber, and lipid) [25]. Banana starch and flour have been used as a starting material to form edible films $[25,26]$.

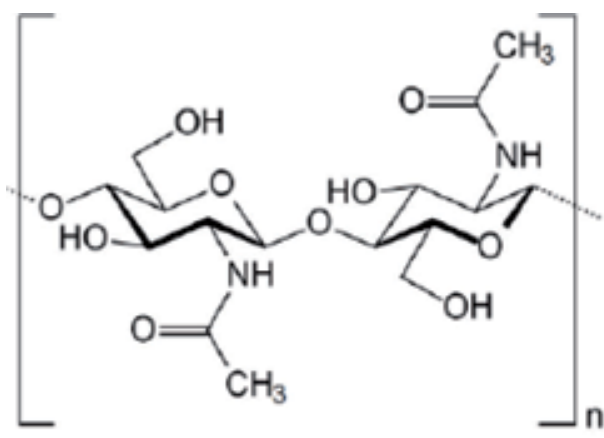

Chitin

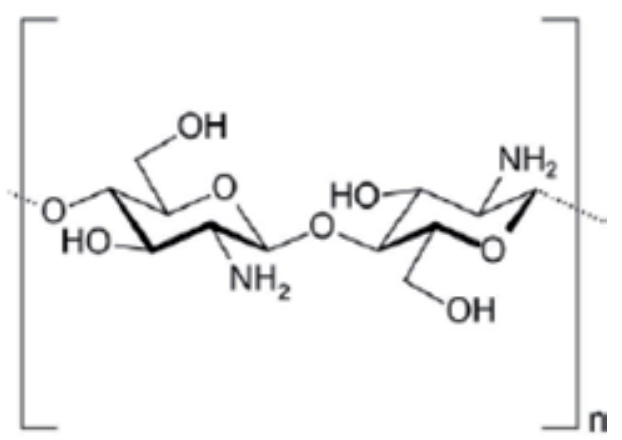

Chitosan

Figure 1.

Chemical structure of chitin and chitosan. 
Mango (Mangifera indica L., Anacardiaceae) is the most important fruit in the tropical region, especially in Thailand. The major by-products of industrial mango processing are peels and kernels which represent about $35-60 \%$ of the total fruit weight [27]. Mango kernels are promising sources of edible oil, starch, flour, and essential amino acids [27-29]. Mango peels have been reported as a good source of pectin, which is considered a high-quality dietary fiber [27]. Thus, pectin extracted from mango peels has a potential for developing packaging films.

Rice (Oryza sativa) is one of the most common foods that people usually consume around the world. According to the FAOSTAT database, the worldwide annual production of rice was over 740 million tons in 2016 [11]. Rice milling process is required to remove unwanted material, prior to cooking. After rice milling process, $70 \%$ rice is obtained, while rice hull (20\%), rice bran ( $8 \%)$, and rice germ ( $2 \%)$ are the by-products [24]. However, some amount of broken rice also occurred during milling process. Broken rice is a good source of starch and flour and can be used to produce as rice starch/flour films. Rice bran is a rich source of fat, protein, carbohydrate, vitamins, minerals, and antioxidants [30]. Rice bran has a potential to produce packaging film; however, it is very scarce to use rice bran as a starting material for film production.

According to the FAOSTAT database, the worldwide annual production of soybean was over 334 million tons in 2016 [11]. Soybean is the most important of legume crops. Soy protein resin is obtained from soybean harvesting and processing as by-products. Soy protein is typically categorized as soy flour (50-59\% protein), soy protein concentrate (SPC) (65-72\% protein), and soy protein isolate (SPI) (>90\% protein) [31]. They are widely used as a starting material to form film due to their abundant, biodegradable, cheap, functional properties and high nutritional quality. Thus, the utilization of soy protein in packaging technology can provide a value to soybean by creating a new route for the marketing of soy protein materials.

\section{Intelligent packaging}

\subsection{Principle}

According to EC [3], intelligent materials and articles are materials and articles which monitor the condition of packaged food products or the surrounding environment of the food. Intelligent packaging refers to packaging materials that provide a total packaging solution and monitor changes in the quality of product or its environment [32]. Poças et al. [33] defined smart or intelligent packaging as a packaging system that is associated with communication. Intelligent packaging can also be defined as the packaging material that contains the communication functions for recording the internal and external environment changes and then inform the users about the packaged food product's status [4].

This packaging system utilizes a variety of sensors or indicators to detect the quality and safety of packaged food products and may inform the product's status and/or environment condition to the producers, retailer, or consumer at any given time. Food freshness, $\mathrm{pH}$ level, microbial growth, gas (carbon dioxide: $\mathrm{CO}_{2}$ and oxygen: $\mathrm{O}_{2}$ ) in the package headspace, time or temperature are an example of sensors or indicators. Smart packaging concepts and types including sensors, i.e., gas sensor and biosensor; indicators, i.e., freshness indicators, time-temperature indicators (TTI), and gas indicators; and radio-frequency identification devices are described in this chapter. 


\subsection{Sensors}

Many smart or intelligent packaging concepts involve the use of sensors. This system is generally used in terms of a combination of sensors with packaging technique such as modified atmosphere (MAP) and vacuum packaging. Kerry [5] defined sensors as a small device that used to detect, locate or quantify energy or matter, giving a signal for the detection or measurement of a physical or chemical property to which the device responds. To qualify as a sensor, a device must provide continuous output of a signal. Most sensors commonly comprise of two basic functional parts, a receptor and a transducer. In the receptor, physical or chemical information is transformed into an energy form, which may be detected by a transducer. The transducer is a device capable of transforming the energy carrying the physical or chemical information about the sample into the signal [5].

\subsubsection{Gas sensors}

Gas sensors are devices that respond to the presence of a gaseous analyte by changing the physical parameters of the sensor and are monitored by external devices [34]. It includes organic conducting polymers, metal-oxide-semiconductor field-effect transistors, potentiometric carbon dioxide sensors, piezoelectric crystal sensors, and amperometric oxygen sensors [5]. Systems commonly contained a solid-state material, which operate on the principle of luminescence quenching or absorbance changes caused by direct contact with the gas analyte [34]. Optochemical sensor based on gas-phase protonated tetraphenylporphyrin (TPP) was developed by Tuerdi et al. [35]. This system was used for detecting volatile amines (ammonia, $\mathrm{NH}_{3}$ ). The authors concluded that this sensor could detect $\mathrm{NH}_{3}$ gas at very low levels $(0.1 \mathrm{ppm})$. Thus, this system is a noninvasive technique, has high sensitivity and fast response-recovery times for gas analysis, and is potentially suitable for applications as smart packaging.

\subsubsection{Biosensor}

Yam et al. [2] defined biosensors as compact analytical devices that are used for detecting, recording, and transmitting information to biological reactions. Biosensors usually comprise of the bioreceptors and transducers [5]. The bioreceptors, including organic or biological materials (enzyme, hormone, microbes, etc.), recognize a target analyte. The transducers, such as electrochemical, acoustic, or optical, can convert biological signals into quantifiable electronic response [2] . Chemiluminescence biosensor for the detection of putrescine (biogenic amines) in meat product was developed by Omanovic-Miklicanin and Valzacchi [36] by covering the Co(II) and enzyme (putrescine oxidase or diamine oxidase) onto glass supports with hydroxyethyl cellulose membrane. Recently, biosensors based on heme entrapped in recombinant silk film on a glass carbon electrode modified with multiwalled carbon nanotubes for detecting nitric oxide (NO) at nanomolar levels in the presence and absence of oxygen were prepared by Musameh et al. [37]. This system should have high sensitivity, accuracy, precision, and stable detection of analyte.

\subsection{Indicators}

Indicators may also be defined as a substance that indicates the absence or presence of another substance or the degree of reaction between two or more substances by means of characteristic changes, especially in color [34]. The difference between 
sensors and indicators is the components; indicators do not contain receptor and transducer components as the sensor, so it provides qualitative information through directly visible color change. According to Smolander [38], changes in color of $\mathrm{pH}$ dye indicator can be proposed to investigate acidic and/or basic volatile compounds and provide an irreversible color change in an appearance.

\subsubsection{Freshness indicators}

Freshness indicators are devices that are printed on the packaging film or in the form of a package label and then attached inside the packaging materials. Freshness indicators have been developed with the aim of investigating the food spoilage process, degree of fermentation, or ripening stage of fruits and vegetables and then informing the users about the freshness of packaged goods through color changes that can be directly detected by the naked eye. Freshness indicators provide direct information of the packaged food quality resulting from chemical changes or microbial growth within a food product. Indicator may react to metabolites that are generated in the package as a result of metabolism or the microbial growth [34]. Freshness indicator concepts based on $\mathrm{pH}$ sensing film, using $\mathrm{CO}_{2}$ as the major target, have been reported [39]. Besides $\mathrm{CO}_{2}$, also other metabolites like the volatile compounds trimethylamine (TMA), dimethylamine (DMA), and ammonia, collectively known as TVB-N; biogenic amines such as histamine, putrescine, tyramine, and cadaverine; ethanol; sulfuric compounds; and organic acids have been studied as suitable target molecules for these $\mathrm{pH}$ sensing indicators [34]. It can sense and share information to the producer, retailer, or consumer at any time. Thus, the development of freshness indicator is based on a broad knowledge of quality-related metabolites closely related to product types, packaging material, the growth of microorganisms, and storage condition.

Various kinds of freshness indicators have been developed [40-43]. Freshness indicators are normally comprised of food spoilage and ripeness indicators [44]. Food spoilage indicators commonly investigate the spoilage of food due to the chemical changes, microbial growth, temperature abuse, or packaging leakage. The concepts for food spoilage indicators are based on changes in color indicator which response to microbial metabolites produced during spoilage process. Ripeness indicators are mostly used in fruit and some kind of vegetable product. However, this indicator is suitable for climacteric fruit rather than non-climacteric fruit because after harvest they still continue to ripen which is easily detected by indicators. During fruit ripening, there are many changes that occur such as loss of chlorophyll; ethylene production; conversion of starch to sugar; aroma development; changes in organic acids, proteins, and fats; etc. [33]. Changes in color indicator can help the consumers to decide the product when these fruits are fully mature, ripen, and ready to eat, e.g., durian, mango, and banana $[7,40]$. However, freshness indicator has a disadvantage; it provides the broad-spectrum color change, which needs to be resolved before being used commercially.

Chen et al. [45] developed on-package indicator labels for the determination of lean pork freshness. The indicator label was based on methylcellulose immobilized with mixed dye (bromothymol blue/methyl red, 3:2). These labels were used to monitor freshness of pork at $5^{\circ} \mathrm{C}$ for 8 days. The indicator label presented visual color changes due to the presence of volatile compound (TVB-N) and aerobic plate counts. The authors reported that the colorimetric freshness indicator was able to recognize fresh (0-3 days) (red), medium fresh (4-5 days) (goldenrod), and spoiled stage (6-8 days) (green). Therefore, the indicator labels could be used 
to monitor the real-time pork freshness as intelligent packaging tool and could enhance the guarantee of pork safety.

\subsubsection{Time-temperature indicators}

Meng et al. [6] defined time-temperature indicators (TTI) as a small device placed on a product or package that can be used to record, monitor, and indicate the time-temperature history on the quality of perishable product during the cold chain transportation and storage from the point of producer to the end consumer. Temperature is a critical factor influencing the food quality and safety during retail outlet or distribution and storage. The temperature history of packaged food is very difficult to control and monitor; thus, it is difficult to predict their shelf life. Thus, TTI can help to monitor and record the temperature condition during distribution and storage. The principle of TTI operation is based on chemical, enzymatic, mechanical, electrochemical, or microbiological change, generally expressed as a visible response in the form of a mechanical deformation, irreversible visible color development, or color change movement [46]. TTI should also be low-cost, reliable, with good stability, flexible to a wide range of temperatures, nontoxic, and easily integrated into a packaging material.

The TTI is useful because it can inform the consumers when the product has been temperature abused. If the temperature of the product is higher than the temperature recommended, the food quality can quickly deteriorate. TTI is mostly used in chilled or frozen foods, where the cold storage during distribution is important for food quality and safety. The role of developed system is to detect the quality changes by evaluating the $\mathrm{pH}$ alteration of the packaged foods during transportation and storage. Different kinds of food material will be stored at different temperatures; the system had the ability to detect temperature changes indirectly with the help of variation of $\mathrm{pH}$ of the food products, which occurred due to the improper temperature for the transportation and storage. Recently, a prototype diffusion-based TTI has been developed by Suppakul et al. [47]. A polydiacetylene (PDA) $/ \mathrm{SiO}_{2}$ nanocomposite was used as the color-developing substance and loaded on the diffusion path. Tween 20 was used as a moving substance. The authors said that when Tween 20 reached the test line of the $\mathrm{PDA} / \mathrm{SiO}_{2}$ nanocomposite, the color of the line changed from blue to red, indicating the TTI endpoint. Moreover, four TTIs were designed by matching the TTI endpoint with the deterioration time of food during storage at different temperatures $\left(5,10,15\right.$, and $\left.25^{\circ} \mathrm{C}\right)$. When diffusionbased TTI was applied on the tested food, the line of the $\mathrm{PDA} / \mathrm{SiO}_{2}$ nanocomposite was matched to the shelf life of the tested food during storage.

\subsubsection{Gas indicators}

It is very difficult to assess the packaged food quality because of many factors such as the production of gas by microorganisms within the package, changing concentration of gas and gas leakage from outside or inside of the packaging materials, or continuing fruit and vegetable respiration. Thus, gas indicators have been developed to solve these problems. Gas indicators, commonly produced in the form of label, are attached inside the food package for monitoring the changes of the level of gas, such as $\mathrm{O}_{2}$ and $\mathrm{CO}_{2}$, and then provide information through visual color changes [48]. A mixed $\mathrm{pH}$ dye-based indicator was developed for checking their ability of changes in color at different concentrations of $\mathrm{CO}_{2}(10-80 \%)$ [48]. This indicator is relatively sensitive to the change of $\mathrm{CO}_{2}$ level by changing the color from blue to green when the $\mathrm{CO}_{2}$ level increased. The principle of gas indicators 
( $\mathrm{pH}$ dye-based) was explained by Puligundla et al. [49]. $\mathrm{CO}_{2}$ generally dissolves in an aqueous solution and then forms carbonic acid $\left(\mathrm{H}_{2} \mathrm{CO}_{3}\right) . \mathrm{H}_{2} \mathrm{CO}_{3}$ dissociates into hydrogen ions $\left(\mathrm{H}^{+}\right)$and bicarbonate ions $\left(\mathrm{HCO}_{3}{ }^{-}\right)$. Then, $\mathrm{H}^{+}$, as a proton, combines with a water molecule to form a hydronium ion $\left(\mathrm{H}_{3} \mathrm{O}^{+}\right)$. This $\mathrm{H}_{3} \mathrm{O}^{+}$reacts with the basic (dissociated) form $\left(\mathrm{In}^{-}\right)$of the $\mathrm{pH}$ dye indicator, resulting in an acid (protonated) form (HIn) which in turn develops a color change in the indicator containing label [49].

\subsection{Radio-frequency identification devices}

RFID, a food traceability system, is a small device that can be attached to the product, so that the product could be identified and tracked in real time. It is commonly grouped under the form wireless automatic identification together with biometrics, magnetic inks, QR codes, barcode, etc. [32]. RFID tags mainly comprise of three components including a tag produced from a microchip linked to a small aerial, a reader capable of discharging radio signals and also accepting answers from the tag in response to the sent signals, and a network system or web server that connects the company and the RFID equipment [50]. There are three categories of RFID, which based on the power supply include passive RFID tags, semi-passive RFID tags, and active RFID tags [32]. This tool is suitable for the large-scale production network, such as food supply chains, which can control material flow and/or give information. It is typically used in order to reduce uncertainties in the food purchasing process by giving information about the whole process in terms of quality and safety.

\section{Sources of dye indicator}

The inclusion of dye indicator into packaging materials is a promising method for the development of smart packaging. Dyes can interact with stimulus; then the color changes are obtained, which can be observed by the naked eye. Color change of dye is cause of the electron at double bonds in the dyes able to absorb the energy at visible range wavelengths $(400-700 \mathrm{~nm})$. Difference structures of dye will absorb different wavelengths, which are related to their colorations. It is an organic or inorganic substance. Generally, there are two main sources of indicator: chemical dye and natural extract (Table 2). These components are widely used as coloring agent because they are sensitive to the condition change and are able to inform the packaged food conditions to the manufacturers and the end consumers. Food deterioration or fermentation process is mostly correlated with $\mathrm{pH}$ change. Thus, $\mathrm{pH}$ indicator dye-based colorimetric is a type of dye indicator that is widely added into materials.

\subsection{Chemical dye}

Most of the chemical dyes are made up of synthetic material, which may be toxic to the consumer and not suitable for use in food application. The commercially available chemical $\mathrm{pH}$ dye is mostly based on halochromic compound and belonged to sulfonephthalein dye and azo dye groups. Sulfonephthalein dyes include phenol red, bromophenol blue, bromocresol green, and bromothymol blue, and azo dye includes methyl red (Figure 2). These chemical dyes are widely used as $\mathrm{pH}$ dye indicator because they exhibit a clear color according to $\mathrm{pH}$. Change in color of $\mathrm{pH}$ dyes is due to a protonation/deprotonation reaction [64]. There are two forms of $\mathrm{pH}$ dye: Hln (acid form) and $\mathrm{In}^{-}$(basic form). Furthermore, the chemical $\mathrm{pH}$-sensitive dye is often limited in the $\mathrm{pH}$ range and showed very narrow color. For example, 
bromophenol blue has only two color transitions: yellow at $\mathrm{pH} 3$ and blue at $\mathrm{pH} 4.6$, and phenol red also exhibits two color transitions, yellow at $\mathrm{pH}$ below 6.4 and pink at $\mathrm{pH}$ above 8.0, which is difficult to observe by the naked eye. Thus, it needs to combine with other chemical dyes to enable $\mathrm{pH}$ indication [65]. Baek et al. [48] studied the combination of two chemical dye indicators at different ratios (methyl $\mathrm{red} /$ bromothymol blue; $1: 9,3: 7,5: 5,7: 3$, and 9:1). The authors suggested that the mixing of two dyes exhibited various color changes in a narrow $\mathrm{pH}$ range, compared to the methyl red alone or bromothymol blue alone. Therefore, the combination of two dyes has been widely used as chemical indicator [7, 39, 48, 52].

\subsection{Natural extract}

Nowadays, the consumers concern about the use of the chemical compounds in foods and some chemical substances that are not generally recognized as safe compounds and may be harmful to the consumers' health. Thus, natural extract is an alternative source of indicator that can be used instead of chemical dye. Anthocyanins are natural colorants and water-soluble pigments belonging to the flavonoids family. These pigment compounds are responsible for the color (red, purple, and blue) of plant leaves, flowers, grains, fruits, and vegetables. Changes in color of anthocyanins are mostly due to the presence of phenolic or conjugated compound. The structure of anthocyanins changes when there is a difference in $\mathrm{pH}$ values [66]. Thus, anthocyanins are compounds that are mostly used as natural $\mathrm{pH}$ dye indicator because it shows a broad color change in function of $\mathrm{pH}$. Color mechanism of anthocyanins can be described as illustrated in Figure 3, and the color chart of anthocyanins extracted from different sources of plants at different $\mathrm{pH}$ levels, compared to chemical dye (resazurin), is shown in Figure 4. Anthocyanins can be exhibited in different chemical structure forms depending on $\mathrm{pH}$. In acidic condition ( $\mathrm{pH} 1)$, intact structure forms of the flavylium cation (red color) are predominantly formed; at $\mathrm{pH}$ between

\begin{tabular}{lll}
\hline Sources & Indicators & References \\
\hline dye & Bromophenol blue & Zaragozá et al. [51], Chen et al. [52], Dirpan et al. \\
& & [40] \\
\cline { 2 - 3 } & Bromocresol green & Pirsa et al. [53] \\
\cline { 2 - 3 } & Methyl orange & Pirsa et al. [53] \\
\cline { 2 - 3 } & Methyl red & Niponsak et al. [7], Chen et al. [52] \\
\cline { 2 - 3 } & Phenol red & Kim et al. [54] \\
\cline { 2 - 3 } & Mixing methyl red and & Rukchon et al. [39], Niponsak et al. [7], Baek et al. \\
& bromothymol blue & [48], Chen et al. [52] \\
\cline { 2 - 3 } & Blueberry & Luchese et al. [55] \\
\cline { 2 - 3 } & Butterfly pea & Rawdkuen et al. [56] \\
\cline { 2 - 3 } & Grape & Ma and Wang [57] \\
\cline { 2 - 3 } & Mulberry & Ma et al. [58] \\
\cline { 2 - 3 } & Purple sweet potato & Liu et al. [59], Choi et al. [60], Yong et al. [61] \\
\cline { 2 - 3 } & Red cabbage & $\begin{array}{l}\text { Pereira et al. [8], Silva-Pereira et al. [62], } \\
\text { Pourjavaher et al. [63] }\end{array}$ \\
& Roselle & Zhai et al. [9] \\
\cline { 2 - 3 } & &
\end{tabular}

Table 2.

Example of dye indicator. 
<smiles>O=C1C=CC(=C(c2ccc(O)cc2)c2ccccc2[S+](=O)[O-])C=C1</smiles>

Phenol red yellow at $\mathrm{pH}<6.4$ red at $\mathrm{pH}>8.0$<smiles>O=S1(=O)OC(c2cc(Br)c(O)c(Br)c2)(c2cc(Br)c(O)c(Br)c2)c2ccccc21</smiles>

$$
\begin{gathered}
\text { Bromophenol blue } \\
\text { yellow at } \mathrm{pH}<3.0 \\
\text { blue at } \mathrm{pH}>4.6
\end{gathered}
$$<smiles></smiles>

Bromothymol blue yellow at $\mathrm{pH}<6.0$ blue at $\mathrm{pH}>7.6$<smiles>CN(C)c1ccc(/N=N/c2ccccc2C(=O)O)cc1</smiles>

\author{
Methyl red \\ red at $\mathrm{pH}<4.4$ \\ yellow at $\mathrm{pH}>6.2$
}

Figure 2.

Structural formulas of some chemical dye indicators used in indicator labels.

2 and 4, the quinoidal blue species are formed; at $\mathrm{pH}$ value between 5 and 6, only two colorless structures (a chalone and a carbine pseudobase) are formed; and in basic conditions $(\mathrm{pH}>7)$, the chemical structure forms are dependent on their substitution groups [67]. Therefore, anthocyanins can go through chemical changes due to $\mathrm{pH}$ variation. It can be successfully used as natural dye indicator for determining the food deterioration. Currently used extracted anthocyanins of some plants as natural indicator are shown in Table 2.

\title{
5. Applications of smart packaging films
}

The main purpose of packaging for fresh meat, poultry, fish, seafood, fruits and vegetables, etc. is to delay chemical, microbial, and biochemical changes, avoid contamination, reduce weight loss, and enhance overall product appearance to meet consumer expectations and preferences [34]. In general, food quality can be investigated through chemical analysis and microbiological evaluation. However, there are some quality attributes that need to alert the producers, retailers, or consumers during the whole supply chain. The qualities of the packaged food always change after processing or during distribution and 
Valorization of Food Processing By-Products as Smart Food Packaging Materials... DOI: http://dx.doi.org/10.5772/intechopen.86245

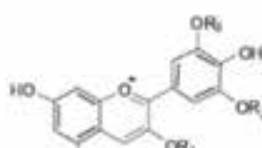

or<smiles>[C+]1CCCC[Al]1</smiles>

(A)<smiles></smiles>

OH $\mathrm{PII}$ ?

(B)<smiles>Cc1cc(-c2oc3cc(=O)ccc-3cc2O)cc(O)c1O</smiles>

or PII )<smiles>Cc1cc(-c2oc3cc(O)cc(=O)c-3cc2O)cc(C(=O)O[Na])c1O</smiles>

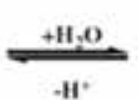

$H^{*}$<smiles>COc1cc(C2Oc3cc(O)cc(O)c3C=C2O)cc(O)c1O</smiles>

pirs<smiles>COc1cc(C(=O)c2cc(O)c(O)c(O)c2)cc(O)c1O</smiles>

pH 6

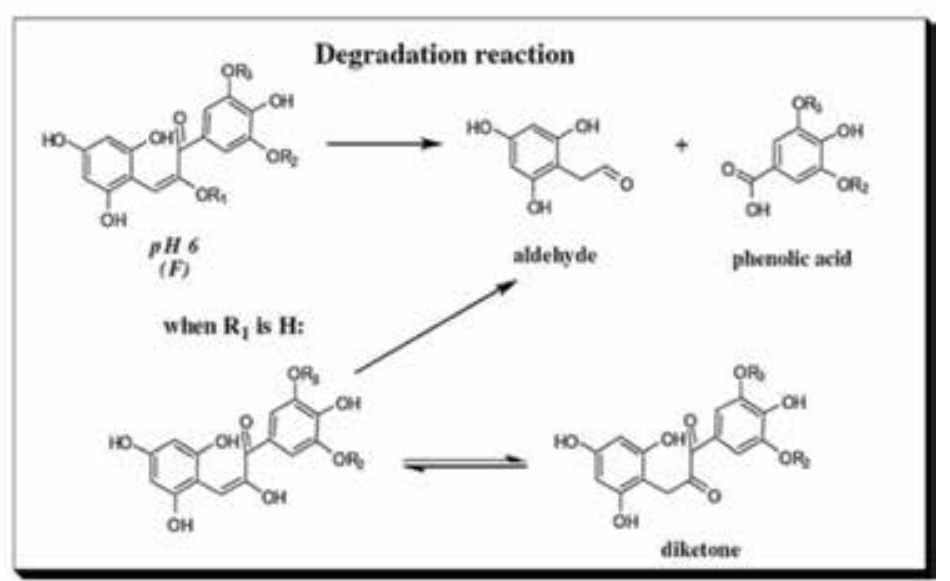

Figure 3.

Anthocyanin chemical structure forms depending on $p H$. Source: Castaneda-Ovando et al. [67].

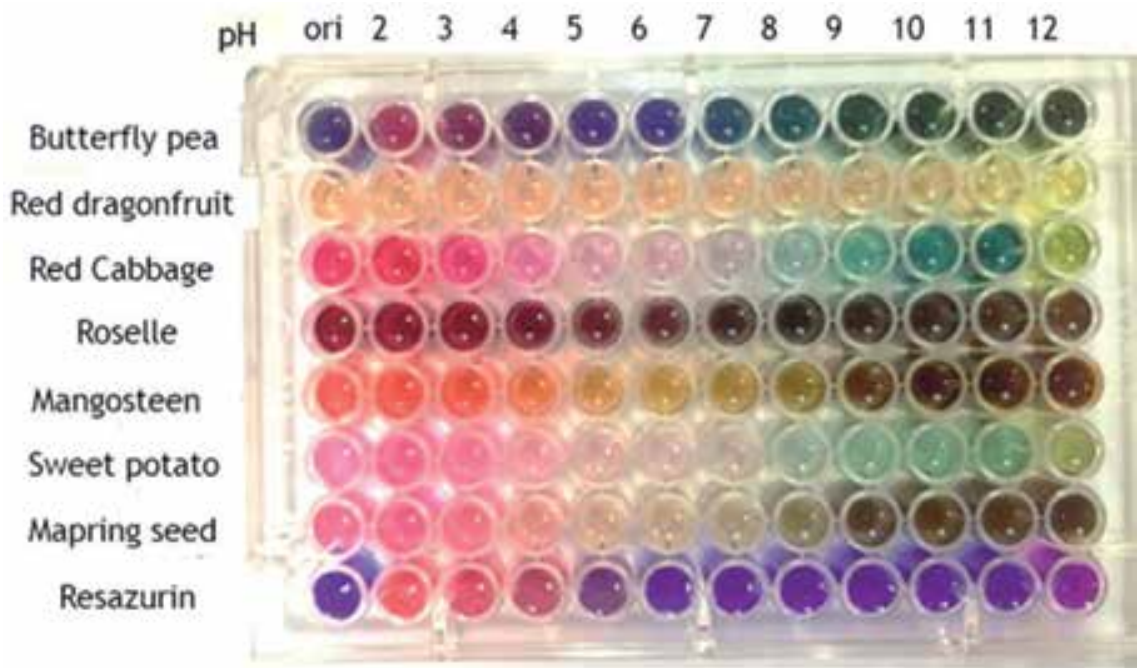

Figure 4.

Color chart of anthocyanins extracted from different sources of plants at different $p H$ levels, compared to chemical dye (resazurin). Source: Rawdkuen et al. [56]. 
storage. Thus, these quality changes of the packaged food are difficult to evaluate by the retailers or consumers. Moreover, different types of food require a specific condition and relative humidity $(\mathrm{RH})$ for their transportation and preservation. With an advantage of smart packaging, it is possible to detect the quality of the food that is packed in the package. Smart packaging tools exhibit some changes in themselves (color development) which relate to the changes in the physicochemical and biological properties of the packaged food. They are mostly placed inside or outside of the package to observe the alteration in the quality of packaged product and to inform the users about the food safety and quality through visible color changes, as illustrated in Figure 5.

In the recent year, the applications of smart packaging tools or devices on food product have been described $[48,53,58]$. Indicators are the most frequently used tool due to their nondestructive method, simplicity, low cost, and easy detection by the naked eye. Chemical and biological changes in food product generally occur during handling, storage, and transportation. Contamination by microorganisms is also the main spoilage of most foods. Microbes can be generated the different chemical metabolites, such as $\mathrm{CO}_{2}$, organic acids, alcohol (ethanol), and hydrogen sulfide $\left(\mathrm{H}_{2} \mathrm{~S}\right)$, and nitrogen containing molecules, which have been proposed as suitable target molecules for indicators [34]. When the levels of these volatile compounds increase, $\mathrm{pH}$ level will also increase. As a consequence, the freshness of packaged food is decreasing. The use of colorimetric indicator film as a smart packaging can inform the real conditions of the packaged food to consumer in real-time monitoring of food quality under certain condition. Smart packaging films are widely applied on high-value products, such as meat, fish, seafood, fruits, and vegetables, for monitoring package headspace and/or perishable food spoilage. Hence, smart packaging would be very helpful in ensuring the packaged food safety and quality throughout the whole distribution chain.
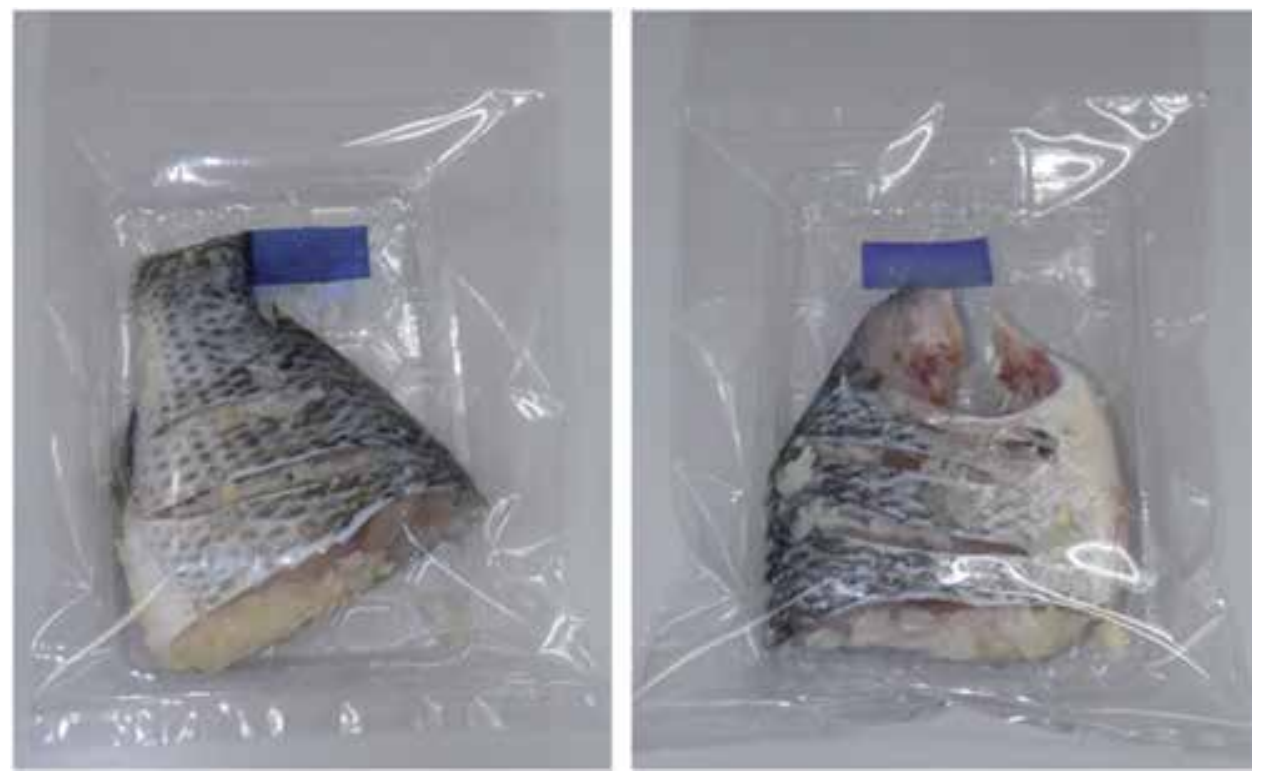

Figure 5.

Example of freshness indicator for monitoring the degree of fermentation of plaa-som, a Thai fermented fish. The indicator produced from gelatin film incorporated with anthocyanins extracted from butterfly pea (left) and gelatin film containing rezasurin (right). 


\subsection{Application of smart packaging on meat products}

Fresh meat is very perishable and susceptible for physicochemical changes. It generally deteriorates within 3-4 days of slaughter, even if it is kept in refrigeration. Meat products also represent excellent basic nutrients and are easily spoiled by microorganisms. The loss of meat freshness means meat has begun to spoil. The shelf life of meat is the storage time until spoilage, which are complex conditions because the combination of biological and physicochemical activities may interact and make the products unacceptable for human consumption [68]. An acceptable level of microbial, unacceptable appearance, and/or off-flavor is strictly depended on the degree of lipid oxidation, autolytic enzyme reaction, and the level of microbial contamination. Microorganism is one of the major meat spoilers. It can produce the compounds that correlate with spoilage, responsible for strong off-odors and discoloration. Slime production would constitute the major qualitative criteria for the rejection of meat. Meat itself comprises an essential nutrient (amino acids, nucleotides, and sugar). These nutrients are adequate for microbial growth, and the metabolism of these compounds leads to the formation of biogenic amines, $\mathrm{H}_{2} \mathrm{~S}, \mathrm{NH}_{3}$, indole, organic acids, and other substances characteristic of meat spoilage [68]. Meat industry requires rapid and simplest tool or device to determine the quality of packaged meat, to predict remaining shelf life of its product, and to provide information on the degree of spoilage. Consequently, smart packaging could be employed to detect microbial metabolites produced on packaged meat sample by reacting with volatile compounds and displaying an irreversible change in visual color, since it can be monitored directly by the naked eye. Applications of smart packaging on meat products are shown in Table 3.

Several freshness indicator concepts based on $\mathrm{pH}$ dyes, using $\mathrm{CO}_{2}$ as the main target metabolite have been proposed. An alternative method for detection of chicken breast freshness was proposed by Rukchon et al. [39]. The authors used a

\begin{tabular}{lllll}
\hline $\begin{array}{l}\text { Food } \\
\text { product }\end{array}$ & Material & Indicators & $\begin{array}{l}\text { Type of } \\
\text { intelligence }\end{array}$ & References \\
\hline $\begin{array}{l}\text { Chicken } \\
\text { breast }\end{array}$ & Chitosan-corn starch & $\begin{array}{l}\text { Hibiscus flower } \\
\text { extract }\end{array}$ & $\begin{array}{l}\text { Freshness } \\
\text { indicator }\end{array}$ & $\begin{array}{l}\text { Othman } \\
\text { et al. [43] }\end{array}$ \\
\hline Chicken & Cassava starch & Blueberry residue & $\begin{array}{l}\text { Freshness } \\
\text { indicator }\end{array}$ & $\begin{array}{l}\text { Luchese } \\
\text { et al. [55] }\end{array}$ \\
\hline Pork & Chitosan & Bauhinia blakeana \\
Dunn. flower extract & $\begin{array}{l}\text { Freshness } \\
\text { indicator }\end{array}$ & $\begin{array}{l}\text { Zhang } \\
\text { et al. [69] }\end{array}$ \\
\hline $\begin{array}{l}\text { Pork } \\
\text { Skinless } \\
\text { chicken } \\
\text { breast }\end{array}$ & Agar-potato starch & $\begin{array}{l}\text { Purple sweet potato } \\
\text { hydroxypropyl }\end{array}$ & $\begin{array}{l}\text { Freshness } \\
\text { indicator }\end{array}$ & $\begin{array}{l}\text { Choi et al. } \\
\text { [60] }\end{array}$ \\
\hline Pork & A4 paper & $\begin{array}{l}\text { Bromothymol blue- } \\
\text { methyl red (ratio } \\
\text { of 2:3) }\end{array}$ & Gas indicator & $\begin{array}{l}\text { Rukchon } \\
\text { et al. [39] }\end{array}$ \\
& Glucoamylase, \\
amylose, and iodine & $\begin{array}{l}\text { Time- } \\
\text { temperature } \\
\text { indicator }\end{array}$ & $\begin{array}{l}\text { Meng et al. } \\
\text { [6] }\end{array}$ \\
\hline Pork & Reverse phase silica gel & Black rice extract & Gas sensor & $\begin{array}{l}\text { Huang } \\
\text { et al. [70] }\end{array}$ \\
\hline
\end{tabular}

Table 3.

Application of smart packaging films on meat products. 
colorimetric mixed $\mathrm{pH}$ dye indicator (bromothymol blue/methyl red, ratio of 2:3) based on a methylcellulose-hydroxypropyl methylcellulose film as a chemical barcode for real-time monitoring of skinless chicken breast spoilage. Changes in color indicator from green to orange-yellow were correlated with $\mathrm{CO}_{2}$ level, microbial growth patterns, and the amount of volatile compounds of skinless chicken breast. The authors also concluded that the degree of chicken spoilage was related to $\mathrm{CO}_{2}$ levels increased due to microbial growth. Zhang et al. [69] present a convenient, nondestructive, and visible method for pork freshness detection. The indicator response was correlated with $\mathrm{pH}$ changes in pork sample, thus enabling real-time monitoring of spoilage. The indicator was prepared by immobilizing natural $\mathrm{pH}$-sensitive dye (Bauhinia blakeana Dunn. flower extract) in chitosan, which responded through visible color changes from red to green.

Recently, a system for monitoring chicken breast freshness was developed by Othman et al. [43] based on hibiscus flower extract. The extract was incorporated into chitosan-corn starch-based film, and changes from purplish-gray to darker gray with green color were observed when $\mathrm{pH}$ increased as a consequence of the spoilage of chicken breast due to the accumulation of amine and ammonia by mesophilic bacteria. Luchese et al. [55] applied the $\mathrm{pH}$ sensing film (anthocyanins extracted from blueberry residue added cassava starch film) on chicken meat indirectly and directly on meat surface for monitoring the spoilage of chicken during storage at $6^{\circ} \mathrm{C}$ for 10 days. The authors found color pigment migration from indicator to surface of chicken when the $\mathrm{pH}$ sensing film was placed directly on chicken meat. This phenomenon may cause the consumer to not accept the product due to changed appearance. Choi et al. [60] developed a pH-sensitive indicator for detecting pork spoilage. $\mathrm{pH}$ indicator was prepared by immobilizing a natural dye (anthocyanins extracted from purple sweet potato) into agar-potato starch film. Trials on pork have verified that the color indicator response (from red to green) correlates with $\mathrm{pH}$ values in pork sample, thus enabling the real-time detection of spoilage. Meng et al. [6] developed enzyme-based TTI for prediction of pork shelf life during cold storage. It is prepared from sodium alginate, amylose, iodine, and glucoamylase microcapsules and then was coated on A4 paper. After activation (cover with agar), PE film was used to seal the TTI. This type of indicator is based on the reaction between an enzyme and a substrate, which can cause a color change in the system to indicate the reaction degree. When this indicator was applied on pork sample, changed in color from mazarine to colorless was observed. The color change represents the spoilage of chilled pork. A gas sensor array has been proposed by Huang et al. [70] and was used for detecting the biogenic amines generated on packaged fresh pork during storage at $5^{\circ} \mathrm{C}$ for 7 days. The colorimetric sensor array was created by printing anthocyanins extracted from black rice extract on reverse phase silica gel plates (inorganic material). The authors found a good relationship between the gas sensor array results (i.e., color change) and biogenic amine content. The authors also demonstrated the reaction between indicator and generated volatile compound; the hydroxyl and carbonyl groups of anthocyanin molecules could be interacted with the amines generated during pork spoilage, resulting in changes in color.

\subsection{Application of smart packaging on fish and seafood products}

Fish and seafood products are classified as extremely perishable products. The decomposition of fish and seafood products can also be due to three mechanisms: enzymatic reactions, oxidative deterioration, and microbial spoilage [71]. Lipid oxidation is the main spoilage of chemical nature. When bacteria grow, they produce metabolic by-products, and their accumulations cause the organoleptic 
rejection. However, microbial spoilage is the major mechanism that influences the quality deterioration of fresh fish and seafood and is responsible for shelf life duration. TVB-N, trimethylamines (TMA), sulfuric compounds, alcohols, aldehydes, ketones, and esters are the most common metabolites with characteristic odor that is produced by microorganisms during fish and seafood spoilage [71]. However, the produced compounds are dependent on the metabolic activity of selected specific spoilage organisms (SSO), which is directly influenced by storage conditions. It is difficult to determine the quality of packaged fish and seafood products; thus, a variety of approaches have been developed to monitor the freshness of fish and seafood products in real time. Indicators, one form of intelligent packaging, can react to changes_-usually chemical or biological-occurring within the headspace of packaging as the fish and seafood spoil. Thus, indicator generally gives characteristic change: a highly visual color change of the indicator allows for a rapid assessment of the quality of the packed fish seafood products. Considering the food quality and safety, intelligent packaging is an alternative tool that can be used to assess the shelf life and freshness status of fish and seafood products during the supply chain. Applications of smart packaging on fish and seafood products are shown in Table 4.

A real-time technique for evaluating fish freshness was prepared by Silva-Pereira et al. [62]. Chitosan-corn starch was used as starting material for making freshness indicator, and red cabbage was used as a dye indicator. The indicator film was used to monitor the fish spoilage storage at room $\left(25^{\circ} \mathrm{C}\right)$ and refrigeration temperature $\left(4-7^{\circ} \mathrm{C}\right)$ during 7 days. The authors found that the color of the indicator film stored at room temperature was completely changed after $72 \mathrm{~h}$ (from blue to yellow), indicating fish spoilage. Ma et al. [41] developed a smart film as indicator for monitoring fish freshness. Smart film was prepared based on tara gum-cellulose nanocrystals containing Vitis amurensis husk extract (by-product from white wine processing). The

\begin{tabular}{|c|c|c|c|c|}
\hline $\begin{array}{l}\text { Food } \\
\text { product }\end{array}$ & Material & Indicators & $\begin{array}{l}\text { Type of } \\
\text { intelligence }\end{array}$ & References \\
\hline Fish & $\begin{array}{l}\text { Chitosan-corn } \\
\text { starch }\end{array}$ & Red cabbage & Freshness indicator & $\begin{array}{l}\text { Silva- } \\
\text { Pereira et al. } \\
\text { [62] }\end{array}$ \\
\hline Fish & $\begin{array}{l}\text { Tara gum- } \\
\text { cellulose } \\
\text { nanocrystals }\end{array}$ & Vitis amurensis husk & Freshness indicator & $\begin{array}{l}\text { Ma et al. } \\
{[41]}\end{array}$ \\
\hline Fish & $\begin{array}{l}\text { PVA-chitosan } \\
\text { nanoparticles }\end{array}$ & Mulberry extract & Freshness indicator & $\begin{array}{l}\text { Ma et al. } \\
{[58]}\end{array}$ \\
\hline $\begin{array}{l}\text { Silver } \\
\text { carp }\end{array}$ & Starch-PVA & Roselle & Freshness indicator & $\begin{array}{l}\text { Zhai et al. } \\
\text { [9] }\end{array}$ \\
\hline Squid & $\begin{array}{l}\text { Aluminum oxide } \\
\text { and silica gel }\end{array}$ & $\begin{array}{l}\text { Thymol blue, bromothymol } \\
\text { blue sodium salt, } \\
\text { bromocresol purple, } \\
\text { dinuclear rhodium complex, } \\
\text { and bromophenol blue }\end{array}$ & $\begin{array}{l}\text { Optoelectronic } \\
\text { nose (sensor) }\end{array}$ & $\begin{array}{l}\text { Zaragozá } \\
\text { et al. [51] }\end{array}$ \\
\hline $\begin{array}{l}\text { Cooked } \\
\text { crabs }\end{array}$ & $\begin{array}{l}\text { Paper cellulose } \\
\text { fibers }\end{array}$ & $\begin{array}{l}\text { Anthraquinone and azo } \\
\text { chromophores }\end{array}$ & Freshness & $\begin{array}{l}\text { Zhang et al. } \\
\text { [72] }\end{array}$ \\
\hline Shrimp & Tara gum-PVA & Curcumin & Sensor & $\begin{array}{l}\text { Ma et al. } \\
{[41]}\end{array}$ \\
\hline
\end{tabular}

PVA: polyvinyl alcohol.

Table 4.

Application of smart packaging films on fish and seafood products. 
colorimetric film was adhered in a sealable bag to directly detect the color difference during fish spoilage. The color changed from pink to yellow-green due to fish spoilage. These color changes were related to the production of volatile basic nitrogen and the increase of $\mathrm{pH}$. Ma et al. [58] developed a $\mathrm{pH}$ indicator which consisted of polyvinyl alcohol (PVA)-chitosan nanoparticles and mulberry extract. This indicator was tested for monitoring fish spoilage. The authors found that change in color indicator from red to green was correlated with the presence of volatile nitrogenous compounds, which is characteristic of fish spoilage. Anthocyanins that were extracted from roselle immobilized onto starch-PVA-based film were proposed by Zhai et al. [9] as visual colorimetric film for volatile nitrogenous compounds released in fish spoilage. The visual changes were monitored along $165 \mathrm{~h}$ refrigeration temperature $\left(4^{\circ} \mathrm{C}\right)$, and the beginning purple color of colorimetric film changed over time to green (at $90 \mathrm{~h}$ ) and finally yellow (after $135 \mathrm{~h}$ ). These color changes indicated that the colorimetric films became more basic due to the increasing TVB-N.

The optoelectronic nose is based on the combination of $\mathrm{pH}$ indicator and selective chromogenic reagents supported on inorganic materials with diverse acidities and topologies [73]. A novel optoelectronic nose to monitor squid spoilage is proposed by Zaragozá et al. [51]. It is based on five pigments prepared by mixing the different corresponding dyes (thymol blue, bromothymol blue sodium salt, bromocresol purple, dinuclear rhodium complex, and bromophenol blue) with two inorganic supports (aluminum oxide and silica gel). Changes in color of sensor array were characteristic of packaged squid, which kept in cold storage for 12 days. The chromogenic array data were assessed with principal component analysis (PCA; qualitative) and partial least squares (PLS; quantitative) study tools. The PCA analysis carried out with CIE Lab showed that the colorimetric array was able to discriminate between fresh and spoiled squid. The statistical models obtained by PLS, with the optoelectronic nose, successfully predicted $\mathrm{CO}_{2}$ and $\mathrm{O}_{2}$ content in the headspace as well as microbial growth. The authors also suggested that this optoelectronic nose could help to evaluate cephalopod freshness, which is easy to use and rapid. Recently, a biosensor (tara gum-PVA-curcumin) was prepared by $\mathrm{Ma}$ et al. [41] for evaluation of shrimp spoilage at ambient temperature. The authors found a linear correlation between changes in total volatile basic nitrogen (TVB-N) and $\mathrm{pH}$ with the colorimetric response of sensor (slightly yellow to orange-red) within 1-3 min. The authors also suggested the possibility of using the developed film as a sensor for monitoring the spoilage of shrimp and other food products.

\subsection{Application of smart packaging on fruits and vegetables}

Fruits and vegetables are extremely perishable products and require appropriate handling and storage conditions over the distribution chain in order to preserve their quality and safety and to prolong the shelf life. These products are living products; it means they keep respiring, consuming $\mathrm{O}_{2}$, and producing $\mathrm{CO}_{2}$ after harvesting. Thus, the postharvest deterioration process is affected by intrinsic factors of the product. One of the major issues of fresh-cut products is the potential microbial spoilage. Smart packaging can be applied in fruit and vegetable product for facilitating the consumer to know the quality of packaged fruits and vegetables and to promote choosing the fruits and vegetables according to freshness or maturity without damaging the packaging. Generally, changes in color indicators represent the extent of ripening of packaged fruit and vegetable products, or in contrast the indicators represent the spoilage condition (microbial growth). According to Poças et al. [33], the packaging-specific requirements for fruits and vegetables are related to maintaining, controlling, and/ or monitoring temperature, gas composition and humidity, and mechanical damage. Applications of smart packaging on fruit and vegetable products are shown in Table 5. 
The use of freshness indicator on fruit and vegetable products has been proposed. Niponsak et al. [7] described a colorimetric mixed $\mathrm{pH}$ dye-based indicator that responds through visible color changes to sulfur-containing volatile compounds released in durian ripening. The strip was obtained by casting method using cassava starch-chitosan, as a based film, and mixing methyl red and bromothymol blue (ratio of 3:2), as indicators. Changes in color in the strip from red to orange and finally turned to yellow indicated the ripening stages of fresh-cut durian. The authors also explained that when the volatile compounds (sulfur; diethyl disulfide, diethyl trisulfide, 3,5-dimethyl-1,2,4-trithiolane) evaporated and reacted with the strip, its changed to the basic form. It is due to the presence of moisture from durian respiration resulting changes in color. Dirpan et al. [40] developed freshness indicator from cellulose membrane and soaked it in bromophenol blue solution and then applied on mango (Mangifera indica L. var. Arummanisa). The authors found that the color indicator changed from blue to green color (over-ripening) and also suggested that this indicator could be used to determine the freshness of mango.

Chen et al. [52] reported a system for freshness indicator based on methylcellulose and mixing of methyl red and bromothymol blue (ratio 3:2). The indicator was tested in the presence of fresh-cut green bell pepper sample during storage at $7 \pm 1^{\circ} \mathrm{C}$ for 9 days. The visible change of freshness indicator was monitored for 9 days, and the color of indicator changed from yellow-green to orange when the sample was completely spoiled. The authors concluded that the deterioration of bell pepper could be detected in real time by freshness indicator. Lee et al. [74] developed a Maillard-type TTI for predicting the maturity of melon (Cucumis melo L.). Maillard-type TTI was based on a combination of d-xylose and glycine to create highly reactive Maillard reaction systems. The color of TTIs changed from colorless to yellow, brown, and finally dark brown. The authors concluded that

\begin{tabular}{|c|c|c|c|c|}
\hline $\begin{array}{l}\text { Food } \\
\text { product }\end{array}$ & Material & Indicators & $\begin{array}{l}\text { Type of } \\
\text { intelligence }\end{array}$ & References \\
\hline $\begin{array}{l}\text { Fresh- } \\
\text { cut } \\
\text { durian }\end{array}$ & $\begin{array}{l}\text { Cassava } \\
\text { starch-chitosan }\end{array}$ & $\begin{array}{l}\text { Mixing methyl red and } \\
\text { bromothymol blue (ratio } \\
\text { of 3:2) }\end{array}$ & $\begin{array}{l}\text { Freshness } \\
\text { indicator }\end{array}$ & $\begin{array}{l}\text { Niponsak } \\
\text { et al. [7] }\end{array}$ \\
\hline Mango & Cellulose membrane & Bromophenol blue & $\begin{array}{l}\text { Freshness } \\
\text { indicator }\end{array}$ & $\begin{array}{l}\text { Dirpan } \\
\text { et al. [40] }\end{array}$ \\
\hline $\begin{array}{l}\text { Fresh- } \\
\text { cut green } \\
\text { bell } \\
\text { pepper }\end{array}$ & Methylcellulose & $\begin{array}{l}\text { Mixing methyl red and } \\
\text { bromothymol blue (ratio } \\
\text { of 3:2) }\end{array}$ & $\begin{array}{l}\text { Freshness } \\
\text { indicator }\end{array}$ & $\begin{array}{l}\text { Chen et al. } \\
{[52]}\end{array}$ \\
\hline Kimchi & Cellulose fiber & $\begin{array}{l}\text { Mixing chlorophenol red } \\
\text { and bromothymol blue } \\
\text { (ratio of 2:3) }\end{array}$ & $\begin{array}{l}\text { Freshness } \\
\text { indicator }\end{array}$ & $\begin{array}{l}\text { Kim et al. } \\
{[54]}\end{array}$ \\
\hline Melon & Transparent pouch & D-xylose and glycine & $\begin{array}{l}\text { Time- } \\
\text { temperature } \\
\text { indicator }\end{array}$ & $\begin{array}{l}\text { Lee et al. } \\
{[74]}\end{array}$ \\
\hline $\begin{array}{l}\text { Salad } \\
\text { leaves }\end{array}$ & $\begin{array}{l}\text { Plastic [poly(isobutyl } \\
\text { methacrylate)] }\end{array}$ & $\begin{array}{l}\text { PtTEPP and } \\
\alpha \text {-naphtholphthalein }\end{array}$ & Gas sensor & $\begin{array}{l}\text { Borchert } \\
\text { et al. [75] }\end{array}$ \\
\hline Kimchi & $\begin{array}{l}\text { Poly(ether-block- } \\
\text { amide) and PET }\end{array}$ & $\begin{array}{l}\text { Mixing methyl red and } \\
\text { bromothymol blue (ratio } \\
\text { of 3:7) }\end{array}$ & Gas indicator & $\begin{array}{l}\text { Baek et al. } \\
{[48]}\end{array}$ \\
\hline
\end{tabular}

PET: polyethylene terephthalate.

Table 5.

Application of smart packaging films on fruits and vegetables. 
Maillard-type TTI was successfully indicated a product's accumulated temperature as color changes during melon cultivation. The authors also suggested that Maillard reaction-based TTI is not only used for predicting melon maturity but also for monitoring the chilled food distribution and cooking time and temperature.

Some studies reported the combination of device and the packaging technique (MAP or vacuum packaging). Borchert et al. [75] developed an optochemical $\mathrm{CO}_{2}$ sensor for measuring $\mathrm{CO}_{2}$ in the headspace of the package under MAP storage. This sensor is composed of phosphorescent Pt-porphyrin (PtTEPP) reporter and a colorimetric $\mathrm{pH}$ indicator $\alpha$-naphtholphthalein bounded in a plastic [poly(isobutyl methacrylate)] combined with tetraoctyl- or cetyltrimethylammonium hydroxide, as a phase transfer reagent. The authors used this sensor to measure the $\mathrm{CO}_{2}$ levels in salad leaves stored under MAP $\left(\mathrm{CO}_{2}, 6.6 \% ; \mathrm{O}_{2}, 21.55 \%\right.$; humidity, $\left.100 \%\right)$. It was demonstrated that the sensor could retain its color and sensitivity to $\mathrm{CO}_{2}$ at $4^{\circ} \mathrm{C}$ for 21 days. Recently, an indicator for monitoring the fermentation stage of kimchi was developed by Baek et al. [48]. It was prepared by coating poly(ether-block-amide) that contained chemical dye (mixing of methyl red and bromothymol blue, ratio of 3:7) on polyethylene terephthalate (PET). The determination was worked on the changes in color produced by the levels of $\mathrm{CO}_{2}$ gas in the packaged kimchi. The authors found that changes in color indicator were correlated with the $\mathrm{CO}_{2}$ levels. Kim et al. [54] prepare an accurate indicator from mixing chlorophenol red and bromothymol blue in a ratio of 2:3 and combined it with cellulose fiber to work as labeling film for the aim to develop freshness indicator. The authors found that a total color difference of indicator was correlated well with $\mathrm{pH}$ and titratable acidity changes, indicating the possibility of using this indicator in commercial kimchi for indicating the degree of fermentation prior to the final purchase decision during distribution and retail sale.

\subsection{Application of smart packaging on milk and dairy products}

Milk and other dairy products are important sources of several essential nutrients. Liquid bovine milk generally comprises approximately $87 \%$ water, $4.9 \%$ carbohydrate, $3.9 \%$ protein, $3.5 \%$ fat, and $0.7 \%$ ash such as vitamins and minerals [76]. However, the milk compositions varied depending on the species and their immediate environment. For cheese, it can generally be classified as soft, semisoft, or hard, depending on their moisture content. Soft cheese contains high levels of moisture (50-80\%), such as cottage cheese and mozzarella, while semisoft and hard cheeses, such as Gorgonzola and Parmesan, respectively, have lower moisture contents and more acidic $\mathrm{pH}$ levels [76]. Thus, a large variety of microorganisms quickly proliferate in soft cheese rather than hard cheese due to their moisture content and pH levels (5.0-6.5). Moreover, the presence of oxygen inside the package is also the factor to control. During milk and dairy product spoilage, a wide variety of metabolic by-products are exhibited and caused off-flavor and off-odor, in addition to visible change in color and texture. Most dairy products are distributed, handled, and stored in the cold chain $\left(<7^{\circ} \mathrm{C}\right)$ to inhibit the microbial growth. However, temperatures should be kept as low as possible $\left(<4^{\circ} \mathrm{C}\right)$ to prolong the storage life, and it has been reported that the shelf life of processed milk increases by decreasing temperatures during storage. To know the quality of milk and dairy products and the environment condition that packaged food product is exposed to, intelligent packaging can be used as a tool or device for detecting the spoilage process in real time and informing the real status of packaged product to the manufacturers and the end consumers by changes in color indicator without opening the packaging. The most recent studies focused on the use of intelligent packaging on milk and dairy products are presented in Table 6.

Pereira et al. [8] prepared a time-temperature indicator (TTI) based on a chitosan-PVA film containing anthocyanins from red cabbage, as a natural dye 
Valorization of Food Processing By-Products as Smart Food Packaging Materials...

DOI: http://dx.doi.org/10.5772/intechopen.86245

\begin{tabular}{lllll}
\hline $\begin{array}{l}\text { Food } \\
\text { product }\end{array}$ & Material & Indicators & $\begin{array}{l}\text { Type of } \\
\text { intelligence }\end{array}$ & References \\
\hline $\begin{array}{l}\text { Pasteurized } \\
\text { milk }\end{array}$ & Chitosan-PVA & Red cabbage & $\begin{array}{l}\text { Time-temperature } \\
\text { indicator }\end{array}$ & $\begin{array}{l}\text { Pereira et al. } \\
{[8]}\end{array}$ \\
\hline Milk & Tara gum-cellulose & Grape skin extract & $\begin{array}{l}\text { Time-temperature } \\
\text { indicator }\end{array}$ & $\begin{array}{l}\text { Ma and } \\
\text { Wang [57] }\end{array}$ \\
\hline $\begin{array}{l}\text { Pasteurized } \\
\text { milk }\end{array}$ & Starch-PVA & Purple sweet potato & $\begin{array}{l}\text { Time-temperature } \\
\text { indicator }\end{array}$ & $\begin{array}{l}\text { Liu et al. } \\
{[59]}\end{array}$ \\
\hline Milk & Starch-nanoclay & Methyl orange and & Freshness & Pirsa et al. \\
indicator & [53]
\end{tabular}

Table 6.

Application of smart packaging films on milk and dairy products.

indicator, for monitoring milk spoilage. During storage at a temperature above the cooling temperature, $\mathrm{pH}$ lowers from 6.7 (unspoiled) to 4.6 (spoiled). This value was correlated with the color values (CIELab) of the indicator. Color of the dye (red cabbage) turned from dark gray to dark pink. Thus, color changes of the indicator represented the milk spoilage. Ma and Wang [57] prepared $\mathrm{pH}$ sensing film from tara gum-cellulose nanocrystal incorporated with natural dye (grape skin extract) to evaluate the $\mathrm{pH}$ changes of the milk at ambient temperature for $48 \mathrm{~h}$. During the test, the color of indicator clearly changed from bright red (acidic) to dark green (alkaline) which correlated with microbial contamination and $\mathrm{pH}$ decreased (from 6.48 to 2.94 ). The authors suggested that the developed $\mathrm{pH}$ sensing film could be used as a visible color indicator and changes in color of the film provide information to monitor the packaged food freshness.

Liu et al. [59] have reported the intelligent packaging made with starch-PVA added with anthocyanins extracted from purple sweet potato as an indicator for monitoring $\mathrm{pH}$ changes in pasteurized milk. The visual changes were monitored along $48 \mathrm{~h}$ storage at room temperature, and the original purple color of starch-PVA-anthocyanin film changed with time to red, which is related to milk spoilage. Recently, Pirsa et al. [53] developed a $\mathrm{pH}$ indicator for determination of milk spoilage. These indicators were based on starch-nanoclay incorporated with methyl orange and bromocresol green. For methyl orange indicator, the color changed from red ( $\mathrm{pH} 3$ ) to yellow ( $\mathrm{pH} 4.5)$, while bromocresol green showed green ( $\mathrm{pH}$ 3.8) to blue ( $\mathrm{pH}$ 5.5). The authors suggested that the colorimetric $\mathrm{pH}$ indicator displayed color changes which correlated to $\mathrm{pH}$ changes. Thus, the use of these indicators is easily visible to the naked eye. Papetti et al. [77] developed an integrated electronic tracking system for analyzing the quality of Italian cheese. The system was able to identify the cheese products, and the consumer can know information with the help of the RFID code.

\section{Conclusion}

Food processing industry including meat, poultry, fish and seafood, fruits and vegetables, and dairy processing generates a large amount of by-products. However, these by-products still contain organic matters that can be recovered and exploited as high value-added compounds. They can be utilized in packaging applications as a starting material. Thus, it is a great potential of food processing by-products for 
effective utilization in the field of food packaging applications that would be more cost-effective, efficient, and sustainable. Currently, low-cost sensing packaging technologies have become increasingly interesting because they can give the real status of packaged food quality through visual indication. Thus, the use of smart packaging can be applied on various types of food-based products for facilitating the consumer to know the quality of packaged food in real time and to promote choosing the products according to its freshness without damaging the packaging. These packaging technologies are a noninvasive method, cost-effective, and rapid and can also reduce food loss and waste at the same time. Thus, the use of smart packaging is an alternative way that could reduce the food loss and waste, which is one of the world's major issues.

\section{Acknowledgements}

The author would like to thank Mae Fah Luang University, College of Maritime Studies and Management, and Chiang Mai University for the financial support.

\section{Author details}

Saroat Rawdkuen ${ }^{1 *}$ and Pimonpan Kaewprachu ${ }^{2}$

1 Unit of Innovative Food Packaging and Biomaterials, School of Agro-Industry, Mae Fah Luang University, Chiang Rai, Thailand

2 College of Maritime Studies and Management, Chiang Mai University, Samut Sakhon, Thailand

*Address all correspondence to: saroat@mfu.ac.th

IntechOpen

(C) 2019 The Author(s). Licensee IntechOpen. This chapter is distributed under the terms of the Creative Commons Attribution License (http://creativecommons.org/licenses/ by/3.0), which permits unrestricted use, distribution, and reproduction in any medium, provided the original work is properly cited. (cc) BY 


\section{References}

[1] Food and Agriculture Organization of the United Nations (FAO) [Internet]. SAVE FOOD: Global initiative on food loss and waste reduction. 2012. Available from: http://www.fao.org/ save-food/resources/keyfindings/en/ [Accessed: 19 September 2018]

[2] Yam KL, Takhistov PT, Miltz J. Intelligent packaging: Concepts and applications. Journal of Food Science. 2005;70:R1-R10

[3] European Commission. Regulation (EC) No. 450/2009. Active and intelligent materials and articles intended to come into contact with food. Official Journal of the European Union. 2009;135:3-11

[4] Yam KL. Intelligent packaging to enhance food safety and quality. In: Yam KL, Lee DS, editors. Emerging Food Packaging Technologies. Cambridge, UK: Woodhead Publishing; 2012. pp. 137-152

[5] Kerry JP. Application of smart packaging systems for conventionally packaged muscle-based food products. In: Kerry JP, editor. Advances in Meat, Poultry and Seafood Packaging. Cambridge, UK: Woodhead Publishing; 2012. pp. 522-564

[6] Meng J, Qian J, Tang Y. A solidstate time-temperature indicator used in chilled fresh pork monitoring. Packaging Technology and Science. 2018;31:353-360

[7] Niponsak A, Laohakunjit N, Kerdchoechuen O, Wongsawadee P. Development of smart colourimetric starch-based indicator for liberated volatiles during durian ripeness. Food Research International. 2016;89:365-372

[8] Pereira Jr VA, de Arruda INQ, Stefani R. Active chitosan/PVA films with anthocyanins from Brassica oleraceae (red cabbage) as time-temperature indicators for application in intelligent food packaging. Food Hydrocolloids. 2015;43:180-188

[9] Zhai X, Shi J, Zou X, Wang S, Jiang $C$, Zhang J, et al. Novel colorimetric films based on starch/polyvinyl alcohol incorporated with roselle anthocyanins for fish freshness monitoring. Food Hydrocolloids. 2017;69:308-317

[10] Ezejiofor TIN, Enebaku UE, Ogueke C. Waste to wealth-value recovery from agro-food processing wastes using biotechnology: A review. British Biotechnology Journal. 2014;4:418-481

[11] Food and Agriculture Organization of the United Nations (FAO) [Internet]. FAOSTAT database. Available from: http://www.fao.org [Accessed: 19 September 2018]

[12] Rathinaraj K, Sachindra NM. Meat, poultry, and eggs. In: Chandrasekaran M, editor. Valorization of Food Processing by-Products. Boca Raton, FL, USA: CRC Press; 2013. pp. 649-684

[13] Song NB, Lee JH, Al Mijan M, Song KB. Development of a chicken feather protein film containing clove oil and its application in smoked salmon packaging. LWT-Food Science and Technology. 2014;57:453-460

[14] Olsen RL, Toppe J, Karunasagar I. Challenges and realistic opportunities in the use of by-products from processing of fish and shellfish. Trends in Food Science and Technology. 2014;36:144-151

[15] Suresh PV, Prabhu GN. Seafoods. In: Chandrasekaran M, editor. Valorization of Food Processing by-Products. Boca Raton, FL, USA: CRC Press; 2013. pp. $685-736$ 
[16] Rawdkuen S, Sai-UT S, Benjakul S. Properties of gelatin films from farmed giant catfish skin and bovine bone: A comparative study. European Food Research and Technology. 2010;231:907-916

[17] Jongjareonrak A, Rawdkuen S, Chaijan M, Benjakul S, Osako K, Tanaka M. Chemical compositions and characterisation of skin gelatin from farmed giant catfish (Pangasianodon gigas). LWT-Food Science and Technology. 2010;43:161-165

[18] Rawdkuen S, Thitipramote N, Benjakul S. Preparation and functional characterization of fish skin gelatins and comparison with commercial gelatin. International Journal of Food Science and Technology. 2013;48:1093-1102

[19] Tongdeesoontorn W, Rawdkuen S. Gelatin-based films and coatings for food packaging applications. In: Reference Module in Food Science. Amsterdam, Netherlands: Elsevier; 2019. pp. 1-15. DOI: $10.1016 /$ B978-0-08-100596-5.22598-5

[20] Hamed I, Özogul F, Regenstein JM. Industrial applications of crustacean by-products (chitin, chitosan, and chitooligosaccharides): A review. Trends in Food Science and Technology. 2016;48:40-50

[21] Rinaudo M. Chitin and chitosan: Properties and applications. Progress in Polymer Science. 2006;31:603-632

[22] Perez-Gago MB, Krochta JM. Formation and properties of whey protein films and coatings. In: Gennadios A, editor. Protein-Based Films and Coatings. Boca Raton, FL, USA: CRC Press; 2002. pp. 159-180

[23] Rawdkuen S, Benjakul S. Whey protein concentrate: Autolysis inhibition and effect on gel properties of surimi from some tropical fish. Food Chemistry. 2008;106:1077-1084
[24] Anal AK. Food Processing by-Products and their Utilization. West Sussex: John Wiley \& Sons; 2017

[25] Orsuwan A, Sothornvit R. Effect of banana and plasticizer types on mechanical, water barrier, and heat sealability of plasticized banana-based films. Journal of Food Processing and Preservation. 2018;42(1):e13380. DOI: 10.1111/jfpp. 13380

[26] Sothornvit R, Pitak N. Oxygen permeability and mechanical properties of banana films. Food Research International. 2007;40:365-370

[27] Berardini N, Knödler M, Schieber A, Carle R. Utilization of mango peels as a source of pectin and polyphenolics. Innovative Food Science and Emerging Technologies. 2005;6:442-452

[28] Kaur M, Singh N, Sandhu KS, Guraya HS. Physicochemical, morphological, thermal and rheological properties of starches separated from kernels of some Indian mango cultivars (Mangifera indica L.). Food Chemistry. 2004;85:131-140

[29] Sai-Ut S, Benjakul S, Kraithong S, Rawdkuen S. Optimization of antioxidants and tyrosinase inhibitory activity in mango peels using response surface methodology. LWT-Food Science and Technology. 2015;64:742-749

[30] Han SW, Chee KM, Cho SJ. Nutritional quality of rice bran protein in comparison to animal and vegetable protein. Food Chemistry. 2015;172:766-769

[31] Park SK, Hettiarachchy NS, Ju ZY, Gennadios A. Formation and properties of soy protein films and coatings. In: Gennadios A, editor. Protein-Based Films and Coatings. Boca Raton, FL, USA: CRC Press; 2002. pp. 978-1587

[32] Vanderroost $M$, Ragaert $P$, Devlieghere F, De Meulenaer B. 
Intelligent food packaging: The next generation. Trends in Food Science and Technology. 2014;39:47-62

[33] Poças MFF, Delgado TF, Oliveira FAR. Smart packaging technologies for fruits and vegetables. In: Kerry J, Butler P, editors. Smart Packaging Technologies for Fast Moving Consumer Goods. West Sussex, England: John Wiley \& Sons; 2008. pp. 151-166

[34] Hogan SA, Kerry JP. Smart packaging of meat and poultry products. In: Kerry J, Butler P, editors. Smart Packaging Technologies for Fast Moving Consumer Goods. West Sussex, England: John Wiley \& Sons; 2008. pp. 33-54

[35] Tuerdi G, Nizamidin P, Kari N, Yimit A, Wang F. Optochemical properties of gas-phase protonated tetraphenylporphyrin investigated using an optical waveguide $\mathrm{NH}_{3}$ sensor. RSC Advances. 2018;8:5614-5621

[36] Omanovic-Miklicanin E, Valzacchi S. Development of new chemiluminescence biosensors for determination of biogenic amines in meat. Food Chemistry. 2017;235:98-103

[37] Musameh MM, Dunn CJ, Uddin MH, Sutherland TD, Rapson TD. Silk provides a new avenue for third generation biosensors: Sensitive, selective and stable electrochemical detection of nitric oxide. Biosensors \& Bioelectronics. 2018;103:26-31

[38] Smolander M, Hurme E, Latva-Kala K, Luoma T, Alakomi HL, Ahvenainen R. Myoglobin-based indicators for the evaluation of freshness of unmarinated broiler cuts. Innovative Food Science and Emerging Technologies. 2002;3:279-288

[39] Rukchon C, Nopwinyuwong A, Trevanich S, Jinkarn T, Suppakul P. Development of a food spoilage indicator for monitoring freshness of skinless chicken breast. Talanta. 2014;130:547-554

[40] Dirpan A, Latief R, Syarifuddin A, Rahman ANF, Putra RP, Hidayat SH. The use of colour indicator as a smart packaging system for evaluating mangoes Arummanis (Mangifera indica L. var. Arummanisa) freshness. IOP Conference Series: Earth and Environmental Science. 2018;157:012031. DOI: 10.1088/1755-1315/157/1/012031

[41] Ma Q, Du L, Wang L. Tara gum/ polyvinyl alcohol-based colorimetric $\mathrm{NH}_{3}$ indicator films incorporating curcumin for intelligent packaging. Sensors and Actuators B: Chemical. 2017;244:759-766

[42] Ma Q, Ren Y, Gu Z, Wang L. Developing an intelligent film containing Vitis amurensis husk extracts: The effects of $\mathrm{pH}$ value of the filmforming solution. Journal of Cleaner Production. 2017;166:851-859

[43] Othman M, Yusup AA, Zakaria N, Khalid K. Bio-polymer chitosan and corn starch with extract of hibiscus rosa-sinensis (hibiscus) as $\mathrm{PH}$ indicator for visually-smart food packaging. AIP Conference Proceedings. 2018;1985:050004. DOI: 10.1063/1.5047198

[44] Janjarasskul T, Suppakul P. Active and intelligent packaging: The indication of quality and safety. Critical Reviews in Food Science and Nutrition. 2018;58:808-831

[45] Chen H-Z, Zhang M, Bhandari B, Yang C-H. Development of a novel colorimetric food package label for monitoring lean pork freshness. LWT-Food Science and Technology. 2019;99:43-49

[46] Taoukis PS. Application of timetemperature integrators for monitoring and Management of Perishable Product 
Quality in the cold chain. In: Kerry J, Butler P, editors. Smart Packaging Technologies for Fast Moving Consumer Goods. West Sussex, England: John Wiley \& Sons; 2008. pp. 61-74

[47] Suppakul P, Kim DY, Yang JH, Lee SB, Lee SJ. Practical design of a diffusion-type time-temperature indicator with intrinsic low temperature dependency. Journal of Food Engineering. 2018;223:22-31

[48] Baek S, Maruthupandy M, Lee K, Kim D, Seo J. Preparation and characterization of a poly (ether-blockamide) film-based $\mathrm{CO}_{2}$ indicator for monitoring kimchi quality. Reactive and Functional Polymers. 2018;131:75-83

[49] Puligundla P, Jung J, Ko S. Carbon dioxide sensors for intelligent food packaging applications. Food Control. 2012;25:328-333

[50] Kumar P, Reinitz HW, Simunovic J, Sandeep KP, Franzon PD. Overview of RFID technology and its applications in the food industry. Journal of Food Science. 2009;74:R101-R106

[51] Zaragozá P, Fuentes A, Ruiz-Rico M, Vivancos JL, Fernández-Segovia I, Ros-Lis JV, et al. Development of a colorimetric sensor array for squid spoilage assessment. Food Chemistry. 2015;175:315-321

[52] Chen HZ, Zhang M, Bhandari B, Guo Z. Applicability of a colorimetric indicator label for monitoring freshness of fresh-cut green bell pepper. Postharvest Biology and Technology. 2018;140:85-92

[53] Pirsa S, Sani IK, Khodaeivandi S. Design and fabrication of starch-nano clay composite films loaded with methyl orange and bromocresol green for determination of spoilage in milk package. Polymers for Advanced Technologies. 2018. DOI: 10.1002/ pat.4397
[54] Kim SJ, Lee JY, Yoon SR, Lee HW, $\mathrm{Ha} \mathrm{JH}$. Regression analysis for predicting the fermentation state of packaged Kimchi using a colorimetric indicator. Journal of Food Engineering. 2019;240:65-72

[55] Luchese CL, Abdalla VF, Spada JC, Tessaro IC. Evaluation of blueberry residue incorporated cassava starch film as $\mathrm{pH}$ indicator in different simulants and foodstuffs. Food Hydrocolloids. 2018;82:209-218

[56] Rawdkuen S, Faseha A, Kaewprachu P, Benjakul S. Application of anthocyanin extract as a color indicator in gelatin films. Food Bioscience. 2019 (submitted)

[57] Ma Q, Wang L. Preparation of a visual $\mathrm{pH}$-sensing film based on tara gum incorporating cellulose and extracts from grape skins. Sensors and Actuators B: Chemical. 2016;235:401-407

[58] Ma Q, Liang T, Cao L, Wang L. Intelligent poly (vinyl alcohol)chitosan nanoparticles-mulberry extracts films capable of monitoring $\mathrm{pH}$ variations. International Journal of Biological Macromolecules. 2018;108:576-584

[59] Liu B, Xu H, Zhao H, Liu W, Zhao L, Li Y. Preparation and characterization of intelligent starch/PVA films for simultaneous colorimetric indication and antimicrobial activity for food packaging applications. Carbohydrate Polymers. 2017;157:842-849

[60] Choi I, Lee JY, Lacroix M, Han J. Intelligent $\mathrm{pH}$ indicator film composed of agar/potato starch and anthocyanin extracts from purple sweet potato. Food Chemistry. 2017;218:122-128

[61] Yong HM, Wang XC, Bai RY, Miao ZQ, Zhang X, Liu J. Development of antioxidant and intelligent $\mathrm{pH}$-sensing packaging films by incorporating 
purple-fleshed sweet potato extract into chitosan matrix. Food Hydrocolloids. 2019;90:216-224

[62] Silva-Pereira MC, Teixeira JA, Pereira-Júnior VA, Stefani R. Chitosan/ corn starch blend films with extract from Brassica oleraceae (red cabbage) as a visual indicator of fish deterioration. LWT-Food Science and Technology. 2015;61:258-262

[63] Pourjavaher S, Almasi H, Meshkini S, Pirsa S, Parandi E. Development of a colorimetric $\mathrm{pH}$ indicator based on bacterial cellulose nanofibers and red cabbage (Brassica oleraceae) extract. Carbohydrate Polymers. 2017;156:193-201

[64] De Meyer T, Steyaert I, Hemelsoet K, Hoogenboom R, Van Speybroeck V, De Clerck K. Halochromic properties of sulfonphthaleine dyes in a textile environment: The influence of substituents. Dyes and Pigments. 2016;124:249-257

[65] Prietto L, Pinto VZ, El Halal SLM, de Morais MG, Costa JAV, Lim LT, et al. Ultrafine fibers of zein and anthocyanins as natural $\mathrm{pH}$ indicator. Journal of Science and Food Agriculture. 2018;98:2735-2741

[66] Miguel MG. Anthocyanins: Antioxidant and/or anti-inflammatory activities. Journal of Applied Pharmaceutical Science. 2011;1:7-15

[67] Castaneda-Ovando A, de Lourdes Pacheco-Hernández M, Páez-Hernández ME, Rodríguez JA, Galán-Vidal

CA. Chemical studies of anthocyanins: A review. Food Chemistry. 2009;113:859-871

[68] Comi G. Spoilage of meat and fish. In: Bevilacqua A, Corbo MR, Sinigaglia $M$, editors. The Microbiological Quality of Food: Foodborne Spoiler. Cambridge, UK: Woodhead Publishing; 2017. pp. $179-210$
[69] Zhang X, Lu S, Chen X. A visual $\mathrm{pH}$ sensing film using natural dyes from Bauhinia blakeana Dunn. Sensors and Actuators B: Chemical. 2014;198:268-273

[70] Huang XW, Zou XB, Shi JY, Guo Y, Zhao JW, Zhang J, et al. Determination of pork spoilage by colorimetric gas sensor array based on natural pigments. Food Chemistry. 2014;145:549-554

[71] Boziaris S, Parlapani FF. Specific spoilage organisms (SSOs) in fish. In: Bevilacqua A, Corbo MR, Sinigaglia M, editors. The Microbiological Quality of Food: Foodborne Spoiler. Cambridge, UK: Woodhead Publishing; 2017. pp. 61-98

[72] Zhang HJ, Hou AQ, Xie KL, Gao AQ. Smart color-changing paper packaging sensors with $\mathrm{pH}$ sensitive chromophores based on azo-anthraquinone reactive dyes. Sensor Actuatior B-Chemical. 2019;286:362-369

[73] Mohebi E, Marquez L. Intelligent packaging in meat industry: An overview of existing solutions. Journal of Food Science and Technology. 2015;52:3947-3964

[74] Lee JH, Morita A, Kuroshima M, Kawamura S, Koseki S. Development of a novel time-temperature integrator/ indicator (TTI) based on the maillard reaction for visual monitoring of melon (Cucumis melo L.) maturity during cultivation. Journal of Food Measurement and Characterization. 2018;12:2899-2904

[75] Borchert NB, Kerry JP, Papkovsky DB. $\mathrm{A} \mathrm{CO}_{2}$ sensor based on Pt-porphyrin dye and FRET scheme for food packaging applications. Sensors and Actuators B: Chemical. 2013;176:157-165

[76] Lu M, Wang NS. Spoilage of Milk and dairy products. In: Bevilacqua A, Corbo MR, Sinigaglia M, editors. 
The Microbiological Quality of Food: Foodborne Spoiler. Cambridge, UK:

Woodhead Publishing; 2017. pp. 151-178

[77] Papetti P, Costa C, Antonucci F, Figorilli S, Solaini S, Menesatti P.

A RFID web-based infotracing system for the artisanal Italian cheese quality traceability. Food Control.

2012;27:234-241 


\title{
Comparative Assessment of Shrimp Hydrolyzates as Alternative Organic Fertilizers for Legumes
}

\author{
John Rojas, Julian Qunitero, Yhors Ciro, Alfredo Moreno, \\ Javier Silva-Agredo and Ricardo A. Torres-Palma
}

\begin{abstract}
The global annual production of shrimp is nearly 4 million metric tons generating almost half of this weight in waste. This study assessed the crop production of legumes fertilized with shrimp exoskeletons obtained by microwaves under greenhouse conditions. Plants were grown under the following fertilization regimes: (i) untreated shrimp waste, (ii) shrimp waste pellets, (iii) shrimp-based pellets having a hydrolysis degree of $42 \%$, (iv) untreated cellulose pellets, (v) untreated soil, (vi) untreated cotton substrate, and (vii) two commercial fertilizers (CF1 and CF2). CF1 and CF2 showed the largest electric conductivity and ionic exchange capability, whereas the fertilizing pellets showed the lowest values. However, $\mathrm{pH}$, densification and conductivity of soil were not affected by fertilization. Shrimp waste showed a high content of $\mathrm{C}, \mathrm{N}, \mathrm{O}, \mathrm{Ca}$ and $\mathrm{P}$ mainly derived from chitin, proteins and minerals. All fertilizers showed typical type II isotherms, but the untreated soil and CF2 per se exhibited the largest water uptake. The soil microbiota increased during the growing cycle and then decreased as the reproductive phase started. Further, soil planted with Phaseolus vulgaris showed a larger microbial population than Pisum sativum. The best plant growth was achieved when treated with CF2, whereas the raw shrimp waste caused a beneficial plant growth and crop yield mainly in Phaseolus vulgaris.
\end{abstract}

Keywords: crop quality, fertilization, fertilizing pellets, legume development, organic fertilizers, shrimp waste

\section{Introduction}

The global annual production of shrimp is nearly 4 million tons generating almost half of this weight in waste. This waste in turn, is composed of chitin, which forms microfibrillar arrangements embedded in a protein matrix with $\mathrm{CaCO}_{3}$. A green alternative for the use of this waste is to use it as an organic fertilizer in form of pellets or as a hydrolyzed material. The search for new organic fertilizers is important due to the limited availability of manure and compost in coast lines 
resulting promising the use of shrimp waste as an alternative organic fertilizer for crops. Currently, there is no information regarding the organic cultivation of legumes fertilized with shrimp-based waste.

A rapid and efficient shrimp waste hydrolysis could be accomplished by microwaves, which are non-ionizing electromagnetic radiation having wavelengths from $1 \mathrm{~mm}$ to $1 \mathrm{~m}$ corresponding to frequencies from $300 \mathrm{GHz}$ to $300 \mathrm{MHz}$, respectively. This radiation could provide the energy required to break the chemical bonds found in organic molecules such as C-C bonds $(347 \mathrm{~kJ} / \mathrm{mol})$, and hydrogen bonds such those found in the lignocellulosic biomass of rice straw $(3.9-10.1 \mathrm{~kJ} / \mathrm{mol})$ rendering a 5-fold increase in the yield of sugars [1].

Leguminous crops have been used for several centuries as a source of food for humans and animals [2]. These plants are originated from the Americas but they are now cultivated all over the world due to their high nutritional and culinary values. In fact, they contain high amounts of protein, vitamins (i.e., thiamine, pyridoxine, and folic acid), dietary fiber, complex carbohydrates (i.e., starch), and nutrients such as iron, potassium, phosphorous, selenium, molybdenum and calcium. They are highly desirable in the human diet since are low in sodium and calories [3]. Further, legumes are so important for human nutrition that $\sim 12$ million tons of Phaseolus vulgaris (PV) are consumed every year worldwide. Moreover, in 2014 the U.S. produced more than 86,700 metric tons of merely kidney beans. In fact, every day $\sim 14 \%$ of the U.S. population eats dry edible beans. Legumes are a vibrant part of food security across the world, especially in many developing countries. Thus, $\sim 400$ million people in the tropics eat beans as part of their daily diet. Legumes also provide income for millions of farmers, typically in Latin America and Africa.

The growth and development of legumes would require appropriate quantities of nutrients for their optimal development; otherwise, physiological deficiency symptoms could occur [4]. Nowadays, the current trend is the use of organic fertilizers for optimal vegetable development. However, the heterogeneity of the physical and chemical characteristics of the different organic fertilizers may give rise to different crop yields. Interestingly, legumes are known to be nitrogen fixers as they take nitrogen from the air by demand and release it into the soil, fulfilling their own nitrogen needs. This implies the need for an organic fertilizer which provides low levels of nitrogen accordingly [5]. For this reason, the intense use of chemical fertilizers for plant development is not advisable since it causes depletion of beneficial soil microbiota and potential pollution of soil and water [6].

Nowadays, organic fertilizers derived from worm castings, peat, manure, and poultry guano have been used to obtain an efficient organic crop production of several plant species [7]. They increase the organic matter and microorganism activity, improve porosity, water retention, and ion exchange capabilities of the soil. They also prevent root burning or destruction of soil microflora since they contain amino acids, organic matter and a variety of micronutrients that replenish the nutrient level of the soil and feeding important soil microorganisms [8]. For instance, the application of vermicompost in soil decreases root rot of beans and produces vigorous plants [9].

The main objective of the current study was to compare the physical characteristics of several shrimp-based fertilizers and their microwave-assisted hydrolyzates on the development of leguminous plants treated with these fertilizers under greenhouse conditions following an organic production. Fertility and substrate management in organic greenhouse production is important in short-term, low fertility requiring crops. Developing organic fertilizers that slowly release nutrients could improve the crop management of legumes produced organically in container production systems. 


\section{Materials and methods}

\subsection{Production of shrimp-based fertilizers and experimental design}

Dry shrimp exoskeletons were obtained from the pacific coast of Tumaco (Colombia), milled on a cutting mill (Model 3, Willey Arthur Thomas Co., Philadelphia, USA), and passed through a \# 100 mesh sieve. This material was labeled as F0. In a separate experimental set, pellets were produced using microcrystalline cellulose (MCC) as a pelletization aid. Thus, pellets made of pure MCC were made by wetting $\sim 20 \mathrm{~g}$ of MCC with $20 \mathrm{~mL}$ of distilled water and passed through a \#16 mesh sieve $(1190 \mu \mathrm{m}$ size $)$ with a force $\leq 11.2 \mathrm{~N} / \mathrm{cm}^{2}$ measured with a load cell (LCGD-10 K, Omega Engineering, Inc., Stamford, CT). The extruded thus obtained was put in the spheronizer chamber (Model 1LA70-4YA60, Siemens), which was operated at the spheronization rate of $15 \mathrm{~Hz}$ and spheronization time of $120 \mathrm{~s}$ producing beads, which were then oven-dried at $40^{\circ} \mathrm{C}$ for $24 \mathrm{~h}$. These pellets were then labeled as FPC. In another experimental set, a 50:50 mixture of raw waste and MCC was wetted with $42.5 \mathrm{~mL}$ of water and submitted to spheronization under the same conditions as explained for the raw MCC. These pellets were labeled as FPE. On the other hand, a hydrolyzed shrimp waste was obtained using a focused microwave apparatus (Samsung, Model MW 630 WA). A 10\% power was applied to ensure reproducibility. Approximately, $20 \mathrm{~g}$ of sample was dispersed in $200 \mathrm{~mL}$ of a $5 \% \mathrm{NaOH}$ solution and submitted to a refluxing action keeping the temperature between 50 and $60^{\circ} \mathrm{C}$. Radiation was continued for the selected exposure times of $0.85 \mathrm{~h}$ so a hydrolysis degree of $42 \%$ was obtained. The hydrolyzed product was then cooled down, neutralized with $1 \mathrm{~N} \mathrm{HCl}$, filtered and dried at $60^{\circ} \mathrm{C}$ for $24 \mathrm{~h}$. Further, pellets of this material were made under the same conditions employed for FPE and labeled as FHPE.

The physicochemical and functional properties of these pellets were compared to those of the untreated soil substrate (SS), untreated cotton substrate (CS) and two commercial fertilizers named as CF1 and CF2. SS was obtained from a local farm and contained a mixture of virgin soil (fine loam) and rice husk at a 3:2 ratio. CF1 and CF2 (N-P-K of 13.2-1-0) corresponded to an organic and extruded synthetic fertilizer, respectively.

\subsection{Treatments and cultural practices}

The greenhouse study was conducted in a non-temperature controlled agricultural research station near Medellin (lat. $6.12^{\circ} \mathrm{N}$, long. $-75.54^{\circ}$ E, altitude $2550 \mathrm{~m}$ ) having a $4 \times 4 \mathrm{~m}$ (width $\times$ length) greenhouse surrounded by a $10-\mathrm{mm}$ light diffusive template glass. The growing condition in the greenhouse was a mean temperature of $23^{\circ} \mathrm{C}$ day $/ 15^{\circ} \mathrm{C}$ night and from 65 to $85 \% \mathrm{RH}$ as recorded during the growth season. No supplementary light or heating was applied in the greenhouse station.

The soil used in the study was a mixture of fine loam (taken from 0 to $30 \mathrm{~cm}$ of a virgin soil) and rice husk at a 3:2 ratio. The soil was put in $2 \mathrm{~kg}$ PVC pots $(15 \mathrm{~cm}$ diameter). Healthy and mature legume seeds were obtained from a retail center of Medellin. Subsequently, one seed was sown in each pot randomly and irrigated uniformly with tap water. A plastic saucer was placed under each pot to prevent water loss by leaching. The plants were irrigated using one dripper per plant (at a discharging rate of $10 \mathrm{~mL} / \mathrm{h}$ ) and the total daily irrigation during the growing season ranged from 240 to $350 \mathrm{~mL} /$ plant. The irrigation volume ensured that soil was maintained wet in the growing medium. 
After germination, only vigorous seedlings were selected for growth in each pot. Five replications of each treatment were arranged in a completely randomized design. The germinated seeds were then treated with $\sim 4 \mathrm{~g}$ of the fertilizers in three amendments and these treatments were started on 1-week-old legume seedlings that emerged from direct seeding [12 d after direct seeding (DADS)]. Four and eight weeks after direct seeding, a second and third treatment was applied, whereas in the control treatments, no fertilizer was added (water only). The composition and physical properties of the fertilizers are listed in Table 1. Legume plants were trained to a single vertical pole around the main stem and fixed to a wooden stick having $1.5 \mathrm{~m}$ high from the ground to support the plant. There was no need to apply pesticides to control insects since plants were healthy and developed normally.

Plant height was evaluated on a monthly basis during the crop cycle. Harvesting started at 90 DADS and finished at 110 DADS. Legume plants were harvested twice a week when the pots reached maturity. Yield parameters that were measured for crop performance included pod length, pod mass, seed mass and pod number. The soil samples for chemical and microbiological analyses were collected from the surface layer $(0-10 \mathrm{~cm})$.

\subsection{Nutrient content of fertilizers and soil samples}

The $\mathrm{pH}$ of the $1 \% \mathrm{w} / \mathrm{v}$ fertilizer dispersion was measured with a handheld combo electrical conductivity (EC) and $\mathrm{pH}$ meter (EC600, Extech Instruments, Melrose, MA, USA). The moisture content of the materials was obtained by gravimetric methods, using a moisture balance analyzer (MB200, Ohaus, Parsippany, NJ, USA) equipped with a halogen lamp at $120^{\circ} \mathrm{C}$. The sensitivity of the measurements was $0.01 \%$. The total ash content was determined following the methodology described in the AOAC [10]. Briefly, samples were heated on a muffle oven (N31R, Mueller and Krempel, Nabertherm, Germany) at $546^{\circ} \mathrm{C}$ for $7 \mathrm{~h}$. The amount of the cooled residue was taken as the total ash content. The content of sugars was determined by the phenol-sulfuric acid colorimetric method [11].

The elemental analysis was conducted by Energy Dispersive X-ray analysis (EDX) (JEOL 6490LV, Peabody, MA). About $0.2 \mathrm{~g}$ of the samples were spread evenly over an aluminum stub and sputter-coated on a vacuum chamber (Desk IV, Denton Vacuum, Moorestown, NJ USA) with a 30\% gold coating for $5 \mathrm{~min}$ and operated at $15 \mathrm{kV}$. X-ray diffraction patterns were taken using an X-ray generator with $\mathrm{CuK} \alpha$ radiation and the linear surface sample scanning was conducted for $300 \mathrm{~s}, 10 \mathrm{~mm}$ depth of field and $50 \mu \mathrm{m}$ diffusion. A Malvern Nano-ZS90 Zetasizer equipped with a Zetasizer Software (vs 7.11, Malvern Instruments Ltd., UK) was employed to determine the particle charge at $25^{\circ} \mathrm{C}$ using the principle of Laser Doppler Velocimetry (LDV). The zeta potential (PZ) measurements were performed by adding $700 \mu \mathrm{L}$ of the sample in a polystyrene cell. Samples were analyzed between 12 and 16 cycles with a voltage of $4 \mathrm{mV}$. The ionic exchange test was carried out by weighing from 0.5 to $1 \mathrm{~g}$ of sample and $10 \mathrm{~mL}$ of $6 \mathrm{~N} \mathrm{HCl}$ was added and allowed to stand for $24 \mathrm{~h}$ followed by centrifugation for $20 \mathrm{~min}$ at $1550 \mathrm{rpm}$. Subsequently, it was submitted to washing with $1 \%$ saline solution twice and titrated with $0.8 \mathrm{~N} \mathrm{NaOH}$ solution. All measurements were expressed on a dry weight basis.

\subsection{Water sorption studies}

Water sorption studies were conducted employing the static gravimetry method on chambers having several saturated salts rendering different relative humidities. Thus, $\mathrm{K}_{2} \mathrm{CO}_{3}, \mathrm{NaBr}, \mathrm{NaCl}, \mathrm{KCl}, \mathrm{KNO}_{3}$ and $\mathrm{H}_{2} \mathrm{O}$ rendered constant relative 


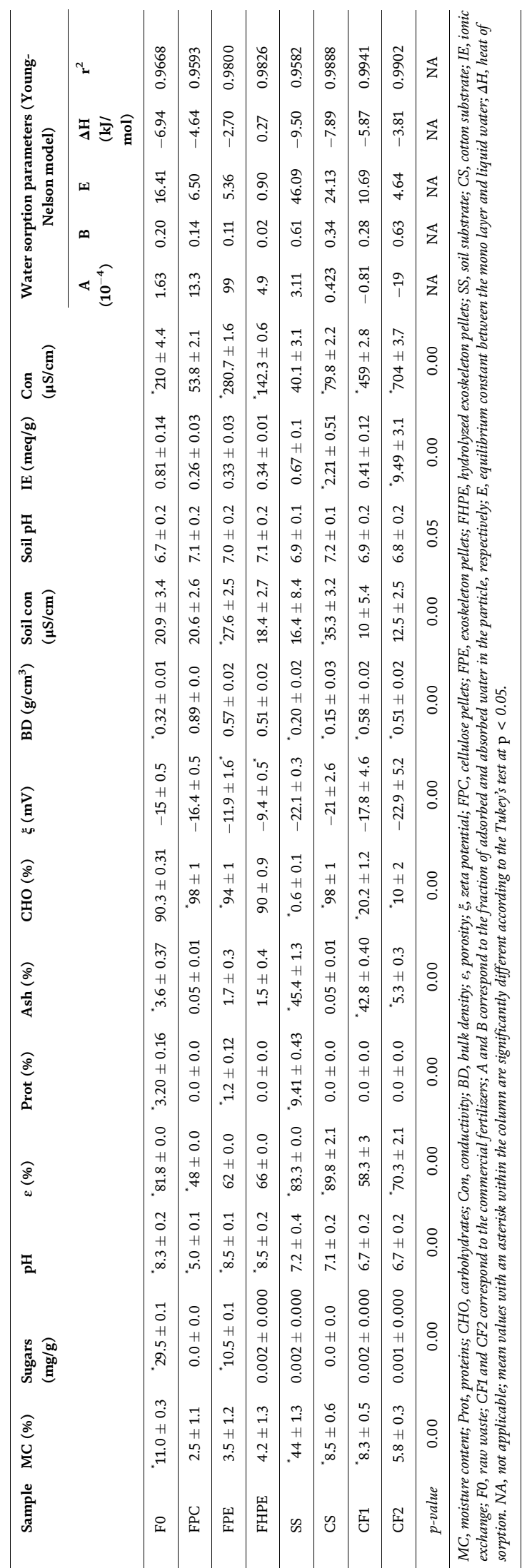

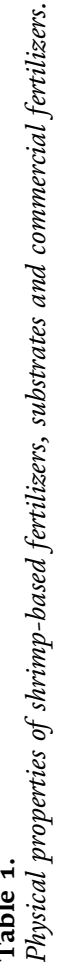


humidities of $43,58,68,75,94$ and $100 \%$, respectively. The isotherms were built at $25^{\circ} \mathrm{C}$ and samples were allowed to reach equilibrium for 2 weeks when the difference between two consecutive measurements was not larger than $0.1 \%$. Data were fitted to several sorption models, and only the one that presented the best fit was discussed in this study. The ability of the fertilizers for water sorption was studied by applying the Young and Nelson model which is expressed as:

$$
\begin{gathered}
m=m_{m}+m_{c}+m_{i} \\
m=\mathrm{A}(\theta+\beta)+\beta \psi \\
\theta=\frac{a_{w}}{a_{w}+\left(1-a_{w}\right) E} \ldots \\
\psi=a_{w} \theta \\
E=e^{-\left(H_{1}-H_{l}\right) / R T} \\
\beta=-\frac{E a_{w}}{E-(E-1) a_{w}}+-\frac{E^{2}}{(E-1)} \operatorname{Ln} \frac{E-(E-1) a_{w}}{E}-(E+1) \operatorname{Ln}\left(1-a_{w}\right)
\end{gathered}
$$

where $m_{m}, m_{c}$ and $m_{i}$ correspond to the tightly bound water, condensed external water and internally absorbed water, respectively. Further, m corresponds to the total moisture content, $\theta$ is the fraction of surface covered by a monomolecular layer, $\psi$ is the fraction of surface covered by a water layer of two or more molecules thick, and $\beta$ is the total amount of adsorbed moisture in the multilayer. Moreover, $\mathrm{H}_{1}, \mathrm{H}_{1}, \mathrm{k}$ and $\mathrm{T}$, correspond to the heat of adsorption of water bound to the surface, heat of condensation, the gas constant and temperature, respectively. A and B are dimensionless constants related to the fraction of adsorbed and absorbed water in the particle, respectively, and $\mathrm{E}$ is the equilibrium constant between the monolayer and liquid water. The product $\mathrm{A} \theta$ is related to the amount of monolayer moisture, $\mathrm{A}$ $(\theta+\beta)$ is the externally absorbed moisture during the sorption phase, whereas $B \psi$ corresponds to the amount of absorbed moisture during the sorption phase [12].

\subsection{Total aerobic bacteria and fungi counts}

These tests were conducted on samples without any previous treatment according to the National Technical Standard 4092 of microbiology. Briefly, $1 \mathrm{~g}$ of sample was dispersed in $10 \mathrm{~mL}$ of peptone water, making the pertinent dilution factors from $1 \times 10^{-1}$ to $1 \times 10^{-10}$. Subsequently, $1 \mathrm{~mL}$ of the solution was poured onto a $20 \mathrm{~mL}$ culture plate (Merck). Samples were then incubated at $37^{\circ} \mathrm{C}$ between 24 and $48 \mathrm{~h}$. The results were reported as colony forming units per gram of fertilizer (CFU/g).

\subsection{Statistical analysis}

The principal component analysis (PCA) was the type of multivariate analysis used to identify and compare the relationships and patterns among the physicochemical and functional properties of the fertilizers. The software Minitab® (v. 16 Minitab, Inc., State College, PA) was used for data processing. The relationship between the different crop characteristics was assessed by the Pearson's correlation coefficient at a significance level of $p<0.05$. Additional post hoc assessment was performed using the Tukey's test $(p<0.05)$ when significant differences between means were observed. The condition of normality was checked using the Shapiro-Wilk test. 


\section{Results and discussion}

\subsection{Preparation and physical properties of the fertilizers}

Microwave radiation accelerated the degradation of alkaline shrimp waste forming a product having a hydrolysis degree of $42 \%$. Thus, hydroxyl radicals of the alkaline media along with microwave radiation contributed to molecular weight reduction of waste compounds such as carbohydrates and proteins and avoided the need for a time-consuming composting of the raw waste and thus, decreased the initial microbial population avoiding further release of putrescine and other nitrous volatile compounds. Shrimp waste possesses the striated type muscle arranged into muscle fibers that are bound together by a connective tissue where the prevalent amino acid is lysine. These muscle proteins are associated to chitin and minerals such as calcium phosphate. The protein and chitin availability are important since they will eventually turn into accessible nitrogen for legumes. The magnitude of the peptide and glycosidic bonds cleavage during microwave hydrolysis rendered an organic fertilizer having a moderate hydrolysis degree.

During the wet massing process MCC was essential as spheronization aid. Previous studies (data not shown) determined the need of at least $50 \% \mathrm{MCC}$ as optimal in order to obtain a spherical pellet having good mechanical properties (FPE and FHPE). Thus, MCC fibers alone or combined with waste coalesced and formed larger particles which were then shaped once they passed through the screen orifices. These, in turn, were molded in the spheronizer which cut-off and rounded-off the sharply and roughly surfaces. The rotating plate operating at the $15 \mathrm{~Hz}$ rate and residence time of 120 s produced a denser and smoother pellet surface due to the combined action of the centrifugal force created by plate rotation, the vertical force formed by collision, and the gravitational force allowing for the formation of a toroidal or twisted rope motion having an spiral pattern. As a result, this high frequency and short residence time generated more frictional and rotational forces where the initial small, oblong and irregular particles experienced growth, folding and edge rounding which was subsequently shaped into dumb bells. These dumb bells were then twisted, broken, rounded and transformed into spherical or semispherical beads.

On the contrary, raw waste per se failed to produce pellets or aggregates due to the lack of plasticity needed for the spheronization process, this fact also occurred by employing a very short residence time resulting in pellets of a predominantly small size, oblong shape and rougher surface. The spheronization platform usually renders bead sizes of about $1000 \mu \mathrm{m}$. In this case, by using a \#20 screen sieves the size of the resulting beads ranged from 1.2 to $3 \mathrm{~mm}$. Particle size tends to increase with residence time and this variable was kept at $120 \mathrm{~s}$ avoiding loss of moisture and maintaining the required plasticity for pellet growth. This high spheronization rate guarantees the formation of beads with diameters larger than $1 \mathrm{~mm}$. The spherical morphology and particle size played a major role on densification and porosity. This occurrence was reflected on the resulting porosity which in turn, decreased with pelletization. On the other hand, the degree of densification decreased by the spheronization process. This is explained by the highly regularly-shaped particles that are less likely to accommodate in the powder bed under the action of an external force as compared to the non-spheronized irregular particles. Flowability is the property that reflects the way in which gravity overcomes the cohesive forces and the interlocking structure of the particles. In general, the flowability of the pellets was high ranging from 13.4 to $16.4 \mathrm{~g} / \mathrm{s}$, independent of the average bead mass. A constant plate diameter of $30 \mathrm{~cm}$ was employed at spheronization rates of $15 \mathrm{~Hz}$ which is equivalent to $900 \mathrm{rpm}$ and peripheral velocity of $1415 \mathrm{~cm} / \mathrm{s}$, 
respectively. This rotational speed and short residence time (120 s) was suitable to obtain spherical beads.

\subsection{Nutritional content of the fertilizers and plant development}

The nutritional content of the shrimp-based fertilizers (SBF) is listed in Table 1. The hydrolyzed product retained much of the initial nutrients contained in the raw shrimp exoskeletons. The alkaline microwave hydrolysis disrupted the inter and intra-molecular hydrogen bond pattern of complex carbohydrates and proteins initially present in the material, disturbing the regularity of the 3D packing and stereochemistry between chains, especially of the most accessible amorphous regions. As a result, the alkaline hydrolysis of the non-crystalline fraction removed monomer blocks of repeated units, especially those located at the crystallite surface and hence, $\mathrm{NaOH}$ accessed the $\beta-1,4 \mathrm{~N}$-acetyl and peptidic linkages, simultaneously. The net result was a reduction in the crystallinity of the shrimp fertilizer. In fact, the application of high intensity waves caused chemical and mechanical degradation in the waste particles, resulting in changes in the native shrimp protein and carbohydrate structure into a molten globule state.

The $\mathrm{pH}$ and moisture content of these fertilizers ranged from 5.0 to 8.5 and from 2.5 to $11 \%$, respectively. Once the fertilizers were incorporated into the soil maintained a slightly neutral ambient ( 6.7-7.2) and the electrical conductivity ranged from $\sim 12$ to $28 \mu \mathrm{S} / \mathrm{cm}$. A neutral $\mathrm{pH}$ ensured a good availability of the nutrients to the leguminous plants. The high moisture content eased the transformation of macromolecular $\mathrm{N}$ into $\mathrm{NH}_{4}{ }^{+}$and $\mathrm{NO}_{3}{ }^{-}$by bacteria action resulting in its mineralization and easy uptake by plants as reported previously [13]. The slightly alkaline $\mathrm{pH}$ of F0 is attributed to the presence of peptides, and elements such as $\mathrm{Ca}^{2+}$ and $\mathrm{Mg}^{2+}$. Further, these divalent ions can then be adsorbed onto the surface of tiny clay particles of the soil which had a net negative charge. The magnesium level in the shrimp-based fertilizers (SBF) was lower than that of calcium so its effect on the soil structure was negligible. The negative surface charge of soil particles is believed to improve $\mathrm{P}$ availability in form of phosphates as present in shrimp waste. These phosphates along with the $\mathrm{P}_{2} \mathrm{O}_{5}$ of CF2 could be responsible for the large $P V$ crop yield found in F0 and CF2, respectively. Conversely, $\mathrm{K}$ was virtually absent in most fertilizers and its synergistic effect on crop yield was not noticed.

The zeta potential indicates the average charge in the particles and gives a measurement of the ion activity of the fertilizers. All materials exhibited a net negative charge and CF2 had the largest ion exchange capability and electrical conductivity altogether. Conversely, FHPE exhibited the smallest value of electrical conductivity. Interestingly, CS showed a large ionic exchange capability, but a moderate electric conductivity due to the residual ionized functional groups present in this type of cellulose.

Table 2 lists the elemental composition of each type of SBF, substrates and commercial fertilizers. Alkaline microwave hydrolysis had a marked effect on the nutritional content of the shrimp waste. This had a large content of essentially $\mathrm{C}, \mathrm{N}$, $\mathrm{Ca}$ and $\mathrm{P}$. On the other hand, $\mathrm{Fe}, \mathrm{Si}, \mathrm{Al}, \mathrm{Mg}$ and $\mathrm{Cl}$ were present as the main microelements. The content of Mg, was larger in the F0 than SS, CS and pellets, whereas the $\mathrm{K}$ content was low in all cases except for $\mathrm{CF} 1$. The $\mathrm{C} / \mathrm{N}$ ratio was slower than 10 for F0, FPE, FHPE, CF2, and FPC whereas CF1 (10.5) and SS (33.1) showed the largest $\mathrm{C} / \mathrm{N}$ ratio due to their low content of $\mathrm{N}$. Further, the SS and CF1 were poor in organic nitrogen, but rich in carbon, silicon and aluminum. On the other hand, CS had a poor content of most elements except for carbon and oxygen. The SS, FPC and CS presented low levels of essential elements such as N, P, and Ca as compared to F0, FPE and FHPE. Interestingly, CF1 and SS showed traces of other 


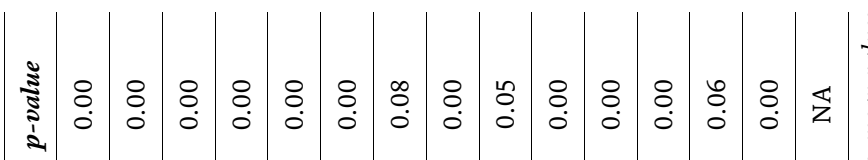

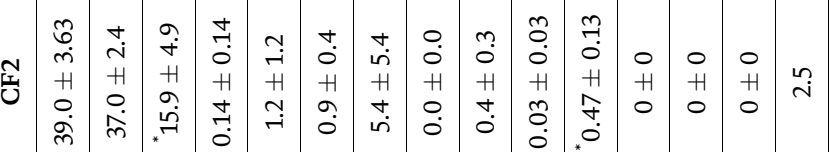

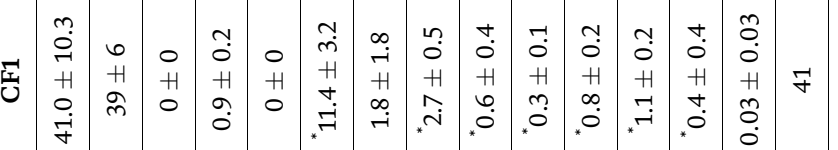

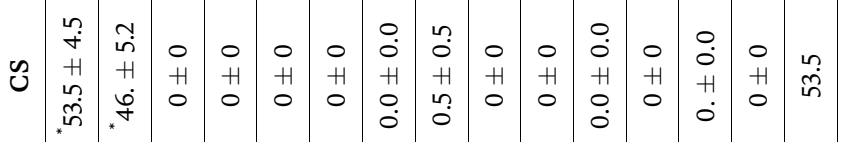

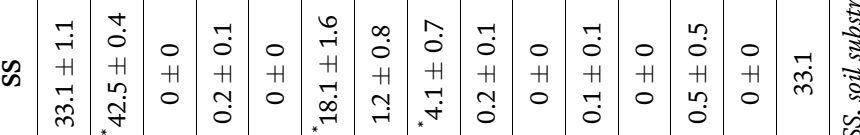

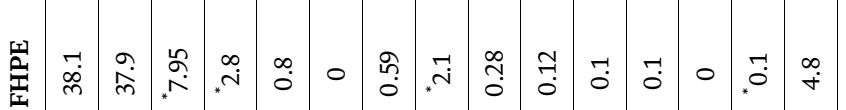

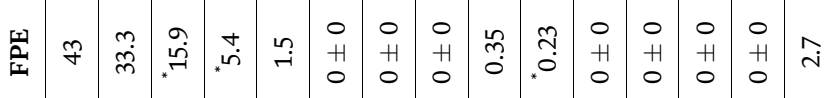

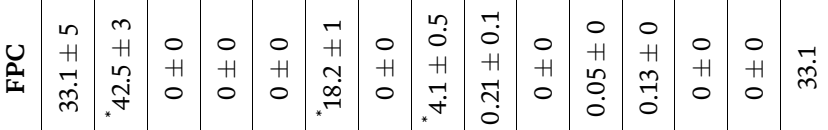

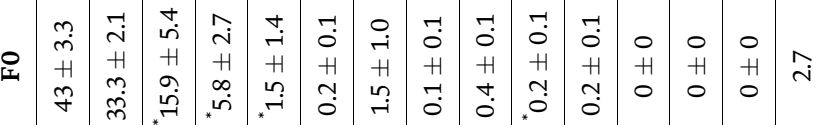

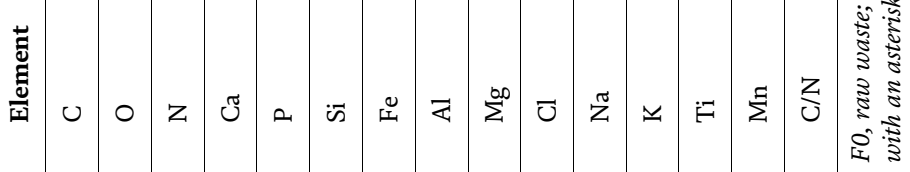


microelements such as $\mathrm{K}, \mathrm{Ti}$, and essentially CF1 was the only fertilizer which contained traces of $\mathrm{Mn}$. On the other hand, CF2 contained $\mathrm{N}$ from urea and $\mathrm{P}$ from $\mathrm{P}_{2} \mathrm{O}_{5}$ at a 13:1 ratio.

\subsection{Water uptake}

The water vapor sorption isotherm of a material describes the relationship between the relative vapor pressure or water activity, $\left(a_{w}\right)$ and water content over a range of $a_{w}$ values obtained at a given temperature [14]. The fitting water sorption parameters obtained from the Young-Nelson model revealed a good fitting to this model having an $\mathrm{r}^{2}$ larger than 0.9582 as compared to other models not shown in this study.

Figure 1a shows that during the first sorption stage $\left(a_{w}<0.45\right)$, the isotherms exhibited a convex shape as the water molecules rapidly sorb onto the available sorption sites until a monolayer is formed. The shape of the isotherms during this first stage did not differ substantially among the different SBF, but was larger for SS and CF2. Thereafter, there was a gradual increase in water content with $\mathrm{a}_{\mathrm{w}}$ up to $\sim 0.80$ where an abrupt increase of water content was observed possibly due to capillary condensation phenomena. Interestingly, most fertilizers showed a steady increase in monolayer and multilayer formation up to $\mathrm{a}_{\mathrm{w}}$ of 0.45 , afterwards the water molecules although still in vapor form, begin to diffuse within the particle core except for SS, FPE and FPC in which this process started at a very low $\mathrm{a}_{\mathrm{w}}$ (Figure 1b). Therefore, in these materials isotherms proved that water did not form a continuous monolayer because the multilayer and particle water absorption occurred simultaneously. This phenomenon has been attributed to the tendency of water molecules to cluster around exchangeable cations found in different soils [14]. As a result, water molecules bind as succeeding layers of water molecules rather to empty sites on the surface of the particle. Thus, the formation of a second layer probably started at lower concentration than those corresponding to the monolayer formation. Clustering was expected to occur in most cases since the amount of water molecules on the particle was higher than the quantity that can be bound within the particle. Further, SS and CF2 per se had an innate ability to uptake and keep water within the particles and were able to preserve the wet environment for the optimal root and microbiota development.

CF2 at all $\mathrm{a}_{\mathrm{w}}$ showed the lowest tendency for clustering, but the largest sorption within the particle core. The deconvoluted curves showed that the monolayer formation presented a type III Langmuir isotherm, whereas the curves for the multilayer sorption showed a type II isotherm. Interestingly, CF2 also showed the largest cation exchange capability and ionic conductivity. This agrees with previous studies that reported a relationship between the high water sorption and the ion exchange capability of the soil [15].

The raw soil substrate (SS) showed the largest E parameter and hence, presented the largest heat of endothermic sorption $(\Delta \mathrm{H})$. Further, SS and CF2 showed the largest intrinsic absorbed water (B parameter), whereas CS showed the largest adsorption ability forming multilayers. CF2 and SS showed the largest hygroscopicity, especially at a water activity larger than 0.4 . Further, these two samples had the largest ability to absorb water intrinsically, whereas SS and CS per se were able to form large water multilayers around the particles. In addition, the water sorption behavior of SBF was comparable to that of CF1.

\subsection{Soil microstructure and microbial activity}

The ionic exchange capability of the SBF decreased upon hydrolysis as compared to F0 due to leakage of some ions such as calcium and phosphates. Further, the 
Comparative Assessment of Shrimp Hydrolyzates as Alternative Organic Fertilizers for Legumes DOI: http://dx.doi.org/10.5772/intechopen.86914

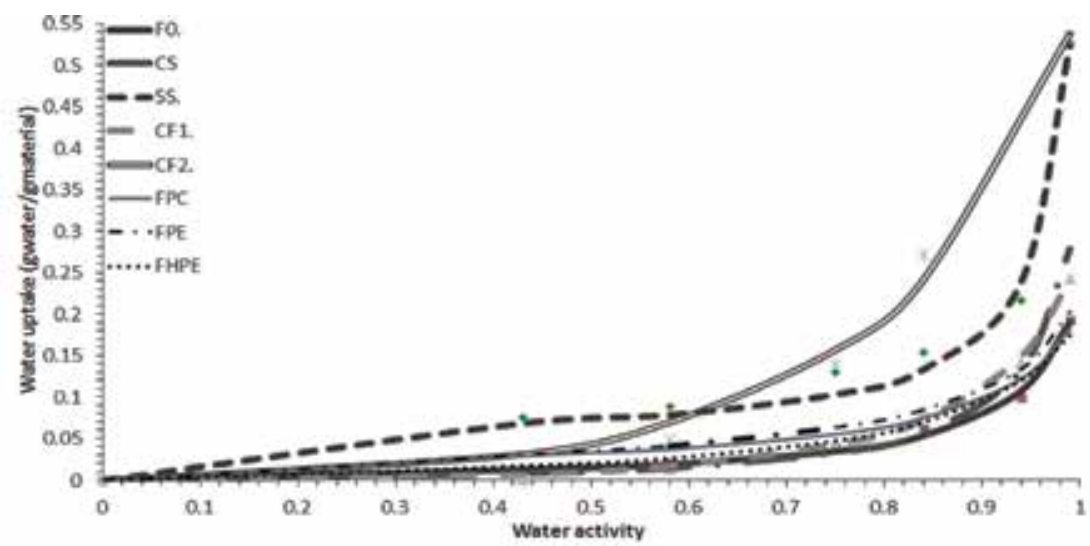

(a)

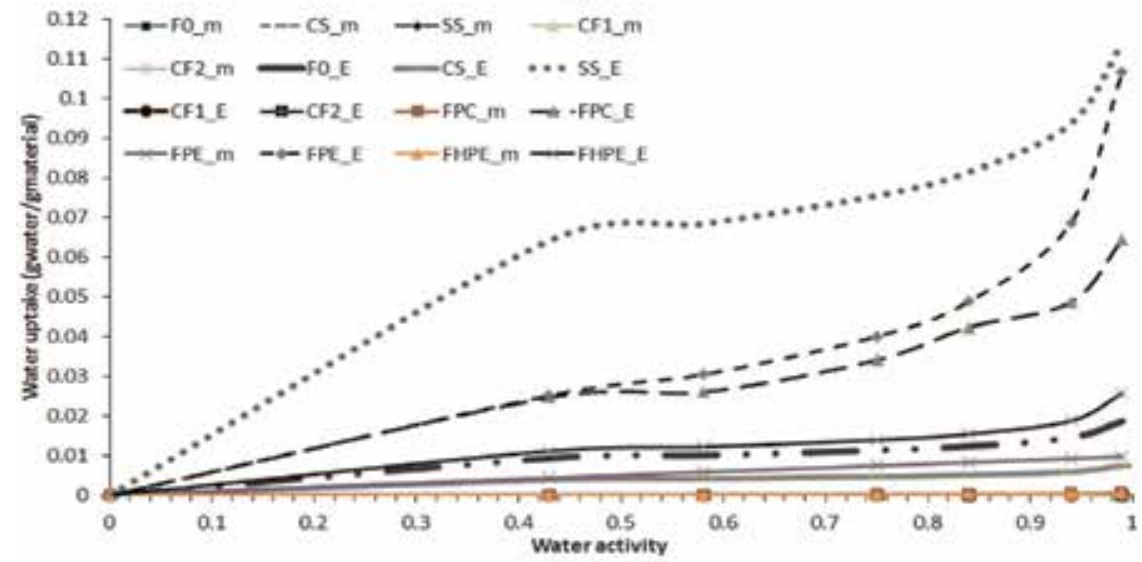

(b)

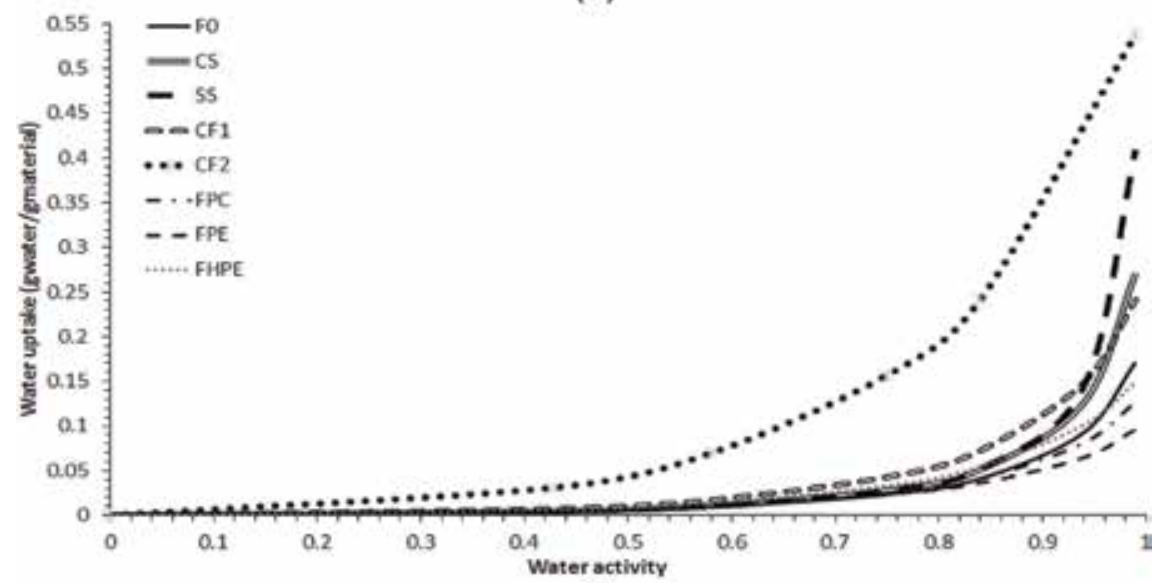

(c)

Figure 1.

Water sorption isotherms fitted to the Young-Nelson model. (a) Fitted isotherms, (b) deconvoluted sorption behavior for the monolayer and multilayers, and (c) deconvoluted sorption behavior for the intrinsic absorbed water $(\mathrm{n}=3)$.

incorporation of these fertilizers into the soil did not have a marked effect on the physicochemical properties of the topsoil due to a dilution effect. Thus, the electrical conductivity of the soil was low $(10-28 \mu \mathrm{S} / \mathrm{cm})$ as compared to the pure fertilizers, but outside the range recommended for other horticultural plants 
(0.76-4.0 $\left.\mathrm{mS} \mathrm{cm}^{-1}\right)$ [16]. Further, the negative charge of the SBF is due to the residual amine groups of chitin and amino acids. The ash content of the SS (45.4\%) and CF1 (42.8\%) were larger than most fertilizers $(<5.3 \%)$ mainly due to their high silicate and carbonate content. The content of carbohydrates of FPE and FHPE (90-94\%) was lower than that of CS and FPC; whereas the content of proteins was relatively low and tended to disappear upon hydrolysis as happened for sugars. Moreover, densification $\left(0.51-0.89 \mathrm{~g} / \mathrm{cm}^{3}\right)$ and porosity $(48-66 \%)$ increased upon pelletization, whereas CS and SS as expected showed the lowest bulk density, but the largest total porosity.

It was estimated that complex carbohydrates present in SBF such as chitin could act as a cementing agents bonding soil particles together improving soil structure and stability. Further, it is reported that calcium ions could act as a cementing agents, bonding soil particles into aggregates resulting in the formation of strong, water-stable aggregates [17]. However, the net postharvest bulk density of the soil did not vary significantly upon treatment with fertilizers probably due to the low applied rate, and density remained in the range generally considered suitable for the normal growth of crops. This low bulk density made root growth and penetration easier and improved the size and system of voids in the soil matrix enabling aeration and water movement. Moreover, the particle size of the powdered fertilizers ranged from 50 to $150 \mu \mathrm{m}$ and that of the soil and pellets were about 300 and $2 \mathrm{~mm}$, respectively being able to decompose slowly matching the particle size of the soil.

Figure 2 depicts legume growth as a function of time. The largest and fastest growing period of both legumes occurred within the first 2 months of the crop cycle. Both plants followed a sigmoid or S-shaped curve during the growing season corresponding to the period of rapid nutrient uptake. Further, both legumes showed the best growing phase upon fertilization with CF2. Conversely, a slow growth profile for both plants was observed once fertilized with FPE and FHPE. This phenomenon is explained by the reduction of essential nutrients different from $\mathrm{C}$ and $\mathrm{O}$.

On the other hand, the pod length, pod mass, and seed mass of $P V$ were outstanding when treated with CF2 and comparable to those of F0 (Table 3). Conversely, crop quality of Pisum sativum $(P S)$ as described by these parameters was superior for SS and only FHPE showed good characteristics among the fertilizing pellets. Further, FPC had the worst crop quality an in this particular case plants were not able to render any kind of grain. Likewise, the fact of having a large pod number was not necessary translated into a large crop yield, but pod length, pod mass and seed mass were all good indicatives of crop yield for both legumes $(r>0.859)$.

The SBF were applied at a rate of $4 \mathrm{~g} / \mathrm{kg}$ soil in three monthly amendments. SBF having $8-20 \% \mathrm{~N}$ had a variable effect on legume growth characteristics depending on the composition. As a result, they showed distinctive quantitative and qualitative
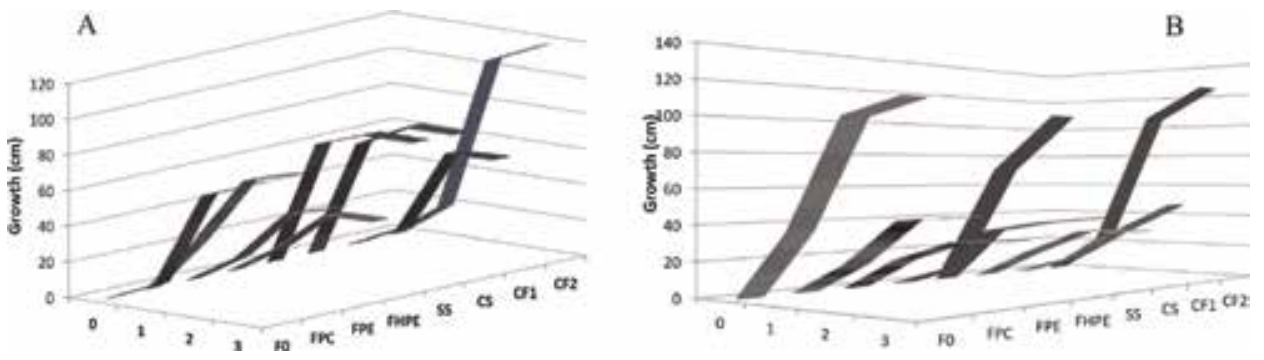

Figure 2.

Growth profiles given by shrimp-based fertilizers, substrates and commercial fertilizers: $(A)$ Phaseolus vulgaris and $(B)$ Pisum sativum. 


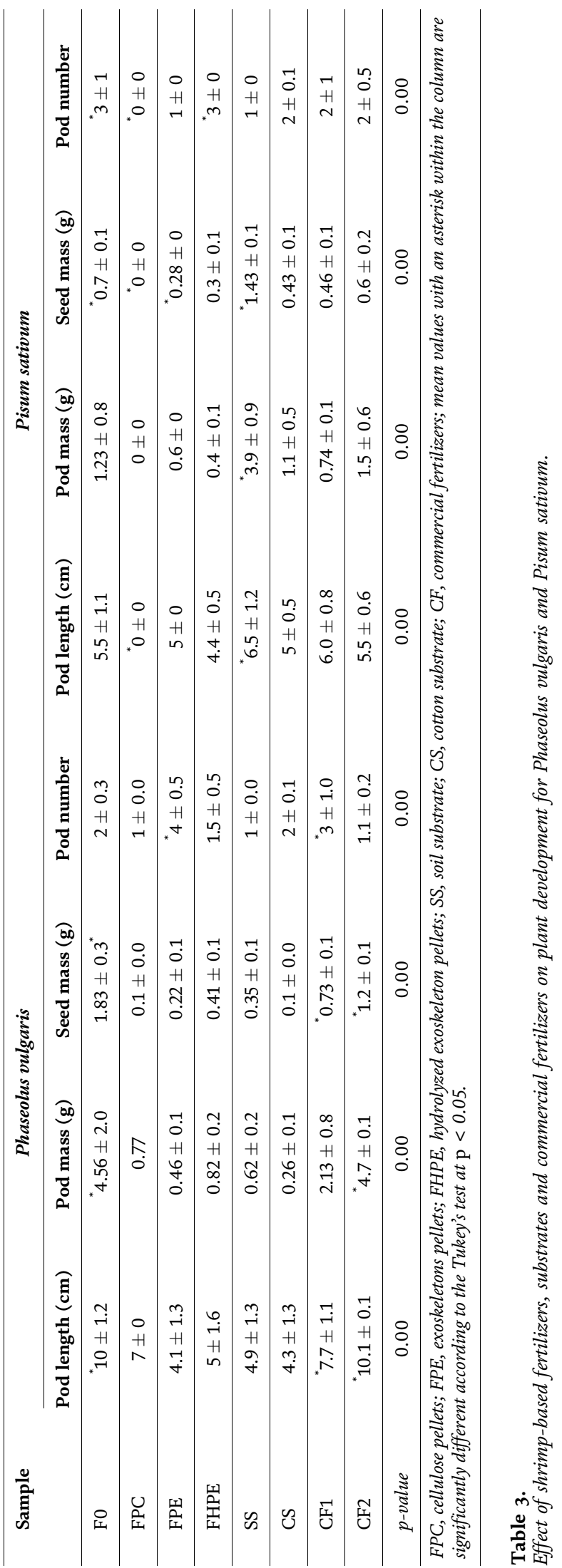


traits of grain yield of legumes, especially for $P V$. It has been reported that a large amendment of $20 \%$ organic fertilizer (vermicompost) was needed to get the highest pod weight, pod number, pod dry weight and pod length of legumes [5]. In this study, there was a remarkable mismatch between plant growth and plant yield. For instance, CF2 and F0 rendered plants with a good growth and crop yield especially for $P V$, whereas CP2 only led to a good plant growth rather than crop yield in $P S$. This is explained by the content of urea: $\mathrm{P}_{2} \mathrm{O}_{5}$ (N/P ratio of 13.2), which is recommended by the supplier for the rapid plant growth. In all cases, the $\mathrm{N}$ uptake and growth rate were prominent within 30 and 60 days after sowing. In other words, the growth rate progressively increased over time during the vegetative growth up to 4-8 weeks after which growth slowed down as the reproductive phase initiated. Legume growth was not significantly improved with most SBF despite of having a considerable content of available $\mathrm{N}$ due to the slow release of this element. However, macroelements such as N, C, P, and Ca were available 45 days after sowing for the appropriate blooming and protein development. Interestingly, the unfertilized CS showed a slow development and crop quality for both legumes, especially for $P S$ and thus these plants were not very efficient as atmospheric $\mathrm{N}$ fixers to compensate for the lack of $\mathrm{N}$ in the CS. In this case, the branched root hair systems of the legumes were not sufficient to ease $\mathrm{N}$ mineralization during the growing phase and as a result, they showed the poorest crop yield.

The soil amended with the fertilizers had $\mathrm{pH}$ values between 6.7 and 7.1, which are considered optimum for the rapid development of most ubiquitous microorganisms. At this $\mathrm{pH}$ range $\mathrm{N}$ loss due to ammonia volatilization is prevented since this phenomenon only occurs at acid $\mathrm{pH}(<6.0)$ [18]. Soil porosity was $\sim 83 \%$ and moisture at saturation was $>40 \%$ and these levels were not affected by fertilization. The lower water content of SBF was attributed to the presence of insoluble carbohydrates, proteins and of calcium ions. The high moisture content in the soil near to field capacity was responsible for the high diversity of viable microbial during the legume developing phase. These in turn, promoted mineralization and increased available $\mathrm{N}$. The high population of aerobic bacteria found during the whole crop cycle eased nitrogen fixation from the fertilizers and the atmosphere. Interestingly, $P V$ was able to modify its own root environment to maximize nutrient uptake. Thus, the inherent absence of $\mathrm{N}$ of the unfertilized substrate forced the plant to increase the root pattern so the nitrogen demand could be obtained by microbial (especially fungi) $\mathrm{N}_{2}$ fixation, as reported previously [19]. However, this $\mathrm{N}$ uptake was not sufficient to achieve an optimum plant growth of $P S$ since the unfertilized substrates showed the poorest growth rate in the CS. Conversely, SS showed better crop quality than CS due to the higher content of $\mathrm{Si}, \mathrm{Mg}, \mathrm{Fe}$ and $\mathrm{Ca}$ which were absent in CS.

It is accepted that during the decomposition of an organic fertilizer the microbial population requires an optimal diet with a C:N ratio of $\sim 15: 1$ to meet their needs for nutrients. Since the F0, FPE, FHPE and CF2 had a C:N ratio of less than 15:1 they had more $\mathrm{N}$ than the microflora require for their own growth in the initial crop cycle and are likely to provide significant plant available $\mathrm{N}$ leading to an increased mineral $N$ levels through mineralization carried out by microbial metabolism (production of $\mathrm{NH}_{4}{ }^{+}$and $\mathrm{NO}_{3}{ }^{-}$) [20]. This phenomenon was reflected on a large microbial population in the soil within the first month $(>50,000 \mathrm{cfu} / \mathrm{g}$ of bacteria and $>100 \mathrm{cfu} / \mathrm{g}$ for fungi). Conversely, the SS, FPC, CS CF1 had a C:N ratio of more than 25:1 and thus, it is assumed a rapid immobilization of the scarce $\mathrm{N}$ by microorganisms in this growing phase [21]. Since those fertilizers had $\mathrm{N}$ content above $2.5 \%$, they are expected to release nutrients once decomposed by the soil microbiota. The N, P and K ratio of the SBF, and SS were $\sim 1-0.1-0.0$, and $0-0-0.1$, respectively. These ratios are different from other reported for fertilizers such as cow manure (0.97-0.69-1.66) and compost of raw straw (0.81-0.18-0.68). 


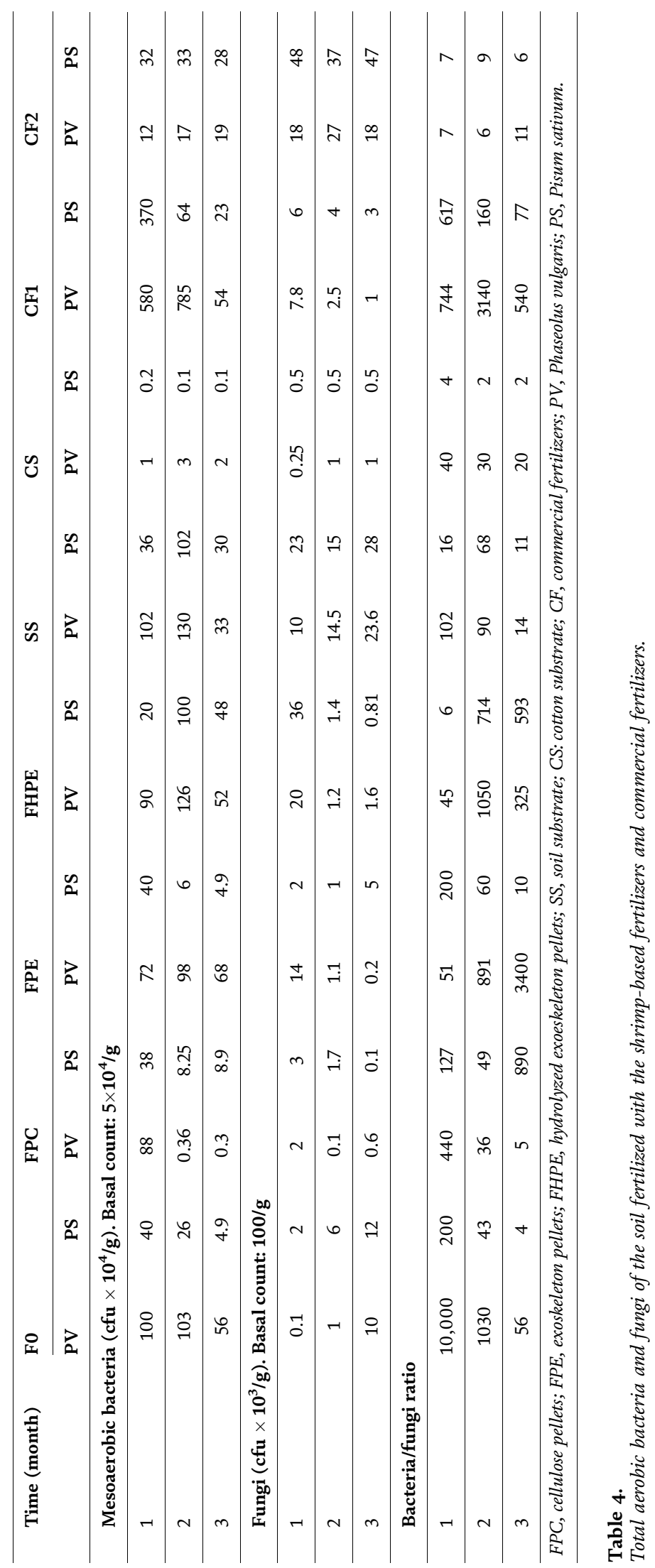




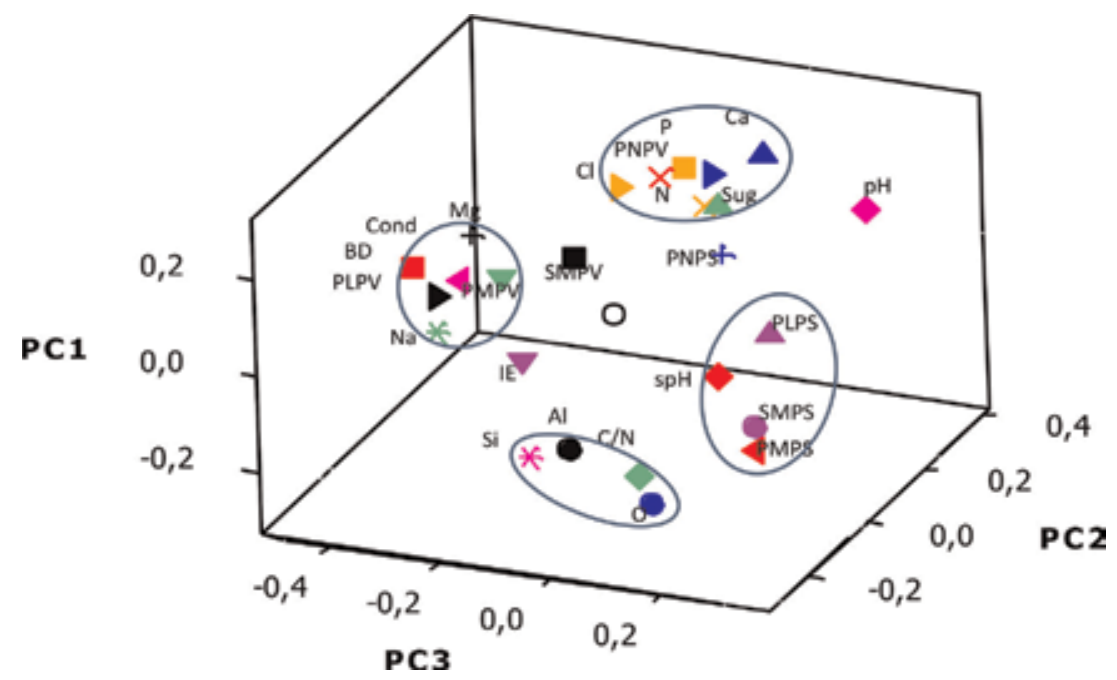

Figure 3.

Principal component plot for key properties of fertilizers.

The fertilizers once incorporated into the soil showed a variable microbial population which decreased over time, possibly due to depletion of soil nutrients that share with plants in a symbiotic way. In fact, the bacteria population was larger in soils containing $P V$ than $P S$ (Table 4). Conversely, the latter favored the proliferation of fungi in the soil. Further, fertilizer type also influenced the bacterial proliferation; for instance, CF1 rendered the largest bacterial population in the soil, whereas CF2 maintained a virtually constant bacterial count. On the contrary, the soil population of fungi tends to increase over time except for soils treated with CF1 and fertilizing pellets where tended to decrease. This fact was reflected on the bacteria to fungi ratio which decreased over time except for the fertilizing pellets and commercial products which increased and remained unchanged, respectively. The high microbial content of the fertilizers mingled with those of the soil microflora favoring the rapid development of bacteria and fungi, which in turn decreased during the crop cycle.

The multivariate analysis rendered interesting facts about this study. The first three components explained $73.3 \%$ of data variability (Figure 3). In the PCA plot four great clusters are observed apart from the center. The first one depicts the influence of $\mathrm{Mg}$ and $\mathrm{Na}$ on crop quality of $P V$ and the second cluster relates the pod number of $P V$ with the content of $\mathrm{Na}, \mathrm{P}, \mathrm{N}$, and sugars. The third cluster is related to the crop quality of $P S$ and soil $\mathrm{pH}$; whereas the fourth cluster relates $\mathrm{Si}, \mathrm{Al}$ with the $\mathrm{C} / \mathrm{N}$ ratio. Moreover, a correlation analysis confirmed that fertilizers having a high content of Si also had high $\mathrm{Al}(r>0.920)$. Likewise, fertilizers having a high level of $\mathrm{N}$ also showed low levels of $\mathrm{O}$ and $\mathrm{C} / \mathrm{N}(r>-0.874)$. Further, high levels of $\mathrm{Mg}$ were correlated with those of $\mathrm{Na}(r=0.806)$ and fertilizers having a high content of $\mathrm{N}$ also showed high levels of $\mathrm{P}(r=0.999)$.

\section{Conclusions}

The raw waste rendered an optimal crop quality, especially for $P V$, but showed a lower growth as compared to CF2. Conversely, the pelletization of raw shrimp waste had a deleterious effect on the crop quality of both legumes. Further, the 
absence of N, Ca and P in the unfertilized substrates limited legume growth, and microbial activity. This suggested that nutrient sufficiency ranges may require minor adjustment for plant development. Further, viable microorganism population increased in the beginning of the crop cycle and then declined possibly due to depletion of nutrients, but provided short-term fertility benefits for the legumes productivity. These fertilizers are considered more ecofriendly, more efficient, and accessible to marginal and small farmers located in the coast lines. Shrimp-based fertilizers were found to be an alternative soil amendment for legume crops grown using organic methods.

\section{Acknowledgements}

The authors are grateful to Colciencias for providing the financial resources for the execution of this study through the Grant No. 111571551545 and contract no. 036-2016. Authors thank CODI for their sustainability strategy 2018-2019 of University of Antioquia.

\section{Conflict of interest}

The authors declare no conflict of interest.

\section{Author details}

John Rojas $^{1 *}$, Julian Qunitero ${ }^{1}$, Yhors Ciro $^{1}$, Alfredo Moreno ${ }^{1}$, Javier Silva-Agredo ${ }^{2}$ and Ricardo A. Torres-Palma ${ }^{2}$

1 Department of Food, College of Pharmaceutical and Food Sciences, University of Antioquia, Medellín, Colombia

2 Grupo de Investigación en Remediación Ambiental y Biocatálisis (GIRAB), Facultad de Ciencias Exactas y Naturales, Instituto de Química, Universidad de Antioquia UdeA, Medellín, Colombia

*Address all correspondence to: jrojasca@gmail.com

\section{IntechOpen}

(C) 2019 The Author(s). Licensee IntechOpen. This chapter is distributed under the terms of the Creative Commons Attribution License (http://creativecommons.org/licenses/ by/3.0), which permits unrestricted use, distribution, and reproduction in any medium, provided the original work is properly cited. (cc) BY 


\section{References}

[1] Bassoyouni FA, Abu-Bakr SM, Rehim MA. Evolution of microwave irradiation and its application in green chemistry and biosciences. Research on Chemical Intermediates. 2012;38:283-322. DOI: 10.1007/s11164-011-0348-1

[2] Brink M, Belay GE. Plant resources of tropical Africa: Conclusions and recommendations based on PROTA 1. In: Cereals and Pulses. Leiden: Backhuys; 2006

[3] Valdez-Perez MA, FernandezLuqueno F, Franco-Hernandez O. Cultivation of beans (Phaseolus vulgaris) in limed or unlimed wastewater, sludge, vermicompost or inorganic amended soil. Scientia Horticulturae. 2011;128: 380-387. DOI: 10.1016/j.scienta.2011. 01.016

[4] Takahashi K. Physiological disorders in Chinese cabbage. In: Talekar NS, Griggs TD, editors. Chinese Cabbage. Shan Hua, Taiwan: AVRDC; 1981. pp. 225-233

[5] Aminul M, Nasrulhaq A, Motior R, Sofian M, Aqeel M. Effects of organic fertilizers on the growth and yield of bush bean, winged bean and yard long bean. Brazilian Archives of Biology and Technology. 2016;59:1-9. DOI: 10.1590/ 1678-4324-2016160586

[6] Derkowska E, Paszt L, Trzcinsky P, Przibyl M, Weszczak K. Influence of biofertilizers on plant growth and rhizosphere microbiology of greenhouse-grown strawberry cultivars. Acta Scientiarum Polonorum-Hortorum Cultus. 2015;14:83-96

[7] Aluko OA, Olanipekun TO, Olasoji JO, Abiola IO, Adeniyan ON, Olanipekun SO, et al. Effect of organic and inorganic fertilizer on the yield and nutrient composition of jute mallow. Global Journal of Agricultural Research. 2014;2:1-9
[8] Ghimire A. A Review of Organic Farming for Sustainable Agriculture. Tribhuvan University; 2002

[9] Cespedes L, Stone MC, Dick RP. Organic soil amendments; impacts on snap bean common root rot and soil quality. Applied Soil Ecology. 2006;31: 199-210. DOI: 10.1016/j.apsoil.2005. 05.008

[10] Association of Official Agricultural Chemists. Method 923.03: Ash of Flour (Direct Method). 2005

[11] Albalasmeh AA, Berhe AA, Ghezzehei TA. A new method for rapid determination of carbohydrate and total carbon concentrations using UV spectrophotometry. Carbohydrate Polymers. 2013;97:253-261. DOI: 10.1016/j.carbpol.2013.04.072

[12] Young JH, Nelson GL. Research of hysteresis between sorption and desorption isotherms of wheat. Transactions of ASAE. 1967;10:756-761

[13] Tucker LC. Comparison of Two Different Organic Fertilizer Sources for Flue-Cured Tobacco. Virginia Polytechnic Institute and State University; 2015

[14] Arthur EM, Tuller PM, de Jonge LW. Evaluation of theoretical and empirical water vapor sorption isotherm models for soils. Water Resources Research. 2016;52:190-205. DOI: 10.1002/2015WR017681

[15] Woodruff WF, Revil A. CECnormalized clay-water sorption isotherm. Water Resources Research. 2011;47:1-15. DOI: 10.1029/ 2011WR010919

[16] Nelson PV, Pitchay DS, Niedziela CE, Mingis NC. Efficacy of soybeanbaseliquid fertilizer for greenhouse 
crops. Journal of Plant Nutrition. 2010;

33:351-361. DOI: $10.1080 /$

01904160903470406

[17] Yang R, Su YZ, Wang T, Yang Q.

Effect of chemical and organic fertilization on soil carbon and nitrogen accumulation in a newly cultivated farmland. Journal of Integrative Agriculture. 2016;15:658-666. DOI: 10.1016/S2095-3119(15)61107-8

[18] Swisher ME. An Investigation of the Potential for the Use of Organic Fertilizer on Small, Mixed Farms in Costa Rica. University of Florida; 1948

[19] Celestin NP. Effects of Inorganic and Organic Fertilizers on Nutrient Uptake, Soil Chemical Properties and Crops Performance in Maize Based Cropping Systems in Eastern Province of Rwanda. Kenyatta University; 2013

[20] Eroa MG. Production and characterization of organic fertilizer from Tubang-Bakod (Jatrophacurcas) seed cake and chicken manure. Asia Pacific Journal of Multidisciplinary Research. 2015;3:9-13

[21] Chavan BL, Vedpathak MM, Pirgonde BR. Effects of organic and chemical fertilizers on cluster bean (Cyamopsis tetragonolobus). European Journal of Experimental Biology. 2015;5: 34-38 



\title{
Chapter 8
}

\section{Cellulosic Fibers from Lignocellulosic Biomass for Papermaking Applications}

\author{
Faten Mannai, Hanedi Elhleli, Ramzi Khiari \\ and Younes Moussaoui
}

\begin{abstract}
This chapter gives a brief overview of the cellulose extraction from Opuntia (Cactaceae) fibers. The suitability of this food waste for pulp and paper production was investigated by the determination of the chemical composition and testing two procedures of delignification: chemical and semichemical pulping processes. Chemical pulping procedure was carried out by using soda-anthraquinone (soda$\mathrm{AQ}$ ) mixture, and semichemical pulping process was performed by softening the raw material using soda-hydrogen peroxide (soda-HP) mixture; this operation was followed by mechanical grinding. The obtained fibrous suspensions were characterized by measuring their dimension parameters (fiber length, fiber width, and fine elements), polymerization degree, and their retention water capacity. The effect of pulping process on yield and fiber characteristics in each pulp was studied. The surface morphologies of the produced papers were studied using scanning electron microscope (SEM), and results show the good distribution and individuality of fibers. The structural and mechanical properties of the prepared paper were presented and discussed. Mechanical strength results show the good tenacity of papers made from soda-HP pulping process.
\end{abstract}

Keywords: Opuntia ficus-indica, food waste, lignocellulosic fibers, deliberate fibers, fibrous suspension, pulping

\section{Introduction}

Opuntia ficus-indica is a xerophyte plant belonging to the Cactaceae family, well adapted to drought conditions thanks to its succulent nature that allows it to store extraordinary quantities of water [1]. Opuntia ficus-indica was used in traditional medicine for therapeutic, cosmetic, anticarcinogenic, anti-inflammatory, antioxidant, antiviral, and antidiabetic goods [2-4]. Thereby, Opuntia ficus-indica waste has received significant attention from numerous researches and was investigated because of its important chemical composition which has a high nutritional value, mainly due to their mineral, protein, dietary fiber, and phytochemical contents [4-9]. By-products of Opuntia ficus-indica were used by Bensadon et al. [4] as a source of good-quality antioxidant dietary fiber. Furthermore, Opuntia ficusindica cladodes have interesting medical antioxidant activity [10, 11]. Likewise, methanol extract of Opuntia ficus-indica flowers has an anti-inflammatory effect on 
carrageenan-induced paw edema test [3]. The fruit syrup of Opuntia ficus-indica has a powerful antioxidant effect and exhibited effective antimicrobial activity against Staphylococcus aureus and Staphylococcus epidermidis [12]. In addition, Cactaceae waste was used also for nonfood applications by testing its ability to decontaminate wastewater through both the adsorption and coagulation-flocculation processes $[13,14]$, and manufacturing cactus fiber/polyester [15] and cactus fiber/polylactic acid [16] biocomposite materials (which contained cellulosic fibers obtained from cladodes) via rotational molding.

Otherwise, cellulosic fibers from Opuntia ficus-indica can be used as a raw material for papermaking. The pulp and paper industry is one of the largest and diversified industrial sectors in the world [17]. More than 400 million tons of paper are produced every year by different methods using many types of raw materials [17]. Traditionally, wood and forest resources were the basic sources of cellulosic fibers used by paper industries, but in recent years and in developing countries, about $60 \%$ of cellulose fibers originate from non-wood raw materials such as bagasse (sugarcane fibers), cereal straw, bamboo, reeds, esparto grass, jute, flax, and sisal [18]. For this reason, the selection of suitable non-wood fibers is critical for the yield of fibrous fraction, ease of processing, quality, and cost of the final fiber-based product [19].

The paper manufacturing process has several stages: raw material preparation, pulp manufacturing, pulp washing, chemical recovery, bleaching, stock preparation, and papermaking [17]. To realize the second stage, various pulping procedures have been utilized for the production of cellulosic fibers from non-wood raw material. These pulping methods might be classified mainly as chemical pulping, semichemical pulping, and mechanical pulping processes. In fact, chemical pulps are characterized by the highest production rate and represent almost pure celluloses; they are produced by combining heat and chemical treatment (kraft pulp) of wood chips with a mixture of sodium hydroxide and sodium sulfide [20]. The soda-anthraquinone (soda-AQ) process is similar to the kraft pulping procedure, which utilizes soda and anthraquinone catalysts. Soda-AQ can reduce the processing time and increases the pulp yield by protecting the carbohydrate compounds. Furthermore, semichemical pulping uses a combination of chemical and mechanical (i.e., grinding) processing to extract pulp fibers [21]. The raw material firstly is partially softened with chemicals, and mechanical methods complete the pulping process. One of the mild oxidant agents for chemical delignification is hydrogen peroxide. Hydrogen peroxide is characterized by its highest efficiency in bleaching and delignification when the reaction is conducted in alkaline medium with a stabilizing agent (diethylenetriamine pentaacetic acid (DTPA), ethylenediaminetetraacetic acid (EDTA)), etc. [22, 23]. Hydrogen peroxide readily decomposes to generate more active radicals which play a prominent role in dissolving lignin, hence releasing the fibers for papermaking [24]. The temperature and time of pulping in chemical and semichemical pulps depend on the type, composition, and source of lignocellulosic fibers. Indeed, in terms of yield, chemical pulping yields are between 45 and $55 \%$ but offer higher strength properties, and the fibers are more easily breached; and semichemical pulps, which apply to the category of chemical pulps, are obtained mainly from hardwoods with yields of between 65 and $85 \%$ (average ca. 75\%) [21]. Moreover, pulp bleaching is often performed to produce special sorts of paper (such print and writing ones), while unbleached pulp can be used in various packing applications (including paperboards, food packaging, and large containment bags) [25]. In order to search for new sources of natural non-woody cellulosic fibers, Opuntia ficus-indica has been considered in this study as food waste source for pulp and papermaking production. It is a cactus from tropical, subtropical, arid, and semiarid regions, which exists in the form of a shrub 
or a tree with a height of up to $5 \mathrm{~m}$ and produces a sturdy trunk as it ages [26]. For paper manufacturing, the Opuntia ficus-indica fibers are firstly pulped by applying two different processes:

i. Chemical procedure using soda-anthraquinone mixture (soda-AQ).

ii. Semichemical procedure using a soft operation of delignification in sodahydrogen peroxide (soda-HP) mixture followed by mechanical operation of fiber deliberation.

\section{Experimental}

\subsection{Raw material preparation and chemical analyses}

Manufacturing of pulp starts with raw material preparation [27]. The Opuntia ficus-indica stems (trunk) was harvested from southwest of Tunisia, debarked, cleaned, cut into chips $\left(2-3 \times 1-2 \times 1.5-2 \mathrm{~cm}^{3}\right)$, dried at room temperature, and temporarily stored for further processing $[28,29]$. The dried raw material was ground in accordance with the T $264 \mathrm{~cm}-07$ standards, and its 40 -mesh fractions were selected for chemical composition analyses. The ash, Klason lignin, holocellulose, and $\alpha$-cellulose fractions in the raw materials were, respectively, quantified using the following TAPPI T211 om-07, T 222 om-06, procedure described by Wise et al. [30], and T $203 \mathrm{~cm}-99$.

\subsection{Pulping processing and testing}

For paper manufacturing, two main step processes are followed in which the Opuntia ficus-indica chips are firstly converted into fibrous mass (pulp) and then the pulp is converted into paper. During pulping of this raw material, two procedures are used:

i. Semichemical pulping using soda-hydrogen peroxide (soda-HP).

ii. Chemical pulping using soda-anthraquinone (soda-AQ).

Multistep of pulping processes was followed to produce pulps from Opuntia ficus-indica chips as shown in Figure 1.

The delignification of Opuntia ficus-indica chips is carried out by adopting a chemical soda-HP process followed by mechanical deliberation operation of fibers [28]. The soda-HP pulping reaction is done under reflux, and the conditions are shown in Figure 1 and listed in Table 1. After pulping, the obtained bleached soda-HP pulp was separated from white liquor by filtration and extensively washed several times with distilled water until neutrality. After that, a mechanical grinding operation is performed to more individualize and deliberate the fibrous suspensions. The obtained soda-HP pulp is purified by the classification of fibers. This operation is used to remove uncooked materials and other large-sized impurities by applying the standard T275 sp-12 method. The obtained soda-HP pulp was stored for further use.

Conventional soda-AQ pulping process was carried out in a rotating batch digesters with electrical heating equipped with thermocouples to monitor possible changes in temperature, and the processing time was automatically selected by the system $[28,29,31,32]$. The soda-AQ pulping was performed by exploring different 


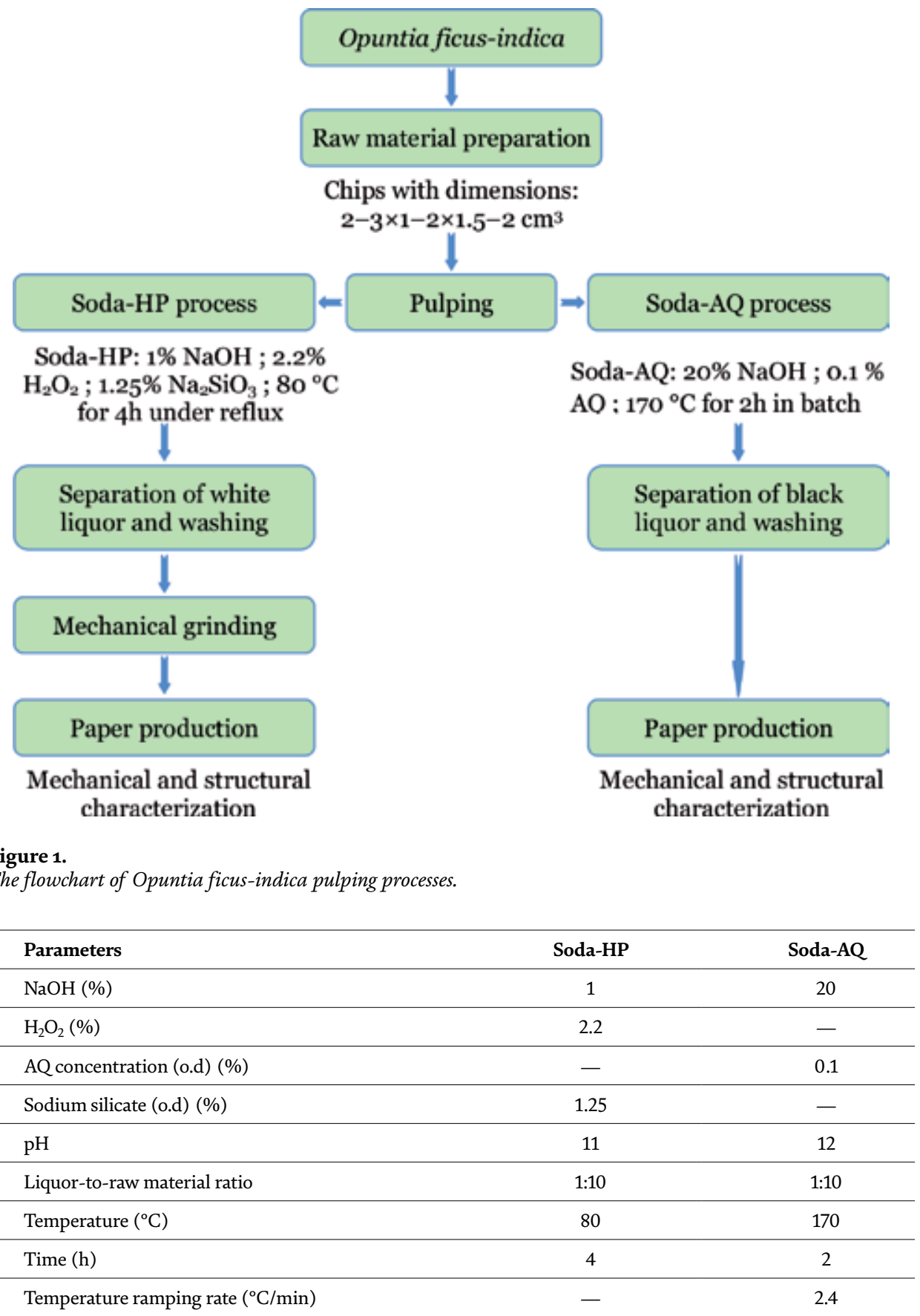

Table 1.

Delignification conditions utilized for Opuntia ficus-indica fibers.

reaction conditions and parameters described in detail in Table 1. After processing, the obtained unbleached soda-AQ pulp was first separated from the black liquor, then carefully washed several times with distilled water, and stored for further use. Soda-AQ pulp will be exploited and characterized without bleaching operation.

The effect of pulping procedure on the yield and the properties of the deliberated fibers were studied using various ad hoc methods. Pulp yield (obtained from both 
processes) was determined as dry obtained on the basis of oven dried raw material. To examine the main morphological parameters (fiber dimensions) of the deliberated fibers (lengths, widths, and fractions of fine elements with lengths below $200 \mu \mathrm{m}), 0.3 \mathrm{mg}$ of pulp was suspended in $8 \mathrm{~L}$ distilled water and passed through the MorFi analyzer (LB01, developed by Techpap-France and the Paper Technical Centre). This technique is based on image analysis (using CCD camera), while more than 3000 fibers were observed in 2 min by the circulation of the fiber suspensions in a flat and transparent channel. The degree of polymerization $\left(\mathrm{DP}_{\mathrm{v}}\right)$ was determined according to the procedure described by Sihtola et al. [33]. The intrinsic viscosity of the deliberated fibers ( $\mathrm{mPas}$ ) was measured in cupriethylenediamine (CED) according to the TAPPI T 230 om-99 standard. The water retention value (WRV) and degree of fiber swelling were estimated using a previously developed procedure [34]. The WRV was experimentally determined by the water retention measured after centrifugation at 3000 times for $15 \mathrm{~min}$. The pulp drainability or Schopper-Riegler degree ( ${ }^{\circ}$ SR: ISO 5267-1) was evaluated by measuring the drainage capacity of a deliberated fibers in experimental conditions. Total ionic charges of the produced pulps (which correlated with the amount of the ionized chemical functions in the contained in the fibers) were determined by "Gran's method" [35].

\subsection{Papermaking and testing}

The deliberated fibers for each pulp were firstly disintegrated using a standard disintegrator T $205 \mathrm{sp}-06$ (shot $3000 \mathrm{rpm}$ at room temperature) and then diluted to $2 \mathrm{~g} / \mathrm{L}$ for paper preparation. Ten laboratory hand sheets with diameters of $20 \mathrm{~cm}$ via the standard ISO 5269-2 method were processed using Franc Rapid-Köthen sheet former apparatus. The produced hand sheets of papers were conditioned for $48 \mathrm{~h}$ at a temperature of $23^{\circ} \mathrm{C}$ and relative humidity of $50 \%$ before testing (ISO 187 standard). The structural and mechanical properties of paper samples were determined according to common standards: basis weights (ISO 536), thickness (ISO 534), air permeability (TAPPI: T452), tensile strength (NF Q 03-002), bursting strength (NF Q 03-053), and tear resistance (NF Q 03-011). Afterward, the bulk value and porosity of the produced paper sheets were calculated. The degree of bleaching (ISO 2470) and yellowness degree were detected by ELREPHO 2000 (yellowness degree measured by D 65/10 C and a $457 \mathrm{~nm}$ wavelength). The morphological analysis of each Opuntia ficus-indica paper was performed using the scanning electron microscopy (SEM, model Philips XL 30, USA).

\section{Chemical properties of raw material}

Table 1 shows the chemical composition results of Opuntia ficus-indica trunk, cladode [36], and other sources of fibers for comparison purposes. A very small fraction of minerals (5.5 $\mathrm{wt} \%)$ was observed in the trunk [28] compared to the total minerals amount in the cladode $(19.6 \mathrm{wt} \%)$. The lower fraction of minerals presents a major advantage, and the utilized raw material was silica free, which was extremely important for papermaking [29]. The total holocellulose contents (64 wt\%) were higher than those of wood [20] and some annual plants [32, 37]. The $\alpha$-cellulose rate was higher in the trunk (53.6 wt\%) than those of cladode and other plants such as wood and annual plants [37]. The lower lignin amounts (Table 2) observed for Opuntia ficus-indica trunk and cladode (do not exceed $5 \mathrm{wt} \%$ ) indicate that this plant was not a woody plant. Non-wood fibers are handled in ways specific to their composition [21]. For this reason, the processes used for Opuntia 


\begin{tabular}{lcccc}
\hline Fiber plant & Ash & K.L & Holo & -Cell \\
\hline Opuntia ficus-indica trunk [28] & 5.5 & 4.8 & 64.5 & 53.6 \\
\hline Opuntia ficus-indica cladode [36] & 19.6 & 3.6 & - & 21.6 \\
\hline Soft-wood [4] & - & $25-31$ & $65-74$ & $40-45$ \\
\hline Annual plants [32, 37] & $2-6.2$ & $17-26$ & $52-70$ & $36-46$ \\
\hline
\end{tabular}

Table 2.

Chemical composition (ash (wt), Klason lignin (KL (wt\%)), holocellulose (Holo (wt\%)) and $\alpha$-cellulose $(\alpha$-cell $(w t \%)))$ of Opuntia ficus-indica trunk, and other values obtained for cladode ( $w / w \%)$.

ficus-indica delignification was adapted in soft conditions to minimize degradation of the fibers and thus maximize pulp yield.

\section{Effect of pulping process on yield and fiber characteristics}

The produced pulps from soda-HP and soda-AQ processes are shown in Figure 2. The obtained pulps from both procedures show a high difference in terms of color. The soda-HP delignification process gives a bleached pulps and soda-AQ pulping process (without bleaching operation) conducted beige-brown (or kraft) color.

The pulp yield obtained for soda-HP pulping process of Opuntia ficus-indica fibers (about $80.8 \%$ ) is $49 \%$ higher than that of soda-AQ pulping process $(41.1 \%$ ) (Table 2). The remarkable differences in the amounts of yields of the obtained pulps may be due to the differences in experimental conditions as well as the alkaline medium (or alkaline charge). However, the yield of the Opuntia ficus-indica pulp obtained from both soda-HP and soda-AQ processes is much higher than the magnitudes reported for most annual plants and agricultural crops (30-35\%) [32, 37]. The high pulp yield is expected because of the higher cellulose content in raw material (Table 2). Due to the low content of lignin in the raw material, the kappa number of the produced Opuntia ficus-indica pulp was not calculated. The basic parameters that affected the paper properties are fiber's dimensions that include fiber length and fiber width [38]. The effect of soda-HP and soda-AQ pulping processes on morphological dimensions and characteristics was studied, and the obtained results are listed in Table 3. The deliberate fibers obtained from soda-HP pulping process present relatively high average fiber length of $764 \mu \mathrm{m}$ than $737 \mu \mathrm{m}$ of fibers made of soda-AQ pulping process. However, fiber length of Opuntia ficusindica issued from both processes is in the range of hardwood fibers $(0.7-1.5 \mathrm{~mm})$ [39]. It was considered as short fiber species. The processing with soda-HP procedure gives thick individualized fibers with width of $38 \mu \mathrm{m}$. This value is in the range of hardwoods fibers (20.0-40.0) [40]. The fibers derived from soda-AQ pulping process are the thicker $(45.6 \mu \mathrm{m})$ than fibers obtained from soda-HP pulping process and hardwood fibers. The processing with soda-AQ mixture and in high temperature $\left(170^{\circ} \mathrm{C}\right)$ resulted in high fine element rate $(29.3 \%)$.

The viscosity of the obtained soluble pulps represented by the DPv for soda-AQ pulp is around 600 (Table 3); this value was higher than those obtained from sodaHP pulp which represents about 500. The DPv values obtained for Opuntia ficusindica pulps are lowest compared to those of woody fibers (1300-1500) and annual plants (900-1200) [32,38]. The WRV obtained for soda-HP pulp is the same as that obtained for soda-AQ pulp. This may be explained by the presence of charged moieties (total charge of $21-22 \mu \mathrm{eq} \mathrm{g}^{-1}$ ) associated with the fibers. In this context, 

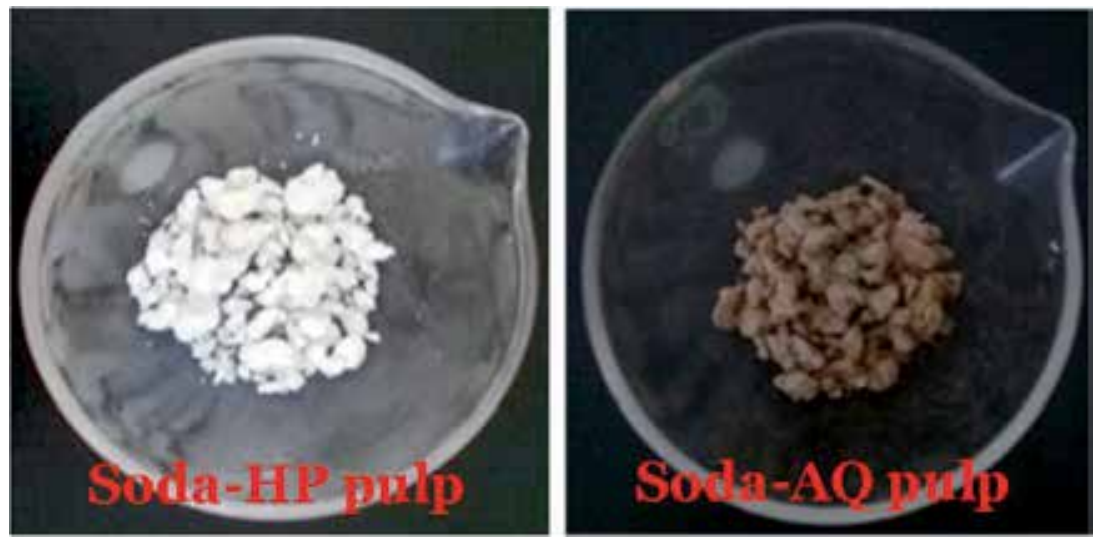

Figure 2.

Digital image of the produced pulps from Opuntia ficus-indica stems.

\begin{tabular}{lcccccccc}
\hline Pulps & $\begin{array}{c}\text { Yield } \\
(\%)\end{array}$ & $\begin{array}{c}\text { Fiber } \\
\text { length } \\
(\boldsymbol{\mu m})\end{array}$ & $\begin{array}{c}\text { Fiber } \\
\text { width } \\
(\boldsymbol{\mu m})\end{array}$ & $\begin{array}{c}\text { Fraction } \\
\text { of fine } \\
\text { elements } \\
(\%)\end{array}$ & DPv & $\begin{array}{c}\text { WRV } \\
(\%)\end{array}$ & $\begin{array}{c}\text { Total } \\
\text { charge } \\
\left(\boldsymbol{\mu} \mathbf{e q g}^{-1}\right)\end{array}$ & ${ }^{\circ}$ SR \\
\hline $\begin{array}{l}\text { Soda-HP } \\
{[28]}\end{array}$ & 80.8 & 764 & 38 & 16.3 & 500 & 67 & 21 & 11 \\
\hline $\begin{array}{l}\text { Soda-AQ } \\
{[29]}\end{array}$ & 41.4 & 737 & 45.6 & 29.3 & 600 & 63.7 & 22 & 17 \\
\hline
\end{tabular}

Table 3.

Effect of pulping process of Opuntia ficus-indica stems on yield, fiber dimensions, and other characteristics (degree of polymerization (DPv), water retention value (\%), total charge, and Schopper degree ( $\left.{ }^{\circ} S R\right)$ ).

it was found that the lignin was totally oxidized according to the appearance of the hydration phenomenon (due to the presence of extra fiber water) [28, 41, 42]. The drainability of the Opuntia ficus-indica soda-HP pulp ( ${ }^{\circ} \mathrm{SR}$ ) is important (11) than those of soda-AQ pulp (17). The ${ }^{\circ} \mathrm{SR}$ observed for soda-HP pulp confirms the good quality of fibers. Thus, based on the properties established for the different pulps, we deduced that the most suitable one is processed by soda-HP procedure.

\section{Evolution of pulping processes on paper properties}

The morphological SEM analysis of the manufactured handmade paper sheets was performed in order to evaluate the effect of pulping processes on paper morphology (Figure 3). The fibers depicted on both sheet surfaces are long, swollen, well separated, homogeneous, and strongly linked together (fiber network). Fine elements were evenly distributed across the paper surface and mainly observed for soda-AQ paper. This is in agreement with MorFi's results.

Structural and mechanical parameters of handmade paper sheets produced from Opuntia ficus-indica soda-HP and soda-AQ pulps were estimated and listed in Tables 4 and 5, respectively. The obtained basic weight for sheets made from soda-AQ pulp $\left(65.2 \mathrm{~g} \mathrm{~m}^{-2}\right)$ was $41 \%$ higher than that of the soda-HP papers. The corresponding bulk values obtained for the both handmade sheet papers are the same $\left(2-2.2 \mathrm{~cm}^{3} \mathrm{~g}^{-1}\right)$; these values were slightly lower than that of the Alfa paper $\left(2.36 \mathrm{~cm}^{3} \mathrm{~g}^{-1}\right)$ [43]. The low value of bulk is mainly due to the lower thickness of the 

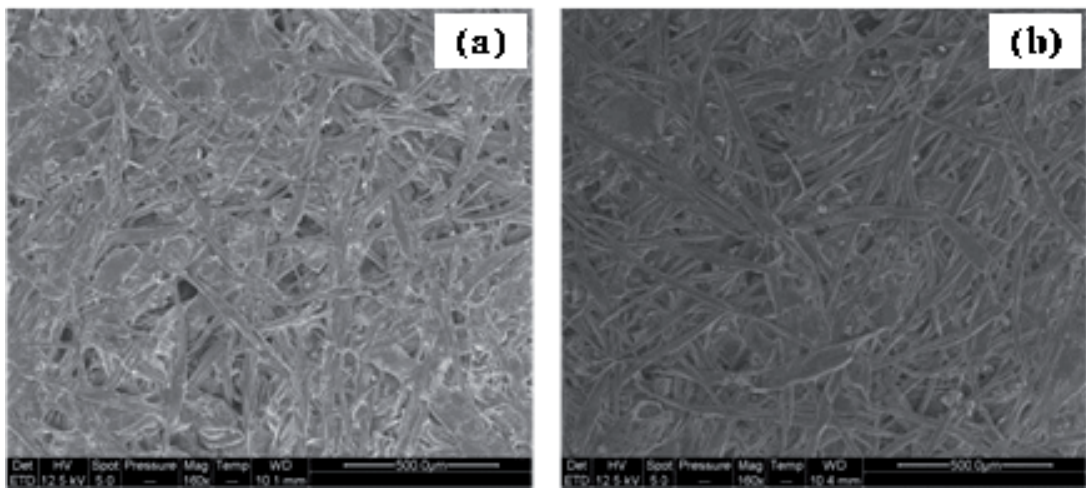

Figure 3.

SEM images [magnification $\times 500 \mu \mathrm{m}$ ] of surface morphologies of papers made from soda-HP pulp (a) and paper made from soda-AQ pulp (b) (the encircled zones show the presence of fine elements).

\begin{tabular}{lccccccc}
\hline $\begin{array}{l}\text { Paper } \\
\text { samples }\end{array}$ & $\begin{array}{c}\text { Basis } \\
\text { weight } \\
\left(\mathbf{g ~ m}^{-2}\right)\end{array}$ & $\begin{array}{c}\text { Thickness } \\
(\boldsymbol{\mu m})\end{array}$ & $\begin{array}{c}\text { Bulk } \\
\left(\mathbf{c m}^{3} \mathbf{g}^{-1}\right)\end{array}$ & $\begin{array}{c}\text { Air } \\
\text { permeability } \\
\left(\mathbf{c m}^{3} / \mathbf{s ~ P a ~ m}^{2}\right)\end{array}$ & $\begin{array}{c}\text { Porosity } \\
(\%)\end{array}$ & $\begin{array}{c}\text { D.B } \\
(\%)\end{array}$ & $\begin{array}{c}\text { D.Y } \\
(\%)\end{array}$ \\
\hline $\begin{array}{l}\text { Soda-HP } \\
{[28]}\end{array}$ & 38.4 & 149 & 2.2 & 231.1 & 71.2 & 67.4 & 6.8 \\
\hline $\begin{array}{l}\text { Soda-AQ } \\
{[29]}\end{array}$ & 65.2 & 135 & 2 & 229.2 & 68.6 & - & - \\
\hline
\end{tabular}

Table 4.

Structural properties, degree of bleaching (D.B.\%) and degree of yellow (D.Y.\%), of papers produced from the Opuntia ficus-indica pulps.

\begin{tabular}{|c|c|c|c|}
\hline Paper samples & Burst index $\left(\mathrm{kPa} \mathrm{m}^{2} \mathrm{~g}^{-1}\right)$ & Tear index $\left(\mathrm{mNm}^{2} \mathrm{~g}^{-1}\right)$ & Breaking length $(\mathbf{k m})$ \\
\hline Soda-HP [28] & 0.67 & 19.2 & 1.9 \\
\hline Soda-AQ [29] & 5.8 & 12 & 1.5 \\
\hline
\end{tabular}

Table 5 .

Mechanical strength properties of papers produced from the Opuntia ficus-indica pulps.

Opuntia ficus-indica papers. However, the porosity and air permeability measured for soda-HP papers were significantly higher than those obtained for soda-AQ papers. In addition, the important degree of bleaching was higher than ISO 11475 and 11476 for newsprint (65\%) as well as for the yellow degree. Therefore, the soda$\mathrm{HP}$ pulping process presents the advantage that relatively white papermaking sheets could be prepared without bleaching.

The burst index obtained for soda-AQ papers was $88 \%$ higher than soda-HP papers. The variation of burst index was mainly affected by fiber width and fine elements present in soda-AQ pulp [44]; it was dependent on pulping methods. The tear index noted for soda-HP papers was higher than those obtained for soda-AQ papers. This is due to the high fiber length which usually had a significant effect on the tearing strength of papers. The breaking length obtained for soda-HP papers was quite higher $(1.9 \mathrm{Km})$ than those obtained for soda-AQ papers. The use of sodaHP pulping process affects the paper properties by increasing the fiber flexibility and strength [21]. Thus, the morphological, structural, and mechanical characteristics of the Opuntia ficus-indica fibers suggest their possible applications for producing paper from non-woody plants. 


\section{Conclusions}

The study revealed that Opuntia ficus-indica can be potentially utilized as a suitable food waste source of non-wood fibers for papermaking application. Its chemical composition showed that the fibers were rich with biopolymers (cellulose $53.2 \mathrm{wt} \%$ ) interconnected with natural resins confirmed by the low presence of lignin (4.8 wt\%). In order to select the best conditions of delignification and reducing the lignin content, various pulping procedures were tested for this raw material. The alkaline peroxide pretreatment (soda-HP pulping process) of the raw material produced bleached pulp and high-quality pulp with good yield (80.8\%). Fibrous mass produced using soda-AQ pulping process gives a brown pulp with a yield about $41.1 \%$. The pulping method described in this chapter affects the pulp properties and paper characteristics. However, the papers obtained from soda-HP pulping process (eco-friendly process) have a white color, good structural properties, and high tear strength compared to those obtained from soda-AQ pulp. Thus, the results obtained in this study indicate that pulps for papermaking applications can be fabricated from agricultural waste, which represent a good option for the countries without forests.

\section{Acknowledgements}

The authors would like to express their deep gratitude to Mohamed Naceur Belgacem, Professor and Director of the Grenoble INP-Pagora and Agefpi, for his valuable advice and assistance, as well as to the Tunisian Ministry of Higher Education and Scientific Research for the financial support.

\section{Conflict of interest}

The authors declare no conflict of interest. 


\section{Author details}

Faten Mannai ${ }^{1}$, Hanedi Elhleli ${ }^{1,4}$, Ramzi Khiari ${ }^{5}$ and Younes Moussaoui ${ }^{2,3 *}$

1 Material Environment and Energy Laboratory (UR14ES26), Faculty of Sciences of Gafsa, University of Gafsa, Tunisia

2 Organic Chemistry Laboratory (LR17ES08), Faculty of Sciences of Sfax, University of Sfax, Tunisia

3 Faculty of Sciences of Gafsa, University of Gafsa, Tunisia

4 Faculty of Sciences of Gabes, University of Gabes, Tunisia

5 High Institute of Technological Studies (ISET), Monastir, Tunisia

*Address all correspondence to: y.moussaoui2@gmx.fr

\section{IntechOpen}

(C) 2019 The Author(s). Licensee IntechOpen. This chapter is distributed under the terms of the Creative Commons Attribution License (http://creativecommons.org/licenses/ by/3.0), which permits unrestricted use, distribution, and reproduction in any medium, provided the original work is properly cited. (cc) BY 


\section{References}

[1] Jimenez-Aguilar DM, Mújica-Paz H, Welti-Chanes J. Phytochemical characterization of prickly pear (Opuntia spp.) and of its nutritional and functional properties: A review. Current Nutrition Food and Science. 2014;10:57-69. DOI: $10.2174 / 157340131001140328120952$

[2] El Kharrassi Y, Mazri MA, Benyahia H, Benaouda H, Nasser B, El Mzouri EH. Fruit and juice characteristics of 30 accessions of two cactus pear species (Opuntia ficus-indica and Opuntia megacantha) from different regions of Morocco. LWT-Food Science and Technology. 2016;65:610-617. DOI: 10.1016/j.lwt.2015.08.044

[3] Ammar I, Ben Salem M, Harrabi B, Mzid M, Sahnoun Z, Attia H, et al. Antiinflammatory activity and phenolic composition of prickly pear (Opuntia ficus-indica) flowers. Industrial Crops and Products. 2018;112:313-319. DOI: 10.1016/j.indcrop.2017.12.028

[4] Bensadon S, Hervert-Hernández D, Sáyago-Ayerdi SG, Goni I. By-products of Opuntia ficus-indica as a source of antioxidant dietary Fiber. Plant Foods for Human Nutrition. 2010;65:210-216. DOI: $10.1007 / \mathrm{s} 11130-010-0176-2$

[5] Rodriguez-Garcia ME, de Lira C, Hernandez-Becerra E, Cornejo-VillegasMA,Palacios-FonsecaAJ, Rojas-Molina I, et al. Physicochemical characterization of nopal pads (Opuntia ficus-indica) and dry vacuum nopal powders as a function of the maturation. Plant Foods and Human Nutrition. 2007;62:107-112. DOI: 10.1007/s11130-007-0049-5

[6] Hernández-PérezT, Carrillo-López A, Guevara-Lara F, Cruz Hernández A, Paredes-López O. Biochemical and nutritional characterization of three prickly pear species with different ripening behavior. Plant Foods and
Human Nutrition. 2005;60:195-200. DOI: $10.1007 / \mathrm{s} 11130-005-8618-y$

[7] Ayadi MA, Abdelmaksoud W, Ennouri M, Attia H. Cladodes from Opuntia ficus-indica as a source of dietary fiber: Effect on dough characteristics and cake making. Industrial Crops and Products. 2009;30:40-47. DOI: 10.1016/j. indcrop.2009.01.003

[8] Rodríguez-Félix A, Cantwell M. Developmental changes in composition and quality of prickly pear cactus cladodes (nopalitos). Plant Foods and Human Nutrition. 1988;38:83-93. DOI: 10.1007/BF01092314

[9] Abdel-Hameed ES, Nagaty MA, Salman MS, Bazaid SA. Phytochemicals, nutritionals and antioxidant properties of two prickly pear cactus cultivars (Opuntia ficus-indica Mill.) growing in Taif, KSA. Food Chemistry. 2014;160:31-38. DOI: 10.1016/j. foodchem.2014.03.060

[10] Kuti JO. Antioxidant compounds from four Opuntia cactus pear fruit varieties. Food Chemistry. 2004;85:527-533. DOI: 10.1016/ S0308-8146(03) 00184-5

[11] Corral-Aguayo RD, Yahia EM, Carrillo-Lopez A, GonzalezAguilar G. Correlation between some nutritional components and the total antioxidant capacity measured with six different assays in eight horticultural crops. Journal of Agricultural Food Chemistry. 2008;56:10498-10504. DOI: 10.1021/ jf801983r

[12] Dhaouadi K, Raboudi F, Funez-Gomez L, Pamies D, Estevan C, Hamdaoui M, et al. Polyphenolic extract of barbary-fig (Opuntia ficus-indica) syrup: RP-HPLC-ESI-MS analysis and determination of antioxidant, 
antimicrobial and cancer-cells cytotoxic potentials. Food Analytical Methods. 2013;6:45-53. DOI: $10.1007 /$ s12161-012-9410-x

[13] Elhleli H, Mannai F, Elaloui E, Moussaoui Y. Nitrophenol removal from wastewater onto prepared activated carbon from Opuntia ficus-indica. In: Kallel A, Ksibi M, Ben Dhia H, Khelifi N, editors. Recent Advances in Environmental Science from the Euro-Mediterranean and Surrounding Regions (EMCEI 2017). Advances in Science, Technology and Innovation (IEREK Interdisciplinary Series for Sustainable Development). Cham: Springer; 2018. pp. 1245-4126

[14] Nharingo T, Moyo M. Application of Opuntia ficus-indica in bioremediation of wastewaters. A critical review. Journal of Environment Management. 2016;166:55-72. DOI: 10.1016/j. jenvman.2015.10.005

[15] Bouakba M, Bezazi A, Boba K, Scarpa F, Bellamy S. Cactus fiber/polyester biocomposites: Manufacturing, quasistatic mechanical and fatigue characterisation. Composites Science and Technology. 2013;74:150-159. DOI: 10.1016/j. compscitech.2012.10.009

[16] Greco A, Maffezzoli A. Rotational molding of biodegradable composites obtained with PAL reinforced by the wooden backbone of Opuntia ficusindica cladodes. Journal of Applied Polymer Science. 2015;132:42447. DOI: 10.1002/app. 42447

[17] Bajpai P. Chap. 1-General introduction. In: Pulp and Paper Industry: Microbiological Issue in Papermaking. 1st ed. Elsevier; 2015. pp. 1-10. DOI: $10.1016 /$ B978-0-12-803409-5.00001-X

[18] Gullichsen J. Fiber line operations. In: Gullichsen J, Fogelholm CJ, editors. Chemical Pulping-Papermaking
Science and Technology. Vol. 2. Finland: Fapet Oy; 2000. p. A19

[19] Anupam K, Lal PS, Bist V, Sharma AK, Swaroop V. Raw material selection for pulping and papermaking using TOPSIS multiple criteria decision making design. Environmental Progress and Sustainable Energy. 2014;33:1034-1041. DOI: 10.1002/ ep.11851

[20] Gharehkhani S, Sadeghinezhad E, Kazi SN, Yarmand H, Badarudin A, Safaei MR, et al. Basic effects of pulp refining on fiber properties-A review. Carbohydrate Polymers. 2015;115:785-803. DOI: 10.1016/j. carbpol.2014.08.047

[21] Bajpai P. Brief description of the pulp and paper making process. In: Biotechnology for Pulp and Paper Processing. New York: Springer; 2012. pp. 7-14. DOI: 10.1007/978-1-4614-1409-4

[22] Gould JM. Studies on the mechanism of alkaline peroxide delignification of agricultural residues. Biotechnology and Bioengineering. 1985;27:225-231. DOI: 10.1002/ bit. 260270303

[23] Alvarez-Vasco C, Zhang X. Alkaline hydrogen peroxide (AHP) pretreatment of softwood: Enhanced enzymatic hydrolysability at low peroxide loadings. Biomass and Bioenergy. 2017;96:96-102. DOI: 10.1016/j. biombioe.2016.11.005

[24] Sun RC, Fang J, Tomkinson J. Delignification of rye straw using hydrogen peroxide. Industrial Crops and Products. 2000;12:71-83. DOI: 10.1016/ S026-6690(00)00039-X

[25] Vallette P. In: Coudhens C, editor. Le bois, la pâte, le papier. 3éme éd ed. France: Centre Technique de l'industrie des Papiers, Cartons et Cellulose; 1992. pp. $19-20$ 
[26] Scalisi A, Morandi B, Inglese P, Lo Bianco R. Cladode growth dynamics in Opuntia ficus-indica under drought. Environment Experimental Botany. 2016;122:158-167. DOI: 0.1016/j. envexpbot.2015.10003

[27] Smook GA. Handbook for Pulp and Paper Technologists. Joint Textbook Committee of the Paper Industry of the United States and Canada. Canada: TAPPI; 1992. p. 425

[28] Mannai F, Ammar M, Yanez J, Elaloui E, Moussaoui Y. Cellulose fiber from Tunisian barbary fig "Opuntia ficus-indica" for papermaking. Cellulose. 2016;23:2061-2072. DOI: 10.1007/ s10570-016-0899-9

[29] Mannai F, Ammar M, YanezJG, ElalouiE, MoussaouiY. Alkaline delignification of Cactus fibers for pulp and papermaking applications. Journal of Polymer and the Environment. 2018;26:798-806. DOI: $10.1007 /$ s10924-017-0968-7

[30] Wise L, Murphy E, Addieco MAA. Chlorite holocellulose: Its fractionation and bearing on summative wood analysis and on studies on the hemicelluloses. Paper Trade Journal. 1946;122:35-43

[31] Moussaoui Y, Ferhi F, Elaloui E, Bensalem R, Belgacem MN. Utilisation of Astragalus armatus roots in papermaking. BioResources. 2011;6:4969-4978

[32] Ferhi F, Satyajit D, Elaloui E, Moussaoui Y, Yanez JG. Chemical characterization and suitability for papermaking applications studied on four species naturally growing in Tunisia. Industrial Crops and Products. 2014;61:180-185. DOI: 10.1016/j. indcrop.2014.07.001

[33] Sihtola H, Kyrklund B, Laamanen L, Palenius I. Comparison and conversion of viscosity and DP values determined by different methods. PapjuPuu. 1963;45:225-232

[34] Silvy J, Romatier G, Chiodi R. Méthodes pratiques de contrôle du raffinage. Revue ATIP. 1968;22:31-53

[35] Gran G. Determination of the equivalent point in potentiometric titrations. Part II. Analyst. 1952;77:661671. DOI: $10.1039 / A N 9527700661$

[36] Malaininea ME, Dufresne A, Dupeyre D, Mahrouz M, Vuong R, Vignon MR. Structure and morphology of cladodes and spines of Opuntia ficus-indica. Cellulose extraction and characterization. Carbohydrate Polymers. 2003;51:77-83. DOI: 10.1016/ S0144-8617(02)00157-1

[37] Ferhi F, Das S, Moussaoui Y, Elaloui E, Yanez JG. Paper from Stipagrostis pungens. Industrial Crops and Products. 2014;59:109-114. DOI: 10.1016/j.indcrop.2014.05.015

[38] Albert S, Padhiar A, Gandhi D. Fiber properties of Sorghum halepense and its suitability for paper production. Journal of Natural Fibers. 2011;8:263-271. DOI: 10.1080/15440478.2011.626236

[39] Jahan MS, Chowdhury DN, Islam MK. Pulping of dhaincha (Sesbaniaaculeata). Cellulose Chemistry \& Technology. 2007;41:413

[40] Comlekcioglu N, Tutus A, Cicekler M, Canak A, Zengin G. Investigation of Isatis tinctoria and Isatis buschiana stalks as raw materials for pulp and paper production. Drvnaindustrija. 2016;67:249-255. DOI: 10.5552/drind.2016.1542

[41] Antunes A, Amaral E, Belgacem MN. Cynara cardunculus L.: Chemical composition and sodaanthraquinone cooking. Industrial Crops and Products. 2000;12:85-91. DOI: 10.1016/S0926-6690(00)00040-6 
[42] Cordeiro N, Belgacem MN, Torres IC, Moura JCVP. Chemical composition and pulping of banana pseudo-stems. Industrial Crops and Products. 2004;19:147-154. DOI: 10.1016/j.indcrop.2003.09.001

[43] Marrakchi Z, Khiari R, Oueslatic H, Mauret E, Mhenni F. Pulping and papermaking properties of Tunisian alfa stems (Stipa tenacissima)_Effects of refining process. Industrial Crops and Products. 2011;34:1572-1582. DOI: 10.1016/j.indcrop.2011.05.022

[44] Monga S, Thapliyal BP, Tyagi S, Naithani S. Relationship between strength properties and fiber morphological characteristics of $E$. tereticornis-Part-2. Regression and artificial neural networks analysis. International Journal of Science and Research. 2017;6:1557-1564 



\section{Edited by Sonia A. Socaci, Anca C. Fărcaş, Thierry Aussenac and Jean-Claude Laguerre}

One of the biggest challenges facing the food industry and society is the reduction of food waste. Annually, all over the world, millions of tons of agro-food waste are produced, and their efficient management and valorization represents one of the main objectives of EU actions towards sustainable development. The book compiles information on the possibilities of the recovery of valuable compounds from food waste and their valorization in different food and non-food applications, as well as new preservation methods for optimizing food waste reduction. 